\title{
Embryonic development in the Fallopian tube : a microsurgical study in the rabbit
}

Citation for published version (APA):

Land, J. A. (1985). Embryonic development in the Fallopian tube : a microsurgical study in the rabbit.

[Doctoral Thesis, Maastricht University]. Rijksuniversiteit Limburg. https://doi.org/10.26481/dis.19851011jl

Document status and date:

Published: 01/01/1985

DOI:

10.26481/dis.19851011jl

Document Version:

Publisher's PDF, also known as Version of record

\section{Please check the document version of this publication:}

- A submitted manuscript is the version of the article upon submission and before peer-review. There can be important differences between the submitted version and the official published version of record.

People interested in the research are advised to contact the author for the final version of the publication, or visit the DOI to the publisher's website.

- The final author version and the galley proof are versions of the publication after peer review.

- The final published version features the final layout of the paper including the volume, issue and page numbers.

Link to publication

\footnotetext{
General rights rights.

- You may freely distribute the URL identifying the publication in the public portal. please follow below link for the End User Agreement:

www.umlib.nl/taverne-license

Take down policy

If you believe that this document breaches copyright please contact us at:

repository@maastrichtuniversity.nl

providing details and we will investigate your claim.
}

Copyright and moral rights for the publications made accessible in the public portal are retained by the authors and/or other copyright owners and it is a condition of accessing publications that users recognise and abide by the legal requirements associated with these

- Users may download and print one copy of any publication from the public portal for the purpose of private study or research.

- You may not further distribute the material or use it for any profit-making activity or commercial gain

If the publication is distributed under the terms of Article $25 \mathrm{fa}$ of the Dutch Copyright Act, indicated by the "Taverne" license above, 
Embryonic development in the Fallopian tube a microsurgicall study in the rabbit 
Drukkeriji Groenevelt b.v. - Landgraaf 


\section{EMBRYONIC DEVELOPMENT IN THE FALLOPIAN TUBE a microsurgical study in the rabbit}

\section{Proefschrift}

ter verkrijging van de graad van doctor in de geneeskunde aan de Rijksuniversiteit Limburg te Maastricht, op gezag van de Rector Magnificus Prof. Dr F.I.M. Bonke, volgens besluit van het College van Dekanen, in het openbaar te verdedigen in de aula van de universiteit op vrijdag 11 oktober 1985 des namiddags te vier uur

door

Jolande Aulikki Land

geboren te Helsinki, Finland. 
Promotores: Prof.Dr J. de Haan, RL Maastricht

Prof.Dr I.A. Brosens, KU Leuven

Co-promotores: Dr J.L.H. Evers, RL Maastricht

Prof.Dr W.D. Boeckx, KU Leuven

Referenten: Prof.Dr J.P.M. Geraedts, RL Maastricht

Prof.Dr J. Schoemaker, VU Amsterdam 
'Beste jongen!' zeide de dokter, 'je schijnt nog wat teergevoelig om te beginnen. Het is waar, de eerste maal is zo iets naar om te zien. Ik zelf zie het altijd ongaarne en vermijd het zoveel mogelijk. Doch het is onontbeerlijk. En je moet begrijpen wij zijn mensen en geen dieren, en het heil van de mensheid en van de wetenschap gaat boven dat van enige konijnen'.

'Hoor je!' zei Pluizer, "de wetenschap en de mensheid!"

'De man der wetenschap,' ging de dokter voort, 'staat hoger dan alle andere mensen. Maar hili moet dan ook de kleine gevoeligheden, die de gewone mensen kennen, laten varen voor dat éne grote: de wetenschap. Wilt ge zulk een mens worden? was dat uw roeping, mijn jongen?"

Johannes weifelde, hij wist nog niet recht wat een roeping was, zomin als de meikewer.

'De kleine Johannes", Frederik van Eeden 



\section{Voorwoord}

Dit proefschrift kwam tot stand binnen de afdeling Obstetrie en Gynaecologie van het Sint Annadal Ziekenhuis te Maastricht, in nauwe samenwerking met het Microchirurgie Centrum van de Dienst Algemene Heelkunde en de Dienst Gynaecologie van de Katholieke Universiteit te Leuven, België.

Het dierexperimentele onderzoek werd uitgevoerd in het Biomedisch Centrum van de Rijksuniversiteit Limburg te Maastricht.

Velen hebben bijgedragen aan het tot stand komen van dit proefschrift.

Bijzondere dank ben ik verschuldigd aan de Leuvense inspirators, Prof.Dr I.A. Brosens, Prof.Dr W.D. Boeckx en Dr R. Pijnenborg.

Mr Eugene Tritt (Springler \& Tritt, Jestetten, W-Germany) kindly made available the microsurgical suture material.

De medewerkers van de Centrale Proefdier Voorziening van het Biomedisch Centrum, Petra Rommers en May Bost in het bijzonder, waren behulpzaam bij het dierexperimentele werk.

De statistische bewerking vond plaats bij de afdeling Medische Informatica en Statistiek van de Rijksuniversiteit Limburg (Ir A. Muytjens). Wim Doesburg en Wim Lemmens gaven enkele waardevolle adviezen.

Dick Willebrand verschafte inzicht in de histologie van de tractus genitalis van het konijn.

De afdeling Medische Fotografie van het Sint Annadal Ziekenhuis en de Audiovisuele Dienst van de Rijksuniversiteit Limburg verzorgden de foto's en de tekeningen. Dick Evers was behulpzaam bij het vervaardigen van de omslag. Mijn ouders verleenden hulp bij het taalkundig corrigeren van de teksten. Mariet Herinx-Strijbos en Roos Zwiersen-Ruwette verzorgden het manuscript. Zonder Hans Evers was het allemaal niet nodig geweest.

Ik ben $u$ allen zeer erkentelijk.

Maastricht, juli 1985 



\section{Contents}

Chapter I. Introduction

page

1.1 Introduction

1.2 Embryology

1.3 Tubal anatomy

1.3.1 Tubal segments

1.3.2 Histology of tubal mucosa

1.3.3 Vascular anatomy

1.3.4 Neuroanatomy

$\begin{array}{lll}1.4 & \text { Tubal physiology } & 23\end{array}$

1.4.1 Ovum pick-up 23

$\begin{array}{lll}1.4 .2 & \text { Sperm transport } & 23\end{array}$

1.4.3 Sperm activation $\quad 24$

$\begin{array}{ll}\text { 1.4.4 Oocyte maturation and fertilization } & 26\end{array}$

1.4.5 Cleavage of the embryo 31

$\begin{array}{lll}\text { 1.4.6 Tubal transport } & 36\end{array}$

1.5 Fluids of the female genital tract 40

$\begin{array}{lll}1.6 & \text { Microsurgery } & 48\end{array}$

1.7 Experimental tubal microsurgery $\quad 53$

$\begin{array}{lll}1.8 & \text { Aim of the study } & 56\end{array}$

Chapter II. Materials and Methods

2.1.1 Choice of the animal 59

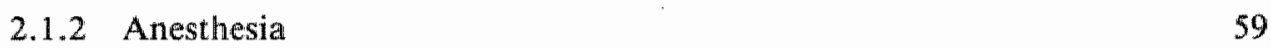

2.1.3 Microsurgical equipment $\quad 60$

$\begin{array}{ll}2.1 .4 & \text { Surgical technique } \\ 2.1 .5 & 60\end{array}$

2.1.5 Postoperative care $\quad 63$

2.1.6 Mating $\quad 63$

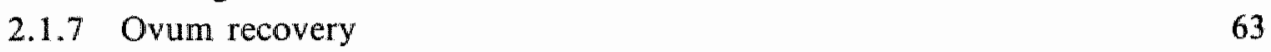

2.1.8 Parameters investigated $\quad 64$

2.1.9 Synopsis of experiments $\quad 66$

$\begin{array}{lll}2.2 & \text { Statistical analysis } & 67\end{array}$ 
Chapter III. Results

3.1 Abbreviations used in tables 69

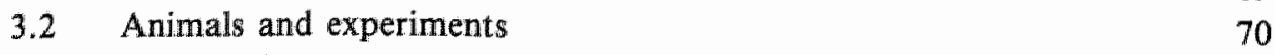

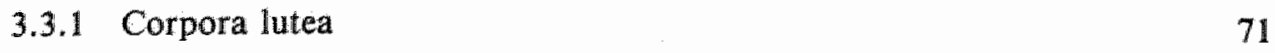

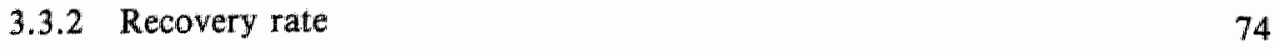

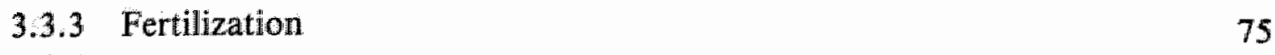

3.3.4 Spermatozoa $\quad 80$

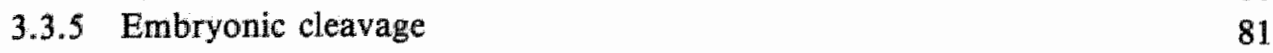

3.3.6 Degeneration $\quad 86$

$\begin{array}{lll}3.3 .7 & \text { Mucin layer } & 87\end{array}$

$\begin{array}{ll}\text { 3.3.8 Tubal transport } & 89\end{array}$

Chapter IV. Discussion

4.1 Nomenclature $\quad 93$

4.2.1 Corpora lutea $\quad 93$

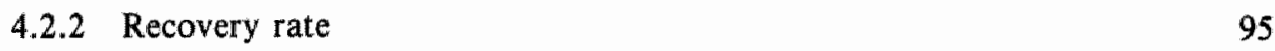

$\begin{array}{llr}4.2 .3 & \text { Fertilization } & 97\end{array}$

$\begin{array}{llr}4.2 .4 & \text { Spermatozoa } & 100\end{array}$

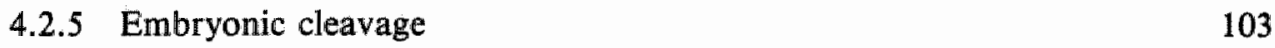

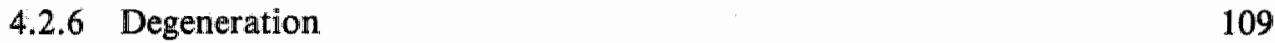

$\begin{array}{ll}4.2 .7 \text { Mucin layer } & 110\end{array}$

$\begin{array}{lll}4.2 .8 & \text { Tubal transport } & 113\end{array}$

$\begin{array}{lll}4.2 .9 & \text { Fecundity } & 116\end{array}$

$\begin{array}{lll}4.3 & \text { Conclusions } & 118\end{array}$

$\begin{array}{ll}\text { Summary } & 121\end{array}$

$\begin{array}{ll}\text { Samenvatting } & 123\end{array}$

$\begin{array}{lr}\text { Yhteenveto } & 125\end{array}$

$\begin{array}{ll}\text { Literature } & 127\end{array}$

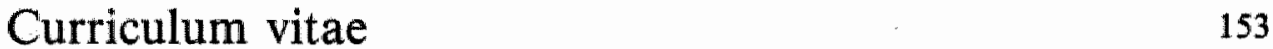




\section{CHAPTER I. Introduction}

\subsection{Introduction}

Infertility affects approximately $10 \%$ of couples. The incidence of tubal pathology in infertility depends on the selection and composition of the population studied, but it is estimated that in $15-35 \%$ of infertile couples a 'tubal factor' is associated with female infertility (Jones and. Pourmand, 1962; Arronet et al, 1969; Speroff et al, 1984).

Operative procedures to reconstruct damaged and occluded tubes have been employed for more than a century. Jacobson and Suarez (1960) first applied microsurgery for the anastomosis of small blood vessels. The first detailed reports of the application of microsurgery to Fallopian tube reconstruction were published by Paterson and Wood (1974) and Winston and McClure Browne (1974). Nowadays microsurgery has become an accepted method in the treatment of tubal infertility.

Sociomedical trends in the last 10-20 years have increased the demand for reconstructive infertility surgery: the current rise of sexually transmitted diseases and the increased use of intrauterine devices have augmented the risk of salpingitis, and the extensive use of female tubal sterilization has created the demand for its reversal (Winston, 1977).

Recent advances in (micro)surgical techniques generally permit satisfactory reconstruction of damaged tubes and restoration of pelvic anatomy. For the evaluation of the efficacy of reconstructive tubal surgery the ratio of the number of patients who either recover tubal patency (patency rate) or become pregnant (pregnancy rate) to the number of patients operated upon, is calculated. Even when technical results are optimal, the clinical outcome remains, however, often disappointing: remarkable is the discrepancy between the patency rate and the pregnancy rate reported (table I.1). Although technical improvement has resulted in increased success in restoring tubal patency, proportional restoration of normal function has not been achieved. Objective assessment of the clinical value of reconstructive tubal surgery is limited by the inability to evaluate tubal function prior to and following surgery. Because of lack of opportunities for systematical examination of tissue from patients who have undergone tubal surgery, few data are availlable about anatomic, morphologic and functional changes after surgery.

A better understanding of tubal anatomy and physiology is a prerequisite for future improvements in reconstructive microsurgery, and to the management of tubal factors in infertility in general. Well-controlled animal studies provide a tool for the enhancement of our knowledge of basic tubal physiology, as well as for the development and refinement of new microsurgical procedures and for the evaluation of their effects. 
Table 1.1

Tubal patency rates and pregnancy rates after reversal of sterihzation

\begin{tabular}{|c|c|c|c|c|c|c|}
\hline Author(s) & Year & $\begin{array}{l}\text { Number } \\
\text { of cases }\end{array}$ & $\begin{array}{l}\text { Operating } \\
\text { procedure }\end{array}$ & $\begin{array}{c}\text { Twbes } \\
\text { patent } \\
(\%)\end{array}$ & $\begin{array}{c}\text { Pregnancy } \\
\text { total } \\
(\%)\end{array}$ & $\begin{array}{c}\text { Pregnancy } \\
\text { wastage }\end{array}$ \\
\hline Boeckx el all & 1977 & 21 rabibits & $\begin{array}{l}\text { microsurgical } \\
\text { reversal of } \\
\text { sterilization }\end{array}$ & 96.0 & 86.0 & \\
\hline Hedon et al & 1980 & 22 rabbits & $\begin{array}{l}\text { microsurgical } \\
\text { transection } \\
\text { reanastomosis }\end{array}$ & $>90$ & 81.0 & \\
\hline Diamond + & $68-71$ & 12 women & $\begin{array}{l}\text { macrosurgical } \\
\text { reversal of } \\
\text { sterilization }\end{array}$ & 50.0 & 41.6 & 16.7 \\
\hline Diamond + & $72-73$ & 12 women & $\begin{array}{l}\text { microsurgical } \\
\text { reversal of } \\
\text { sterilization } \\
\text { using stents }\end{array}$ & 91.7 & 66.6 & 16.6 \\
\hline Diamond + & 1974 & 16 women & $\begin{array}{l}\text { microsurgical } \\
\text { reversal of } \\
\text { sterilization } \\
\text { without stents }\end{array}$ & 93.8 & 75.0 & 12.5 \\
\hline Gomel & 1977 & 16 women & $\begin{array}{l}\text { microsurgical } \\
\text { reversal of } \\
\text { sterilization }\end{array}$ & 93.8 & 56.3 & 6.6 \\
\hline
\end{tabular}

* including first and second trimester abortions, ectopic pregnancies

* published 1977

\subsection{Embryology}

In the absence of a $\mathrm{Y}$ chromosome in the human embryo the paramesonephric or Müllerian ducts begin to develop in the 6th week of embryonic life. Each commences as a groove-like invagination of the coelomic epithelium. The blind ends grow caudally on the lateral aspects of the mesonephric ridge and acquire a lumen as they lengthen. At the caudal end of the mesonephros the paramesonephric ducts turn medially, cross the mesonephric ducts and enter the genital cord. The two paramesonephric ducts fuse into one uterovaginal primordium.

The cranial part of each duct forms the Fallopian tube, clearly distinguishable in the 12th week of embryonic life. The original coelomic invagination remains as the 
pelvic opening of the tube, the fimbriae becoming defined at the cranial end as the mesonephros degenerates. The caudal fused portions of the paramesonephric ducts, forming the uterovaginal primordium, give rise to the forming of the uterus.

Fusion of the paramesonephric ducts also brings together two peritoneal folds, forming the broad ligaments. Between the layers of each broad ligament loose connective tissue and smooth muscle appear: the parametrium.

Mesonephric remnants may persist in the broad ligament between the ovary and the Fallopian tube (paroöphoron and epoöphoron) or beside the lateral wall of the uterus or vagina (duct of Gärtner).

\subsection{Tubal anatomy}

Gabriele Falloppio is said to have been the first who accurately described the human uterine tube, in Observationes Anatomicae (1561) (figure 1.1):

'This seminal duct originates from the cornua uteri; it is thin, very narrow, of white color, and looks like a nerve. After a short distance it begins to broaden and to coil like a tendril, winding its folds almost up to the end. There, having become very broad, it shows an extremitas of the nature of skin and color of flesh, the utmost end being very ragged and crushed like the fringe of wornout clothes. Further, it has a great hole which is held closed by the fimbria which lap over each other. However, if they spread out and dilate, they create a kind of opening which looks like the flaring bell, the brazen tube. Because the course of the seminal duct, from its origin up to its end, resembles the shape of this classic instrument, whether the curves are existing or not, I named it tuba uteri'.

In the human female the tube measures $8-12 \mathrm{~cm}$ and is enclosed within the leaves of the broad ligament. This portion of the peritoneum is designated the mesosalpinx. The proximal end of the tube opens into the uterine cavity, the distal orifice opens into the pelvic cavity.

In the rabbit (figure 1.2) there are two separate uterine horns, ending by way of two cervices in a single vagina throughout their lengths $(6-10 \mathrm{~cm})$. The tubes are supported at the abovarian side by a peritoneal fold, the mesosalpinx. At the ovarian (antimesosalpingeal) side the mesotubarium superius extends as a thin membrane, terminating in a free border along which the fimbria ovarica is found. The fatty mesotubarium inferius curves medially to the upper pole of the ovary. The distal part of the tube forms a loop, while the two mesotubaria create an open peritoneal pocket around the ovary. 
Meatus uero ifte feminarius grecilis \& anguftus admotum orieur nerueus ac candidus à cornu ipfiu uteri, cumque parum recefferit ab co latior fenfim redditur, \& capreo li modo crifpat fe donccueniat pro pè finem, tunc dimiffis capreolaribus rugis, arque ualde latus reditus finit in extremum quodam, quod membranofum carneumque ob co lorem rubrum videtur, extremumque lacerum ualde \& attritum eft; ueluti funt pannorum attritorum fimbriz, \& foramen amplum habet, quod femper claufum iacet concidétibus fimbriis illis extremis, qua tamen fi diligenter aperiantur,ac di latentur tub $x$ cuiufdam anex extre mum orificium exprimunt. Quare cum huius claffici organi demptis capreolis, uel etiam iifdem additis meatus feminarius a principio ufq ad extremum fpeciem gerat, ideò me uteri tuba uocatus eft. Ita fe hac habent in omnibus non folum humanis, fed etiam ouinis, 26 yacipis eadaueribus, reliquisque brutornm omnium, que cgo fecui . 


\subsubsection{Tubal segments}

\section{Infundibulum}

In the human and in the rabbit the trumpet-shaped distal part of the oviduct is the infundibulum, containing the abdominal ostium. In the human the diameter of the ostium is $1-1 \frac{1}{2} \mathrm{~cm}$, surrounded by fimbriae. The muscularis is thin, with an outer longitudinal and an inner circular muscle layer. The mucosa is extensively plicated. The epithelium is densely ciliated, the ciliated cells representing more than $60 \%$ of the epithelial cell population in healthy, fertile women (Brosens and Vasquez, 1976). All ciliated cells beat uniformly in a prouterine direction (Gaddum-Rosse and Blandau, 1976).

Observations in the human by culdoscopy or laparoscopy indicate that during the ovum pick-up the fimbriae and oviductal ostium are brought into close contact with the ovary by contraction of the smooth muscles of the mesosalpinx and tuboovarian ligaments (Decker, 1951). The fimbria ovarica is attached to the adjacent tubo-ovarian peritoneum, which may be of importance for normal ovum pick-up (Cohen and Katz, 1978).

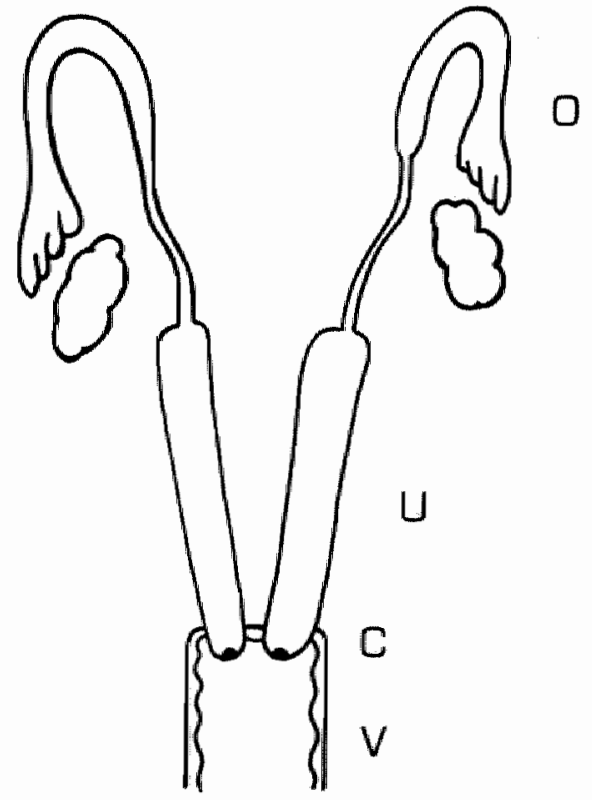

Figure 1.2 Rabbit female reproductive system

A single vagina (V), two cervices (C), a double uterus (U) and two oviducts $(O)$

\section{Ampulla}

The ampulla is the longest of the tubal segments. In the rabbit the ampullary seg- 

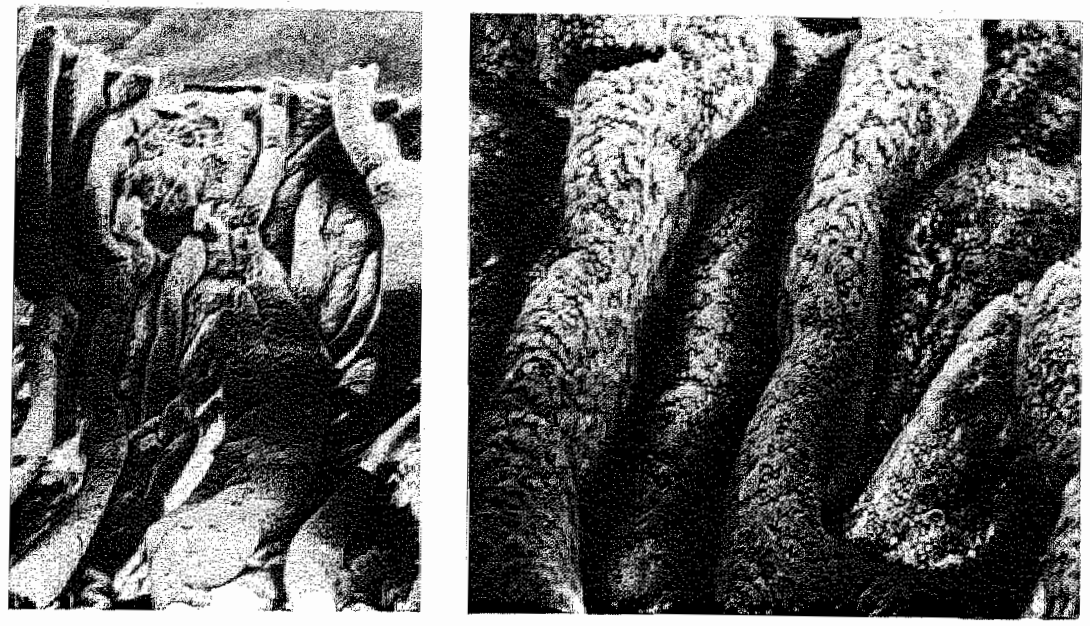

a
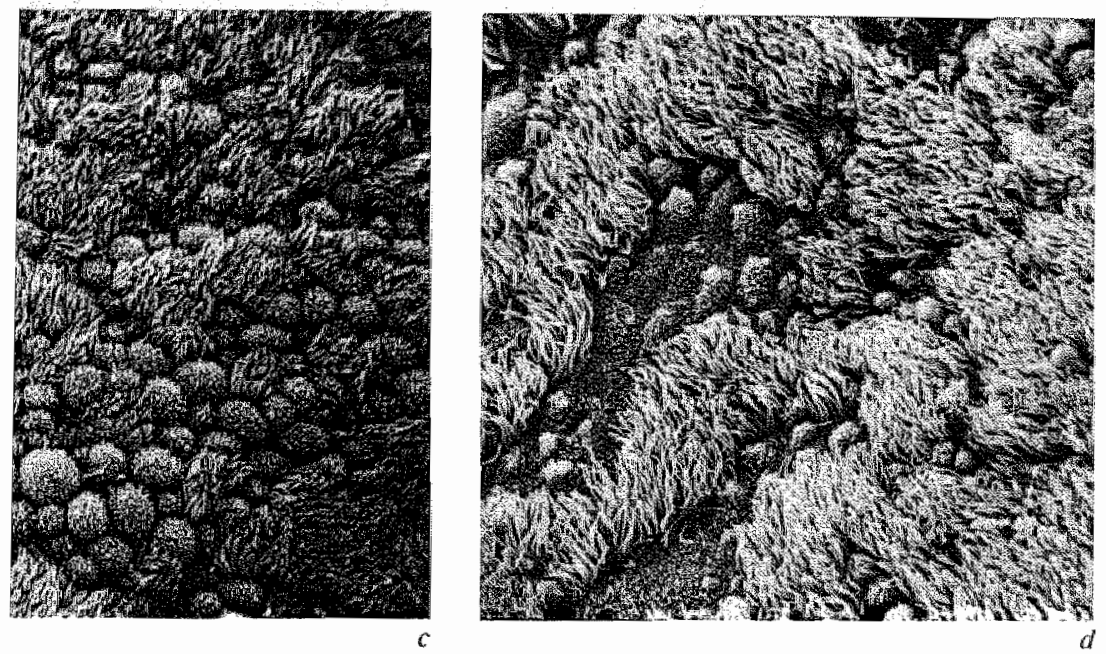

bit ampulla

on microsicopy $x 60(a), x 240(b), x 1220(c)$ and $x 1400$ (d). Courtesy of Dr Gloria Vasquez, olgium

up approximately $60 \%$ of the tubal length. The diameter of the lumen 1-2 mm at the ampullary-isthmic junction to $1 \mathrm{~cm}$ near the infundibuapulla has a thin muscular layer. The mucosa contains 3 to 5 longitudifolds. Between the large primary folds are numerous intermediately siIll ones that leave just a virtual lumen. The mucosa is densely ciliated, i representing 40-60\% of the epithelial cells. The cilia are numerous at the mucosal folds and their number diminishes towards the tops (Vas980a)(figure 1.3). The ciliary beat throughout the ampulla is uniformly e direction. Those particles that come into contact with the apical seg2 mucosal folds are transported most rapidly (Gaddum-Rosse and Blan- 

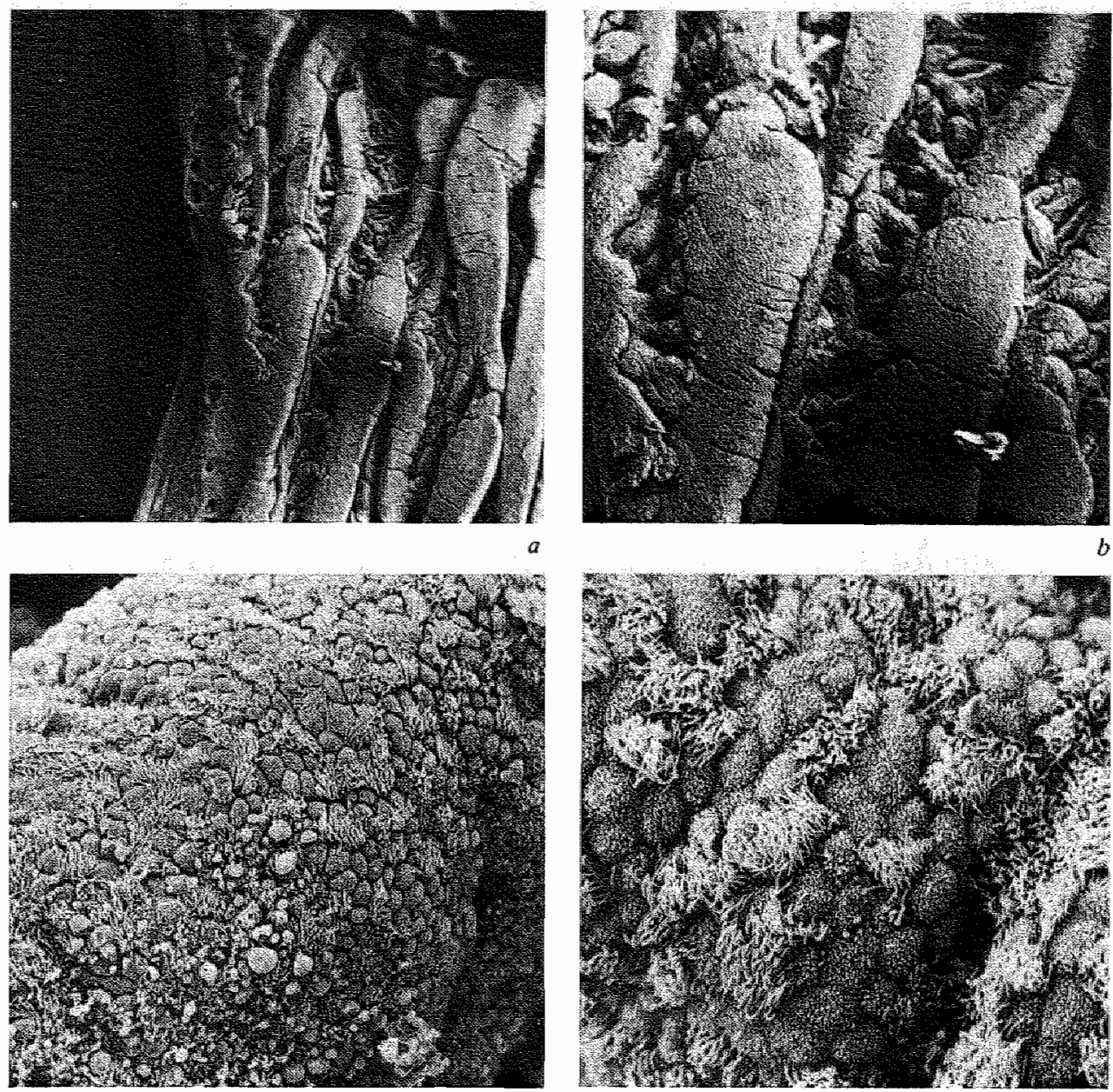

Figure I. 4 Rabbit isthmus

Scanning electron microscopy $x 28(a), x 68(b), x 625$ (c) and $x 1350(d)$. Courtesy of Dr Oloria Vasqueq, KU Lewwen, Belgimm

\section{Isthmus}

The isthmus is the most proximal segment of the extrauterine oviduct in the human as well as in the rabbit. Its lumen ranges from $0.1 \mathrm{~mm}$ near the utero-isthmic junction to 1-2 $\mathrm{mm}$ at the ampullary-isthmic junction. The isthmus has a well developed muscle layer, consisting of an outer and inner longitudinal layer with a circular layer in between. The mucosa contains 4 to 5 low and slightly rounded folds. The amount of ciliated cells has diminished to $20-25 \%$ of the epithelial cells (Vasquez et al, 1980a)(figure 1.4). In the rabbit pro-ovarian ciliary currents have been observed in the lower isthmic segment (Gaddum-Rosse and Blandau, 1973). Contrary to the du- 
al pathways in the rabbit isthmus, in the human the transport of particles is consistently in a downward direction towards the uterus (Gaddum-Rosse et al, 1973). The isthmus is thought to be important in regulating the passage of gametes: the passage of spermatozoa into the ampulla and the passage of the ovum into the uterus.

\section{Intramural segment}

In the human the intramural, or interstitial, part of the uterine tube may follow a straight or tortuous course in the uterine wall. The muscular coat is composed of an inner and an outer longitudinal layer, and an intermediate, circular layer, which is arranged in a spiral-like fashion. The 2 to 3 tubal epithelial folds may extent into the uterine cavity or end a few millimeters before. The transition from intramural endosalpinx to cornual endometrium is marked by a transitional area, with characteristic histologic features: there is a marked decrease in the number of ciliated cells, and the secretory cells tend to be flattened and assume a polygonal, elongated shape rather than their usual rounded dome appearance (Fadel et al, 1976). The intramural segment is considered by some investigators to function as a sfincter between the oviduct and the uterine cavity (Vasen, 1959).

\subsubsection{Histology of tubal mucosa}

In the human as well as in the rabbit the three histologic layers of the oviduct are made up by a mucosal membrane, a wall of smooth muscle and a serosal coat (figure 1.5; page 20). The tubal mucosa consists of an epithelial layer and an underlying lamina propria. There is no submucosa, the muscular coat surrounds the mucosal membrane directly. The lamina propria resembles the endometrial stroma. It is highly vascular and rich in lymphatic vessels, giving turgor to the epithelial folds and holding them erected. The lamina propria contains a network of reticular fibres and various types of cells including mast cells.

In the human four different cell types have been described in the tubal epithelium:

1. The ciliated cell is relatively square in contour and contains finely granular cytoplasm. The central nucleus is large in comparison with the cytoplasmatic volume, and is round or oval in shape. The percentage of ciliated cells in the mucosa increases gradually from $20-25 \%$ in the isthmus to over $60 \%$ in the fimbriae (Vasquez et al, 1980a). Cilia have been demonstrated to play an important role in ovum pick-up and transport (Odor and Blandau, 1973; Halbert et al, 1976b). Brosens and Vasquez (1976) reported a correlation to exist between fertility and the percentage of ciliated cells on the human fimbriae. Reports of normal fertility in wornan suffering from the immotile cilia syndrome (Afzelius et al, 1978; Jean et al, 1979) cast doubt, however, upon the indispensability of motility of the cilia to human reproduction. 
2. The secretory cell contains a granular cytoplasm with fine granules. The mucleus is wedge- or ovalshaped and dark. Its position in the cell varies with the phase of the ovarian cycle. During the follicular phase of the cycle, the epithelium attains its greatest height and the secretory and ciliated cells are equally prominent, so that the epithelium has a regular luminal border. During the luteal phase, the ciliated cells become broader and lower, and the secretory cells protrude above the level of ciliated cells. Late in the luteal phase, the cupolas of the secretory cells rupture, extruding cytoplasmic and nuclear material into the tubal lumen. Subsequently a marked irregularity of the border is seen, due to diminution in height of nonciliated cells.

3. The 'peg' cells, or intercalary cells, are so named because they look like slender pegs driven between the other cells. The nuclei frequently appear as wedgelike masses close to the basement membrane and are surrounded by a small amount of cytoplasm. The 'peg'cells are present in largest number in the premenstrual and menstrual periods. In a certain phase they cannot be distinguished from the secretory cells. The two types are thought to represent different phases of the same life cycle (Novak and Woodruff, 1979; Patek, 1979).

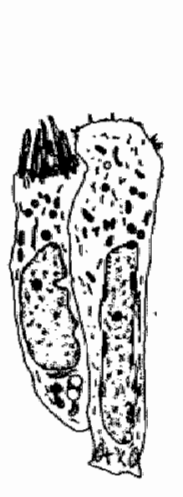

Eartiv Ferilleutor

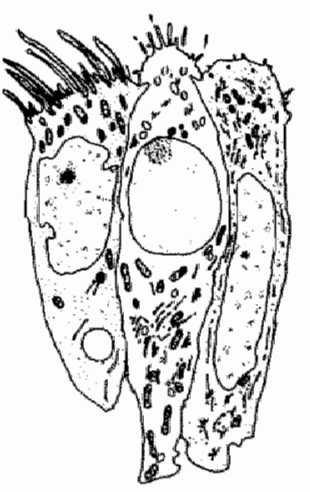

Mid- andilicular

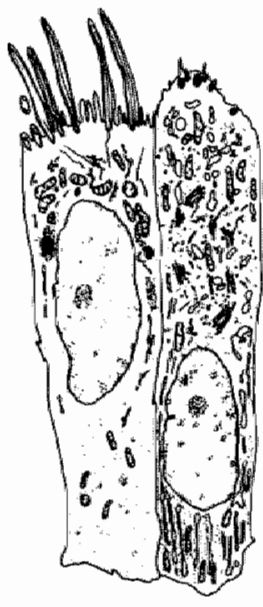

Gate Follicular

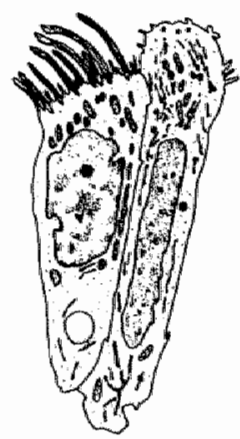

Heile lubat

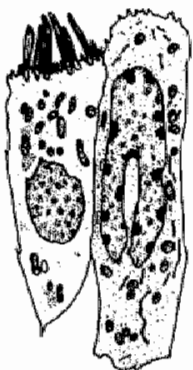

Finginatint

Figure 1.6 Cyclic changes in rubal epithelium in women

(reprinted with permission from Verhage et al, Obstet. Gyntecol. Surv. 1980, 35: 653-657)

4. The 'indifferent' cells form a small population of cells. They lie along the base of the normal epithelium and cannot be identified by scanning electron microscopy because of their deep position (Fadel et al, 1976). The function of the 'indifferent' cells is not yet fully understood. They may be the progenitors of the epithelial and stromal elements (Pauerstein and Woodruff, 1967; Novak and Woodruff, 1979), or have a function in immunologic defence. Van Bogaert et al (1978) postulated that the 'indifferent' cells may act as granulocytes. According 


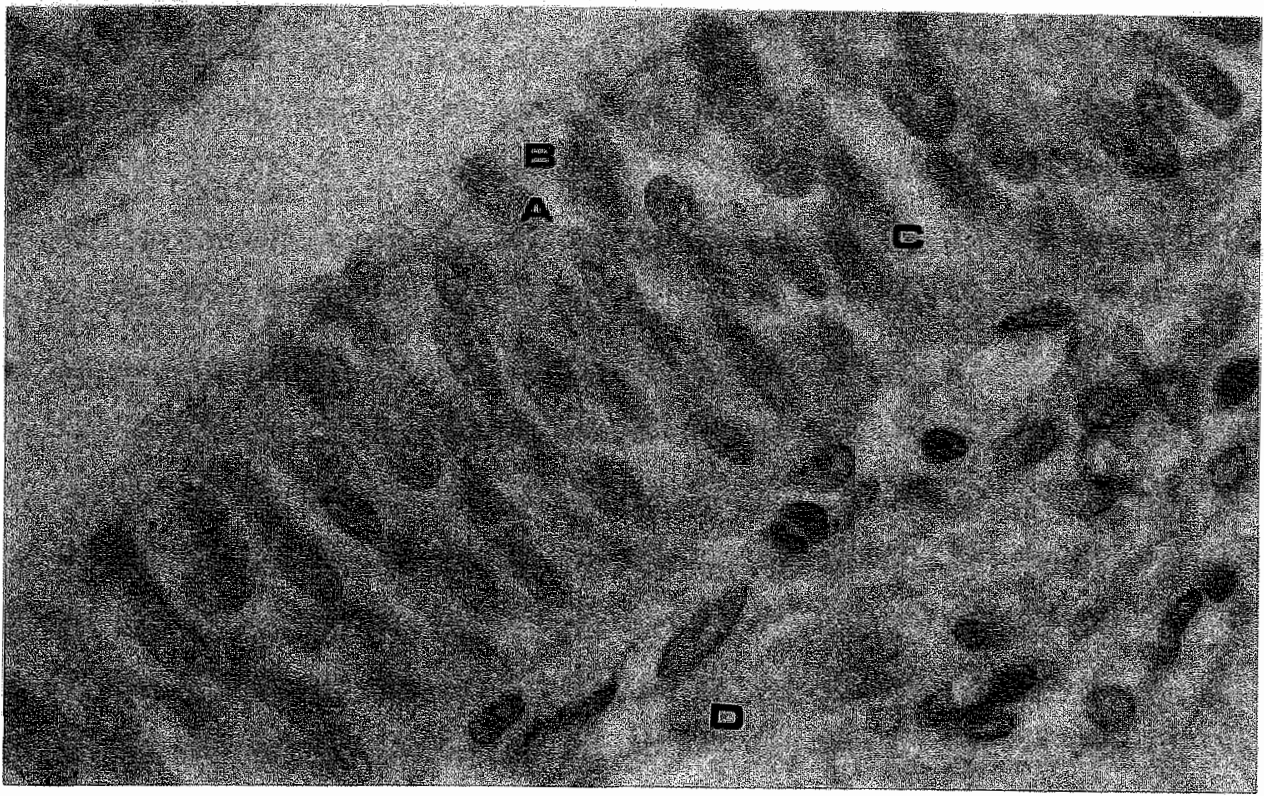

Figure 1.5 Histology fubal mucosa (P.AS-sfaining)

A secretory cell $B$ cilloted cell $C$ peg cell $D$ stroma

to Odor (1974) the 'indifferent" cells actually may be lymfocytes.

There is disagreement as to specific changes in the detailed morphology and distribution of the ciliated cells during the cycle. Both ciliated and secretory cells individually respond to ovarian steroid fluctuations with morphologic alterations, such as an increase in size, number of cytoplasmic granules and mitochondria (figure 1.6). The cyclic changes are just slight compared with the alterations in the uterine glandular epithelium. Some renewal of ciliated cells does probably occur, although mitotic activity rarely has been observed (Patek, 1979). There is no evidence for transformation of ciliated into secretory cells in the human oviduct, nor for desquamation of ciliated cells, nor for cyclic changes in the distribution of ciliated cells (Novak and Everett, 1928; Clyman, 1966; Patek et al, 1972a; Brosens and Vasquez, 1976). Some degree of deciliation and reciliation in the fimbriae and distal ampulla has been reported to occur during the menstrual cycle in the rhesus monkey, however (Brenner, 1969). Verhage et al (1979) studying the oviductal epithelium in women, found some deciliation during the late luteal phase, particularly in the fimbriae. Deciliation coincided with increased levels of progesterone in the peripheral plasma, and Verhage et al assumed that the induction and maintenance of a mature tubal epithelium is controlled by estradiol, and that this effect is antagonized by pro- 


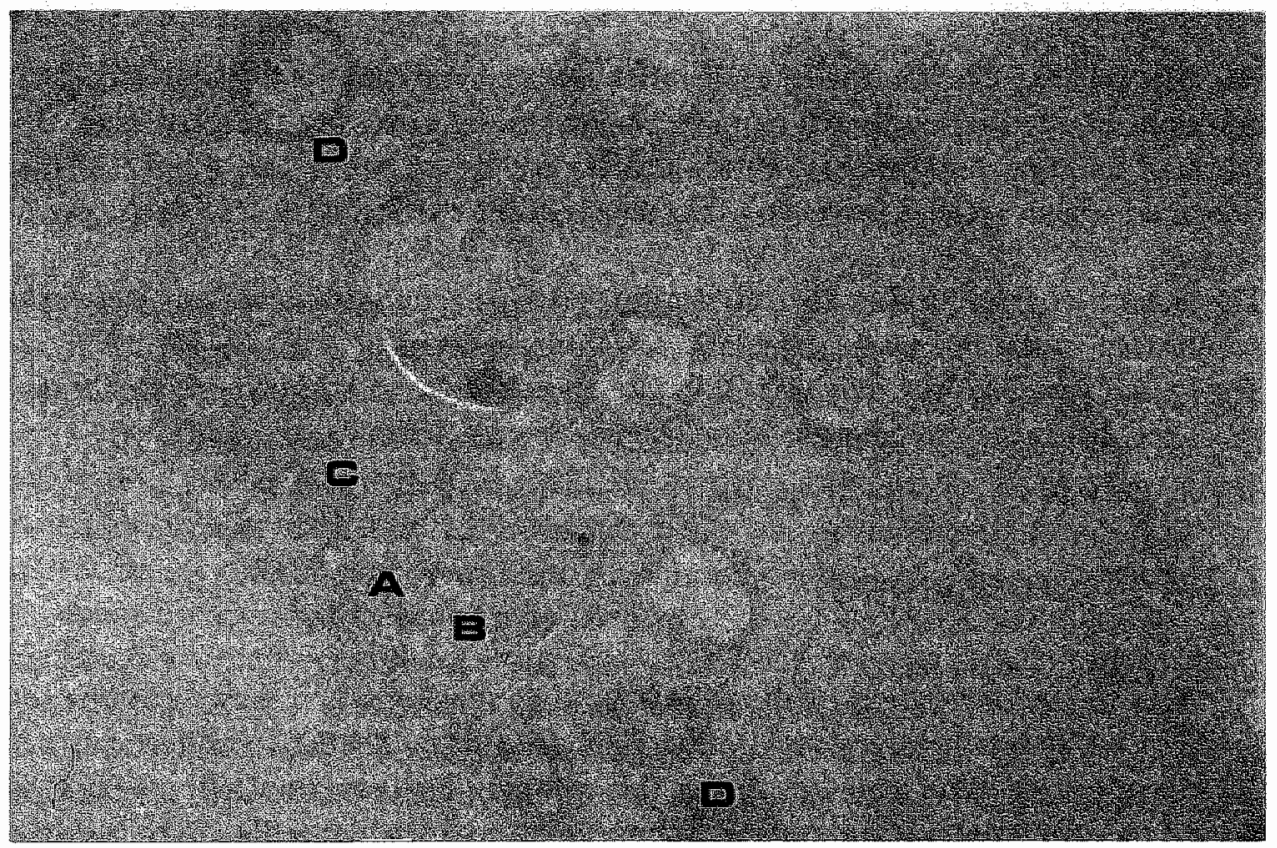

Figure 1.7 Rabbit ovary

A primary aocyte $B$ primordial follicle $C$ preantral follicle $D$ aniral follicle

gesterone in spite of the continued presence of estradiol in the system. They found the process of cellular flattening and deciliation to continue in pregnancy. In a group of women in the first 15 years of the menopause Patek et al (1972b) never observed any deciliation in the ampullary nor in the infundibular tubal epithelitum. In a group consisting of women 20 to 30 years past the menopause they found in the isthmus large areas of flattened epithelium without any cilia where no secretion took place, which suggests that tubal mucosal cells may be more refractory to ovarian steroids than those of the endometrium. Although there is disagreement concerning the morphological changes in ciliated tubal cells, it is generally accepted that it is the individual cell rather than a tissue which undergoes a cycle (Ludwig and Metzger, 1976).

\subsubsection{Vascular anatomy}

The arterial blood supply of the oviduct is derived from the uterine and ovarian arte- 
ries. The relative contribution of each varies greatly in individual women. Generally, branches of the uterine artery supply the intramural part and the proximal twothirds of the tube, and branches of the ovarian artery the lateral one-third. The uterine and ovarian arteries have extensive shunts in the oviduct as well as in the mesosalpinx.

The venous drainage follows the arterial supply. Interconnected capillary networks are located in the mucosa, muscularis and subserosa.

The lymph vessels of the oviduct follow the course of the ovarian lymphatic drainage. They discharge into the aortic or lumbar lymph nodes.

\subsubsection{Neuroanatomy}

The autonomic innervation of the tube is both sympathetic and parasympathetic. Some of the sympathetic preganglionic fibers arise from Th10-L2 and terminate in the inferior mesenteric ganglion. From this ganglion postganglionic fibers pass via the hypogastric plexus to supply the isthmus and proximal ampulla. Other sympathetic preganglionic fibers from Th10-Th11 synapse in the celic, aortic and renal ganglia and send postganglionic fibers to the distal ampulla and fimbriae. The postganglionic fibers that originate in the inferior mesenteric ganglia are called 'long adrenergic neurons'. In addition to these, preganglionic fibers are running along the hypogastric nerve to supply ganglia at the level of the cervico-vaginal junction. The postganglionic fibers originating in these peripheral ganglia are called 'short adrenergic neurons'. The intrinsic adrenergic innervation of the myosalpinx is about equally derived from both long and short neurons. A dense adrenergic innervation has been identified in the circular muscle coat of the isthmus and at the ampullaryisthmic junction. The neurotransmitter content has been reported to vary during the ovarian cycle, the noradrenaline concentration being higher during the luteal phase than during the follicular phase (Sjöberg et al, 1977). The adrenergic supply to the ampullary smooth muscle cells is sparse (Owman et $\mathrm{al}$, 1967).

The afferent innervation of the tube accompanies the sympathetic nerves and is derived from Th11 and Th12 and the upper lumbal nerves. The afferent visceral fibers travel from the tube to the central nervous system via the autonomic system. Sensory nerves from the fimbriae and ampulla may pass to the spinal cord via the ovarian plexus and splanchnic nerve.

The parasympathetic supply to the tube is also dual. The lateral portion of the tube is supplied by vagal fibers from the ovarian plexus. The interstitial segment of the isthmus is supplied by postganglionic fibers originating in the terminal ganglia of the pelvic plexus, which in turn are supplied by fibers derived from S2-S4. 


\subsection{Tubal physiology}

\subsubsection{Ovum pick-up}

Many hypotheses have been formulated about the mechanism underlying the transfer of freshly ovulated ova from the ruptured follicle to the oviduct.

An early theory suggested that ova were drawn into the tube by a negative pressure caused by tubal peristalsis. Clewe and Mastroianni (1958) demonstrated that suction is not an essential factor in ovum pick-up in the rabbit. In the normal rabbit the ovulated cumulus mass is initially attached to the side of the stigma. It has been suggested that at the time of ovulation the fimbriae are brought into apposition with the ovary by contraction of the muscles of the fimbriae ovarica and muscular elements in the paraovarian tissue (Okamura et al, 1977; Pauerstein and Eddy, 1979). The programming of the muscular activity may be related to the changes in the ovarian steroid concentrations periovulatory (Boling and Blandau, 1971). The ova in their cumuli oophori are transported rapidly by the beat of the cilia over the fimbrial surfaces through the ostium into the ampulla (Wheeler, 1982). Direct ciliary contact with the cumulus oophorus seems to be of primary importance in ovum pick up. If the fimbriae are removed surgically and the female ovulates, the ovulated masses adhere to the ovarian surface for a long time, instead of being rapidly transported (Halbert and McComb, 1981). Odor and Blandau (1973) demonstrated that marked deciliation of the fimbriae is associated with delayed and less effective ovum transport. However, there is no absolute infertility in the absence of fimbriae (Beyth and Winston, 1981; Perez et al, 1981a), and even tubal fistulas are able to pickup ova (Metz and Mastroianni, 1979). From studies of different kinds of neofimbriae Halbert et al (1981a) postulated that surface area of the neofimbrial end and physical approximation to the ovary of the pick-up structure are of importance for the efficacy of ovum pick-up. The adherence of ova to the (neo)fimbriae seems to be dependent on the stickiness of the cumulus and on the percentage of ciliated cells. Variations in the pick-up pattern surely exist, as evidenced by women who achieve pregnancy despite having only one ovary, and a single tube located on the contralateral side (First, 1954).

\subsubsection{Sperm transport}

Sperm transport in the female genital tract evokes still unresolved physiologic questions. The normal human ejaculate contains more than 100 million sperm. Sperm counts below 10 million per $\mathrm{ml}$ are associated with infertility (Edwards, 1980c). Yet fewer than 200 of the total number arrive at the ampulla of the uterine tube (Ahlgren, 1975). Similarly in other species investigated, a small number of sper- 
matozoa only finds its way to the site of fertilization (Thibault, 1972). The passage of sperm into the oviducts is restricted, and probably regulated by various barriers, including the utero-tubal junction (Austin, 1975a) and the isthmus (Ahlgren, 1975; Overstreet and Cooper, 1978b). Excessive numbers of spermatozoa in the ampulla may be deleterious to fertilization. Hunter and Léglise (1971) reported an increased incidence of polyspermic fertilization, resulting in early embryonic loss, after resection of the oviductal isthmus in rabbits. Spermatozoa obtained from the peritoneal cavity reveal no abnormal forms (Asch, 1976), which indicates that some form of selection operates. Spermatozoa reaching the site of fertilization may represent a highly selected sample of gametes relatively free of defects and more capable of achieving fertilization than most others present in the ejaculate.

A second question concerns the mechanism by which sperm are transported in the female genital tract. The ascent of spermatozoa from the vagina to the oviduct occurs more rapidly than the intrinsic motility of the spermatozoa could account for. Sperm have been recovered from the oviduct within minutes of deposition into the vagina in the human (Settlage et al, 1973), as well as in the rabbit (Overstreet and Cooper, 1978a). The number of sperm reaching the oviduct has been shown to remain constant for at least 15-45 minutes following the appearance of sperm in the oviduct, which suggests continuous replacement of those lost in the peritoneal cavity by others from reservoirs below (Settlage et al, 1973). There seems to be an active system operating in the female genital tract to transport sperm. Muscle contractions may assist sperm transport. Antiperistalsis in the isthmus, in ampullary direction, during the periovulatory period has been postulated (Blandau et al, 1979). Oviductal fluid currents, evoked by ciliary and muscle action and moving towards the ovary have been demonstrated (Gaddum-Rosse and Blandau, 1976) and might contribute to sperm transport. The role of the cilia per se in sperm transport is unknown. In some mammals dual cilliary pathways have been identified, while in others, as the human, ciliary beat is uniformly in pro-uterine direction (Gaddum-Rosse and Blandau, 1973; Gaddum-Rosse et al, 1973). If a universal mechanism of sperm transport in the isthmus is suggested, it is likely to involve muscle contractility rather than ciliary activity.

\subsubsection{Sperm activation}

The classic experiments of Chang (1951) and Austin (1952) demonstrated that fresh epididymal sperm are unable to penetrate and fertilize oocytes. The fertilizing ability is gained after morphological and physiological alterations, including sperm capacitation and the acrosome reaction, have taken place (Austin, 1967; Bedford, 1970). Capacitation may be initiated after removal of inhibitory substances, the decapacitation factor (Chang, 1957), from the plasma membrane of the spermatozoon (Austin, 1975b). The capacitation process is believed to involve the removal of sur- 


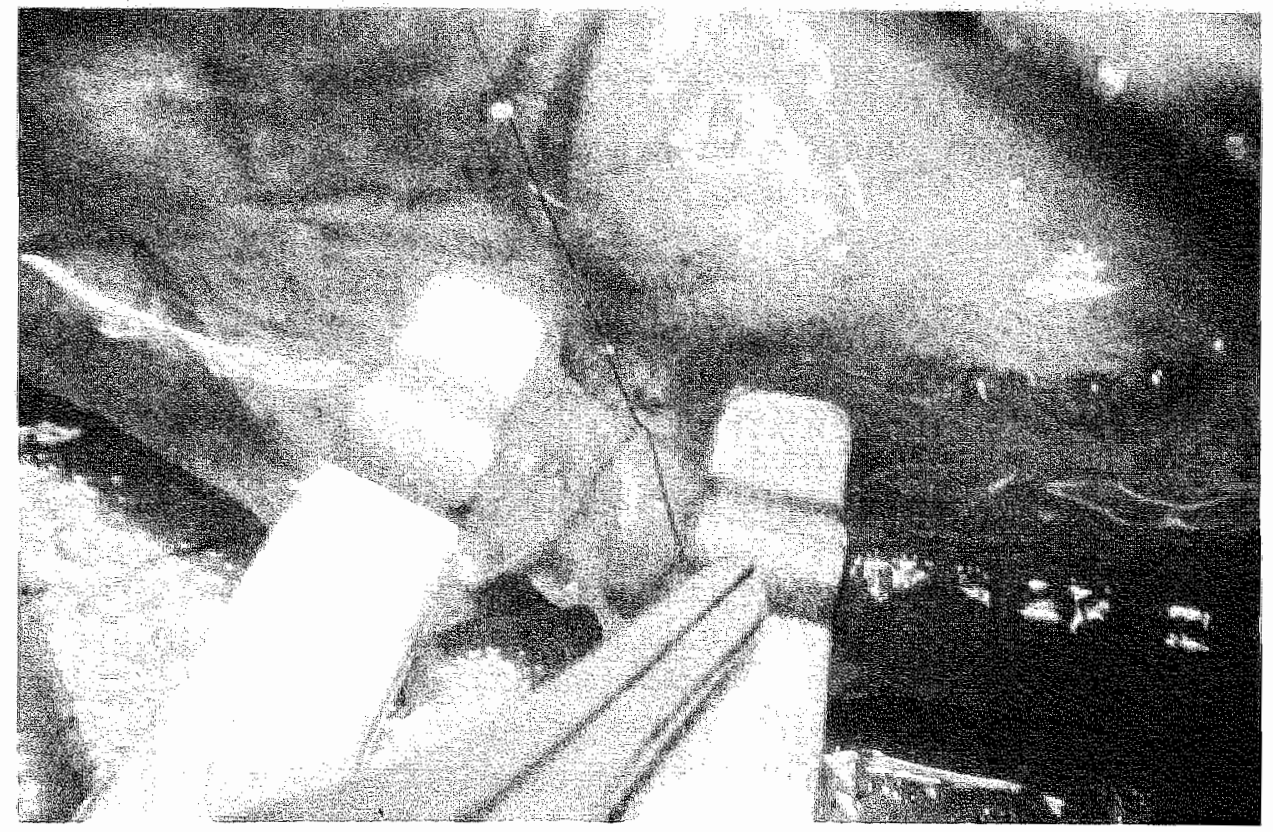

Figure 2.2 Reanastomosis of the rabbit oviduct

A stitch is placed, including the serosa and muscular coat of the oviduct. Tubal clamps keep blood loss at a mimimum during the surgical procedure

face coats from the spermhead membranes. It affects sperm metabolism and leads to sperm 'activation' in which flagellation increases and sperm movement changes in character. The capacitation process is followed by the acrosome reaction, which results in the release or activation of enzymes. Although both acrosome-reacted and unreacted sperm are seen in the cumulus and entering the zona pellucida, only acrosome-reacted sperm can penetrate the inner zona and fuse with the oolemma (Bedford, 1968). Evidence exists that the active life of the mammalian spermatozoon may be limited to 1 to 2 hours once the acrosome reaction has occurred (Fleming and Yanagimachi, 1982).

Capacitation is required in all mammalian species examined, including man (Talbot, 1984). The length of time required to prepare sperm to attain fertilizability varies between species. It takes 6-8 hours in rabbits (Chang, 1951; Bedford, 1970). In vitro fertilization of zona-intact pre-ovulatory human ova indicates that capacitation takes 3-4 hours (Lopata et al, 1978), but synergism between different regions in the female tract may accelerate the process in vivo (Adams and Chang, 1962b). The changes associated with capacitation and the acrosome reaction can be completed 
successfully in the female reproductive tract and in appropriate in vitro culture conditions.

Conflicting data have been reported on the role of ova in the induction of the acrosome reaction. Some authors presume the acrosome reaction to occur only after the spermatozoon has bound to the zona pellucida (Blandau, 1980). Others have pointed out that ova do not play an important role, however, because a normal acrosome reaction of in vitro capacitated spermatozoa does occur in the presence of foreign zona-free ova (Yanagimachi et al, 1976), and even in the total absence of ova (Talbot and Franklin, 1976). Evidence exists that the female reproductive tract has an effect on the sperm activating process. Yanagimachi $(1969,1970)$ demonstrated in follicular fluid and in blood serum two components which seem to be essential for efficient sperm capacitation and for the acrosome reaction, i.e. albumin and a small molecule referred to as the sperm-stimulating factor (Yanagimachi 1969).

Mammalian spermatozoa exposed to capacitating conditions become acrosomereacted asynchronously: only $10 \%$ of the spermatozoa exhibit a response after the minimal period of capacitation. This heterogeneity may be modulated further by the length of time that individual spermatozoa reside in the various compartments of the female genital tract (Bedford, 1983).

\subsubsection{Oocyte maturation and fertilization}

During embryonic life the primordial germ cells which reach the genital ridge in the female proliferate by mitotic divisions. Those residing in the developing ovarian cortex are termed oogonia. Germ cells which have lost the power of mitotic division are designated primary oocytes.

As the primary oocyte forms, ovarian stromal cells surround it and form a single layer of flattened (pre)granulosa cells, thus constituting a primordial follicle (figure 1.7 ; page 21). During intrauterine life the follicle undergoes a sequence of events including oocyte cytoplasmatic enlargement and proliferation of several layers of granulosa cells (Peters and McNatty, 1980). The preantral follicle (figure 1.7) is characterized by an oocyte that is in the growth phase with one or more layers of granulosa cells surrounding it. When follicle growth begins, the oocyte increases in size. The ovum acquires an acellular jellylike coat, the zona pellucida, which is in intimate contact with the surface of the oocyte. Evidence suggests that the zona pellucida is a product of the oocyte and the granulosa cells (Bousquet et al, 1981). In the preantral follicle granulosa cells enlarge and multiply forming the multilayered membrana granulosa. Small patches of fluid become evident among the cells and the theca layer begins to evolve. It differentiates into a highly vascular theca interna (with granular cells producing estrogens) and a theca externa, a collagen containing layer which may play a part in ovulation (Rondell, 1970; Espey, 1974). In the neonatus and during childhood varying degrees of maturation, i.e. primordial, preantral and antrall 
follicles, can be seen in the ovaries. Gonadotrophins are necessary for normal follicular growth during childhood as in their absence antral follicles do not form (Peters, 1979). The transition from a preantral to an antral (or Graafian) follicle (figure 1.7) is gradual. As the granulosa cells multiply there is a concomitant increase in the production and accumulation of fluid, which leads to the formation of a follicular cavity (antrum). As the amount of fluid increases, the oocyte becomes displaced to a more eccentric position within the follicle (figure 1.7). The granulosa cells can be distinguished as those which form the follicular wall and those which form the hillock in which the oocyte is situated (cumulus oophorus). The cells immediately surrounding the oocyte form the corona radiata. In antral follicles that become preovulatory many changes occur. A marked expansion of the whole follicle takes place shortly before follicular rupture, the follicle comes to lie close to the surface and usually bulges from it. In order to allow the oocyte to exit, a localized part of the wall of the ovary and of the follicle wall has to desintegrate. The cumulus oophorus detaches from the mural granulosa and the cells surrounding the oocyte begin to disperse.

In order to give rise to an euploid zygote the gametes have to contain the haploid number of chromosomes. To this end gametogenesis includes two meiotic divisions (figure 1.8). During fetal life primary oocytes begin the first meiotic division and enter a 'resting' stage shortly before or after birth. The first meiotic division is resu-

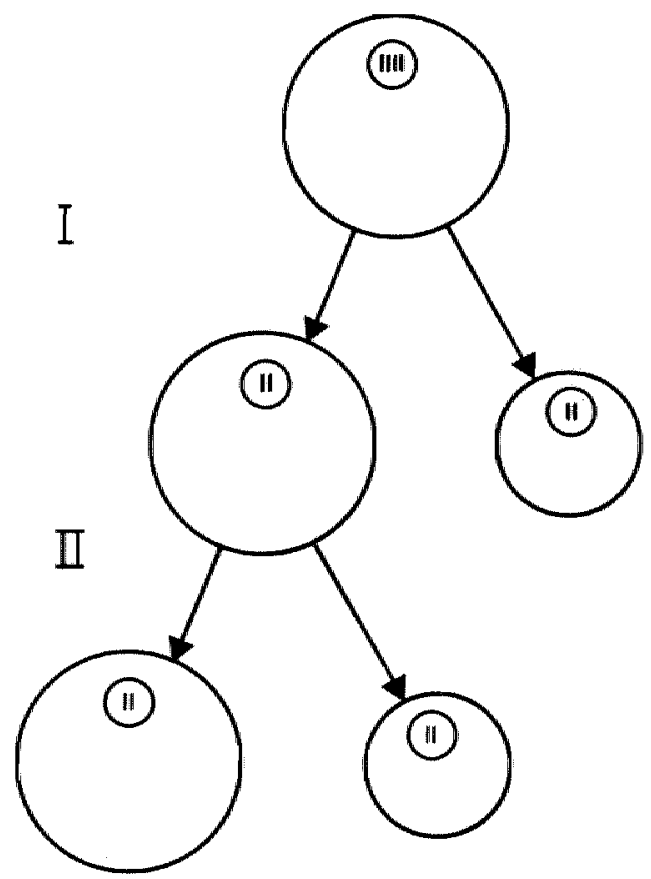

primary oocyte

secondary oocyte, first polar body

mature ovum, second polar body

Figure 1.8 Meiotic divisions

$I$ first meiotic division, II second meiotic division 
med during oocyte maturation shortly before ovulation in response to LHstimulation. The first meiotic division is a reduction division, during which the diploid or full complement of chromosomes is halved. One haploid set of chromosomes remains in the oocyte. The other set becomes isolated in a small cytoplasmatic satellite, the first polar body. In this way the secondary oocyte is formed. The polar body is assumed to take no further part in the process of maturation and later degenerates. The secondary oocyte proceeds to the metaphase of the second maturation division in a few minutes after the extrusion of the first polar body. A delay occurs at metaphase II, while the ovum is ovulated and enters the Fallopian tube. Only if fertilization takes place the second maturation division is completed and the second polar body is extruded (figure 1.9). Therefore, the second maturation division does not involve a strict reduction. The haploid set of chromosomes is split longitudinally into chromatids. Each of the resultant two cells receives an equal amount of genetic

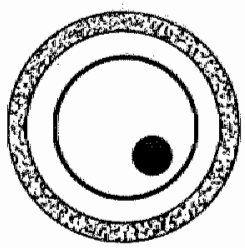

A

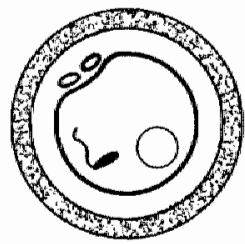

D.

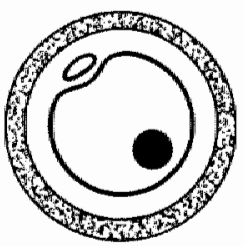

B

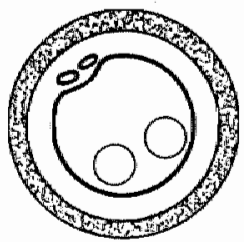

$E$

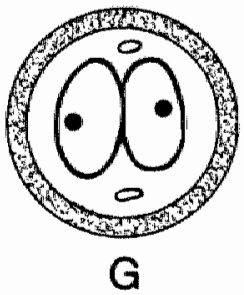

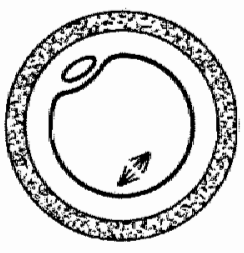

C

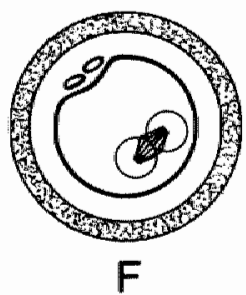

Figure 1.9 Oocyte maturation and fertilization

A primary oocyle

$B$ secondary oocyle

$C$ secondary aocyte at ovulation, second meiotic division

D sperm has entered the oocyte, second polar body and female promucleus are formed

$E^{*}$ spermhead has eniarged to form the male pronucleus

F mitotic spindlle is formed in preparation of the first cleavage division

$G \quad 2$-cell embryo 


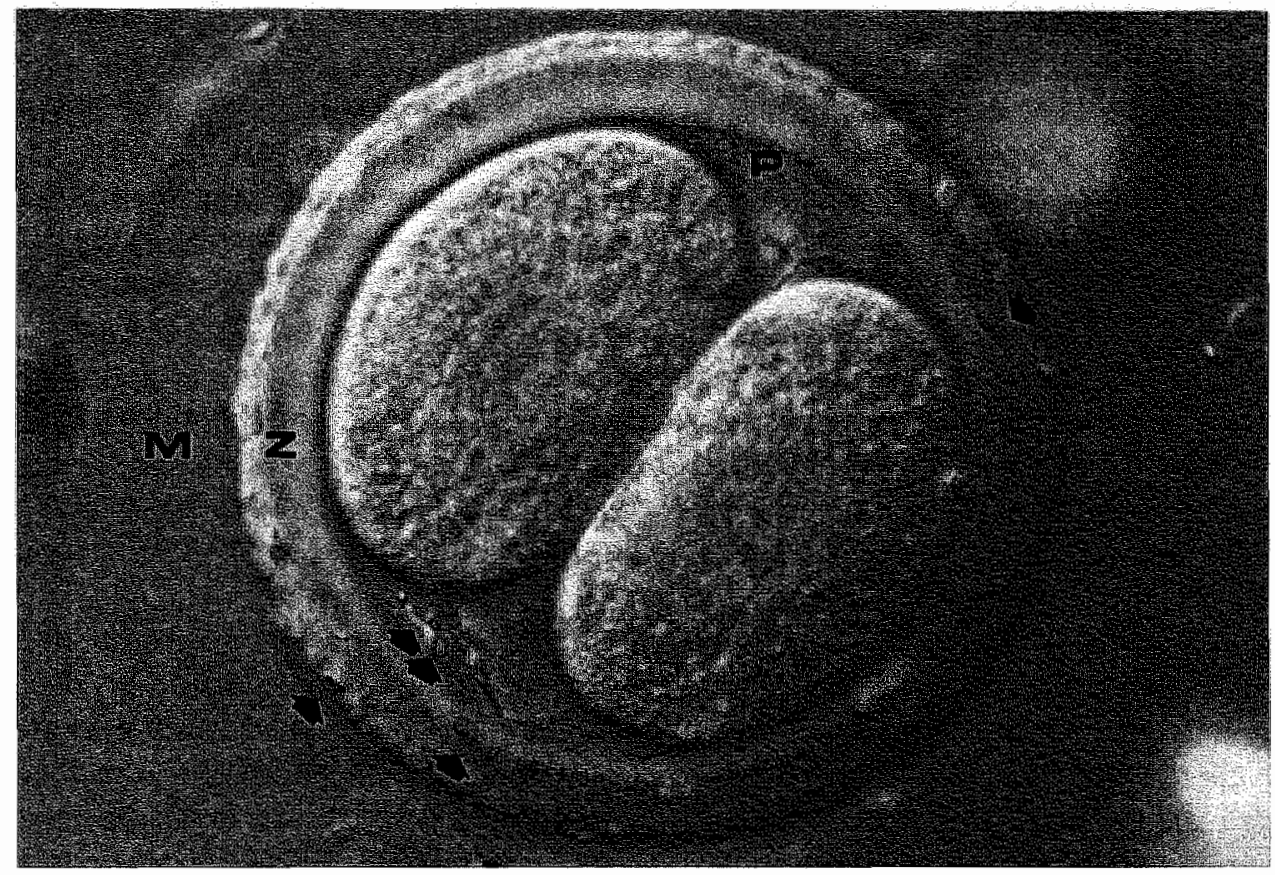

Figure 4. I Two-cell embryo recovered 24 hours after mating

Sperm (arrows) has entered the zona pellucida $(Z)$ and the periwitelline space $(P)$. The embryo is surrounded by a mucus layer $(M)$

material, although the content of this material is dissimilar genetically. The interval between resumption of ocyte maturation and ovulation varies amongst mammalian species, being 36 hours in the human and less than 12 hours in the mouse and rabbit (Edwards and Gates, 1959; Edwards, 1965).

Freshly ovulated ova in the human and in the rabbit are surrounded by the zona pellucida and by the cumulus oophorus. The period spent by the ova in the oviduct af. ter ovulation and before fertilization has been shown to be necessary not only to provide adequate time for the sperm to undergo capacitation, but also to allow the ova to attain complete maturity (Chang, 1955; Zamboni, 1970; Trounson et al, 1982). Considerable changes take place in tubal ova prior to sperm penetration: modifications in structure and arrangement of the ovum chromosomes into a dyad form accur, there is a numerical increase in cortical granules (Sathananthan and Trounson, 1982) and the tubal environment causes dispersal of the cumulus oophorus and corona cells (Zamboni et al, 1965; Zamboni, 1970). The cumulus investment surrounding the ovum remains intact from several hours to two days after ovula- 
tion, depending on the species. In the rabbit the ovum is denuded in 16 to 20 hours after mating (Dickmann, 1963).

After ovulation the fertilizable life span of the rabbit ovum is between 6 and 8 hours (Adams and Chang, 1962a). The fertilizable life span of human ova is unknown. Probably it is only a relatively short period after ovulation (not more than 10-12 hours) (Trounson, 1982). The fertile life of spermatozoa within the female genital tract is shorter than their motile life (Noyes and Thibault, 1962). The durations of sperm fertility in the oviduct is about 30 hours in rabbits (Noyes and Thibault, 1962; Austin, 1975a). The fertile life of spermatozoa in women has not been accurately determined but was previously estimated at 28 to 58 hours around ovulation time (Cohen and Stein, 1951; Tietze, 1960). Evidence exists that this is an underestimate, for pregnancies have been recorded after coitus to occur several days before the rise in basal body temperature (Edwards, 1980a). Pre- and postmenstrually the survival is very brief and inconsistent.

In mammals contact of sperm with the ovum takes place in the ampulla of the oviduct (Harper, 1965). Several distinct events occur during the fertilization process. A small number of spermatozoa which have undergone the acrosome reaction penetrate through the cumulus and the corona cells, and bind temporarilly to the zona pellucida. The zona pellucida contains spermreceptors which are highly speciesspecific and capable of binding capacitated sperm (Gwatkin, 1982). Thereafter the spermatozoa move rapidly through the zona pellucida to enter the perivitelline space. The movement of spermatozoa through the zona pellucida requires a period of only several minutes in various laboratory animals (Edwards, 1980b). Acrosomal enzymes, often referred to as 'zona lysins' (Austin, 1975b), may assist the movement of spermatozoa through the zona pellucida. Other reports, however, cast doubt upon the role of these enzymes, because the spermatozoa may pass through the zona pellucida solely by their own motility (Bedford and Cross, 1978). Once the sperm has entered the ovum the spermhead becomes adherent to the ovular plasma membrane, and membrane binding occurs. Sperm penetration of the ovum is associated with ovum activation (Wolf, 1979), which includes the resumption of the second maturation division and the release of corticale granules to establish a block to polyspermic fertilization. Resumption of the second maturation division, arrested just prior to avulation, results in the expulsion of the second polar body and the formation of the female pronucleus. The spermhead differentiates into the male pronucleus within a few hours of penetration. In several mammals the male pronucleus is to distinguish from the female pronucleus because of its larger size. Both pronuclei become active metabolically, enlarge and move together, but never fuse completely at syngamy (Thompson et al, 1974). Fertilization is usually considered to be completed at syngamy, when the maternal and paternal chromosomes become intermixed. After fertilization in mammalian ova two distinct blocks to polyspermy exist. One occurs rapidly, within a few seconds after fertilization, and another after several hours (Wolf, 1978). The nature of the rapid block remains to be elucidated, but it has been suggested that it is electrically mediated (Jaffe, 1976). The block establis- 
hed several hours after fertilization involves the cortical granules in the ovum. Exocytosis from these granules into the perivitelline space induces changes in the plasma membrane of the oocyte (the plasmalemma block) and the zona pellucida (the zona reaction) (Austin and Braden, 1956; Austin, 1975b; Wolf, 1979). The relative importance of these two reactions varies between species. The zona reaction is strong in the human, but weak in Lagomorphs, permitting spermatozoa to continue to enter the perivitelline space for some time after fertilization has occurred (Fraser and Dandekar, 1975). In many species the block to polyspermy becomes weaker if ova are not fertilized for some time after ovulation. The block to polyspermy may even be temporary, becoming reversed with time even in fertilized ova. This may lead to the phenomenon of 'refertilization', although the late-entering spermatozoa may fail to form pronuclei (Gulyas, 1974).

\subsubsection{Cleavage of the embryo}

If fertilization has occurred in the ampulla, embryos begin their cleavage divisions as they move through the oviduct. In most mammals transport of the ovum through the oviduct requires approximately 3 days (Croxatto and Ortiz, 1975), but the stage of development when the ovum enters the cavum uteri is species dependent. In the rabbit ova enter the uterus when the transition from morula to blastocyst is about to take place (Adams, 1958). Exact figures concerning the human are not available. Embryos in various stages have been flushed from the human uterus, the earliest being a 12-cell embryo (Croxatto et al, 1972a). Species variations between mammals exist in several aspects of the cleavage of the early embryo, including the timing of the interval between successive divisions. In the rabbit cleavage is more rapid than in other species (table I.2).

Although there is some evidence that embryos may cleave more slowly in vitro than in vivo (Bowman and McLaren, 1970; Binkerd and Anderson, 1979), it is generally assumed that the cleavage rate of embryos in vitro does not substantially differ from their development in vivo. Cleavage involves a series of mitotic divisions and the parcelling out of the cytoplasm of the oocyte into blastomeres. Because cleavage reduces the size of the blastomeres until the nuclear-cytoplasmic ratio approaches values similar to adult somatic cells, the early embryo cleaves without increase in diameter. At least in the very early stages cleavage divisions are synchronous, the blastomeres are distinct and of equal size. Whether or not irregular cell division accompanied by fragmentation is a sign of diminished developmental potential in the embryo is not known so far. Recent human in vitro fertilization programs have given evidence that in spite of degeneration or arrested development in part of the cells in an early embryo, the remaining viable cells have still the potential for continued growth and development into a normal embryo (Trounson et al, 1985).

In the 8- to 16 - cell stage, in most mammalian species, changes occur in the structure 
Timing of embryonic development in the human and the rabbit (hours after insemination)

\begin{tabular}{|c|c|c|c|}
\hline \multirow[b]{2}{*}{ Cell stage } & \multicolumn{2}{|c|}{ Human in vilro } & \multirow{2}{*}{ 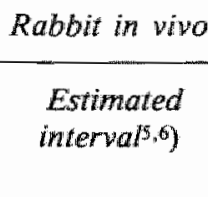 } \\
\hline & $\begin{array}{l}\text { Earliest lime- } \\
\text { latest time') }\end{array}$ & $\begin{array}{l}\text { Estimated mid- } \\
\text { point } \pm \text { standard } \\
\left.\text { error }{ }^{2}\right)\end{array}$ & \\
\hline $\begin{array}{l}\text { 1-cell } \\
2 \text { polar bodies } \\
2 \text { pronuclei }\end{array}$ & $12-31$ & & $\left.10-24^{4}\right)$ \\
\hline $2-c e l l \mid$ & $27-43$ & $34.9 \div 1.9$ & $31-39$ \\
\hline 4-cell & $36-65$ & $51.2 \pm 1.9$ & $36-44$ \\
\hline 8-cell & $45-73$ & $67.9 \pm 2.5$ & $46-54$ \\
\hline 16-cell & $68-85$ & $84.6 \pm 3.4$ & $50-65$ \\
\hline morula & $100-3)$ & $100.2 \pm 3.0$ & $\left.58-78^{4}\right)$ \\
\hline early blastocyst & & $112.7 \pm 3.8$ & \\
\hline blastocyst & $\left(20-3^{3}\right)$ & & \\
\hline
\end{tabular}

1) Lopata, 1982

2) Edwards, $1980 d$

3) Edwards, 1977
4) Brinster, 1973

5) Adams, 1956

6) Janiak, 1971

and properties of the plasma membranes and the cytoplasm of the blastomeres. Many of the modifications in the cytoplasm and cellular organelles reflect the increasing complexity in the metabolism of the embryo. In the rabbit in the morula stage individual outer blastomeres become indistinct as they adhere to each other by the formation of tight junctions, a process called compaction (Ducibella and Anderson, 1975). In the human embryo compaction of the blastomeres occurs at the 16-cell stage of development (Lopata et al, 1983). A distinct outer layer of cells is formed, enclosing one or more cells within them. The outer layer of cells gives rise to the trophectoderm and the inner layer formes the inner cell mass of the embryo. The secretion of blastocoelic fluid accumulating in the blastocoelic cavity, results in the typical appearance of the blastocyst. Chorionic gonadotropin and progesterone are secreted by the trophoblast cells. Both hormones could be carriers of information between the maternal and embryonic system which signal the presence of the blastocyst before cellular contact and implantation (Beier, 1979).

In human cleavage stage embryos the perivitelline space, i.e. the space between the surface of the blastomeres and the zona pellucida, has been shown to be filled with floccular material. Embedded in this material there are always sperm, membrane fragments and vesicles of different shape and content.

In the rabbit oviduct cleavage stage embryos are surrounded by two layers of extracellular material: the zona pellucida, formed in the ovary, and a mucin layer. The mucin is a highly sulphated mucosubstance with a low protein content (Denker and Gerdes, 1979). During estrus mucin is synthesized and stored by the secretory cells 
under the influence of estrogens. After ovulation mucin is released by the action of progesterone (Greenwald, 1958). Ova and corpora aliena are normally surrounded by a mucin layer, deposited during their transport through the oviduct (Blandau, 1978). In non-physiological conditions the mucin coating may be disturbed. Resection of the isthmus (McComb et al, 1981c), oviduct ligation and restriction of the embryos to the ampulla (Stone and Hamner, 1977) and estrogen injection following mating (Greenwald, 1957) are associated with a reduced mucin layer. The function of the mucin coating is as yet unresolved. It does not seem to be essential for normal embryonic development nor for implantation (Greenwald, 1962; Stone and Hamner, 1977). Furthermore, human ova are devoid of mucin layers (Novak and Everett, 1928).

In the rabbit the embryo coverings reach their maximum thickness within the first 72 hours, during the passage of the embryo through the oviduct (Adams, 1958; Beier et al, 1983a). When the embryo has passed into the uterus and has differentiated into an early blastocyst, expansion of the blastocyst occurs, which results in stretching and reduction of the thickness of the coverings. The perivitelline space virtually disappears and dissolution of the zona pellucida becomes obvious. Five days after mating the zona pellucida has completely vanished, and is replaced by a layer called neozona. Probably at least part of the neozona material derives from the blastocyst. (Denker and Gerdes, 1979). After $61 / 2$ days post coitum the first traces of uterine secretion material, forming the gloiolemma (Böving, 1957) can be found deposited on the outer surface of the blastocyst coverings. At the implantation stage, i.e. 7 to 8 days after mating, enzymatic lysis of the blastocyst coverings sets in (Denker and Gerdes, 1979) (figure 1.10).

Synchrony of embryonic and maternal systems after ovulation is considered to be important in the timing of embryo-endometrium interactions as well as in providing a favorable environment for the developing embryo. Experimental evidence exists that rabbit embryos fail to survive if transferred prematurely to the uterus (Adams,

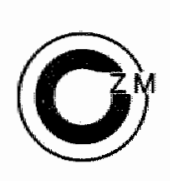

$24 h P C$ A

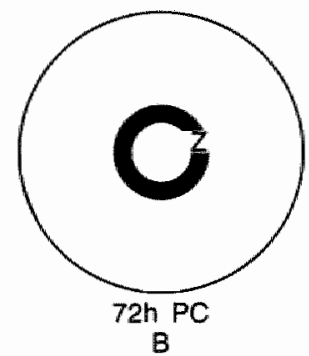

B

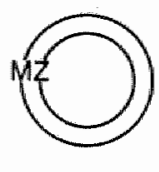

$3 / 2 d P C$

$\mathrm{C}$

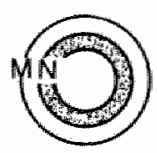

5d PC

D

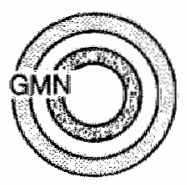

$6 \% / 2 \mathrm{PC}$

$\mathrm{E}$

Figure 1.10 Ovum coverings

$A$ deposition of mucus layer (M) on zona pelitucida $(Z)$

$B$ marimal thickness of mucus layer

C dissolution of zona pellucida

$D$ replacement by neazona (N)

$E$ deposition of gloiolemma (G) 
1979). The situation may well be different in women, however, as indicated by reports of successful Estes" operations, designed to allow ovulation, fertilization and cleavage in the uterine cavum (Iklé, 1961). The occurrence of pregnancies following early embryo replacement (18-28 hours after insemination) in human in vitro fertilization programs (Feichtinger and Kemeter, 1985) also questions the importance of synchrony in the human.

Reports of asynchrony between embryonic and maternal systems almost invariably relate to experimental situations, such as during treatment with estrogens or progestational agents. The detrimental effects of systemic steroids on preimplantation development are most often attributed to disruption of normal transport of embryos down the reproductive tract and/or exposure of the embryos to an asynchronous, unreceptive uterus (Greenwald, 1961; Chang and Yanagimachi, 1965; Chang and Harper, 1966; Adams, 1974). Progesterone, even in subcontraceptive levels, near the time of ovulation may interfere with sperm transport and capacitation, thereby causing aging of the gametes resulting in embryonic degeneration (Chang, 1967; Chang and Hunt, 1970; Allen and Foote, 1973).

Evidence exists that the uterine environment, which is under steroidal control, contains specific factors which influence embryogenesis (Adams, 1958; El-Banna and Daniel, 1972; Beier et al, 1983a). An 'asynchronous' uterine milieu might be deleterious to the developing embryo (Maurer and Beier, 1976; McCarthy et al, 1977). Furthermore, systemic steroids profoundly influence processes within the oviduct, effecting fluctuations in fluid volume and causing qualitative and quantitative changes in the constituents of the fluid (Feigelson and Kay, 1972), which may alter the capability of the oviductal fluid to serve as a favorable culture medium for embryos (Stone et al, 1977). Changes evidently occur in the composition of tubal fluid during the days following ovulation. Fluid taken from rabbit oviducts between days 2 and 9 of pregnancy supports the growth of embryos into blastocysts. The development of embryos into blastocysts is impaired, however, if culture takes place in tubal fluid collected during estrus (Kille and Hamner, 1973).

Addition of steroids in physiological doses to the culture media does not influence early embryonic development (Allen and Foote, 1973; Cline et al, 1977), in contrast with administration in high concentrations, which block cleavage (Daniel and Levy, 1964). Stone and Hamner (1977) incubated embryos in the oviducts of long-term ovariectomized rabbits, whose genital tract fluids where free of ovarian hormone influence. Their experiments suggest that ovarian hormonal stimulation is not indispensable for the normal development of preimplantation embryos in the oviduct. Estrogen dominance, effectuated by treating the ovariectomized rabbits with estrogens, impaired embryonic development. Since embryos will grow normally in vitro in relatively simple media (table I.3), hormones or hormone-induced conditions may not be imperative during the tubal preimplantation period. During the intrauterine period of preimplantation, however, the normal development of the rabbit blastocyst requires a favorable, synchronized uterine environment (Beier et al, 1983a). The transition to blastocyst represents a critical phase in embryogenesis because by this 


\begin{tabular}{|c|c|c|c|c|c|c|c|}
\hline $\begin{array}{c}\text { Ingredients } \\
(\mathrm{mg} / \mathrm{l})\end{array}$ & $\begin{array}{l}\text { Whitten's } \\
\text { medium }\end{array}$ & $\begin{array}{c}\text { Ham 's } \\
\text { Flo }\end{array}$ & $\begin{array}{c}\text { Eagle's } \\
\text { minimum } \\
\text { essential } \\
\text { medium }\end{array}$ & $\begin{array}{l}\text { Modified } \\
\text { Tyrode"s }\end{array}$ & $\begin{array}{c}\text { Brinster's } \\
\text { mouse } \\
\text { ova } \\
\text { culture } \\
\text { medium } \\
5\end{array}$ & $\begin{array}{c}\text { Synthetic } \\
\text { medium } \\
\text { for nabbit } \\
\text { embryo } \\
\text { culture } \\
6\end{array}$ & $\begin{array}{c}\text { Synthetic } \\
\text { oviduct } \\
\text { flnid } \\
7\end{array}$ \\
\hline $\mathrm{NaCl}$ & 5140 & 7400 & 6800 & 5900 & 5546 & 6019 & 6300 \\
\hline $\mathrm{KCl}$ & 356 & 285 & 400 & 200 & 356 & 356 & 533 \\
\hline $\mathrm{CaCl}_{2}$ & - & 44 & 200 & 200 & 189 & 251 & 190 \\
\hline $\mathrm{MgSO}_{4 \cdot} 7 \mathrm{H}_{2} \mathrm{O}$ & 294 & 153 & - & - & 294 & 294 & - \\
\hline $\mathrm{MgCl}_{2} \cdot 6 \mathrm{H}_{2} \mathrm{O}$ & - & - & 200 & 100 & - & - & 100 \\
\hline $\mathrm{NaHCO}_{3}$ & 1900 & 1200 & 2000 & 3000 & 2106 & 2106 & 2106 \\
\hline Ca lactate & 527 & - & - & - & - & - & - \\
\hline Na lactate & 2416 & - & - & $1.5 \mathrm{ml}$ & 2253 & - & 370 \\
\hline Na pyruvate & 36 & 110 & - & 10 & 56 & - & 36 \\
\hline Glucose & 1000 & 1100 & 1000 & 810 & 1000 & 1800 & 270 \\
\hline Amino acids & - & + & + & + & - & + & - \\
\hline $\begin{array}{l}\text { Bovine serum } \\
\text { albumin. }\end{array}$ & 3000 & varies & varies & 15000 & 5000 & 15000 & 32000 \\
\hline
\end{tabular}

\section{Gwathin, 1972}

2 Ham, 1963

3 Eagle, 1959

4 Yanagimachi, 1982
5 El-Badrawi and Hafez, 1982

6 Beier et al, 1983a

7 Trevit et al, 1972

time the endogenous reserve is nearly depleted and an exogenous supply of nutrients, provided by the uterine milieu, must be invoked (Adams, 1958).

Factors influencing early embryonic development have been subject of study: Roblero and Izquierdo (1976) described the existence of a macromolecular protein fraction in mouse serum. This protein was bound to progesterone and stimulated the cleavage rate of early embryos. They reported a significant increase in the mean number of blastomeres per blastocyst when embryos were cultured in medium supplemented with this macromolecular fraction of serum in the presence of progesterone. Urzua et al (1970) demonstrated a macromolecular protein (blastokinin) to be present in uterine fluid of pregnant rabbits. This protein appeared under the influence of progesterone and seemed to affect the in vitro development of preimplantation embryos. Krishan and Daniel (1967) described blastokinin as an inducer and a regulator of blastocyst development in the rabbit uterus. Recently Beier (1982), however, suggested the function of uteroglobin (a more appropriate name for blastokinin, although this protein has been identified in rabbit tubal fluid too (Kay and Feigelson, 1972)) not to be embryotrophic. Stone et al (1977) found significantly less pronuclear rabbit zygotes developing normally to the morula stage in estrogen influenced oviduct fluid, as compared to progesterone influenced fluid. They suggested 
the presence of an estrogen mediated, low molecular weight inhibitor of embryonic development to be present in oviduct fluid.

\subsubsection{Tubal transport}

Ovum transport seems to be programmed in a way that allows adequate time for fertilization and development of the embryo to a stage that is optimal for survival in the endometrial environment. Although major differences exist in the details of entrance into and transit through the various segments of the oviduct, the overall time course of ovum transport is remarkably similar in all mammalian species examined: about 3 days are required for ova to travel from the oviduct to the uterus. In women the transport of ova is characterized by the retention in the ampulla for approximately 72 hours, including a period of 30 hours at the ampullary-isthmic junction, followed by rapid transit through the isthmus (Croxatto and Ortiz, 1975; Croxatto et al, 1978a). Human embryos normally enter the uterus about 80 hours after ovulation (Croxatto et al, 1978a; Pauerstein, 1978).

In the rabbit freshly ovulated ova are rapidly transported from the ostium of the oviduct to the proximal end of the ampulla in no more than 10 minutes (Harper, 1965; Boling and Blandau, 1971). During the brief time an ovum is transversing the ampulla, it is contained within its cumulus, which has a volume up to 100 times that of a denuded ovum. As long as the cumulus oophorus is intact, the probability of ovum transport across the ampullary-isthmic junction will be slight, since the isthmus is less distensible than the ampulla. The ova are retained near the ampullaryisthmic junction and do not enter the isthmus until about 24 hours after ovulation (Bolling and Blandau, 1971; Pauerstein et al, 1974a). Subsequently, the embryos stay for at least 36 hours in the distal part of the isthmus (Greenwald, 1961; Blair and Beck, 1976). After passing rapidly through the proximal isthmic portion, ova enter the uterus 72 to 80 hours after the ovulation inducing stimulus, i.e. about 70 hours after ovulation (Greenwald, 1961; Pauerstein et al, 1974a; Croxatto and Ortiz, 1975; Hodgson and Pauerstein, 1976).

With the notable exception of findings in the horse fertilized and unfertilized ova are transported in the oviduct at the same rate. In the mare unfertilized ova are retained within the oviducts, where they undergo cytoplasmatic degeneration (Betteridge and Mitchell, 1974). The reason for this difference in transport is unknown, but an endocrine influence of the embryo on tubal function might be a plausible explanation. In other mammals a loss of unfertilized ova occurs after passage into the uterus. In rats unfertilized ova are expelled from the uterus (Villalon et al, 1982). Selective retention and subsequent implantation of viable embryos may be associated with physicochemical changes in the zona pellucida after fertilization (Chang and Hunt, 1956), or with steroids produced by the blastocyst that act as local regulatory signals (Villalon et al, 1982). 
In the rabbit the ovum is picked up from the ovarian surface by gentle massage-like undulatory movements of the fimbriae. Progress of the ovum within its cumulus mass is relatively slow and constant as it enters the ostium and passes through the first millimeters of the oviductal lumen. Ovum transport through this segment is effected primarily by cilia activity (Boling and Blandau, 1971). After this ovum transport is characterized by a complex pattern of rapid forward and backward movements associated with segmental contractions of the ampullary wall. Pharmacological inhibition of muscular activity in the rabbit oviduct changes the to-and-fro movements of cumulus masses in the ampulla into a slow uniform prouterine movement, attributed to ciliary activity (Halbert et al, 1976a; Halbert et al, $1976 \mathrm{~b}$ ). The cumulus masses stop and remain motionless at the ampullary-isthmic junction. The net velocity of transport through the ampulla does not change when the smooth muscle activity is blocked. Reversal of $1 \mathrm{~cm}$ segments of the rabbit oviductal ampulla completely prevents pregnancy (Eddy et al, 1978). Tubal transport of ova was arrested in the interface between the cilia beating towards the uterus and those in the reversed segment towards the ovary. Both observations suggest a crucial role for the cilia in transport of ova through the ampulla. The specific contributions of the muscle and the cilia to ovum transport in the ampulla remain still an unresolved question, however. The muscle mechanism may be equally effective in transporting the cumulus masses as the cilia, and it may even dominate over the cilia mechanism when active (Halbert et al, 1976a). Blandau et al (1979) postulated that under normal conditions the cilia in the ampulla might act as ratchets, stabilising the cumulus masses and preventing them from moving backwards.

Most investigators have credited muscular contractions as the primary force for the transfer of the ovum through the isthmus. Two components of muscular function in the isthmus have been implicated in the control of ovum passage: the ability to constrict and to act as a sphincter, and the ability to contract peristaltically and thus propel the ovum. Oviductal motility changes during the periovulatory period. The contractile activity intensifies during the period of ovum retention and diminishes during the subsequent period of more rapid prouterine movement (Blair and Beck, 1976; Spilman et al, 1978). The intensity of isthmic muscular activity is at its maximum 24 hours after mating, and decreases after 60-72 hours in the rabbit (Marsafy and $\mathrm{Hafez}$, 1981; Fredericks et al, 1982). Ovarian steroids, adrenergic innervation and prostaglandins interact to influence oviductal contractility and the process of ovum transport. Despite the numerous studies made of oviductal motility consistent patterns of activity have not been described.

Adrenergic nerves supply the thick muscular coating of the isthmus. The circular muscle layer is most richly innervated (Brundin and Wirsén, 1964). Both stimulatory $(\alpha)$ and inhibitory $(\beta)$ adrenergic receptors have been demonstrated (Rosenblum and Stein, 1966). The transmitter content in the tubal nerves as well as the response of the receptors to adrenergic stimuli change with hormonal status in the human (Sjöberg et $\mathrm{al}, 1977$ ) and in the rabbit (Bodkhe and Harper, 1972; Hodgson and Pauerstein, 1974). Estrogens have been shown to potentiate $\alpha$-adrenergic receptor activi- 
$t y$, and progesterone to potentiate $\beta$-adrenergic activity (Hodgson and Pauerstein, 1974; Howe and Black, 1973). There is a transient elevation of progesterone and estrogen concentrations in the ovarian venous plasma during the first few hours after mating in rabbits. During ovulation the output of all ovarian sex steroids is at its nadir, increasing 72 hours later (Hilliard and Eaton, 1971). Harrington and Rothermel (1977) demonstrated peripheral plasma levels of progesterone to increase progressively some 30 hours after mating. Contradictory results have been reported regarding tubal contractility in relation to changing hormone levels. In the presence of physiologic estrous concentrations of estrogen the oviductal muscles are least active (Boling and Blandau, 1971). The transient elevation in estrogen release following mating might well serve to enhance muscular activity during the ovulatory process, and the subsequent estrogen withdrawal might be associated with the quiescent phase of muscular activity which follows ovulation and coincides with the 3-day period of tubal transport (Hilliard and Eaton, 1971). Spilman et al (1978), however, found no statistically significant correlations between oviductal motility and any of the ipsilateral ovarian vein steroid concentrations. From this they concluded that either the effect of ovarian hormones on oviductal motility is mediated by the peripheral levels of the steroids, or that there are differences in phase between the changes in ovarian steroid concentration and the changes in oviductal motility. In contradiction to the postulation made by Hilliard and Eaton (1971) concerning the role of estrogen in tubal transport, Spilman et al hypothesized progesterone to be the ovarian sex steroid which determinates tubal transport. Spilman et al suggested that preovulatory steroid surges induce an increase in the amplitude of contractions of the oviductal isthmus which impedes passage of ova through the oviduct. The postovulatory slow increase in progesterone secretion may decrease oviductal motility, eventually allowing the ova to move through the isthmus into the uterus. Progesterone has been demonstrated to block the postovulatory isthmic constricture (Blair and Beck, 1976), decreasing the resistance to ovum passage and allowing ova to pass.

Another mechanism, explaining the preisthmic delay in ovum transport, has been suggested recently by Verco et al (1984). Studying oviductal microvascular architecture they observed 24 hours after mating the isthmic venous subserosal plexus to be dilated, occluding the isthmic lumen to ova. After 48 hours upon mating distension was no longer evident, and subsequently ovum transport into the isthmus took place. Verco et al suggested tubal venous capacity to be affected by estradiol. The rise in estradiol concentration in rabbit ovarian venous blood after mating may give rise to venous distension, especially in the isthmus, which is provided with an extensive subserosal venous plexus.

A second means of control of isthmic muscular activity appears to be feasible by local action of prostaglandins. Much of the recent evidence is controversial due to an apparent contradiction in the reported action of specific prostaglandins upon tubal function in vivo when compared with their effect in vitro, and also due to different effects of specific prostaglandins on the longitudinal and circular layers of 
muscle. Generally, prostaglandins of the F-series (PGF) stimulate and prostaglandins of the E-series (PGE) suppress spontaneous isthmic activity (Coutinho and Maia, 1971; Aref et al, 1973; Spilman and Harper, 1975). Progesterone decreases oviductal tissue PGF concentration (Saksena and Harper, 1975) and decreases the response of the isthmus to PGF- $2 \alpha$ (Spilman, 1974). Progesterone increases the responsiveness of the proximal isthmus to the inhibitory effect of PGE-1 (Spilman, 1974). Estradiol causes an increase in isthmic tissue concentration of PGF up to 30 hours after its release (Saksena and Harper, 1975).

Spilman and Harper (1975) postulated that the preovulatory increase in estradiol se-

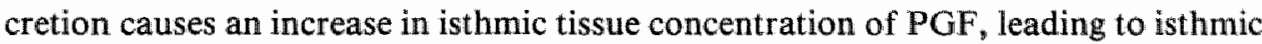
muscular activity 12-24 hours after mating and causing isthmic occlusion. The (peripheral) plasma level of progesterone progressively increases about 30 hours after mating (Harrington and Rothermel, 1977) and may be responsible for the contractility pattern observed 48 hours post coitum, which is characterized by the disappearance of active contractions (Marsafy and Hafez, 1981). Plasma progesterone reaches a high level 72 hours after mating (Hilliard and Eaton, 1971) and isthmic specific binding of PGE dominates (Wakeling and Spilman, 1973). Both events probably result in a relaxation of isthmic muscles, allowing ova to pass into the uterus. Attemps to modify tubal function as a method of studying its physiology in ovum transport have involved three major pharmacological as apart from surgical approaches: by interference with levels of steroid hormones or of prostaglandins, or by application of adrenergic agents. The data obtained from these experiments are difficult to interpret, because the processes investigated are influenced by various conditions: the dose of the hormones used, the actual composition of the pharmacological compound administered and the moment of administration related to ovulation. Injections of supraphysiological amounts of hormone may result in pharmacological reactions quite different from those occurring naturely. Lack of information on the normal blood levels before and during ovum transport and on the blood levels attained with experimental treatment make it impossible to differentiate between physiologic and pharmacologic effects. The design and instrumentation of the study may influence ovum transport as well (e.g. the 'observation chamber' of Blandau, 1971). Finally, anesthesia applied during the observations may interfere with normal tubal transport.

Review of the literature suggests that low levels of estrogens, or the presence of estrogen antagonists, tend to accelerate ovum transport in the rabbit. In contrast, large pharmacologic doses of estrogens prolong the sojourn of the ovum in the rabbit oviduct (Greenwald, 1961; Boling and Blandau, 1971; Hodgson, 1976). High doses of estrogens cause 'tube-locking' by increasing the isthmic resistance (Chang and Harper, 1966). Pauerstein et al (1976) demonstrated that high pharmacologic doses of estrogens can exert two opposed effects on ovum transport: delay at the ampullary-isthmic junction resulted when estrogens were administered before or at the time of the ovulation inducing stimulus, whereas acceleration occurred when estrogens were given 12 to 24 hours later. 
The effect of progesterone on ovum transport is also related to the timing of administration. Progesterone accelerates ovum transport when given prior to or at ovulation, but either delays or does not affect transport when given after ovulation (Greenwald, 1961; Chang, 1967; Chang and Hunt, 1970; Pauerstein et al, 1970b). When administered prior to ovulation, progesterone significantly, but incompletely, antagonizes the arrest of ova induced by pharmacologic doses of estrogens (Pauerstein et al, 1973).

In the rabbit PGF-2 $\alpha$ has been shown to accelerate transport of ova (Chang and Hunt, 1972; Aref et al, 1973). Timing, dose and duration of treatment all are important in determing the degree of disruption of normal postovulatory events (Hodgson, 1976). Although PGF-2 $\alpha$ caused an increase in tubal motility in women, it fails to accelerate ovum transport (Croxatto et al, $1978 \mathrm{~b}$; Croxatto et al, 1979). The difference found between the PGF- $2 \alpha$ actions in the human and in the rabbit may be explained by anatomical dissimilarities in the utero-isthmic junction. In contrast to the Lagomorpha, the primate oviduct passes through the myometrium for a considerable distance before opening into the uterine cavity. Simultaneous stimulation of the uterus by the prostaglandin may lead to consiriction of the intramural portion, which may interfere with passage of ova.

Pharmacological or surgical denervation of the oviduct does not disrupt ovum transport (Pauerstein et al, 19.74b). Several authors have failed to alter significantly normal ovum transport with adrenergic agonists and antagonists (Pauerstein et al, 1970a; Polidoro et al, 1973). Autotransplantation of the oviduct and ovary does not prevent normal pregnancy in the rabbit (Winston and McClure Browne, 1974). This also questions the importance of tubal adrenergic innervation. Sympathetic nerves seem to play only a minor part in the regulation of normal ovum transport. Estrogen-induced 'tube-locking' and progesterone-induced acceleration of ovum transport are partially antagonized by the depletion of transmitter from the intrinsic adrenergic nerves of the oviduct, which suggests that at least some of the effects of sex steroids on ovum transport are mediated by adrenergic nerves (Pauerstein et al, 1970a; Pauerstein et al, 1974b).

\subsection{Fluids of the female genital tract}

In 1827 Von Baer investigated an uterus 8 days after conception. He described the contents of the opened uterus as viscous, mucous fluid, which most likely contained protein. In 1869 German workers ligated the tubes in rabbits and observed the accumulation of fluid 6 weeks later, proving that the oviduct is able to secrete (Gregoire et al, 1961). These observations aroused interest in the fluids of the female genital tract and initiated its scientific analysis.

Since the oviduct is the site of fertilization and subsequent cleavage of the embryo, oviductal secretions may play a part in sperm capacitation, fusion of the gametes 
and early embryogenesis. From the experiments of Chang (1950) it is known that a synchrony exists between embryonic development and reproductive tract changes in response to postovulatory stimuli. Kille and Hamner (1973) demonstrated that tubal fluid can support growth and development of the preimplantation rabbit embryo, but that all tubal fluid samples collected on various days after ovulation do not support embryonic development to the same degree. Embryonic development in vitro can be influenced by uterine proteins (Maurer and Beier, 1976). In the rabbit direct interaction between oviduct and embryo has been shown by the incorporation of radiolabeled tubal compounds into embryos (Friz and Mey, 1959), and even a local influence of the preimplantation embryo on the synthetic activity of the tubal epithelium has been suggested (Stone and Hamner, 1975).

Nowadays it is generally accepted that the tubal and uterine fluids contain a spectrum of biologically active components, mainly regulated by the prevailing balance of ovarian hormones and changing during early gestation to meet the varying embryonic requirements.

Oviductal fluid is the resultant of selective transudation from the blood and active secretion by tubal epithelial tissue. The rather diverse molecular weights, disregarding any preference for small components, and the disparity in the relative amounts of the proteins in tubal fluid compared to their serum proportions, emphasize the selectivity of the transudation process. Tubal fluid also receives fluid contributions from the uterus, the peritoneal cavity and, in the postovulatory situation, from the follicular antrum.

In the mammals studied, the volume of tubal fluid is found to be at its maximum during estrus and immediately postovulatory. The volume decreases to approximatelly half the maximum value by the third day after ovulation in the rabbit (Mastroianni and Wallach, 1961). The secretory activity is influenced by the hormonal condition of the animal, and reflects the variations in estrogen concentration. This is demonstrated in the estrous rabbit after ovariectomy, when tubal secretion drops from $1.2 \mathrm{ml} / 24$ hours to $0.2 \mathrm{ml} / 24$ hours, whereas systemic injections of estradiol restore fluid production to estrous levels (Bishop, 1956).

In the human, volumes of tubal fluid correlate with serum estradiol determinations. The greatest volumes of tubal fluid are observed at midcycle, coinciding with the estrogen peak. Average daily production volumes of $3.9 \mathrm{ml}$ on cycle days 14 and 15 were noted, which decreased to an average of $2.2 \mathrm{ml} /$ day for days 16 and 17 . Even smaller volumes were measured prior to day 12 and after day 17 of the menstrual cycle (Lippes et al, 1981).

Since sophisticated physicochemical methods, particularly high resolution electrophoresis and chromatography, have become available, detailed analyses of the fluids of the female genital tract have been performed. Various techniques have been used for tubal fluid collection: double ligation, cannulation, aspiration and flushing. Long-term cannulation of the rabbit oviduct has been shown neither to traumatize the tissue nor to cause changes in the fluid composition (Sloan and Johnson, 1974), and normal fetuses have been obtained from a number of does with oviductal can- 
Tubal fluid ions (mean concentration; collected at body temperature)

Rabbil

\begin{tabular}{|c|c|c|c|}
\hline & $\begin{array}{c}\text { preovulatory } \\
\qquad, 2\end{array}$ & $\begin{array}{c}\text { postovulatory } \\
\qquad 1,2\end{array}$ & $\begin{array}{c}\text { plasma } \\
3\end{array}$ \\
\hline $\mathrm{Na}^{+}(\mathrm{mEq} \cdot / \mathrm{L})$ & $141.1-144.6$ & $138.1-142.6$ & $141-144$ \\
\hline $\mathrm{Cl}^{-}$ & $109.7-118.7$ & $112.2-118.7$ & $102-106$ \\
\hline $\mathrm{K}^{+}$ & $5.2-6.1$ & $5.5-6.2$ & $3.5-3.9$ \\
\hline $\mathrm{Ca}^{2+}$ & 4.0 & 5.5 & $?$ \\
\hline
\end{tabular}

Human

\begin{tabular}{lccc} 
& $\begin{array}{c}\text { preovulatory } \\
4,5\end{array}$ & postovulatory & \multicolumn{2}{c}{ serum } \\
& 4,5 & 6 \\
\hline $\mathrm{Na}^{+}(\mathrm{mEq} . / \mathrm{L})$ & $139.5-142.1$ & $139.0-148.6$ & $136-145$ \\
$\mathrm{Cl}^{-}$ & $119.6-127.8$ & $112.1-116.1$ & $100-106$ \\
$\mathrm{~K}^{+}$ & $6.7-9.7$ & $7.0-7.5$ & $3.5-5.0$ \\
$\mathrm{Ca}^{2+}$ & 7.8 & 9.4 & $8.5-10.5$ \\
\hline
\end{tabular}

1 Holmdahl and Mastroianni, 1965

2 Mastroianni and Wallach, 1961

3 Brunton and Busilow, 1979
4 Lippes, 1969

5 David et al, 1973

6 Wallach, 1978

nulla (Sloan et al, 1974). Nevertheless, minor interference of most techniques with tubal physiology cannot be excluded, and one has to be critical in regarding the results.

The major constituents of tubal fluid and their (assumed) roles in the processes occurring in the oviduct will be discussed:

- Ions:

Sodium is found to be the major cation and chloride the major anion in human and rabbit tubal fluid. The concentrations of some ions differ from those in the blood (table I.4).

The calcium concentration in tubal fluid of the rabbit increases after ovulation (Holmdahl and Mastroianni, 1965). Calcium has been shown to be necessary in sperm capacitation and the acrosome reaction (Reyes et al, 1978; Singh et al, 1978). In culture media without calcium no transformation of the embryos into blastocysts takes place, because compaction is completely inhibited (Ducibella and Anderson, 1975). The increase in sperm metabolism in tubal fluid has been attributed to the presence of bicarbonate ion (Hamner and Williams, 1964). Furthermore, bicarbonate is known to be involved in dispersal of the corona radiata from the ovum (Stambough et al, 1969). 
- Enzymes and enzyme inhibitors:

Trypsin inhibitor activity has been found in human tubal fluid (Moghissi, 1970). In rabbits trypsin inhibitors are found at low lewels at estrus and at high levels several days after ovulation (McLaughlin and Hamner, 1975). These inhibitors may play a part in the regulation of fertilization by limiting the fertilizability of an ovum to the immediate periovulatory period.

Lactic dehydrogenase ( $(\mathrm{DH})$ has been found in higher concentrations in human tubal fluid relative to serum (Lippes et al, 1972). In the rabbit oviductal tissue LDH activity increases significantly after ovulation (Varma et al, 1974). Lactate, upon conversion to pyruvate by tubal $\mathrm{LDH}$, is a likely major substrate for embryonic energy production (Stone and Hamner, 1975).

\section{- Prostaglandins:}

Ogra et al (1974) demonstrated that human tubal fluid has cyclic variations in PGF- $2 \alpha$ levels. They reported mean values of $7.12 \mathrm{ng} / \mathrm{ml}$ in preovulatory fluid and $5.0 \mathrm{ng} / \mathrm{ml}$ in postovulatory tubal fluid. At the time of ovulation $2.2 \mathrm{ng} / \mathrm{ml}$ of unbound PGF-2 $\alpha$ was found. PGF- $2 \alpha$ levels in human tubal fluid are significantly higher than those normally found in serum $(0.5 \mathrm{ng} / \mathrm{ml}$ or less $)$, which suggests synthesis by the oviduct. The presumed role of prostaglandins in tubal transport of embryos has been already described.

\section{- Metabolic substrates:}

The early mammalian embryo appears to require lactate and pyruvate for energy (Brinster, 1965). Glycolysis plays a relatively minor role in the rabbit until the blastocyst stage (Kane and Buckley, 1977).

Gupta et al (1970) demonstrated changes in the lactic acid concentration to occur in relation to the localization of embryos in the oviduct. The lactic acid concentration appeared to be at its maximum value in the tubal segment containing the embryos. Lactic acid concentration of the tubal fluid of rabbits has been shown to increase during the first three days of pregnancy, probably by diffusion from the tubal tissue (Mastroianni and Wallach, 1961). In vitro studies have demonstrated that the (human) endosalpinx preferentially utilizes the anaerobic route of metabolism (Mastroianni et al, 1958). It is suggested that the rise in lactic acid level of the tubal tissue, and concomitantly of the tubal fluid, is associated with the early embryonic energy requirements.

Lippes (1979) found glucose in human tubal fluid at levels of $58.0 \mathrm{mg} \%$ preovulatory and $44.4 \mathrm{mg} \%$ postovulatory. Holmdahl and Mastroianni (1965) noted in rabbit tubal fluid a postovulatory decline in the glucose concentration ( $8.5 \mathrm{mg} \%$ versus $4.9 \mathrm{mg} \%$ ). In tubal fluid collected at a temperature between $+2{ }^{\circ} \mathrm{C}$ and $+4{ }^{\circ} \mathrm{C}$, the glucose concentration was $25.7 \mathrm{mg} \%$ preovulatory and $28.9 \mathrm{mg} \%$ after ovulation. The difference found between 'warm' and 'cold' tubal fluid was attributed to enzymatic breakdown of glucose in the non-refrigerated specimens. 


\section{- Amino acids:}

In the rabbit tubal fluid all blood amino acids are present, most of them at a lower level (Thibault, 1972). The first cleavage division of the rabbit zygote can take place in vitro in the absence of amino acids in the culture medium. The second cleavage requires at least cysteine, tryptophane, phenylalanine, lysine, arginine and valine. Subsequent cleavage (at least to the morula stage) requires in addition methionine, threonine and glutamine (Daniel and Olson, 1968). Serine, glutamic acid, alanine and glycine levels are significantly lower during estrus and the preovulatory period compared to the period of early pregnancy in the rabbit (Thibault, 1972). It is interesting to note that these four amino acids are not essential for cleavage at least up to the morula stage. Thus, their postovulatory increase cannot be related to a large need of the early embryo for these amino acids. Uptake of amino acids by the embryo is required for the synthesis of proteins (Epstein, 1975). It has been suggested that free amino acids are necessary for the growth of the developing embryo, and may be utilized by spermatozoa as well (Gregoire et al, 1961).

\section{- Proteins:}

The major protein in tubal fluid is albumin, making up $60 \%$ of total tubal proteins. Tubal fluid contains $\alpha, \beta$ and $\gamma$ globulins. IgG and $\operatorname{IgA}$ have been identified (Lippes et al, 1970), and IgM in trace amounts (Moghissi, 1970). Electrophoretic separation of the proteins in tubal fluid has resulted in the identification of three major bands: albumin, transferrin and a postalbumin fraction (Maas, 1979). Protein concentrations of tubal fluid are reported to be higher in postovulatory fluid than those pertaining to preovulation: in the human Lippes et al (1972) found preovulatory $0.1-6.6 \mathrm{~g} \%$ and postovulatory $3.5-8.6 \mathrm{~g} \%$; Holmdahl and Mastroianni (1965) reported in the rabbit $2.2 \mathrm{~g} \%$ and $2.7 \mathrm{~g} \%$ respectively. The rabbit embryo is able to develop from the two-cell stage to the morula in a medium containing an amino-nitrogen source as the only metabolizable component. This amino-nitrogen source can be albumin, but also certain single amino acids (Brinster, 1970). Albumin seems to be necessary for sperm capacitation (Miyamoto and Chang, 1973) and for penetration of the spermatozoon through the zona pellucida (Quinn and Whittingham, 1982).

The quality as well as the quantity of the endometrial secretions depend on the estrogen-progesterone ratio in the maternal system. In all species investigated, including the human, ovulation is associated with the production of a voluminous, protein-rich uterine secretion of low viscosity (Lutwak-Mann et al, 1960). The physical function of these uterine fluids is thought to be dilating of the uterine lumen, creating a passage through for the spermatozoa (Aitken, 1979).

During the luteal phase the uterus produces yet another type of secretion. After ovulation epithelial cells of the genital tract release secretions which contain considerable amounts of proteins. This luteal phase secretion may serve to induce and main- 
tain embryonic activity until implantation. The possible role of these secretions in stimulating and maintaining blastocyst activity has been deduced from studies in species exhibiting facultative or obligate forms of delayed implantation. In all these species the reactivation of the blastocyst at the end of the diapause is associated with a temporary increase in uterine protein secretion (Aitken, 1977). In most species investigated, the progestational endometrial secretions consist of a complex mixture of proteins, many of which possibly have a transport function (Aitken, 1979). At the end of the preimplantation period in the rabbit the protein secretion by the endometrium changes from one where all regions of the lining are secreting, to one where the secretory activity becomes localized at the implantation sites (Daniel, 1972).

There is evidence that the implanting blastocyst in the rabbit may exert local stimulatory effects on protein synthesis and transudation (Aitken, 1979). It has been suggested that some proteins only appear in endometrial secretions in the presence of an embryo. Such a stimulus may be particularly important in the human. If no conception has occurred during the luteal phase of the menstrual cycle, the quantity of uterine protein released is rather low (Maathuis and Aitken, 1978a; Beier, 1982). In the human the protein patterns in oviductal and uterine fluids are not markedly different quantitatively and qualitatively. This situation differs from all other species studied, in which essential differences are found in protein patterns between tubal and uterine fluids (Beier et al, 1983b). The similarity in tubal and uterine secretion protein patterns in man, compared at the identical stage of the cycle, suggests that the embryo may be sustained in the tubal as well as in the uterine milieu during the preimplantational period. Consequently, the time of arrival in the uterus may not be critical to early embryonic development in the human. For successful implantation, however, synchronization between embryonic development and endometrial receptivity is mandatory. The incidence of tubal implantation, occurring exclusively in the human and in an occasional subhuman primate, could biologically reflect the similarity in tubal and uterine protein environments (Beier et al, 1983b).

The uterine environment during the preimplantation phase of pregnancy has been the object of many investigations. Of all mammals the rabbit is most extensively studied. Rabbits are reflex ovulators, so all preimplantation events occur at fixed, known intervals after mating and ovulation.

During estrus and before implantation the rabbit uterine fluid contains serum derived proteins and proteins secreted by the endometrial cells. Among the latter the occurrence of uterine specific proteins, not found in serum, has been disclosed. The first specific protein described in rabbit uterine secretions was named blastokinin (Krishnan and Daniel, 1967), uteroglobin (Beier, 1968) or cone-forming protein (Kay and Feigelson, 1972). Blastokinin and uteroglobin have been proven to be identical, cone-forming protein is at least immunologically identical (Noske and Feigelson, 1976). Uteroglobin is a glycoprotein, presenting the predominant fraction on electrophoretic separation in the postalbumin region (Beier, 1974). It is a small macromolecule, with a molecular weight of approximately 25,000 Dalton (Beier, 1968; Krishnan and Daniel, 1968; Urzua et al, 1970). Uteroglobin levels in uterine 
fluid were noted to increase during early pregnancy (Krishnan and Daniel, 1967), pseudopregnancy (Johnson, 1972) and after progesterone administration (Arthur and Daniel, 1972). Uteroglobin has been identified in tubal fluid in estrous and pregnant rabbits (Goswami and Feigelson, 1974). By immunoelectrophoretic means uteroglobin is first detectable in uterine fluid 16 hours after mating, i.e. about 4 hours after ovulation (Kirchner, 1972). Its concentration increases rapidly until the second day after mating, and thereafter remains nearly constant in comparison with albumin levels. In pregnant rabbits the total protein content in uterine secretions begins to rise on the seventh day of pregnancy. The uteroglobin concentration on the contrary falls to undetectable amounts after day 8-9 (Bahrfield et al, 1976). In pseudopregnancy uteroglobin is found in substantial quantity through day 14 (Bahrfield et al, 1976).

Immunofluorescence techniques reveal that in the uterine cells uteroglobin synthesis starts during estrus (Kirchner, 1972). Also in the oviduct uteroglobin can be detected in a few cell groups during estrus (Kirchner, 1976). In the uterus uteroglobin synthesis and release are mainly controlled by progestins (Urzua et al, 1970; Arthur and Daniel, 1972) that modulate the cellular concentration of its specific mRNA (Atger and Milgrom, 1977). In estrogen-treated castrated does uteroglobin is present in the epithelial cells, but it is not discharged into the cavum uteri (Kirchner, 1976). While progesterone induces a dramatic rise in uteroglobin levels, it does not sustain those levels in pregnant does. Uteroglobin levels diminish to very low values in uterine fluid by day 9 of pregnancy at a time when progesterone levels still continue to rise (Hilliard and Eaton, 1971). Implantation itself may terminate uteroglobin release or synthesis (Beier, 1979). Also the estrogen rise in early pregnancy is thought to be responsible for the disappearance of uteroglobin by day 9 of pregnancy, thus antagonizing the stimulation by progesterone (Kumar and Bullock, 1982).

Evidence is available that estrogen instead of progesterone controls the synthesis and release of uteroglobin in the oviduct, however (Goswami and Feigelson, 1974; El Entreby et al, 1983). Analysis of blastocoelic fluid, taken from rabbit blastocysts on day 6 of pregnancy, revealed that uteroglobin is one of the major protein components in the embryonic fluid (Krishnan and Daniel, 1967; Kirchner, 1976). But in blastocysts cultured in media devoid of uterine secretions, uteroglobin was not detectable (Beier and Maurer, 1975). All evidence now agrees with the concept that uterine secretion proteins permeate into the blastocyst coverings (Kirchner, 1972), the blastocyst cells (Kirchner, 1976) and the blastocyst fluid (Kulangara and Crutchfield, 1973).

Uteroglobin was thought to be a specific component of rabbit oviductal and uterine secretions until it was detected by immunological means in the rabbit respiratory and digestive tracts as well (Noske and Feigelson, 1976). Recently an uteroglobinlike antigen has been identified in the rabbit epididymis and in spermatozoal membranes (El Entreby et al, 1983).

A series of functions have been assigned to uteroglobin. A blastotropic activity was assumed (Krishnan and Daniel, 1967; El-Banna and Daniel, 1972), possibly related 
to the ability of uteroglobin to bind progesterone, so supplying it to the embryo in a non-toxic form (Arthur and Daniel, 1972; Arthur and Chang, 1974; Maurer and Beier, 1976). In vitro experiments with media lacking uterine proteins and uteroglobin suggest, however, that the environmental proteins do not bring about specific embryotropic activity, but more likely have general embryo supporting effects (Beier, 1982). Furthermore, relatively simple media can meet the in vitro requirements of the preimplantation embryo of all species, including man (table 1.3). This observation makes it unlikely that stimulatory uterine factors are indispensable. Uteroglobin was thought to possess protease inhibiting properties, thus regulating proteases in uterine fluids which control the structural metabolism of the blastocyst coverings (Beier, 1979). Hackenberg and Beier (1982) demonstrated that uteroglobin itself has no protease inhibiting potency, but that the activity is due to a minor component present in the electrophoretic uteroglobin fraction, but chromatographically belonging to a different range of molecular weight. Beier (1974) postulated that the function of uteroglobin is more a protective one. Crosslinking of HL-A antigen with uteroglobin could have a masking effect on the HL-A antigens of the embryonic and trophoblast cells, so preventing the maternal lymphocytes from recognizing the embryo as an allograft (Beier, 1982). Similarly, an uteroglobin coating of the sperm head could mask the cell surface antigens of the male gametes, preventing immunologic reactions in the female genital tract. Another role for uterine-specific proteins has been suggested by Cook and Hunter (1978) concerning the provision of the means of maintenance of the structural integrity of the trophoblast during the phase of rapid expansion of the embryonic membranes. In the absence of sufficiently rapid accumulation of fluid in the blastocoele, a collapse of the trophoblast might occur that would be detrimental to the blastocyst. Uterine proteins might contribute by making available substances which could modify surface tension effects, in the way surfactant does in the fetall lung.

Several studies have been made in order to determine the occurrence of non-plasma proteins in human uterine and tubal secretions. The number of non-plasma protein bands reported differ in each study, as does the electrophoretic mobility of the observed proteins. Few studlies have tried to exclude the possibility of contamination of the uterine fluid sample by semen, cervical mucus, tubal fluid or blood. Moreover, all investigations have been performed during ovulatory cycles in which conception did not occur. These various and differing conditions certainly have influenced the results. Most studies on the secretions of the human female genital tract agree in only one aspect: no human tubal and uterine fluids contain a quantitatively dominant protein in any phase of the cycle (Wolf and Mastroianni, 1975; Roberts et al, 1976; Maathuis and Aitken, 1978b; Beier et al, 1983b). Electrophoresis, however, demonstrates several remarkable fractions, among which one prealbumin and one posttransferrin fraction seem to lack any equivalent fraction in blood plasma (Beier, 1982). A comparable posttransferrin band was observed by Moghissi (1970) in human tubal fluid. Shirai et al (1972) and Daniel (1973) showed the presence of postalbumins in human uterine secretions, and speculated that one of these 
proteins might be analogous to uteroglobin. But, as pointed out by Roberts et al (1976), the postalbumins reported by Shirai et al (1972) are probably related to the heavy contamination with blood resulting from their technique to obtain the samples. Immunoelectrophoretic methods using goat antiserum against rabbit uteroglobin, have been used to investigate fluids from the human female genital tract. Crossreactivity between the antiserum and samples containing endometrial proteins have been reported (Daniel, 1973; Noske and Feigelson, 1976; Beier, 1982), but these results could not be confirmed by others (Roberts et al, 1976; Maathuis and Aitken, 1978b).

Furthermore immunologically identical molecules do not have to be biologically similar. The search for a non-plasma protein, dominating in human progestational genital tract secretions, in analogy to uteroglobin in the rabbit, has been unsuccessful so far. This may be due to the unphysiologic conditions prevailing when the samples were collected. And interaction of an embryo with the endometrium may be necessary to trigger the secretion of particular proteins.

Sutcliffe et al $(1978,1980)$ detected a human uterine protein that appears in pregnant uterine tissue, in decidual tissue and in amniotic fluid. This probably tissuespecific protein is characterized as $\alpha 2$-uterine globuline. Another immunologically identified protein has been described by Joshi et al (1980a, 1980b) as a progesteronedependent protein of the human endometrium. Evidence exists that it concerns a specific uterine secretory protein, not found in blood of pregnant or non-pregnant women. Greater knowledge with regard to the biological activity and significance of these proteins is needed to understand the mechanisms involved in intrauterine development and implantation of the early embryo.

\subsection{Microsurgery}

The use of magnification for tubal surgery was first reported by Walz in 1959, using a colposcope with a magnification $\times 10$ for tubal reconstruction in women (Walz, 1959). Nowadays tuboplastic microsurgery has become a widely accepted technique for the restoration of female fertility. Microsurgery does imply more than the use of magnification only. More importantly, microsurgery encourages an approach to surgery which is as atraumatic as possible and aims to maintain the correct anatomical relationships in the pelvic cavity. The advantages of gentle tissue handling are prevention of unnecessary adhesion formation and preservation of the physiologic function of the ovaries and of the oviducts. In fact, this approach ought to be applied to all pelvic surgery in women during their fertile years, since previous pelvic surgery is known to be an important iatrogenic course of infertility. Darling (1982) reported that of the new patients with proven tubal infertility referred to his clinic during a 3 months period in $1979,73 \%$ had a history of some previous pelvic surgery. 
Furthermore, there is no doubt that microsurgery is a remarkably useful research tool. It presents the possibility to study accurately the effects of removal of tubal segments, problems related to tubal healing and some aspects of ovum and embryo transport. The reversibility of various current sterilization techniques has been studied in animal models (Hulka and Ulberg, 1975; Boeckx et al, 1977), and reversal techniques have been refined before applying them to the human.

In microsurgery the principles of atraumatic surgery are emphasized. Any abrasion of the peritoneum causes petechial hemorrhages on the surface which may lead to adhesion formation. Peritoneal irritation should be prevented by handling the tissues as little as possible and avoiding the use of clamps and forceps; manipulation with smooth glass rods is to be preferred. The peritoneum may be injured by contact with dry swabs or gloves covered with starch powder (Yaffe et al, 1978). Peritoneal damage is minimized by washing the powder from the gloves before opening the abdomen and by moistening the packs or swabs before use. Drying out of tissues should be prevented. Continuous irrigation with warmed isotonic fluids is suitable. Water alters the ionic concentration in the tissues and causes edema. All raw peritoneal surfaces should be covered either by suturing the loose edges together or by peritoneal grafting. Precise hemostasis, preferably by electrocautery with a bipolar forceps, has to be taken care of. This provides coagulation at low voltage, restricted to the tissue between the electrode tips. It is doubtful whether the presence of blood in the peritoneal cavity per se gives rise to subsequent adhesion formation. Nisell and Larsson (1978) demonstrated in rats that surgical trauma to the serosa induces adhesion formation and not the presence of blood or fibrinogen. However, bleeding results in an impeded view and has to be avoided. Non-absorbable sutures of fine calibre, $8 / 0$ or less, are preferred. The superiority of nylon sutures can probably be ascribed to its combination of small size, great strength and non-reactive nature. Absorbable sutures, especially catgut, require active phagocytosis for their absorbtion and cause marked inflammatory response (MacKay and Khoo, 1972; Kosasa et al, 1976). Recently histologic investigations revealed that some fibrosis is also detectable around nylon and propylene sutures 80 days postoperatively. Polyglactin-910 (Vicryl) and polydioxanone (PDS), synthetic absorbable materials, do incite less tissue reaction (Gomel et al, 1980; Delbeke et al, 1983), and may become of importance to microsurgery.

The importance of excluding the tubal endosalpinx when performing tubal surgery has been examined (Seki et al, 1977). Microsurgical reconstruction of the rabbit oviduct was undertaken utilizing either through-and-through sutures including the mucosa, or sutures penetrating only the serosa and muscularis. Patency and pregnancy rates did not vary with the technique used. On histologic examination, however, abnormal mucosal patterns were observed in anastomoses including the mucosa. These might cause future tubal obstruction and of fer the possibility of ectopic pregnancy in the human. Formerly hoods and stents were used and left in situ for months in order to maintain tubal patency. But splintage has appeared to be counterproductive: its prolonged use leads to an inflammatory reaction in the mucosa, to 
the loss of cilia and to the accumulation of debris within the lumen which persists for a long time after removal of the splint (Winston, 1975). Pregnancy rates in the rabbit decline the more, the longer a splint has remained in situ postoperatively (Khoo and Mackay, 1972). However, splinting the tube for the period of the actual anastomosis can be very useful to attain stability during suturing.

Perioperative administration of corticosteroids, dextran and hydropertubation have been advocated in order to minimize adhesion and scar tissue formation. Although steroids are widely used, intraperitoneally or systematically, and are considered to be effective (Gomel, 1977; Winston, 1980), the rationale for their use is debatable. Steroids delay reperitonealization of raw areas. Adequate primary peritoneal covering is mandatory before their use. Most microsurgeons agree about withholding steroids from patients undergoing tubal anastomosis for fear of delaying good healing (Winston, 1980). Seitz et al (1973) compared the use of saline with steroids, intramuscularly and intraperitoneally, in monkeys and found no improvement in prevention of adhesion formation. In rats the use of intraperitoneal and parenteral corticosteroids, in comparison with the use of intraperitoneal saline, did not reduce adhesion formation, but produced healing disturbances (Gomel, 1977). Dextran has been thought to produce a mechanical effect by keeping peritoneal surfaces apart during healing and to have an effect on the polymerization of the fibrin monomers, making the fibrin more susceptible to lysis by plasmin (Tangen et al, 1972). 30\% dextran 70 (Hyskon) has been used for this purpose. Experimental results on the effects of dextrans are controversial: Neuwirth and Khalaf (1975) found in rabbits, after surgically induced injuries, the number of adhesions to be markedly diminished in the group which had received dextran intraperitoneally as compared to a control group. On the contrary, Boeckx (1982) reported no evidence for a protective effect of dextran 70 on adhesion formation nor on tubal patency in rabbits after a microsurgical salpingostomy for hydrosalpinx.

Hydropertubation has become obsolete in most centers since it has several major disadvantages. It is painful to the patient and adds a considerable risk of postoperative infection. Furthermore, it is unlikely that at pressures which could be tolerated by a conscious patient, a sufficient head of pressure can be produced at the fimbrial end of the oviduct to dislodge clots or debris.

Recently a reduction has been reported in postoperative adhesion formation in rabbits that received high doses of ibuprofen in the perioperative interval (Nishimura et al, 1983, 1984; Siegler et al, 1980). Ibuprofen is a nonsteroidal antiinflammatory agent. It inhibits prostaglandin metabolism and appears to reduce adhesion formation through suppression of fibroproliferative inflammation.

It still remains questionable whether the use of different adjunctive medical treatments to reduce adhesion formation after microsurgical procedures is capable to improve the results obtained by meticulous surgery alone.

Most authors comparing microsurgical to macrosurgical procedures agree that microsurgery seems to give superior functional results. Microsurgical tuboplasties result in increased frequencies of term pregnancies, especially in patients who have un- 
dergone anastomosis, and a decreased frequency of ectopic pregnancies (Gomel, 1977; Winston, 1978; Diamond, 1979; Siegler and Kontopoulos, 1979). Experimental work on laboratory animals has substantiated the clinical data (Eddy et al, 1980; Boeckx, 1982). Macrosurgical tuboplastic procedures give poor results. Although the recorded patency rate is $50 \%$ to $70 \%$ (Crane and Woodruff, 1968), term pregnancies in patients after macrosurgical reversal of sterilization do not exceed $30 \%$ (Diamond, 1979). The use of microsurgery results in an improvement in patency and in the term pregnancy rate: patency has been improved to over $90 \%$ and term pregnancies to $70 \%$ and more (Gomel, 1977; Diamond, 1979; Winston, 1980). Concurrent surgical techniques, such as the so-called 'microsurgical principles' of gentle tissue handling, fine sutures and bipolar microcoagulation may partially account for the enhanced fertility rates. The significance of the use of the microscope itself is less clear. Delicate macrosurgical methods may be comparable to microsurgical ones (Jones and Rock, 1978). Studies on laboratory animals comparing the results of tubal anastomoses obtained by using a microscope to those by using loupes, but observing microsurgical principles in both, indicate that no significant differences exist in adhesion formation and pregnancy rates whether minimum magnification ( $\mathrm{x} 2$ to $\mathrm{x} 4)$ or the operating microscope ( $\mathrm{x} 2$ to $\mathrm{x} 40$ ) be used (Hedon et al, 1980; Goldfarb et al, 1983). Histologic differences seem to exist, however. In rabbits which underwent macrosurgical reanastomosis, a noticeable incidence of anatomic disturbances occurred (Khoo and MacKay, 1972; MacKay and Khoo, 1972). These included loss of mucosal folds, diminution or absence of ciliated and secretory cells and fibrous replacement of damaged muscle tissue. When tissue trauma is severe and widespread, cellular death will be extensive and will be followed by repair through fibroblastic proliferation and connective tissue formation. The resultant disruption may lead to loss of patency and loss of function. Evaluation of a rabbit oviduct anastomosis performed by an experienced microsurgeon showed that in no instance the gross anatomy of the oviduct was disturbed severely (Eddy and Bajpai, 1982). Scanning electron microscopy revealed that the endosalpinx was continuous across the anastomosis on the first day after operation (Boeckx, 1982). By day 14 the healing was complete. Finally, healing occurred without scar tissue formation or stenosis. Two weeks after surgery a high degree of functional integration had been restored, consistent with normal fertility (Perez et al, 1981b; Eddy and Bajpai, 1982). The ability of microsurgically performed anastomosis in the rabbit oviduct to generate and propagate spontaneous action potentials across the anastomosis site has been demonstrated 3 weeks after surgery (Archer et al, 1979).

In conlusion, although pregnancy rates are comparable, at histologic examination the anastomoses performed with the use of a microscope are generally of better quality and contain less fibrosis and ectopic mucosa compared to anastomoses performed by using the naked eye or loupes. A greater preservation of physiologic function is attained by higher magnifications because of better determination of tissue normality, identification of exact anatomical planes, precision of suture placement and minimization of tissue trauma because $10 / 0$ or $11 / 0$ sutures can be applied. The 
accuracy of the anastomosis is most important in the human, as in this species usually only one ovum travels down the tube in a menstrual cycle. Moreover, there is considerable evidence that minor disturbances of the tubal architecture may lead to the development of an ectopic pregnancy, a condition unknown in other mammals. Despite the introduction of the microscope and of microsurgical principles into tubal reconstructive surgery, the pregnancy rate achieved has not become as high as the rate of tubal patency (table 1.1).

Criteria applied to the selection of patients determine the rate of success to a great extent, and have led to scoring systems, developed to determine the operability and prognosis of a patient (Boer-Meisel et al, 1985; Van Assen, 1977). The etiology of tubal obstruction is of importance. Preexisting epithelial pathology is unfavorable as it is still unknown whether muscular elements and mucosa can regenerate. Microsurgical techniques have failed to reverse postinfectious infertility in the majority of cases (Frantzen and Schlösser, 1982). There appears to be a correlation between ciliation index and the occurrence of subsequent pregnancies (Brosens and Vasquez, 1976). The residual length of the tube correlates with the pregnancy rate; a tube with an extrauterine length of $3 \mathrm{~cm}$ or less gives a poor prognosis (Silber and Cohen, 1980; Winston and Margara, 1980). Gomel (1980) reported an inverse relationship between the total remaining length of the reconstructed tube and the interval between surgery and the occurrence of pregnancy.

Microsurgery has been proven less successful in reversal of sterilization in patients who were sterilized several years before. Vasquez et al $(1980 \mathrm{~b})$ have shown that with prolonged tubal interruption the mucosa becomes flattened and atrophic, and shows loss of ciliated cells. Epithelial polyps are common. The success rate of reversal was halved in patients who had been sterilized more than 5 years previously.

Ovulatory dysfunction after tubal ligation in patients ovulating prior to surgery, was noted by DeCherney et al (1983). Berger et al (1978) and Donnez et al (1981) described decreased midluteal progesterone levels in sterilized women compared to controls, but others were unable to demonstrate differences in progesterone levels (Corson et al, 1981). Alvarez-Sanchez et al (1981) reported no differences in midluteal progesterone levels, but found significantly lower preovulatory LH and 17- $\beta$ estradiol peaks as well as average levels in women with a previous tubal ligation compared to a control group of normally menstruating women. Their results reveal that ovarian function may be altered after surgical sterilization. In rabbits a slight but non-significant reduction in the number of corpora lutea on the operated side was observed (Winston, 1980; Boeckx et al, 1977; Verhoeven et al, 1982). There appeared to be neither any correlation between the reduction of the number of corpora lutea and the amount of tubal or mesosalpingeal resection, nor between the reduction of the number of corpora lutea and the proximity of the anastomosis to the ovary (Verhoeven et al, 1982, 1983). After fimbriectomy, however, McComb et al (1981b) found in rabbits a significant difference in corpora lutea between the operated and the non-operated oviduct. But Halme et al (1982) microsurgically removed both tubes in toto and reported neither difference in the mean number of corpora lutea nor 
in the serum progesterone levels. Altered ovarian blood flow and altered luteal function with a change in hormone production, or a disruption of the neural linkage between ovary and oviduct have been proposed as possible mechanisms by which ovulatory dysfunction might be caused. No major alteration in tubal microvascular architecture was observed, however, after Pomeroy sterilization (Verco et al, 1983). Evidence for a direct effect of tubal vascular interruption on ovarian blood supply is still lacking. The possible role of ovulatory dysfunction in the failure of reconstructive tubal surgery remains to be elucidated (Hamilton et al, 1985).

Furthermore, the success rate of microsurgery is influenced by formation of peivic adhesions de nowo or reocclusion of the oviducts, which is likely to occur when not all pathologic tissue has been excised.

DeCherney et al (1983) analysed the failures of microsurgical anastomosis after tubal ligation. After a follow-up period from 18 months up to 5 years $28 \%$ of the total population had failed to conceive. About one third of these failures remained unexplained. Future work needs to be directed at the elucidation of these cases.

\subsection{Experimental tubal microsurgery}

Once the techniques being established, tubal microsurgery has proven to be of considerable value as a research tool with which to examine tubal reproductive physiology, and to study various infertility problems. In order to study the critical length and the relative importance of the various segments of the oviduct in infertility, microsurgical resection of different lengths and of different segments has been performed in the rabbit.

Halbert et al (1981b) studied the effects of microsurgical transection reanastomosis of the isthmus in seven rabbits. They concluded that anastomosis, without resection of any segment, appears to be associated with delayed ovum transport as well as with a modest reduction in fertility. This stands in contrast with results obtained by others (Eddy, 1978; Boeckx, 1982), who reported that transection and even resection of small segments of isthmus or ampulla does not interfere with normal fertility in the rabbit. The importance of training in microsurgical techniques has been stressed by Boeckx (1982). Extensive microsurgical training on animals is needed to master the technique. Boeckx (1982) performed transection reanastomoses of the oviduct and found that only after execution of 135 anastomoses the tubal and ovarian functioning on the operated side was comparable to that of the control side. Progressive shortening of the isthmus, adjacent to the utero-isthmic junction, resulted in a progressive decrease in fertility, leveling off at $50 \%$ of the normal pregnancy rate and nidation index when the complete isthmus was removed (Boeckx, 1982). The presence of the intramural portion only of the isthmus seems to be sufficient to allow pregnancies to occur in the rabbit. Absolute infertility was observed after excision of the utero-isthmic junction, the ampullary-isthmic junction and the whole isthmus 
(McComb et al, 1981c). Most ova recovered from the experimentally altered tubes had been fertilized, but were degenerating on examination 64 hours or more after mating. All ova in the experimental tubes were devoid of a mucin coating, and many more sperm tails were present in their zonae pellucidae than in ova in the contralateral control tubes. Polyspermia was observed in ova from the experimental tubes in two of the eight does. In addition to the abnormal development of the fertilized ova in the experimental tubes, ovum transport was disturbed as well. In one of the two animals studied 136 hours after mating, one ovum persisted for up to 6 days on the ampullary side of the (patent) anastomosis. The overall ovum recovery rate was low in the operated tubes as compared to the control sides ( $20 \%$ versus $83 \%$ ), which suggests that most ova could have been lost from the experimental sides by premature entrance into the uterus and subsequent expulsion from the vagina.

Various studies have proven that the utero-isthmic and ampullary-isthmic junctions are not critical to reproduction in the rabbit. Fertility is unaltered after resection of the utero-isthmic junction or the ampullary-isthmic junction (Eddy et al, 1977; Winston et al, 1977; Pauerstein and Eddy, 1979; Perez et al, 1981b), which demonstrates that no essential sphincters exist on these sites. The isthmus itself appears to be responsible for the transistory retardation in ovum transport. According to Blair and Beck (1976) sphincter action is not restricted to a small localized segment of the oviduct, but occurs along the whole length of the isthmus.

Experiments, methodologically subjected to criticism, have been performed on this subject, too, and provide contradictory results. The results obtained by David et al (1969) have been cited by many authors, but seem to disagree with the studies mentioned above: from their experiments on resection of the utero-isthmic junction they concluded that this junction is necessary to normal fertility since 10 out of 25 rabbits failed to have pregnancies. They did not include controls for the effects of their operating procedures, however. In contrast to all investigators cited before David and coworkers did not fully apply the 'microsurgical principles', but placed sutures through the endosalpinx and left a splint in situ for 15 days postoperatively. Postoperative investigation of the rabbits revealed, however, that their oviducts were immobilized by adhesions. In all likelihood these adhesions invalidate the conclusion drawn by David et al about the function of the utero-isthmic junction.

Progressive removal of segments of the ampulla produced a linear decrease in the pregnancy rate which became zero when more than $60 \%$ had been excised (Boeckx, 1982). McComb and Gomel (1979) resected segments of the oviduct of different length adjacent to the utero-isthmic junction and found a significant linear correlation between remaining tubal length and number of implantations, which suggests that more than $47 \%$ of the oviduct must remain intact for implantations and pregnancies to occur. In the doe the isthmus accounts for approximately $40 \%$ of the total tubal length. McComb et al (1981a) subjected rabbits to microsurgical resection of differing lengths of ampulla with preservation of the complete isthmus. When only perfect, albeit modified, adnexal anatomy was accepted, 13 out of 22 rabbits were left for study. In these the correlation between fertility parameters and the percenta- 
ge of ampulla remaining was poor. When all rabbits were included for study, however, regardless of the presence or absence of adnexal adhesions, a significant correlation appeared between nidation indices and residual ampullary lengths. The reason for the infertility in the presence of greatly reduced ampullary length is speculative. It may be the result of interrupted transport, of inadequate ovum retention or of loss of capacity for fertilization. In addition to these factors adverse effects may also result from peritubal adhesions and disturbance of the tubo-ovarian spatial relationship.

Intact fimbriae with a fimbria ovarica are not essential for ovum capture. Ampullary fistulas have been shown to be able to pick-up ova (Metz and Mastroianni, 1979). In experiments performed by Beyth and Winston (1981), in which fimbriectomy was combined with removal of the terminal $2 \mathrm{~cm}$ of ampulla, 15 out of 19 rabbits conceived. Perez et al (1981a) removed a $1 \mathrm{~cm}$ segment of the distal ampulla including the fimbriae, and then made a distal ampullary flap which was sewn over the exposed ovarian cortex in order to restore tubo-ovarian relationship. The mean number of ova released from the ovaries on control (6.00) and operated (4.88) sides did not differ significantly, but the mean number of implantations and the mean nidation indices did ( 4.57 versus $1.72,73.2 \%$ versus $37.8 \%$ ). These results suggest that in the rabbit ovum pick-up is possible in the absence of fimbriae but that ovum pick-up is less efficient and leads to reduced fertility.

Halbert and Patton (1981) performed infundibular salpingostomies, but made no attempts to improve approximation of the neofimbria to the ovary. The infundibular salpingostomies manifested nearly normal ovum capture rates (63\% versus $80 \%$ ). Distal ampullary cuff salpingostomies were demonstrated to have an adequate function, albeit less efficient than the infundibular salpingostomies (Halbert et al, 1981a) on the control sides $77 \%$ of ova were retrieved, compared to $27 \%$ on the experimental sides. Scanning electron microscopy revealed a propensity of the everted mucosal folds to hypertrophy and to become remarkably similar to natural fimbriae. Finally, fertility after fimbriectomy, excision of at least half of the adjoining ampulla, and performance of a proximal ampullary cuff salpingostomy as well, was studied by Halbert and McComb (1981). The modified oviducts were unable to retrieve ipsilaterally ovulated ova, and transport of surrogate ova placed on the neofimbriae was severely reduced. Scanning electron microscopy showed the everted mucosa of the proximal ampulla to be far less richly endowed with cilia than the mucosa of the normal fimbriae. The mucosal folds did not show the propensity to hypertrophy as observed in the distal ampullary cuff. The results suggest that the proximal ampulla in the rabbit is unsuitable for reconstruction of a functional Fallopian tube.

In assessing the relative contributions of ciliary and contractile activity to ovum transport in the animal model, segments of the oviduct have been reversed and reanastomozed. Eddy et al (1976) reversed a segment of proximal tubal isthmus in two rabbits. Both became pregnant and a nidation index (i.e. the number of implantations divided by the number of ovulations multiplied by one hundred) of 60 was 
found. In a further series of isthmic reversal Eddy et al (1978) obtained a pregnancy rate of $75 \%$ and a nidation index not different from the contralateral control values ( 52 versus 56). These results are confirmed by experiments done by Boeckx (1982), who reported no significantly altered tubal function after reversal of isthmic segments.

However, reversal of ampullary segments resulted in a greater reduction of tubal function. Reversal of $1 \mathrm{~cm}$ segments of ampulla by Eddy et all (1978) prevented pregnancy in all 19 rabbits but one, and the nidation index was reduced to nearly zero. McComb et al (1980) also reported one single pregnancy only in 10 rabbits with reversed ampullary segments. The observations that double transection and reanastomosis of segments had neither an effect on ovum transport nor on fertility demonstrate that reversal of the segment, rather than surgical manipulation itself, is responsible for the changes observed (Eddy et al, 1978). Comparison of oviduct function after reversal of an ampullary segment with reversal of an isthmic segment by Boeckx (1982) showed no significant difference. The lack of apparent effect may be due to his small number of observations. Winston (1978) reported that in his studies rabbits with reversed ampullary segments did not conceive shortly after surgery, but that three out of eight rabbits became pregnant when 4 months or more had elapsed. He postulated that ampullary ciliary beat direction may change when sufficient time has elapsed. This, however, could not be confirmed by in vitro studies performed by McComb et al (1980). Transport across a reversed ampullary segment may either represent a chance occurrence, muscular activity overcoming the proovarian ciliary beat, or reflect adaptation of transport mechanisms. Studies by Halbert and Patton (1979) revealed an important facultative role for muscle actions in ampullary ovum transport that facilitates ovum transport when ciliary activity is impeded. The differences in ability to alter fertillity by isthmic and ampullary reversal suggest that the cilia of the isthmus do not play a vital role in reproduction. Another interpretation is that ciliary cells of the isthmus may not be programmed to beat uniformly in the same direction. Dual ciliary currents have been observed in the isthmus of the rabbit (Gaddum-Rosse and Blandau, 1973).

A valuable warning has been given by Margara and Winston (1980) against general deductions from experiments in which one tube is left intact to serve as a control for the experimental contralateral oviduct. Margara and Winston, resecting one ovary and removing or clipping the contralateral oviduct in a series of rabbits, found transmigration in such animals surprisingly often to occur: in one animal six ovulations resulted in six pregnancies at the opposite side.

\subsection{Aim of the study}

The effects of tubal microsurgery on tubal physiologic processes and fertility have been the object of investigations during the last decade. The main issues have been 
ovum transport and pregnancy rates in the surgically altered oviduct. Little research, however, has been directed to the investigation of processes taking place between ovulation and implantation.

This study was undertaken to examine the impact of microsurgically altered tubal conditions upon early embryonic development in the rabbit. Resection reanastomoses of various length (20\% and $80 \%$ respectively) and localization (isthmic and ampullary respectively) were performed. All does were mated either 3 weeks or 12 weeks after surgery. Subsequently early embryonic parameters were studied 24,36 and 48 hours after mating.

The actual types of microsurgical resection reanastomoses were selected on several grounds. Boeckx (1982) evaluated the relative importance of each segment of the oviduct by analysing the effect of progressive shortening (i.e. 1-40\%, 41-60\% and $61-100 \%$ ) of the isthmus and ampulla. Resection of $20 \%$ and $80 \%$ segments of isthmus and ampulla in our study would enable comparison of the data obtained with results reported by Boeckx. Furthermore, from a clinical point of view $20 \%$ shortenings of isthmus or ampulla correlate with the degree of tubal shortening found after reversal of sterilization by Fallope rings, Hulka clips, Filshie clips or bipolar coagulation. More extensive tubal damage is encountered after unipolar diathermy sterilization. Subsequent refertilization will necessitate resection reanastomoses of $60-80 \%$ of total isthmic or ampullary length. The clinical application of knowledge about early embryonic development in shortened oviducts would be the prediction of prognosis after tubal surgery for sterilization reversal. The prognosis after surgery for pelvic inilammatory disease or ectopic pregnancy will be determinated both by tubal surgery outcome as well as by preexistent epithelial pathology.

To evaluate the effect of the duration of the postoperative interval early embryonic developmental processes were studied shortly after surgery (in casu 3 weeks) and after a relatively long recovery period as well (in casu 12 weeks).

It was decided to study the embryonic processes up to the morula stage. For this purpose all observations were done 24 hours, 36 hours and 48 hours after mating. i.e. about 12 hours, 24 hours and 36 hours after ovulation. 



\section{CHAPTER II. Materials and methods}

\subsubsection{Choice of the animal}

The rabbit was selected for the present experiments for several reasons. In the doe the genital tract is composed of double ovaries, oviducts, uteri and cervices (figure 1.2); consequently one side can be used as a control. Rabbits are reflex ovulators, i.e. ovulation is elicited by copulation. Stimulation of the hypophysial cells occurs immediately after mating, and sufficient luteinizing hormone to cause ovulation is discharged within 35 to 50 minutes after copulation (Firor, 1933). Mating is followed by ovulation in 12 to 14 hours (Harper, 1961, 1963). Consequently, the rabbit model provides definitive information about temporal aspects of reproductive processes. In addition, in literature most data concerning tubal function experiments have been derived from studies using rabbits. Finally, the rabbit is an accepted training model for human tubal microsurgery.

Sexually mature female Dutch belted rabbits (O.cuniculus discolor Neerlandicus), weighing 1500-3800 grams (mean 1974 grams) and 4-6 months of age (mean 4.4 months) were used. The animals were caged individually at a constant environmental temperature of $20^{\circ} \mathrm{C}$, and subjected to a light/dark cycle of $12 / 12$ hours. They were fed 150 grams of rabbit chow daily and allowed water ad libitum throughout the period of the experiments.

\subsubsection{Anesthesia}

Before operation each doe received $125 \mathrm{mg}$ of ampicillin prophylactically by intravenous injection.

Anesthesia was induced with atropine intramuscularly, $0.2 \mathrm{mg}$ per $\mathrm{kg}$ of body weight, and Hypnorm (Duphar, Amsterdam) intramuscularly, $0.5 \mathrm{ml} \mathrm{per} \mathrm{kg}$ of body weight. Hypnorm is a neuroleptanalgesic for veterinary use, containing $10 \mathrm{mg}$ fluanizone and $0.2 \mathrm{mg}$ phentanyl per $\mathrm{ml}$.

When anesthesia was achieved, each rabbit was intubated with an endotracheal tube of 1.5-2.0 mm diameter. A mixture of halothane (0.5-1.0\%), oxygen $(1 \mathrm{l} / \mathrm{min})$ and nitrous oxide $(2 \mathrm{l} / \mathrm{min})$ was given through a closed loop inhalation anesthesia system (Keuskamp Infant Ventilator MK 2, Amsterdam). 


\subsubsection{Microsurgical equipment}

A Zeiss OPMI 6 microscope and an auxiliary light source were used. The microscope fitted a $125 \mathrm{~mm}$ objective lens, $160 \mathrm{~mm}$ binocular tubes, $x 12.5$ eyepieces and a 0.5 to 2.5 magnification factor in the zoom system, so allowed magnifications from $x 8$ to $\times 40$, facilitating the identification of the tubal anatomy as well as the surgical procedures.

Vannas and Castroviejo microscissors with curved blunt tips, fine jeweller's forceps and an $O^{\prime} B r i e n$ needle holder with small angulated jaws were used (figure 2.1). Acland-Winston tubal clamps with diameters of $0.7 \mathrm{~mm}$ and $1.0 \mathrm{~mm}$ were used to keep blood loss at a minimum during the surgical procedure. The tip of the clamps is semicircular, compressing the vessels in the tubal wall without occluding the lumen (figure 2.1). A $5 \mathrm{~cm}$ long, $0.45 \mathrm{~mm}$ thick polyethylene splint was used to stabilize the oviduct after transection during suturing. A bipolar coagulator (Karl Storz, Los Angeles) was used for hemostasis. A high-frequency electric current is generated through the insulated jaws of a jeweller's forceps, enabling localized coagulation without burning the surrounding tissues. The rabbit oviduct was stabilized during surgery by a $3-4 \mathrm{~cm}$ wide stainless steel platform with rounded edges, which could be hooked on to the main operation table (Boeckx and Desmedt, 1977). The exposed tissues were continuously irrigated with physiological saline solution throughout the complete surgical procedure. For suturing $10 / 0$ and $11 / 0$ monofilament nylon, with round-bodied 70 micron needles, was used.

\subsubsection{Surgical technique}

For the microsurgical resection reanastomosis of the oviduct, the animal was placed in supine position and the left flank shaved, prepared with an iodine solution and draped with sterile towels. A 3 to $4 \mathrm{~cm}$ flank incision was made between the inguinal ligament and lateral margin of the musculus rectus abdominis. The musculi obliqui abdominis externus and internus were coagulated locally before being cleaved. Meticulous hemostasis was performed. Wet swabs were brought into the abdominal cavity to protect the intestines and to expose the left oviduct. The tubal half containing the segment which was to be resected was delivered through the incision and placed on the steel platform.

Thereafter the microscope was adjusted. During the time the abdomen was open, desiccation of the exposed tissues was prevented by irrigation with a physiological saline solution.

The isthmic or ampullary half of the tube being exposed, the ampullary-isthmic junction was identified. The thickening of the tubal wall towards the isthmus, the alteration in tubal diameter and the insertion of a prominent leash of vessels were 


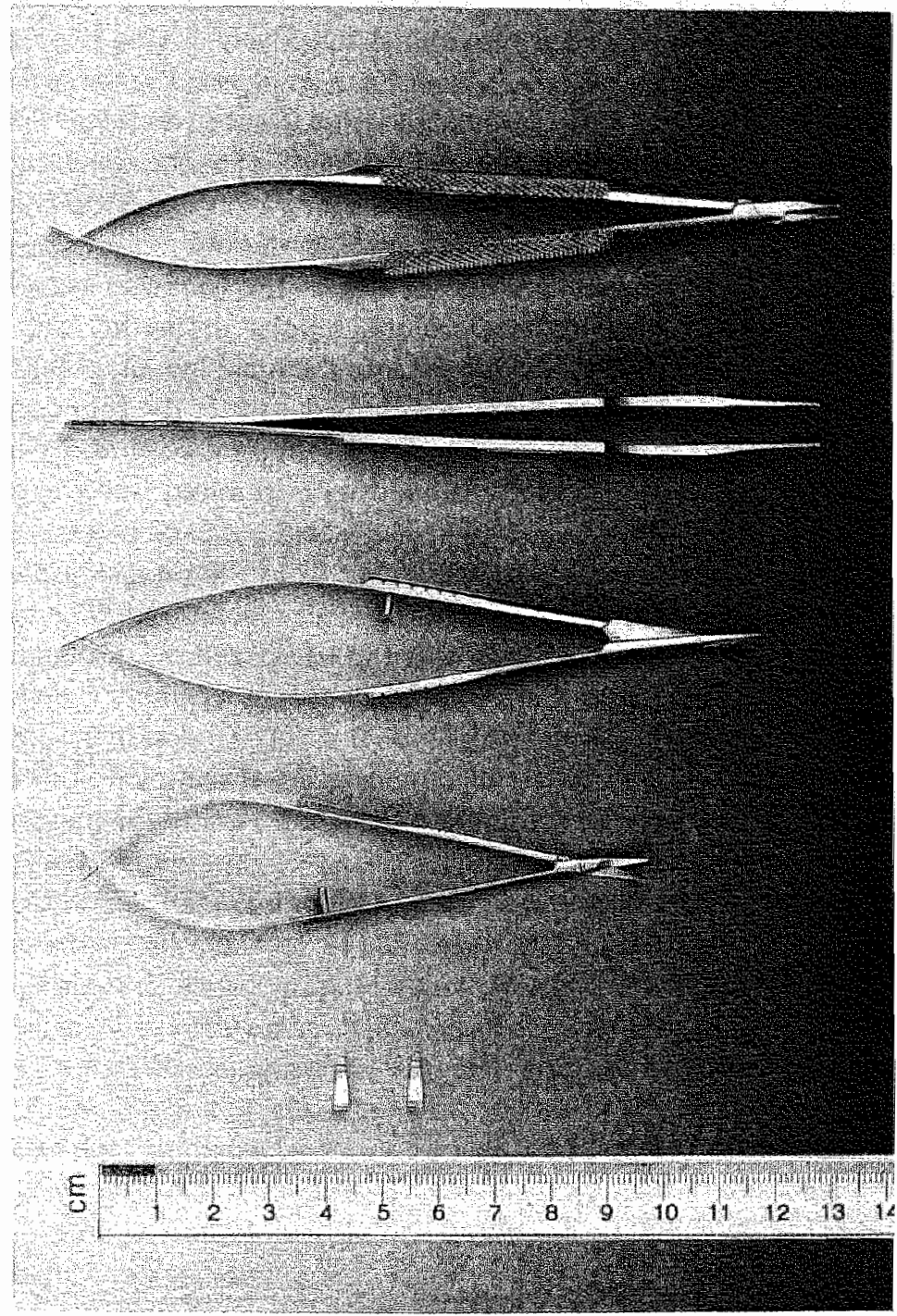

Figure 2.1 Microsurgical instruments, from top to bottom:

- O'Brien needle holder

- jeweller's forceps

- Castroviejo microscissors

- Vamnas microscissors

- Acland-Winston tubal clamps 
the junctional characteristics searched for. Under magnification, the blood vessels in the mesotubarium superius were coagulated selectively. Using scissors, a linear incision was made in the mesotubarium superius to gain access to the oviduct. Blood vessels parallel to the oviduct were coagulated at the transection sides. Tubal clamps of appropriate diameter were applied across the oviduct, at the distal and proximal ends of the segment which was to be resected (figure 2.2; page 25). Using scissors, an oviductal segment containing approximately $20 \%$ or $80 \%$ of isthmus or ampulla was resected. The utero-isthmic junction as well as the fimbriae were always left intact (figure 2.3). When bleeding was evident, bipolar diathermy was applied to obtain hemostasis. The splint was introduced into the tubal lumen, obliquely perforating the uterine and tubal walls at both ends in order to fix the splint and to allow removal afterwards. The tubal clamps helped to stabilize the splint, by holding the tubal ends in apposition. Methylene blue dye was introduced into the cut ends of the oviduct, staining the mucosa and muscularis. Stitches were placed in a circular fashion repairing the anterior wall first, starting from the mesosalpinx. After rotating the clamps by 180 degrees the posterior wall was sutured. The oviduct was reanastomosed in a single layer, suturing only the serosa and the muscular coat, and carefully excluding the mucosa. Care was taken to approximate the serosa accurately to avoid raw surfaces. Seven to eight $10 / 0$ or $11 / 0$ nylon interrupted sutures were usually sufficient to perform the anastomosis. After completion of the anastomosis both tubal clamps and the splint were removed. Finally the mesosalpinx and mesotubarium superius were reconstructed with two or three supplementary stitches each. The abdominal cavity was rinsed with physiological saline solution and closed in two layers. The peritoneum and muscular layer were closed by interrupted

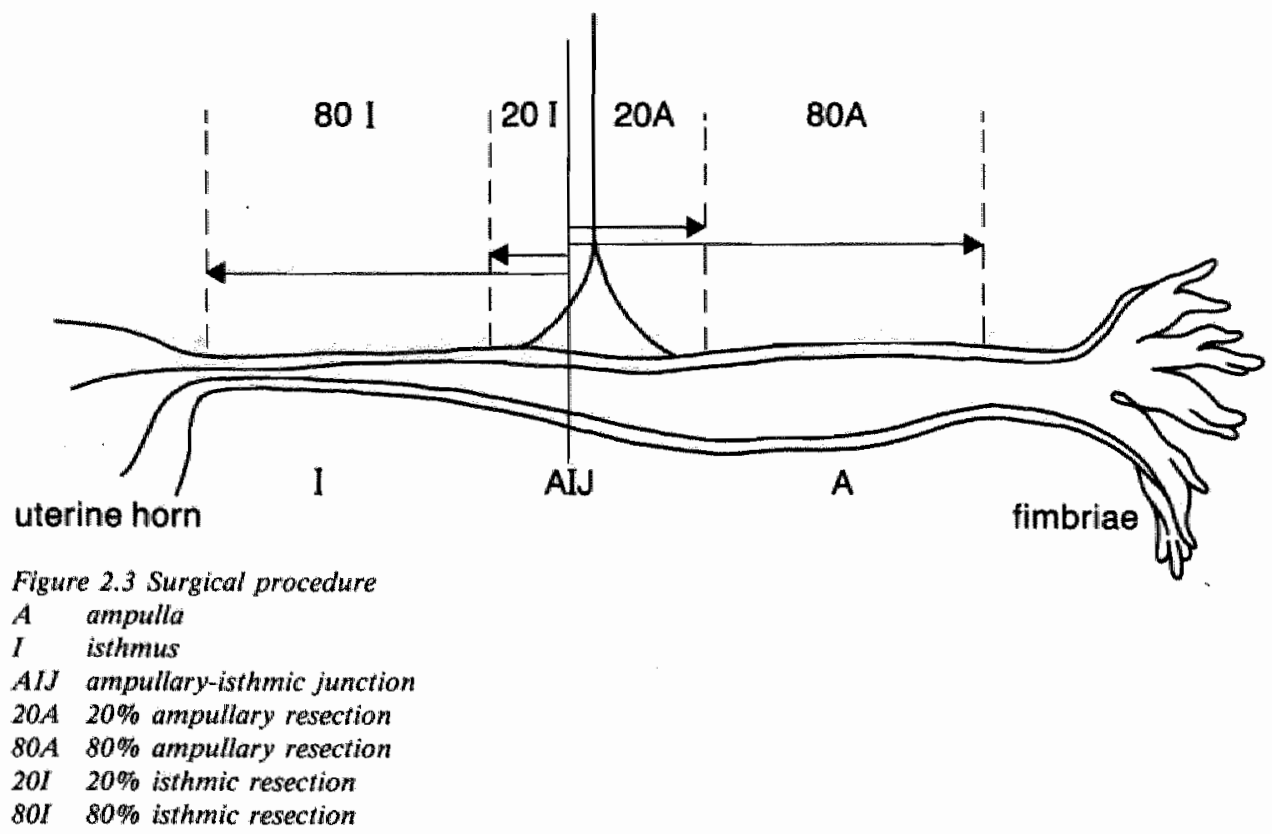


everting sutures in order to minimize adhesion formation. The right adnexum was left untouched.

In the sham-operated animals the abdominal cavity was opened in the same manner. Swabs were deposited, and the left oviduct was exposed through the flank incision. The tube was placed on the operating platform and kept moist for a period which would have been required to perform a resection reanastomosis. Afterwards the abdomen was closed in two layers. Pre- and postoperative management was essentially the same in operated and sham-operated animals.

\subsubsection{Postoperative care}

The rabbits recovered in a warm cage. A single dose of ampicillin $(50 \mathrm{mg})$ was given intramuscularly immediately after the end of the surgical procedures. Water nor chow were restricted postoperatively.

\subsubsection{Mating}

After 3 weeks of convalescence half of the operated animals were caged with a buck of proven fertility. The does were mated, if necessary on successive days, until adequate copulation and ejaculation had taken place. Thereafter the does were given 125 IU of human chorionic gonadotropin (Pregnyl (i), Organon, Oss) intramuscularly to ensure and synchronize ovulation. The remaining half of the operated animals underwent the same procedure 12 weeks postoperatively. The control does (see 2.1.9) were mated a few weeks after their arrival at the laboratory animal house. In the first 20 does studied a laparoscopy was performed to assess whether ovulation stigmata were present after mating. Because all does appeared to have ovulated after adequate mating and administration of human chorionic gonadotropin, laparoscopy was omitted subsequently.

\subsubsection{Ovum recovery}

Further studies were conducted at three intervals: 24 hours after mating (about 12 hours after ovulation), 36 hours after mating (about 24 hours after ovulation) and 48 hours after mating (about 36 hours after ovulation). Anesthesia was induced with Rompun (Bayer, Leverkusen, W-Germany) $0.5 \mathrm{ml}$ per $\mathrm{kg}$ of body weight and Ketaset (Bristol Laboratories, New York) $0.4 \mathrm{ml}$ per $\mathrm{kg}$ of body weight by intramuscular injections. The effective compounds in Rompun and Ketaset are respectively 
Table II.I

Adhesion score according to Winston (1975)

grade $1=$ no adhesions: no adhesions visible under magnification

grade $\mathrm{II}=$ mild adhesions: some adhesions visible with the operating microscope only and at the level of the anastomosis for less than $5 \mathrm{~mm}$ in either direction

grade $11 \mathrm{I}=$ moderate adhesions: some adhesions can be seen with the naked eye and adjacent parts of the oviduct or its mesosalpinx are involved

grade IV $=$ severe adhesions: adhesions extent to the uterus, bladder, intestine or abdominal wall

xylazine and ketamine. Blood was obtained by intracardial puncture. Thereafter the does were sacrificed by an overdose of pentobarbital intravenously or intracardially. Laparotomy was performed and adhesion formation assessed. Both uteri, oviducts and ovaries were excised in toto.

Under a Wild M8 stereomicroscope (magnifying from $x 6$ to $\times 50$ ) excessive fat was trimmed off the preparation. The number of corpora lutea in both ovaries was determined. Adhesion formation at the level of the anastomosis was evaluated under magnification and classified according to Winston (1975)( table II.1). Finally the uterus was dissected at the utero-isthmic junction and the remaining oviduct divided into three approximately equal segments, representing the isthmus, the ampullaryisthmic junction and the ampulla. The anastomosis was always situated at the end of one of these segments. Each segment was flushed with $5 \mathrm{ml}$ of physiological saline solution, the uterus was flushed with $7 \mathrm{ml}$. The flushings were collected in Petri dishes, and checked for the presence of ova or embryos under magnification. Their mucus layer thickness was measured applying a graticule (Wild 376119). Thereafter, ova and embryos were inspected under a Beck-Kassel microscope magnifying x100 to $\times 450$.

\subsubsection{Parameters investigated}

In each doe the number of corpora lutea was noted in the right and left ovaries separately.

The number of ova and embryos recovered from each oviduct was recorded as well. Based on this information the recovery rate was calculated: this is expressed as the number of ova and embryos retrieved divided by the number of corpora lutea, multiplied by one hundred, assuming that each corpus luteum represents a single ovulation.

Tubal transport was examined by identifying the tubal segment(s) which contained embryos at the three established intervals post-coitum.

For each embryo the embryonic cleavage stage was determined. 


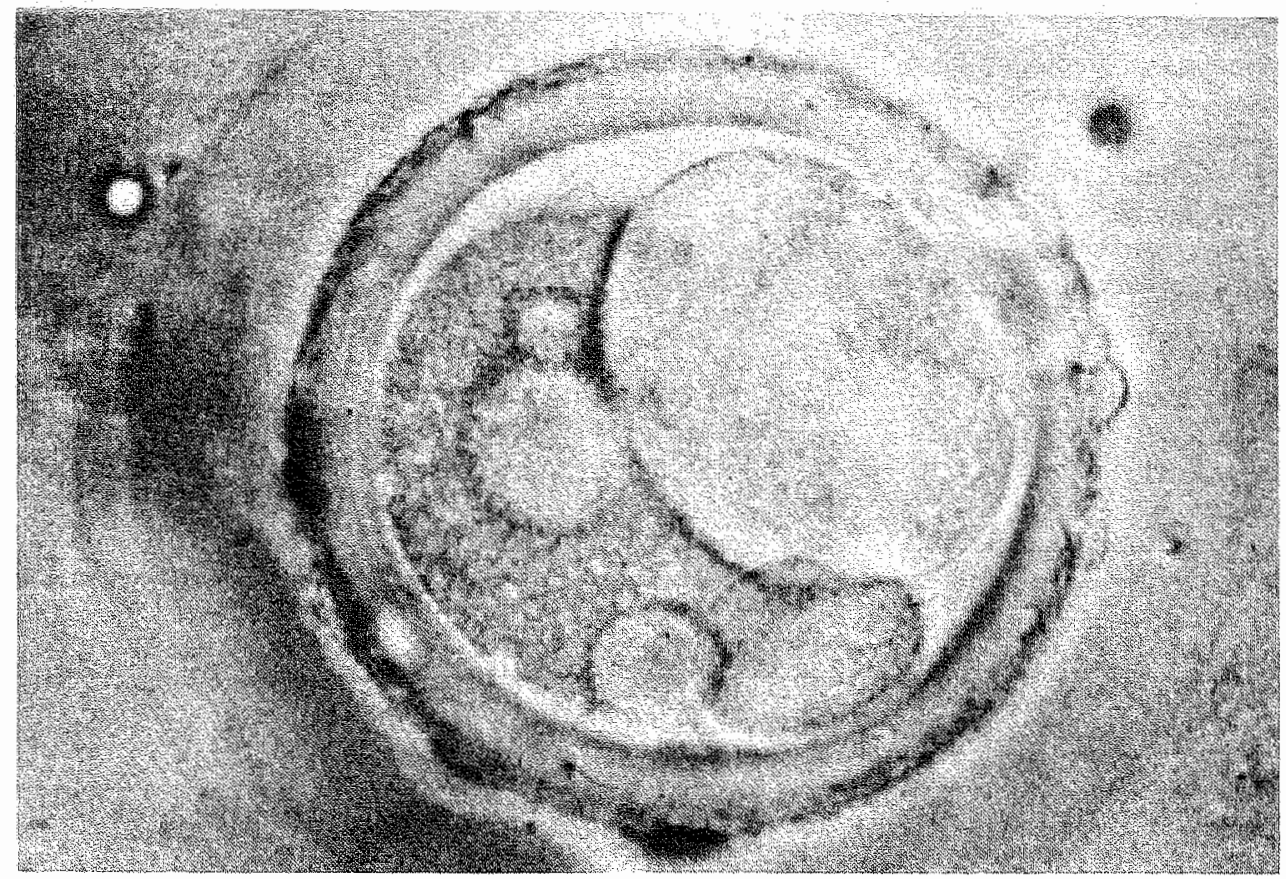

Figure 2.4 Degenerate ovum recovered 24 hours after mating

Note the number of blastomeres and ihe discrepancy in size between the blastomeres. Symproms of cyloplasmatic vacuolization are present

The fertilization rate was calculated in each oviduct, i.e. the number of ova fertilized divided by their total number, multiplied by one hundred. Criteria for fertilization were the presence of male and female pronuclei in the vitellus of the ovum, the presence of two polar bodies, or the presence of sperm in the perivitelline space.

The mucus layer surrounding the zona pellucida was measured with a graduated ocular.

The number of spermatozoa in the zona pellucida and the perivitelline space was determined on focussing on the equatorial plane of the embryo, and considering the number of spermatozoa in the equatorial plane as representative.

The number of degenerate ova and embryos was determined. They were classified as degenerate if showing one or more of the following characteristics: irregularity in appearance, especially fragmentation of the vitellus, unusual discrepancy in size between the blastomeres in one embryo, edematous alteration or herniation of the zona pellucida or symptoms of cytoplasmatic vacuolization (granular texture or dark, brown-coloured spots in the blastomeres) (figure 2.4). 


\section{Group 1}

$20 \%$ isthmic reduction (20 I)

$80 \%$ isthmic reduction $(80 \mathrm{I}$ )

$20 \%$ ampullary reduction $(20 \mathrm{~A})$

$80 \%$ ampullary reduction $(80 \mathrm{~A})$

\section{Group 2}

sham-operation

exposed tubes

control tubes

Group 3

non-operated controls

control tubes

\begin{tabular}{lll}
\hline & $\begin{array}{c}\text { surgery-mating } \\
\text { interval }\end{array}$ & $\begin{array}{c}\text { mating-autopsy } \\
\text { interval }\end{array}$ \\
\hline groups $1+2$ & 3 weeks & 24 hours \\
& & 36 hours \\
& 48 hours \\
& 12 weeks & 24 hours \\
& & 36 hours \\
& & 48 hours \\
group 3 & - & 24 hours \\
& & 36 hours \\
& & 48 hours \\
\hline
\end{tabular}

\subsubsection{Synopsis of experiments}

In the present work three groups of animals were studied.

The first group consisted of does which had been subjected to tubal resection reanastomosis. Four different types of microsurgical resection reanastomosis were performed: $20 \%$ isthmic, $80 \%$ isthmic, $20 \%$ ampullary and $80 \%$ ampullary resections. All resection reanastomoses were made in the left oviducts. The untouched contralateral right sides served as first order controls.

In the second group of animals sham-operations were performed. The left oviducts were exposed, and the contralateral right oviducts served as second order controls. The third group was composed of control animals, in which no surgical procedures were performed. The left as well as the right oviducts in these rabbits served as third order controls. 


\begin{tabular}{|c|c|c|c|c|c|c|}
\hline & & $24 h^{*}$ & $36 h$ & \multicolumn{2}{|l|}{$48 \mathrm{~h}$} & total \\
\hline $20 \mathrm{I}$ & & 12 & 8 & \multicolumn{2}{|l|}{8} & 28 \\
\hline $80 \mathrm{I}$ & & 12 & 8 & \multicolumn{2}{|l|}{11} & 31 \\
\hline $20 \mathrm{~A}$ & & 12 & 8 & \multicolumn{2}{|l|}{8} & 28 \\
\hline $80 \mathrm{~A}$ & & 12 & 9 & \multicolumn{2}{|l|}{10} & 31 \\
\hline SH & & 11 & 8 & \multicolumn{2}{|l|}{8} & 27 \\
\hline \multirow[t]{2}{*}{$\mathrm{C}$} & & 6 & 5 & 4 & & 15 \\
\hline & & & & \multicolumn{3}{|r|}{160} \\
\hline \multicolumn{4}{|c|}{ 3. weeks** } & \multicolumn{3}{|c|}{12 weeks } \\
\hline & $24 h$ & $36 h$ & $48 h$ & $24 h$ & $36 h$ & $48 h$ \\
\hline $20 \mathrm{I}$ & 6 & 4 & 4 & 6 & 4 & 4 \\
\hline $80 \mathrm{I}$ & 6 & 4 & 6 & 6 & 4 & 5 \\
\hline $20 \mathrm{~A}$ & 6 & 4 & 4 & 6 & 4 & 4 \\
\hline $80 \mathrm{~A}$ & 6 & 5 & 5 & 6 & 4 & 5 \\
\hline $\mathrm{SH}$ & 6 & 4 & 4 & 5 & 4 & 4 \\
\hline
\end{tabular}

* mating-autopsy interval

** surgery-mating interval

In order to study early embryonic development all does were mated with bucks of proven fertility. In all rabbits which had been subjected to surgery (i.e. does in group 1 and group 2), mating took place either 3 weeks or 12 weeks after the operation. Control animals (group 3) were mated on arbitrarily chosen days. Autopsies were performed 24,36 and 48 hours after mating respectively in all does.

Table II.2 shows the characterization of the various experimental and control groups, and their subdivisions according to surgery-mating and mating-autopsy interval, In table II. 3 the numbers of does are depicted, classified as described before and shown in table II.2.

\subsection{Statistical analysis}

The aim of this study was to provide a general introduction into the possible changes in early embryonic development, brought about by tubal interventions. To explore the matter in its generality and to try to avoid restriction to single details, an experi- 
mental design was chosen in which small groups of animals were subjected to a large variety of interventions. Consequently the reflection of the data obtained had to be primarily descriptive, showing mutual correlations instead of focussing on individual absolute values. The data were summarized in percentages and in averages. The most commonly used averages are the arithmetic mean and the median. For reasons of uniformity and compendiousness in presentation only one of both measures is given. It was decided for several reasons to present the results as arithmetic means. Most data obtained clustered around a single value. Minor differences between groups would therefore remain unnoticed if median values would be used. Differences between mean values would be slight either, but to indicate tendencies its use was preferred because of the greater discriminating ability of the mean. Furthermore, in case of numerical discrete data (for example the number of corpora lutea) calculation of median values could be biased by the classification of one single observation. An advantage of the mean is its amenability to statistical treatment and consequently its extended use throughout literature. Presentation of our results as mean values enables comparison with data reported by others. The arithmetic mean has the chief disadvantage of being affected by extreme values. But with regard to the results obtained in this study, distributions of data appeared to have only a minor tendency towards extreme values.

Statistical analysis was performed of the differences in the parameters of early embryonic development between the operated oviducts and their controls. Comparison between the means of three or more categories was determined by one-way analysis of variance, using BMDP1V (Dixon and Brown, 1981). The t-test was performed for the comparison of two independent means. To analyse differences between pairs of observations the paired t-test and the sign-test were used. Two-sided levels of significance are given when the t-test, the paired t-test or the sign-test have been used. The difference between two mutually exclusive proportions, as presented in $2 \times 2$ frequency tables, was tested by means of the Pearson's Chi-square test. For the validity of the Chi-square calculation it is assumed that the expected count in each category is at least five. In case of smaller cell sizes the two-sided Fisher's exact probability test was performed for comparison of two proportions. Results were considered statistically significant if $\mathrm{p}$-values were $\leqslant 0.05$.

The following assumptions have been made:

- all parameters of early embryonic development studied within each individual animal are independent, and consequently will not influence other aspects of early embryonic development concomitantly

- the left and right genital tracts in the female rabbit are identical. This allows one to use permanently one tract (in casu the left one) as the experimental side and the contralateral tract (in casu the right one) as the control side. 


\section{CHAPTER III. Results}

\subsection{Abbreviations used in tables}

\begin{tabular}{|c|c|}
\hline CL & $=$ corpora lutea \\
\hline $\mathrm{L}$ & $=$ left oviduct \\
\hline $\mathbf{R}$ & $=$ right oviduct \\
\hline $\mathrm{n}$ & $=$ number of does or ova \\
\hline NS & $=$ not statistically significant \\
\hline sd & $=$ standard deviation \\
\hline $20 \mathrm{I}$ & $=$ does subjected to $20 \%$ isthmic resection reanastomosis \\
\hline $80 \mathrm{I}$ & $=$ does subjected to $80 \%$ isthmic resection reanastomosis \\
\hline $20 \mathrm{~A}$ & $=$ does subjected to $20 \%$ ampullary resection reanastomosis \\
\hline $80 \mathrm{~A}$ & $=$ does subjected to $80 \%$ ampullary resection reanastomosis \\
\hline $\mathrm{SH}$ & $=$ sham-operated does \\
\hline $\mathrm{C}$ & $=$ control does \\
\hline $20 \%$ & $=$ does subjected to a minor resection reanastomosis \\
\hline $80 \%$ & $=$ does subjected to a major resection reanastomosis \\
\hline I & $=$ does subjected to isthmic resection reanastomosis \\
\hline A & $=$ does subjected to ampullary resection reanastomosis \\
\hline $3 w k$ & $=$ postoperative recovery period of 3 weeks \\
\hline 12 wk & $=$ postoperative recovery period of 12 weeks \\
\hline $24 \mathrm{~h}$ & $=$ mating-autopsy interval of 24 hours \\
\hline $36 \mathrm{~h}$ & $=$ mating-autopsy interval of 36 hours \\
\hline $48 \mathrm{~h}$ & $=$ mating-autopsy interval of 48 hours \\
\hline$\leqslant 60 \mathrm{~min}$ & $=$ operation duration of $\leqslant 60$ minutes \\
\hline $60-120 \mathrm{~min}$ & $=$ operation duration of $60-120$ minutes \\
\hline$>20 \mathrm{~min}$ & $=$ operation duration of $>120$ minutes \\
\hline grade I & $=$ adhesion score grade $\mathrm{I}$ \\
\hline grade II & $=$ adhesion score grade II \\
\hline grade III & $=$ adhesion score grade III \\
\hline grade IV & $=$ adhesion score grade IV \\
\hline$<1750 \mathrm{gr}$ & $=$ body weight of $<1750$ grams \\
\hline $1750-2250 \mathrm{gr}$ & $=$ body weight of $1750-2250$ grams \\
\hline$>2250 \mathrm{gr}$ & $=$ body weight of $>2250$ grams \\
\hline segment 1 & $=$ ampullary segment \\
\hline segment 2 & $=$ ampullary-isthmic junction \\
\hline segment 3 & $=$ isthmic segment \\
\hline
\end{tabular}




\subsection{Animals and experiments}

Of the 154 does which underwent a microsurgical resection reanastomosis or a sham-operation, 145 were used for data collection. Five animals died and were excluded: two died during surgery due to failures in anesthesia, one on the second postoperative day due to a mechanical ileus, and two animals died in the second week after operation for unknown causes. Four does were excluded from the experiments after mating: in one doe a swab was left in situ accidentally, and three does had to be rejected due to mating errors.

Flushing of the genital tracts and ovum retrieval were performed in 145 operated does and in 15 control animals. Their numerical subdivision according to surgical intervention, surgery-mating interval and mating-autopsy interval is depicted in table II.3.

Table III.1 shows some general characteristics of all operated, sham-operated and control does. Mean body weight appeared to be higher in the control does, but this was due to one rabbit of 3800 grams. The mean mating-autopsy interval variation represents the mean variation in the time that autopsy took place before or after the end of the preconceived interval (i.e. 24, 36 and 48 hours) following mating. Postoperative adhesion scores did not differ markedly in the animals subjected to a resection reanastomosis. As a consequence of the sham-operation adhesion scores were lower in animals in which this procedure had been performed (table III.1). All tables referred to in the following text present either numbers of does or numbers of ova. The results obtained concerning early embryonic development will be classified and presented in various manners. First, all results were classified according to surgical intervention (i.e. size and site of reduction, sham-operation and no intervention (i.e. control animaly) and according to side (i.e. left experimental oviduct and right control oviduct). Second, in all reanastomosed oviducts the impact of several factors upon parameters reflecting early embryonic development was evaluated. Resection reanastomoses of the isthmus have been compared to resection reanastomoses of the ampulla. All 20\% resection reanastomoses were combined and compared to all $80 \%$ resection reanastomoses. In spite of the differences between isthmic and ampullary segments, resection reanastomoses of these two locations have been combined in order to study the influences of extensive versus minor tubal resection reanastomoses. The effect of the length of the postoperative recovery period was studied by comparing results obtained 3 weeks after surgery to results obtained after 12 weeks. The influence of the mating-autopsy interval was evaluated by comparing data obtained 24 hours, 36 hours and 48 hours after mating respectively. Operation duration has been subdivided into three mutually exclusive categories (i.e. $\leqslant 60$ minutes, $60-120$ minutes and $>120$ minutes), and results are depicted, classified according to these categories of operation duration. Concerning body weight all does were classified either as 'light" ( $<1750$ grams), 'medium' (1750-2250 grams) or 'heavy' ( $>2250$ grams). Data on early embryonic development are presen- 
General characteristics of operated, sham-operated and control does (mean $\pm s d)$

\begin{tabular}{|c|c|c|c|c|c|c|}
\hline & $20 I$ & $80 I$ & $20 . A$ & $80 . A$ & $S H$ & $C$ \\
\hline number & 28 & 31 & 28 & 31 & 27 & 15 \\
\hline $\begin{array}{l}\text { mean } \\
\text { weight (gr) }\end{array}$ & $\begin{array}{r}1985.7 \\
\pm 246.7\end{array}$ & $\begin{array}{r}1991.9 \\
\pm 251.0\end{array}$ & $\begin{array}{r}1937.5 \\
\pm 196.6\end{array}$ & $\begin{array}{r}1996.1 \\
\pm 177.2\end{array}$ & $\begin{array}{r}1920.3 \\
+178.8\end{array}$ & $\begin{array}{r}2100.0 \\
\pm 543.8\end{array}$ \\
\hline $\begin{array}{l}\text { mean } \\
\text { operation } \\
\text { duration (min) }\end{array}$ & $\begin{array}{r}90.2 \\
\pm 29.1\end{array}$ & $\begin{array}{r}91.5 \\
\pm 30.3\end{array}$ & $\begin{array}{r}82.5 \\
\pm 22.3\end{array}$ & $\begin{array}{r}99.8 \\
\pm 21.3\end{array}$ & $\begin{array}{r}69.8 \\
\pm 11.8\end{array}$ & - \\
\hline $\begin{array}{l}\text { mean } \\
\text { postoperative } \\
\text { recovery period } \\
\text { (days) }\end{array}$ & $\begin{array}{r}56.8 \\
\pm 35.4\end{array}$ & $\begin{array}{r}54.3 \\
\pm 32.9\end{array}$ & $\begin{array}{r}55.3 \\
\pm 33.4\end{array}$ & $\begin{array}{r}53.6 \\
\pm 34.0\end{array}$ & $\begin{array}{r}53.0 \\
\pm 32.2\end{array}$ & - \\
\hline $\begin{array}{l}\text { mean } \\
\text { mating } \\
\text { variation (min) }\end{array}$ & $\begin{array}{r}8.5 \\
\pm 16.4\end{array}$ & $\begin{array}{r}11.0 \\
\pm 14.9\end{array}$ & $\begin{array}{r}11.9 \\
\pm 13.0\end{array}$ & $\begin{array}{r}8.3 \\
\pm 10.2\end{array}$ & $\begin{array}{r}6.7 \\
+16.5\end{array}$ & $\begin{array}{r}13.7 \\
\pm 15.4\end{array}$ \\
\hline $\begin{array}{l}\text { mean } \\
\text { adhesion } \\
\text { score }\end{array}$ & $\begin{array}{r}2.5 \\
\pm 1.1\end{array}$ & $\begin{array}{r}2.5 \\
\pm 1.0\end{array}$ & $\begin{array}{r}2.8 \\
\pm 1.0\end{array}$ & $\begin{array}{r}2.5 \\
\pm 0.8\end{array}$ & $\begin{array}{r}1.1 \\
\pm 0.6\end{array}$ & - \\
\hline
\end{tabular}

ted according to these weight categories. Occasionally other classifications have been used aside from the ones listed above. These infrequently used classifications will be explained in the related chapters.

Some variables concerning early embryonic development studied are known to depend on the time which elapses after ovulation (e.g. cleavage stage, mucin coating, tubal transport). Other aspects were expected to depend on the length of the postoperative recovery period (e.g. cleavage rate, fertilization rate). For this reason in some cases the mating-autopsy interval and the postoperative recovery period are considered as conditions instead of variables with regard to early embryonic development.

\subsubsection{Corpora lutea}

All does ovulated after mating and subsequent administration of 125 IU of human chorionic gonadotropin. Table III.2.1 shows the mean number of corpora lutea in 160 does. 
Number of corpora lutea in does (mean $\pm \$ d$ )

\begin{tabular}{|c|c|c|c|}
\hline & $n$ & $L$ & $R$ \\
\hline 201 & 28 & $3.8 \pm 1.6$ & $4.3 \pm 2.1$ \\
\hline 801 & 31 & $3.6 \pm 1.3$ & $4.4 \pm 1.4$ \\
\hline $20 \mathrm{~A}$ & 28 & $4.0 \pm 1.8$ & $4.8 \pm 1.9$ \\
\hline $80 \mathrm{~A}$ & 31 & $3.9 \pm 1.6$ & $3.6 \pm 1.4$ \\
\hline $\mathrm{SH}$ & 27 & $3.7 \pm 1.8$ & $4.0 \pm 1.4$ \\
\hline $\mathrm{C}$ & 15 & $3.9 \pm 1.8$ & $4.0 \pm 1.3$ \\
\hline 20070 & 56 & $3.9 \pm 1.7$ & \\
\hline $80 \%$ & 62 & $3.7 \pm 1.4$ & \\
\hline $\mathbb{I}$ & 59 & $3.7 \pm 1.4$ & \\
\hline$A$ & 59 & $3.9 \pm 1.7$ & \\
\hline 3 weeks & 60 & $3.7 \pm 1.7$ & \\
\hline 12 weeks & 58 & $3.9 \pm 1.4$ & \\
\hline 24 hours & 48 & $3.3 \pm 1.4$ & $4.4 \pm 1.8$ \\
\hline 36 hours & 32 & $4.2 \pm 1.5$ & $4.2 \pm 1.7$ \\
\hline 48 hours & 38 & $4.1 \pm 1.7$ & $4.2 \pm 1.7$ \\
\hline$\leqslant 60 \mathrm{~min}$ & 11 & $3.5 \pm 1.4$ & \\
\hline $60-120 \mathrm{~min}$ & 97 & $3.9 \pm 1.6$ & \\
\hline$>120 \mathrm{~min}$ & 10 & $3.3 \pm 1.3$ & \\
\hline grade I & $1 \|$ & $3.7 \pm 1.3$ & \\
\hline grade II & 52 & $4.1 \pm 1.6$ & \\
\hline grade III & 26 & $3.7 \pm 1.6$ & \\
\hline grade IV & 27 & $3.5 \pm 1.6$ & \\
\hline$<1750 \mathrm{gr}$ & 23 & $3.7 \pm 1.6$ & \\
\hline $1750-2250 \mathrm{gr}$ & 117 & $3.8 \pm 1.6$ & \\
\hline$>2250 \mathrm{gr}$ & 20 & $4.2 \pm 1.7$ & \\
\hline
\end{tabular}

Table III.2.2 depicts the mean number of corpora lutea in does which have been mated during the natural breeding season (arbitrarily restricted between February 15th and June 15 th), and in does which have been mated out of the natural breeding season. Also the effect of increasing surgical skill on ovulatory function was evaluated: the mean number of corpora lutea was determined in eight groups of animals. Each group consisted of 15 (or 13) does in which tubal anastomoses had been performed, in consecutive order. These results are depicted in table III.2.2 as well as in figure 3.1 .

A paired t-test was used for statistical comparison of the operated and control side. 
Number of corpora lutea in does (mean $\pm s d$ )

\begin{tabular}{lccc}
\hline & $n$ & $L$ & $R$ \\
\hline Feb. 15th-June 15th & 76 & $3.8 \pm 1.8$ & $4.2 \pm 1.7$ \\
June 16th-Feb. 14th & 83 & $3.7 \pm 1.5$ & $4.2 \pm 1.7$ \\
Groups of animals & & & \\
$1-15$ & 15 & $3.6 \pm 1.4$ & $3.7 \pm 1.7$ \\
$16-30$ & 15 & $3.7 \pm 1.6$ & $3.3 \pm 1.3$ \\
$31-45$ & 15 & $4.2 \pm 1.3$ & $4.3 \pm 1.2$ \\
$45-60$ & 15 & $3.5 \pm 1.3$ & $4.5 \pm 2.1$ \\
$61-75$ & 15 & $4.3 \pm 1.8$ & $3.9 \pm 1.8$ \\
$76-90$ & 15 & $3.7 \pm 2.0$ & $5.1 \pm 1.5$ \\
$91-105$ & 15 & $4.1 \pm 1.7$ & $4.6 \pm 1.8$ \\
$106-118$ & 13 & $3.4 \pm 1.3$ & $4.5 \pm 2.2$ \\
\hline
\end{tabular}

No statistically significant differences were found between the left and right ovaries in the operated, sham-operated and control does (table III.2.1), with the exception of the findings 24 hours after mating in the operated animals. In these animals significantly less corpora lutea were counted at the left sides (3.3) than at the contralateral right sides $(4.4 ; \mathrm{p}<0.05)$. At 36 and 48 hours upon mating, however, no significant differences were noted. The differences between the operated and contralateral control sides in the eight groups of consecutively operated animals did not reach a level of statistical significance (table III.2.2).

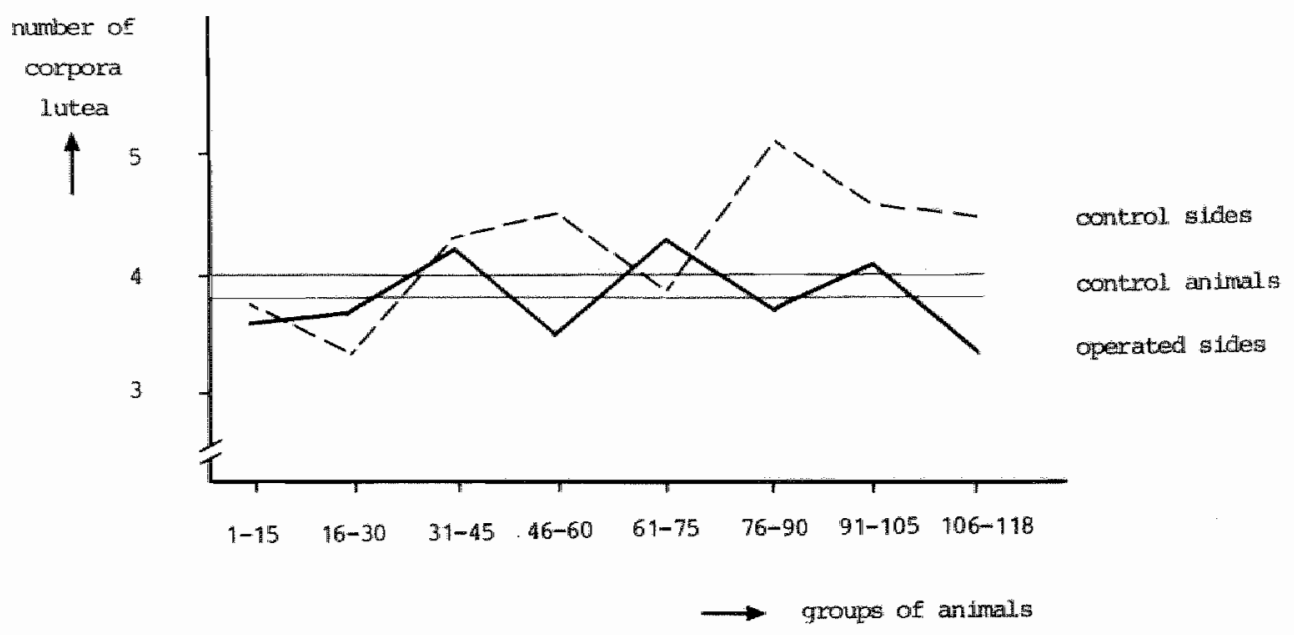

Figure 3.1 Mean number of corpora luted in groups of does 


\begin{tabular}{|c|c|c|c|}
\hline & $n$ & $\begin{array}{c}L \\
(\%)\end{array}$ & $\begin{array}{c}R \\
(\%)\end{array}$ \\
\hline $20 I$ & 28 & $92.1 \pm 28.1$ & $88.2 \pm 27.7$ \\
\hline $80 I$ & 31 & $97.2 \pm 24.5$ & $94.9 \pm 20.3$ \\
\hline $20 \mathrm{~A}$ & 28 & $62.7 \pm 38.9$ & $108.4 \pm 37.7$ \\
\hline $80 \mathrm{~A}$ & 31 & $64.5 \pm 46.6$ & $103.4 \pm 32.7$ \\
\hline $\mathrm{SH}$ & 27 & $92.9 \pm 36.7$ & $100.6 \pm 27.9$ \\
\hline $\mathrm{C}$ & 15 & $102.4 \pm 32.8$ & $99.7 \pm 20.7$ \\
\hline $20 \%$ & 56 & $77.4 \pm 36.8$ & \\
\hline $80 \%$ & 62 & $80.9 \pm 40.4$ & \\
\hline I & 59 & $94.8 \pm 26.2$ & \\
\hline A & 59 & $63.7 \pm 42.8$ & \\
\hline 3 weeks & 60 & $80.8 \pm 40.4$ & \\
\hline 12 weeks & 58 & $77.6 \pm 36.9$ & \\
\hline$\leqslant 60 \mathrm{~min}$ & 11 & $80.3 \pm 20.5$ & $:$ \\
\hline $60-120 \mathrm{~min}$ & 97 & $78.5 \pm 40.4$ & \\
\hline$>120 \mathrm{~min}$ & 10 & $84.5 \pm 38.9$ & \\
\hline grade I & 11 & $86.8 \pm 17.3$ & \\
\hline grade II & 52 & $77.3 \pm 37.1$ & \\
\hline grade III & 26 & $73.7 \pm 47.8$ & \\
\hline grade IV & 27 & $83.5 \pm 39.8$ & \\
\hline
\end{tabular}

\subsubsection{Recovery rate}

Of 160 does the recovery rates were calculated, i.e. the number of ova and embryos retrieved from one oviduct divided by the number of corpora lutea counted in the ipsilateral ovary, multiplied by one hundred.

Table III.3.1 shows the mean recovery rates. Does have been subdivided as described in chapter 3.2. Statistical comparison was performed using one-way analysis of variance. The mean recovery rates in the right oviducts did not differ significantly, whereas the mean recovery rates in the left oviducts did $(\mathrm{p}<0.001)$. A $t$-test was used to compare means in the left oviducts. The resulting probabilities are depicted in table III.3.2.

Table III.3.3 presents the percentage of does which had recovery rates exceeding $100 \%$ on either side. The frequencies in the right and left oviduct were tested for differences by a binomial test for $p=1 / 2$ as described by Lienert (1975). In does sub- 
Statistical analysis of recovery rate in left oviducts (t-test)

\begin{tabular}{lccccc}
\hline & $20 I$ & $80 I$ & $20 A$ & $80 A$ & $S H$ \\
\hline $20 \mathrm{I}$ & & & & & \\
$80 \mathrm{I}$ & $\mathrm{NS}$ & & & & \\
$20 \mathrm{~A}$ & $\mathrm{p}<0.01$ & $\mathrm{p}<0.001$ & & & \\
$80 \mathrm{~A}$ & $\mathrm{p}<0.01$ & $\mathrm{p}<0.001$ & $\mathrm{NS}$ & & \\
SH & $\mathrm{NS}$ & $\mathrm{NS}$ & $\mathrm{p}<0.01$ & $\mathrm{p}<0.01$ & \\
$\mathrm{C}$ & $\mathrm{NS}$ & $\mathrm{NS}$ & $\mathrm{p}<0.001$ & $\mathrm{p}<0.001$ & $\mathrm{~N}$ \\
\hline
\end{tabular}

Table III.3.3

Number and percentage of does with recovery rate $>100 \%$

\begin{tabular}{llrrr}
\hline & $n$ & $\begin{array}{c}L \\
(\%)\end{array}$ & $n$ & $\begin{array}{c}R \\
(\%)\end{array}$ \\
\hline $20 \mathrm{I}$ & 2 & 7.1 & 1 & 3.6 \\
$80 \mathrm{I}$ & 3 & 9.7 & 2 & 6.5 \\
$20 \mathrm{~A}$ & 1 & 3.6 & 8 & 28.6 \\
$80 \mathrm{~A}$ & 2 & 6.5 & 6 & 19.4 \\
SH & 4 & 14.8 & 5 & 18.5 \\
$\mathrm{C}$ & 2 & 13.3 & 2 & 13.3 \\
\hline
\end{tabular}

jected to a $20 \%$ ampullary resection reanastomosis a statistically significant leftright difference was found $(\mathrm{p}<0.05)$.

\subsubsection{Fertilization}

The fertilization rate was calculated for each oviduct, $i$.e. the number of ova fertilized divided by the total number of ova retrieved, multiplied by one hundred. Table III.4.1 demonstrates the mean fertilization rates. Does are classified as described in chapter 3.2. For comparison between the left and right oviduct in all operated, sham-operated and control does, 3 weeks after surgery as well as 12 weeks postoperatively, a paired t-test was used. No statistically significant differences were found between the left and right oviducts. In all does which had been subjected to tubal surgery, however, mean fertilization rates in the left operated oviduct were lower than the mean fertilization rates in the right control oviduct. This left-right difference is statistically significant (sign-test on corresponding pairs; $p<0.01$ ). Analysis of the mean fertilization rates in all left oviducts was performed by using 
Fertilization rate in does (mean \pm sd)

\begin{tabular}{|c|c|c|c|c|c|c|}
\hline & $n$ & $\begin{array}{c}L \\
3 \text { weeks } \\
(0 / 0)\end{array}$ & $\begin{array}{c}R \\
3 \text { weeks } \\
(\% 0)\end{array}$ & $n$ & $\begin{array}{c}L \\
12 \text { weeks } \\
(\%)\end{array}$ & $\begin{array}{c}R \\
12 \text { weeks } \\
(\%)\end{array}$ \\
\hline 201 & 13 & $79.5 \pm 39.8$ & $89.4 \pm 28.8$ & 13 & $82.1 \pm 37.0$ & $87.7 \pm 27.8$ \\
\hline 801 & 15 & $76.3 \pm 40.2$ & $77.8 \pm 41.1$ & 15 & $79.2 \pm 29.0$ & $94.0 \pm 12.8$ \\
\hline $20 \mathrm{~A}$ & 13 & $54.5 \pm 52.2$ & $65.2 \pm 46.6$ & 14 & $97.4 \pm 9.2$ & $98.8 \pm 4.5$ \\
\hline $80 \mathrm{~A}$ & 16 & $66.1 \pm 41.9$ & $68.5 \pm 43.5$ & 15 & $88.9 \pm 29.6$ & $94.2 \pm 13.8$ \\
\hline SH & 14 & $90.8 \pm 28.7$ & $85.7 \pm 36.3$ & 13 & $100.0 \# 0.0$ & $98.1+6.9$ \\
\hline$C^{*}$ & 15 & $89.3 \pm 29.1$ & $84.9 \pm 29.8$ & & & \\
\hline $20 \%$ & 24 & $68.1 \pm 46.4$ & & 26 & $89.8 \pm 27.5$ & \\
\hline $80 \%$ & 29 & $71.3 \pm 40.6$ & & 27 & $83.5 \pm 29.1$ & \\
\hline 1 & 28 & $77.8 \pm 39.3$ & & 28 & $80.6 \pm 32.3$ & \\
\hline A & 25 & $61.0 \pm 46.1$ & & 25 & $93.3 \pm 21.5$ & \\
\hline 24 hours & 21 & $75.8 \pm 41.5$ & & 22 & $90.9 \pm 23.4$ & \\
\hline 36 hours & 15 & $68.3 \pm 43.9$ & & 13 & $83.1 \pm 37.3$ & \\
\hline 48 hours & 17 & $63.9 \pm 45.8$ & & 18 & $83.8 \pm 27.2$ & \\
\hline$\leqslant 60 \mathrm{~min}$ & 8 & $85.4 \pm 35.0$ & & 3 & $100.0 \pm 0.0$ & \\
\hline $60-120 \mathrm{~min}$ & 42 & $65.5 \pm 45.0$ & & 45 & $84.9 \pm 30.0$ & \\
\hline$>120 \mathrm{~min}$ & 3 & $88.9 \pm 19.2$ & & 5 & $93.3 \pm 14.9$ & \\
\hline grade I & 6 & $83.3 \pm 40.8$ & & 5 & $86.0 \pm 21.9$ & \\
\hline grade II & 22 & $81.5 \pm 33.9$ & & 26 & $90.4 \pm 22.7$ & \\
\hline grade III & 10 & $46.7 \pm 50.2$ & & 14 & $91.1 \pm 27.0$ & \\
\hline grade IV & 15 & $62.8 \pm 47.0$ & & 7 & $61.9 \pm 44.8$ & \\
\hline$<1750 \mathrm{gr}$ & 4 & $50.0 \pm 57.7$ & & 11 & $86.7 \pm 30.6$ & \\
\hline $1750-2250 \mathrm{gr}$ & 39 & $67.4 \pm 43.6$ & & 39 & $85.5 \pm 28.8$ & \\
\hline$>2250 \mathrm{gr}$ & 10 & $87.5 \pm 31.7$ & & 3 & $100.0 \pm 0.0$ & \\
\hline
\end{tabular}

* Control does: no postoperative recovery period

a t-test: 3 weeks after surgery the mean fertilization rate in does subjected to a $20 \%$ ampullary resection reanastomosis $(54.5 \%)$ was significantly reduced as compared to the mean fertilization rate in sham-operated $(90.8 \%)$ and control animals $(89.3 \%)$, as well as to these two combined $(90.0 \%$; $p<0.05)$. The mean fertilization rate in the left oviducts in does in which a $80 \%$ ampullary resection reanastomosis had been performed $(66.1 \%)$ did not differ significantly from the rate in shamoperated and control animals combined $(90.0 \%)$. In the left tubes no statistically significant differences were noted in fertilization rates between isthmic and ampullary operated does, nor between four rabbits weighing less than 1750 grams and ten 
Number and percentage of does with 0\%-fertilization rate

\begin{tabular}{|c|c|c|c|c|}
\hline & $n$ & $\begin{array}{l}3 \text { weeks } \\
(\%)\end{array}$ & $n$ & $\begin{array}{c}12 \text { weeks } \\
(\%)\end{array}$ \\
\hline $20 \mathrm{I}$ & 1 & 7.7 & 1 & 7.7 \\
\hline 801 & 3 & 20.0 & - & - \\
\hline $20 \mathrm{~A}$ & 3 & 23.1 & - & - \\
\hline $80 \mathrm{~A}$ & 4 & 25.0 & - & - \\
\hline $\mathrm{SH}$ & 2 & 14.3 & - & - \\
\hline$C^{*}$ & 1 & 6.7 & - & - \\
\hline $20 \%$ & 4 & 16.7 & 1 & 3.8 \\
\hline $80 \%$ & 7 & 24.1 & - & - \\
\hline I & 4 & 14.3 & 1 & 3.6 \\
\hline A & 7 & 28.0 & - & - \\
\hline 24 hours & 3 & 14.3 & - & - \\
\hline 36 hours & 3 & 20.0 & 1 & 7.7 \\
\hline 48 hours & 5 & 29.4 & - & - \\
\hline grade I & 1 & 16.7 & - & - \\
\hline grade II & 3 & 13.6 & - & - \\
\hline grade III & 3 & 30.0 & - & - \\
\hline grade IV & 4 & 26.7 & 1 & 14.3 \\
\hline$<1750 \mathrm{gr}$ & 2 & 50.0 & - & - \\
\hline $1750-2250 \mathrm{gr}$ & 9 & 23.1 & 1 & 2.6 \\
\hline$>2250 \mathrm{gr}$ & 1 & 10.0 & - & - \\
\hline
\end{tabular}

* Control does: no postoperative recovery period

does weighing over 2250 grams. Animals with relatively few adhesions (grade I and II combined) had a mean fertilization rate of $81.9 \%$ (grade I $83.3 \%$, grade II $81.5 \%$ ) 3 weeks after surgery and $89.7 \%$ (grade I $86.0 \%$, grade II $90.4 \%$ ) 12 weeks postoperatively. In rabbits which had relatively many adhesions (grade III and IV combined) the mean fertilization rates were $56.3 \%$ (grade III $46.7 \%$, grade IV $62.8 \%$ ) 3 weeks after surgery and $81.3 \%$ (grade III $91.1 \%$, grade IV $61.9 \%$ ) 12 weeks postoperatively. Three weeks after operation the difference in mean fertilization rate between does with little adhesions and does with many adhesions reached a level of statistical significance $(p<0.05)$. For analysis of differences in fertilization rates in does after different postoperative recovery periods the sign-test was performed. Mean fertilization rates in the left and right oviducts in all operated does were lower 3 weeks after surgery as compared to their corresponding rates 12 weeks after operation. This 3 week-12 week difference was statistically significant $(\mathrm{p}<0.05)$. 


\begin{tabular}{|c|c|c|c|c|c|c|c|c|}
\hline & $\begin{array}{l}L \\
n\end{array}$ & $\begin{array}{c}L w k \\
(00)\end{array}$ & $\begin{array}{c}R \\
n\end{array}$ & $\begin{array}{c}R \\
3 w k \\
(\%)\end{array}$ & $\begin{array}{l}L \\
n\end{array}$ & $\begin{array}{c}L \\
12 w k \\
(\%)\end{array}$ & $\begin{array}{l}R \\
n\end{array}$ & $\begin{array}{c}R \\
12 w k \\
(\%)\end{array}$ \\
\hline 201 & 1 & 7.7 & 1 & 7.7 & 2 & 15.4 & 3 & 23.1 \\
\hline 801 & 3 & 20.0 & 1 & 6.7 & 6 & 40.0 & 3 & 20.0 \\
\hline $20 \mathrm{~A}$ & - & - & 2 & 15.4 & 1 & 7.7 & $\mathfrak{1}$ & 7.7 \\
\hline $80 \mathrm{~A}$ & 4 & 28.6 & 3 & 18.8 & 1 & 8.3 & 3 & 20.0 \\
\hline $\mathrm{SH}$ & 1 & 8.3 & - & - & - & - & $\mathbb{1}$ & 7.7 \\
\hline$C^{*}$ & 1 & 6.7 & 3 & $20.0^{+}$ & & & & \\
\hline $20 \%$ & 1 & 4.2 & & & 3 & 11.5 & & \\
\hline $80 \%$ & 7 & 24.1 & & & 7 & 25.9 & & \\
\hline 1 & 4 & 14.3 & & & 8 & 28.6 & & \\
\hline A & 4 & 16.0 & & & 2 & 8.0 & & \\
\hline 24 hours & 2 & 9.5 & & & 3 & 13.6 & & \\
\hline 36 hours & 3 & 20.0 & & & 1 & 7.7 & & \\
\hline 48 hours & 3 & 17.6 & & & 6 & 33.3 & & \\
\hline$\leqslant 60 \mathrm{~min}$ & 1 & 12.5 & & & - & - & & \\
\hline $60-120 \mathrm{~min}$ & 6 & 14.3 & & & 9 & 20.0 & & \\
\hline$>120 \mathrm{~min}$. & 1 & 33.3 & & & 1 & 20.0 & & \\
\hline grade I & - & - & & & 2 & 40.0 & & \\
\hline grade II & 5 & 22.7 & & & 5 & 19.2 & & \\
\hline gradle III & 1 & 10.0 & & & 1 & 7.1 & & \\
\hline gradle IV & 2 & 13.3 & & & 2 & 28.6 & & \\
\hline$<1750 \mathrm{gr}$ & - & - & & & 2 & 18.2 & & \\
\hline $1750-2250 \mathrm{gr}$ & 7 & 17.9 & & & 8 & 20.5 & & \\
\hline$>2250 \mathrm{gr}$ & 1 & 10.0 & & & - & - & & \\
\hline
\end{tabular}

* Control does: no postoperative recovery period

+ All originating from does autopsied 36 hours after mating

In the rabbit the mean proportion of ova fertilized ranges from 90-95\% (Adams, 1960; Adams and Chang, 1962a, 1962b). To study the total absence of fertilization and suboptimal fertilization the animals were categorized according to their fertilization rates ( $0 \%$ and $1-90 \%$ respectively). Table III.4.2 shows all does from which no fertilized ova were recovered, and thus represents the $0 \%$-fertilization rate. Statistical analysis was performed by using Fisher's exact probability test. A $0 \%$-fertilization rate was more frequently encountered in does subjected to a $80 \%$ resection reanastomosis and in does in which ampullary resections had been perfor- 
Adjusted number of spermatozoa per ovum, in does (mean \pm sd)

\begin{tabular}{|c|c|c|c|c|c|c|c|c|c|c|c|}
\hline & \multicolumn{6}{|c|}{ A. zona pellucida } & \multicolumn{5}{|c|}{ B. perivitelline space } \\
\hline & $n$ & & $L$ & & $n$ & $R$ & $n$ & & $L$ & $n$ & $R$ \\
\hline 201 & 14 & 2.1 & \pm & 2.2 & 12 & $2.4 \pm 3.0$ & 16 & 2.8 & \pm 1.8 & 12 & $3.4 \pm 4.0$ \\
\hline 801 & 14 & 6.1 & \pm & 6.7 & 13 & $3.4 \pm 5.1$ & 15 & 6.1 & \pm 5.7 & 15 & $3.6 \pm 4.0$ \\
\hline $20 \mathrm{~A}$ & 7 & 3.9 & \pm & 3.2 & 10 & $1.4 \pm 1.2$ & 8 & 6.5 & \pm 5.6 & 12 & $3.7 \pm 4.0$ \\
\hline $80 \mathrm{~A}$ & 11 & 2.9 & \pm & 5.9 & 12 & $1.6 \pm 1.2$ & 15 & 3.4 & \pm 6.0 & 16 & $2.6 \pm 1.8$ \\
\hline $\mathrm{SH}$ & 16 & 2.3 & \pm & 2.1 & 14 & $2.2 \pm 3.0$ & 18 & 4.7 & \pm 4.4 & 14 & $5.1 \pm 5.5$ \\
\hline C & 11 & 3.3 & \pm & 3.7 & 10 & $2.3 \pm 1.7$ & 11 & 3.8 & \pm 4.0 & 10 & $3.4 \pm 3.7$ \\
\hline $20 \%$ & 21 & 2.7 & \pm & 2.6 & & & 24 & 4.0 & \pm 3.8 & & \\
\hline $80 \%$ & 25 & 4.7 & \pm & 6.4 & & & 30 & 4.7 & \pm 5.9 & & \\
\hline $\mathbb{1}$ & 28 & 4.1 & \pm & 5.3 & & & 31 & 4.4 & \pm 4.4 & & \\
\hline A & 18 & 3.3 & \pm & 4.9 & & & 23 & 4.5 & \pm 5.9 & & \\
\hline 3 weeks & 23 & 3.6 & \pm & 4.7 & & & 24 & 4.0 & \pm 5.0 & & \\
\hline 12 weeks & 23 & 4.0 & \pm & 5.6 & & & 30 & 4.8 & \pm 5.2 & & \\
\hline 24 hours & 15 & 3.5 & \pm & 5.4 & & & 20 & 4.4 & \pm 5.1 & & \\
\hline 36 hours & 14 & 4.7 & \pm & 5.5 & & & 16 & 5.7 & \pm 5.6 & & \\
\hline 48 hours & 17 & 3.3 & \pm & 4.8 & & & 18 & 3.4 & \pm 4.5 & & \\
\hline$\leqslant 60 \min$ & 11 & 3.4 & \pm & 3.5 & & & 11 & 4.7 & \pm 4.4 & & \\
\hline $60-120 \mathrm{~min}$ & 34 & 4.0 & \pm & 5.6 & & & 42 & 4.5 & \pm 5.3 & & \\
\hline$>120 \mathrm{~min}$ & 1 & 0.0 & \pm & 0.0 & & & 1 & 0.0 & \pm 0.0 & & \\
\hline grade I & 10 & 3.1 & \pm & 3.3 & & & 11 & 4.4 & \pm 4.9 & & \\
\hline grade III & 29 & 4.0 & \pm & 5.2 & & & 32 & 4.6 & \pm 5.0 & & \\
\hline grade $\mathbb{I I}$ & 3 & 6.7 & \pm 1 & 11.5 & & & 6 & 6.5 & \pm 6.9 & & \\
\hline grade IV & 4 & 2.0 & \pm & 2.4 & & & 5 & 1.2 & \pm 1.6 & & \\
\hline
\end{tabular}

med. Statistical comparison, however, revealed that these percentages did not differ significantly from the percentages found in does with $20 \%$ tubal resections and isthmic reanastomoses respectively. In $14.3 \%$ of does with few adhesions (grade I $(16.7 \%)$ and II ( $13.6 \%)$ combined), and in $28.0 \%$ of does with many adhesions (grade III (30.0\%) and IV (26.7\%) combined) a $0 \%$-fertilization rate was observed. This difference did not reach a level of statistical significance. Of all does which had a $0 \%$-fertilization rate 13 had been mated 3 weeks after surgery, whereas one single doe had a postoperative recovery period of 12 weeks. This difference (13 versus 1$)$ was statistically significant $(\mathrm{p}<0.001$ ).

In table III.4.3 1-90\%-fertilization rates are depicted. Statistical comparison between 1-90\%-fertilization rates in does subjected to $20 \%$ and $80 \%$ resection re- 
Table III.5.2

Statistical analysis of number of spermatozod on zonae pellucidae (t-lest)

\begin{tabular}{lccccc}
\hline & $20 I$ & $80 I$ & $20 A$ & $80 A$ & $S H$ \\
\hline $20 I$ & & & & & \\
$80 I$ & $p<0.05$ & & & \\
$20 \mathrm{~A}$ & NS & NS & & \\
$80 \mathrm{~A}$ & $\mathrm{NS}$ & NS & NS & NS & \\
SH & NS & $\mathrm{p}<0.05$ & NS & NS \\
C & NS & NS & NS & NS & NS \\
\hline
\end{tabular}

Tabel III.5.3

Number and percentage of fertilized and unfertilized ova respectively, recovered from the left and right owiducts, which contained neither spermatozoa on their zonae pellucidae nor in their perivitelline spaces

\begin{tabular}{|c|c|c|c|c|c|c|c|c|}
\hline & \multicolumn{4}{|c|}{ zona pellucida } & \multicolumn{4}{|c|}{ perivitelline space } \\
\hline & $n$ & $\begin{array}{c}L \\
(\%)\end{array}$ & $n$ & $\begin{array}{c}R \\
(0 \%)\end{array}$ & $n$ & $\begin{array}{c}L \\
(\%)\end{array}$ & $n$ & $\begin{array}{c}R \\
(\%)\end{array}$ \\
\hline fertilized ova & 33 & 18.1 & 41 & 18.6 & 27 & 14.0 & 26 & 11.3 \\
\hline unfertilized ova & 25 & 92.6 & 39 & 79.6 & 30 & 90.9 & 50 & 100.0 \\
\hline
\end{tabular}

anastomoses respectively was made by using Fisher's exact probability test. The difference found did not reach a level of significance. Neither did the difference in $1-90 \%$ fertilization rate between does in which isthmic and ampullary reanastomoses had been performed.

\subsubsection{Spermatozoa}

In a random sample of 510 ova spermatozoa were counted on the zonae pellucidae and in the perivitelline spaces. Table III.5.1 depicts the mean numbers of spermatozoa. The does, from which the $\mathbf{5 1 0}$ ova were recovered, are classified as described in chapter 3.2. Statistical analysis was performed using a t-test. The mean numbers of spermatozoa noted in the perivitelline spaces of ova recovered from the left oviducts from the different groups of animals did not differ significantly between groups. In the left oviducts the mean number of spermatozoa on the zonae pellucidae, however, did. P-values, belonging to the $t$-test performed on the mean numbers of spermatozoa on the zonae pellucidae, are shown in table III.5.2. 
Table III.6.l

Percentage of fertilized ova in control does, according to developmental stage

\begin{tabular}{|c|c|c|c|c|c|c|}
\hline & $\begin{array}{c}L \\
24 \text { howrs }\end{array}$ & $\underset{36 \text { hours }}{L}$ & $\begin{array}{c}\text { L } \\
48 \text { hours }\end{array}$ & $\begin{array}{c}R \\
24 \text { hours }\end{array}$ & $\begin{array}{c}R \\
36 \text { howrs }\end{array}$ & $\begin{array}{c}R \\
48 \text { hours }\end{array}$ \\
\hline \multirow[t]{2}{*}{$n$} & 17 & 19 & 13 & 29 & 10 & 4 \\
\hline & $(\%)$ & $(\%)$ & $(0 \%)$ & $(\%)$ & $(\% \%)$ & $(0)$ \\
\hline - cell & 5.9 & 5.3 & - & 17.2 & - & - \\
\hline 2-cell & 88.2 & - & - & 82.8 & - & - \\
\hline 3 -cell & 5.9 & - & - & - & - & - \\
\hline 4-cell & - & 15.8 & - & - & 10.0 & - \\
\hline 5 -cell & - & 5.3 & - & - & - & - \\
\hline 6-cell & - & 5.3 & 7.7 & - & 10.0 & 7.7 \\
\hline 7 -cell & - & 10.5 & - & 一 & 10.0 & - \\
\hline 8-cell & - & 57.9 & 15.4 & - & 70.0 & 7.7 \\
\hline 10-cell & - & - & 7.7 & - & - & 7.7 \\
\hline 12-cell & - & - & 30.8 & - & - & 16.7 \\
\hline 14-cell & - & - & 15.4 & - & - & 23.1 \\
\hline$>14$ cell & - & - & 23.1 & - & - & 38.5 \\
\hline
\end{tabular}

Table III.5.3 lists fertilized and unfertilized ova, which contained no spermatozoa on their zonae pellucidae nor in their perivitelline spaces.

\subsubsection{Embryonic cleavage}

Concerning embryonic cleavage all unfertilized ova were excluded from analysis. Table III.6.1 shows the developmental stages noted in fertilized ova retrieved from control does 24,36 and 48 hours after mating.

Table III.6.2 presents the overall embryonic development, expressed as mean number of blastomeres per embryo. In the present investigation embryos retrieved 48 hours after mating were omitted from further studies on embryonic cleavage. The precise determination, by light microscopy, of the number of blastomeres in an embryo is not accurate beyond the 8-cell stage. To ascertain the exact number of blastomeres beyond this stage the embryos have to be stained and sectioned. To include the embryos retrieved 48 hours after mating, despite determination of the number of blastomeres by light microscopy, would pretend an unrealistic precision. The does from which the embryos were recovered have been classified as described in chapter 3.2. The classification according to the tubal segment from which the embryos were retrieved has been added in table III.6.2. The sign-test was used for statistical comparison of the embryonic cleavage stage between does which had been 
Overall embryonic development in does (mean number of blastomeres \pm sd) 24 hours after mating

\begin{tabular}{|c|c|c|c|c|c|c|}
\hline & $n$ & $\begin{array}{c}\text { L } \\
24 \text { hours } \\
3 \text { weeks }\end{array}$ & $\begin{array}{c}R \\
24 \text { hours } \\
3 \text { weeks }\end{array}$ & $n$ & $\begin{array}{c}L \\
24 \text { hours } \\
12 \text { weeks }\end{array}$ & $\begin{array}{c}R \\
24 \text { hours } \\
12 \text { weeks }\end{array}$ \\
\hline 201 & 4 & $2.4 \pm 1.1$ & $2.0 \pm 0.9$ & 6 & $2.2 \pm 0.4$ & $2.1 \pm 0.4$ \\
\hline 801 & 5 & $2.0 \pm 0.4$ & $1.9 \pm 0.4$ & 6 & $2.1 \pm 1.1$ & $2.2 \pm 1.0$ \\
\hline $20 \mathrm{~A}$ & 5 & $2.0 \pm 0.0$ & $2.0 \pm 0.1$ & 6 & $2.2 \pm 0.5$ & $2.3 \pm 0.9$ \\
\hline $80 \mathrm{~A}$ & 4 & $1.5 \pm 0.6$ & $1.6 \pm 0.5$ & 6 & $2.2 \pm 1.1$ & $2.3 \pm 0.9$ \\
\hline $\mathrm{SH}$ & 6 & $2.2 \pm 0.5$ & $1.9 \pm 0.1$ & 5 & $1.7 \notin 0.4$ & $2.0 \pm 0.2$ \\
\hline $\mathrm{C}^{*}$ & 6 & $1.9 \pm 0.5$ & $1.9 \pm 0.2$ & & & \\
\hline $20 \%$ & 8 & $2.2 \pm 0.7$ & & 12 & $2.2 \pm 0.4$ & \\
\hline $80 \%$ & 9 & $1.8 \pm 0.5$ & & 10 & $2.2 \pm 1.0$ & \\
\hline 1 & 9 & $2.2 \pm 0.7$ & & 11 & $2.2 \pm 0.8$ & \\
\hline A & 8 & $1.8 \pm 0.5$ & & 11 & $2.2 \pm 0.8$ & \\
\hline$\leqslant 60 \mathrm{~min}$ & 3 & $2.0 \pm 0.0$ & & - & - & \\
\hline $60-120 \mathrm{~min}$ & 13 & $2.0 \pm 0.7$ & & 17 & $2.1 \pm 0.7$ & \\
\hline$>120$ mir & 1 & $2.0 \pm 0.0$ & & 5 & $2.6 \pm 0.9$ & \\
\hline$<1750 \mathrm{gr}$ & 1 & $4.0 \pm 0.0$ & & 4 & $1.8 \pm 0.5$ & \\
\hline $1750-2250 \mathrm{gr}$ & 14 & $1.8 \pm 0.4$ & & 15 & $2.3 \pm 0.8$ & \\
\hline$>2250 \mathrm{gr}$ & 2 & $2.0 \pm 0.0$ & & 3 & $2.0 \pm 1.0$ & \\
\hline segment 1 & 4 & $1.8 \pm 0.5$ & & 6 & $2.3 \pm 0.8$ & \\
\hline segment 2 & 12 & $2.0 \pm 0.7$ & & 15 & $2.1 \pm 0.9$ & \\
\hline segment 3 & 2 & $2.0 \pm 0.0$ & & 2 & $2.5 \pm 0.7$ & \\
\hline
\end{tabular}

* Control does: no postoperative recovery period

mated 3 weeks after tubal surgery and does which had a recovery period of 12 weeks. Pairs of observations were matched for surgical procedure, mating-autopsy interval and left versus right oviduct. The overall difference between a postoperative recovery period of 3 and 12 weeks was statistically significant $(p<0.05)$.

Tables III.6.3 and III.6.4 deal with embryonic cleavage 24 and 36 hours after mating respectively. They present the percentages of embryos retrieved and classified according to the number of blastomeres they contain. Statistical analysis was performed by using Fisher's exact probability test. In the left oviducts, 24 hours after mating, $5.9 \%$ of the embryos retrieved from control animals had cleaved beyond the 2 -cell stage. In operated and sham-operated does combined $10.3 \%$ of the embryos had. In the right oviducts the percentages of embryos consisting of more than two blastomeres were $0 \%$ and $8.9 \%$ respectively. Neither the difference in the left nor in the 
Overall embryonic development in does (mean number of blastomeres \pm sd) 36 hours after mating

\begin{tabular}{|c|c|c|c|c|c|c|}
\hline & $n$ & $\begin{array}{c}L \\
36 \text { hours } \\
3 \text { weeks }\end{array}$ & $\begin{array}{c}R \\
36 \text { hours } \\
3 \text { weeks }\end{array}$ & n & $\begin{array}{c}L \\
36 \text { hours } \\
12 \text { weeks }\end{array}$ & $\begin{array}{c}R \\
36 \text { hours } \\
12 \text { weeks }\end{array}$ \\
\hline $20 \mathrm{I}$ & 4 & $7.2 \pm 1.0$ & $6.3 \pm 1.7$ & 3 & $7.0 \pm 1.7$ & $6.6 \pm 0.0$ \\
\hline $80 I$ & 3 & $7.0 \pm 0.3$ & $6.5 \pm 2.2$ & 3 & $7.5 \pm 0.9$ & $8.0 \pm 0.0$ \\
\hline $20 \mathrm{~A}$ & 3 & $7.8 \pm 1.2$ & $7.5 \pm 0.5$ & 4 & $8.0 \pm 0.0$ & $7.7 \pm 0.3$ \\
\hline $80 \mathrm{~A}$ & 4 & $7.7 \pm 0.6$ & $6.9 \pm 1.6$ & 4 & $8.3 \pm 0.5$ & $6.1 \pm 3.4$ \\
\hline SH & 2 & $7.1 \pm 1.3$ & $8.7 \pm 0.9$ & 4 & $8.1 \pm 1.0$ & $8.3 \pm 2.1$ \\
\hline $\mathrm{C}^{*}$ & 4 & $6.7 \pm 1.3$ & $7.5 \pm 0.7$ & & & \\
\hline $20 \%$ & 5 & $7.4 \pm 1.0$ & & 6 & $7.5 \pm 1.2$ & \\
\hline $80 \%$ & 6 & $7.3 \pm 0.6$ & & $s$ & $7.8 \pm 0.8$ & \\
\hline I & 6 & $7.1 \pm 0.7$ & & 6 & $7.3 \pm 1.3$ & \\
\hline A & 5 & $7.7 \pm 0.7$ & & 5 & $8.1 \pm 0.3$ & \\
\hline$\leqslant 60 \min$ & 4 & $7.9 \pm 0.7$ & & 1 & $5.0 \pm 0.0$ & \\
\hline $60-120 \mathrm{~min}$ & 7 & $7.1 \pm 0.6$ & & 10 & $7.9 \pm 0.5$ & \\
\hline$>120 \mathrm{~min}$ & - & - & & - & - & \\
\hline$<1750 \mathrm{gr}$ & 1 & $8.0 \pm 0.0$ & & 2 & $8.0 \pm 0.0$ & \\
\hline $1750-2250 \mathrm{gr}$ & 7 & $7.4 \pm 0.9$ & & 9 & $7.6 \pm 1.1$ & \\
\hline$>2250 \mathrm{gr}$ & 3 & $7.1 \pm 0.4$ & & - & - & \\
\hline segment 1 & 1 & $8.0 \pm 0.0$ & & - & - & \\
\hline segment 2 & 10 & $7.3 \pm 0.8$ & & 11 & $7.7 \pm 1.0$ & \\
\hline segment 3 & 2 & $7.0 \pm 1.4$ & & 1 & $8.0 \pm 0.0$ & \\
\hline
\end{tabular}

* Control does: no postoperative recovery period

right tubes did reach a level of statistical significance. At 36 hours upon mating no embryos in the left oviducts had cleaved beyond the 8-cell stage in control animals, whereas $4.1 \%$ of embryos recovered from the operated and sham-operated does combined had. In the contralateral right oviducts the corresponding percentages were almost identical: $0 \%$ and $4.0 \%$. 
Percentage of fertilized embryos containing 1.5 blastomeres 24 hours after mating

\begin{tabular}{|c|c|c|c|c|c|c|c|c|c|c|c|c|}
\hline & \multicolumn{6}{|c|}{ left oviduct } & \multicolumn{6}{|c|}{ right oviduct } \\
\hline & $\mathrm{n}$ & $\begin{array}{c}1 \\
(\%)\end{array}$ & $\begin{array}{c}2 \\
(\%)\end{array}$ & $\begin{array}{c}3 \\
(\%)\end{array}$ & $\begin{array}{c}4 \\
(\% \%)\end{array}$ & $\begin{array}{c}5 \\
(\%)\end{array}$ & $\mathrm{n}$ & $\begin{array}{c}1 \\
(0 \%)\end{array}$ & $\begin{array}{c}2 \\
(0 \%)\end{array}$ & $\begin{array}{c}3 \\
(\%)\end{array}$ & $\begin{array}{c}4 \\
(\%)\end{array}$ & $\begin{array}{c}5 \\
(70)\end{array}$ \\
\hline 201 & 39 & 25.6 & 59.0 & 5.1 & 10.3 & - & 38 & 5.3 & 73.7 & 10.5 & 10.5 & - \\
\hline 801 & 35 & 34.3 & 57.1 & - & 8.6 & - & 49 & 20.4 & 71.4 & 2.0 & 6.1 & - \\
\hline $20 \mathrm{~A}$ & 24. & 12.5 & 79.2 & 4.2 & 4.2 & - & 59 & 20.3 & 71.2 & 3.4 & 5.1 & - \\
\hline $80 \mathrm{~A}$ & 16 & 31.3 & 56.3 & - & 12.5 & - & 32 & 21.9 & 75.0 & - & 3.1 & - \\
\hline $\mathrm{SH}$ & 39 & 15.4 & 76.9 & 2.6 & 2.6 & 2.6 & 46 & 13.0 & 82.6 & 4.3 & - & - \\
\hline $\mathrm{C}$ & 17 & 5.9 & 88.2 & 5.9 & - & - & 29 & 17.2 & 82.8 & - & - & - \\
\hline \multicolumn{13}{|c|}{3 weeks } \\
\hline $20 \mathrm{I}$ & 20 & 35.0 & 50.0 & - & 15.0 & - & 17 & 5.9 & 64.7 & 11.8 & 17.6 & - \\
\hline $80 \mathrm{I}$ & 19 & 31.6 & 63.2 & - & 5.3 & - & 25 & 28.0 & 68.0 & 4.0 & - & - \\
\hline $20 \mathrm{~A}$ & 12 & 16.7 & 83.3 & - & - & - & 31 & 22.6 & 77.4 & - & - & - \\
\hline $80 \mathrm{~A}$ & 6 & 50.0 & 50.0 & - & - & - & 14 & 35.7 & 64.3 & - & - & - \\
\hline $\mathrm{SH}$ & 19 & - & 89.5 & - & 5.3 & 5.3 & 27 & 18.5 & 77.8 & 3.7 & - & - \\
\hline \multicolumn{13}{|c|}{12 weeks } \\
\hline 201 & 19 & 15.8 & 68.4 & 10.5 & 5.3 & - & 21 & 4.8 & 81.0 & 9.5 & 4.8 & - \\
\hline $80 . I$ & 16 & 37.5 & 50.0 & - & 12.5 & - & 24 & 12.5 & 75.0 & - & 12.5 & - \\
\hline $20 \mathrm{~A}$ & 12 & 8.3 & 75.0 & 8.3 & 8.3 & - & 28 & 17.9 & 64.3 & 7.1 & 10.7 & - \\
\hline $80 \mathrm{~A}$ & 10 & 20.0 & 60.0 & - & 20.0 & - & 18 & 11.1 & 83.3 & - & 5.6 & - \\
\hline SH & 20 & 30.0 & 65.0 & 5.0 & - & - & 19 & 5.3 & 89.5 & 5.3 & - & - \\
\hline
\end{tabular}




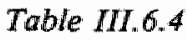

Percentage of embryos containing $1-14$ blastomeres 36 hours after mating

\begin{tabular}{|c|c|c|c|c|c|c|c|c|c|c|c|c|c|}
\hline \multicolumn{2}{|c|}{ left oviduct } & $\begin{array}{c}I \\
(\%)\end{array}$ & $\begin{array}{c}2 \\
(\%)\end{array}$ & $\begin{array}{c}3 \\
(\% 0)\end{array}$ & $\begin{array}{c}4 \\
(\%)\end{array}$ & $\begin{array}{c}5 \\
(\%)\end{array}$ & $\begin{array}{c}6 \\
(\%)\end{array}$ & $\begin{array}{c}7 \\
(\%)\end{array}$ & $\begin{array}{c}8 \\
(0 \%)\end{array}$ & $\begin{array}{c}9 \\
(\%)\end{array}$ & $\begin{array}{c}10 \\
(\%)\end{array}$ & $\begin{array}{c}12 \\
(\%)\end{array}$ & $\begin{array}{c}14 \\
(\%)\end{array}$ \\
\hline 201 & 23 & - & - & 4.3 & 4.3 & 4.3 & 13.0 & 13.0 & 60.9 & - & - & - & - \\
\hline 801 & 18 & - & 5.6 & - & - & 5.6 & - & 22.2 & 66.7 & - & - & - & - \\
\hline $20 \mathrm{~A}$ & 14 & - & - & - & - & - & - & 7.1 & 85.7 & - & 7.1 & - & - \\
\hline $80 \mathrm{~A}$ & 15 & - & - & - & 一 & - & - & 6.7 & 86.7 & - & 6.7 & - & - \\
\hline SH & 24 & - & - & - & 8.3 & - & 20.8 & - & 62.5 & - & 4.2 & 4.2 & - \\
\hline$C$ & 19 & 5.3 & - & - & 15.8 & 5.3 & 5.3 & 10.5 & 57.9 & - & - & - & - \\
\hline \multicolumn{14}{|c|}{3 weeks } \\
\hline $20 \mathrm{I}$ & $\mathbb{1}$ & - & - & - & - & 9.1 & 27.3 & 27.3 & 36.4 & - & - & - & - \\
\hline $80 I$ & 7 & - & - & - & - & 14.3 & - & 57.1 & 28.6 & - & - & - & - \\
\hline $20 \mathrm{~A}$ & 4 & - & - & - & - & - & - & 25.0 & 50.0 & 25.0 & - & - & - \\
\hline $80 \mathrm{~A}$ & 9 & - & - & - & - & - & - & 11.1 & 88.9 & - & - & - & - \\
\hline $\mathrm{SH}$ & 12 & - & - & - & 16.7 & - & 33.3 & - & 50.0 & - & - & - & - \\
\hline
\end{tabular}

12 weeks

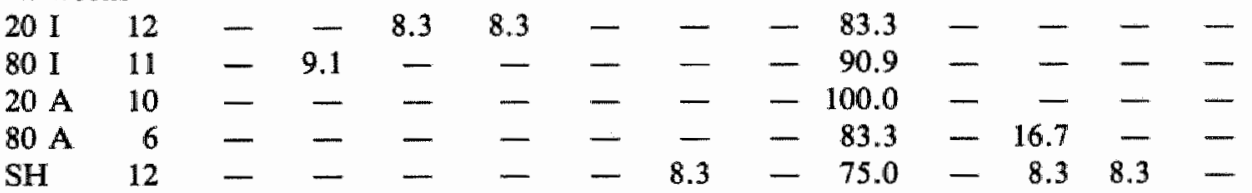

right oviduct

$\begin{array}{lrrlllllllllll}20 \mathrm{I} & 30 & 6.7 & - & 3.3 & 13.3 & 6.7 & 13.3 & 6.7 & 50.0 & - & - & - & - \\ 80 \mathrm{I} & 21 & - & - & - & 4.8 & - & - & 14.3 & 81.0 & - & - & - & - \\ 20 \mathrm{~A} & 32 & - & - & - & 3.1 & 3.1 & 6.3 & 9.4 & 78.1 & - & - & - & - \\ 80 \mathrm{~A} & 24 & 8.3 & - & - & 4.2 & - & 8.3 & 8.3 & 66.7 & 4.2 & - & - & - \\ \mathrm{SH} & 18 & - & - & - & 16.7 & - & - & - & 61.1 & - & 5.6 & 11.1 & 5.6 \\ \mathrm{C} & 10 & - & - & - & 10.0 & - & 10.0 & 10.0 & 70.0 & - & - & - & - \\ 3 \text { weeks } & & & & & & & & & & & & & \\ 20 \mathrm{I} & 16 & - & - & 6.3 & 25.0 & - & 25.0 & 12.5 & 31.3 & - & - & - & - \\ 80 \mathrm{I} & 14 & - & - & - & 7.1 & - & - & 21.4 & 71.4 & - & - & - & - \\ 20 \mathrm{~A} & 14 & - & - & - & - & 7.1 & 7.1 & 21.4 & 64.3 & - & - & - & - \\ 80 \mathrm{~A} & 12 & 8.3 & - & - & - & - & 16.7 & 16.7 & 58.3 & - & - & - & - \\ \text { SH } & 4 & - & - & - & - & - & - & - & 75.0 & - & 25.0 & - & - \\ 12 \mathrm{weeks} & & & & & & & & & & & & & \\ 20 \mathrm{I} & 14 & 14.3 & - & - & - & 14.3 & - & - & 71.4 & - & - & - & - \\ 80 \mathrm{I} & 7 & - & - & - & - & - & - & - & 100.0 & - & - & - & - \\ 20 \mathrm{~A} & 18 & - & - & - & 5.6 & - & 5.6 & - & 88.9 & - & - & - & - \\ 80 \mathrm{~A} & 12 & 8.3 & - & - & 8.3 & - & - & - & 75.0 & 8.3 & - & - & - \\ \text { SH } & 14 & - & - & - & 21.4 & - & - & - & 57.1 & - & 7.1 & 7.1 & 7.1\end{array}$




\subsubsection{Degeneration}

Table III.7.1 depicts the percentage of fertilized and unfertilized ova among degenerate ova.

Table III.7.I

Number and percentage of degenerate ova

( $n$ tot $=$ total number of ova retrieved; $n$ deg $=$ number of degenerate ova)

\begin{tabular}{|c|c|c|c|c|c|c|}
\hline & $\begin{array}{c}L \\
n \\
\text { tor }\end{array}$ & $\begin{array}{c}L \\
n \\
\operatorname{deg}\end{array}$ & $\begin{array}{c}L \\
(\%)\end{array}$ & $\begin{array}{c}R \\
n \\
t o t\end{array}$ & $\begin{array}{c}R \\
n \\
\operatorname{deg}\end{array}$ & $\begin{array}{c}R \\
(0 \%)\end{array}$ \\
\hline fertilized ova & 390 & 20 & 5.1 & 561 & 25 & 4.5 \\
\hline unfertilized ova & 66 & 38 & 57.6 & 90 & 57 & 63.3 \\
\hline
\end{tabular}

Table WI.7.2

Number and percentage of degenerate fertilized ova

\begin{tabular}{|c|c|c|c|c|c|c|}
\hline & $n$ & $\begin{array}{c}L \\
(\%)\end{array}$ & $n^{\prime \prime}$ & $n$ & $\begin{array}{c}R \\
(\%)\end{array}$ & $n d^{\prime}$ \\
\hline $20 \mathrm{I}$ & 8 & 10.4 & 6 & 2 & 2.0 & 2 \\
\hline $80 \mathrm{I}$ & 1 & 1.3 & 1 & 4 & 3.6 & 3 \\
\hline $20 \mathrm{~A}$ & - & - & - & 1 & 0.9 & 1 \\
\hline $80 \mathrm{~A}$ & 4 & 7.7 & 3 & 4 & 4.4 & 4 \\
\hline $\mathrm{SH}$ & 5 & 5.7 & 2 & 13 & 13.8 & 4 \\
\hline $\mathrm{C}$ & 2 & 4.1 & 2 & 1 & 2.0 & 1 \\
\hline $20 \%$ & 8 & 6.4 & & 3 & 1.4 & \\
\hline $80 \%$ & 5 & 3.8 & & 8 & 4.0 & \\
\hline I & 9 & 5.8 & & 6 & 2.9 & \\
\hline A & 4 & 4.0 & & 5 & 2.4 & \\
\hline 3 weeks & 6 & 4.0 & & 12 & 4.9 & \\
\hline 12 weeks & 12 & 6.3 & & 12 & 4.5 & \\
\hline 24 hours & 8 & 5.2 & & 17 & 7.1 & \\
\hline 36 hours & 1 & 0.9 & & 4 & 3.0 & \\
\hline 48 hours & 11 & 8.9 & & 4 & 2.2 & \\
\hline$<1750 \mathrm{gr}$ & 9* & 5.3 & & & & \\
\hline $1750-2250 \mathrm{gr}$ & $34^{*}$ & 4.0 & & & & \\
\hline$>2250 \mathrm{gr}$ & $2 *$ & 1.5 & & & & \\
\hline
\end{tabular}

" number of does degenerate fertilized ova retrieved from

* left and rigt added 
Table III.7.2 shows degenerate fertilized ova and their classification as described in chapter 3.2 .

Because of the small number of degenerate fertilized ova and the only slight differences between the various groups no statistical comparisons were made.

\subsubsection{Mucin layer}

Table III.8.1 shows the mean mucin layer thickness on tubal ova of does, classified according to the description in chapter 3.2. Mucin layer thickness is expressed in $\mu$ ('mu' $=1.10^{-6} \mathrm{~m}$ ). Statistical comparison of the mean mucin layer thickness between ova recovered from reanastomosed oviducts and from oviducts in shamoperated and control does was made using a paired t-test. No significant difference was found 24 hours after mating. Mucin layer thickness on ova in the right oviducts subtracted from the thickness in the left oviducts was $-19 \mu$ in the operated oviducts 36 hours after mating, and $2 \mu$ in the control animals and sham operated oviducts (referred to as 'controls'). The difference reached a level of statistical significance $(\mathrm{p}<0.05)$. At 48 hours upon mating the left-right difference in mucin layers measured $-40 \mu$ in the operated animals and $-2 \mu$ in the 'controls'. This was significant at the level of $\mathrm{p}<0.001$.

The difference in mucin layer thickness between ova recovered from the operated oviducts in does subjected to isthmic resection reanastomoses, ampullary reanastomoses and ova recovered from 'controls' was evaluated by using a t-test. No statistically significant difference was noted 24 hours after mating. At 36 hours upon mating mean mucin layer thickness $(13 \mu)$ was significantly reduced in ampullary reanastomosed oviducts as compared to the one in isthmic reanastomosed $(30 \mu$; $\mathrm{p}<0.05$ ) and 'control' oviducts $(35 \mu ; \mathrm{p}<0.01)$. Comparison of these same groups 48 hours after mating demonstrated that the mean mucin layer thickness on ova in ampullary $(30 \mu)$ as well as isthmic $(32 \mu)$ resected and reanastomosed oviducts differed significantly from the mean layer thickness in the 'controls' $(74 \mu)$, at the level of $p<0.001$. Comparison of mean mucin layer thickness between ova recovered from $20 \%$ resected oviducts and $80 \%$ resected oviducts revealed no statistically significant differences for each individual mating-autopsy interval.

Table III.8.2 depicts mucin layer thickness on ova retrieved from all right control oviducts. Mucin layer thickness is compared in ova retrieved from the right ampullary segment, ampullary-isthmic junction and isthmic segment respectively, and from does with five or less corpora lutea and 11 or more, respectively. Mucin layer thickness on fertilized versus unfertilized, and on degenerate versus non-degenerate ova is compared. Finally a correlation between mucin layer thickness and embryonic cleavage stage has been looked for. Statistical comparison of mean mucin layer thickness between fertilized and unfertilized as well as degenerate and nondegenerate ova was made by using a t-test. No differences were found between ferti- 


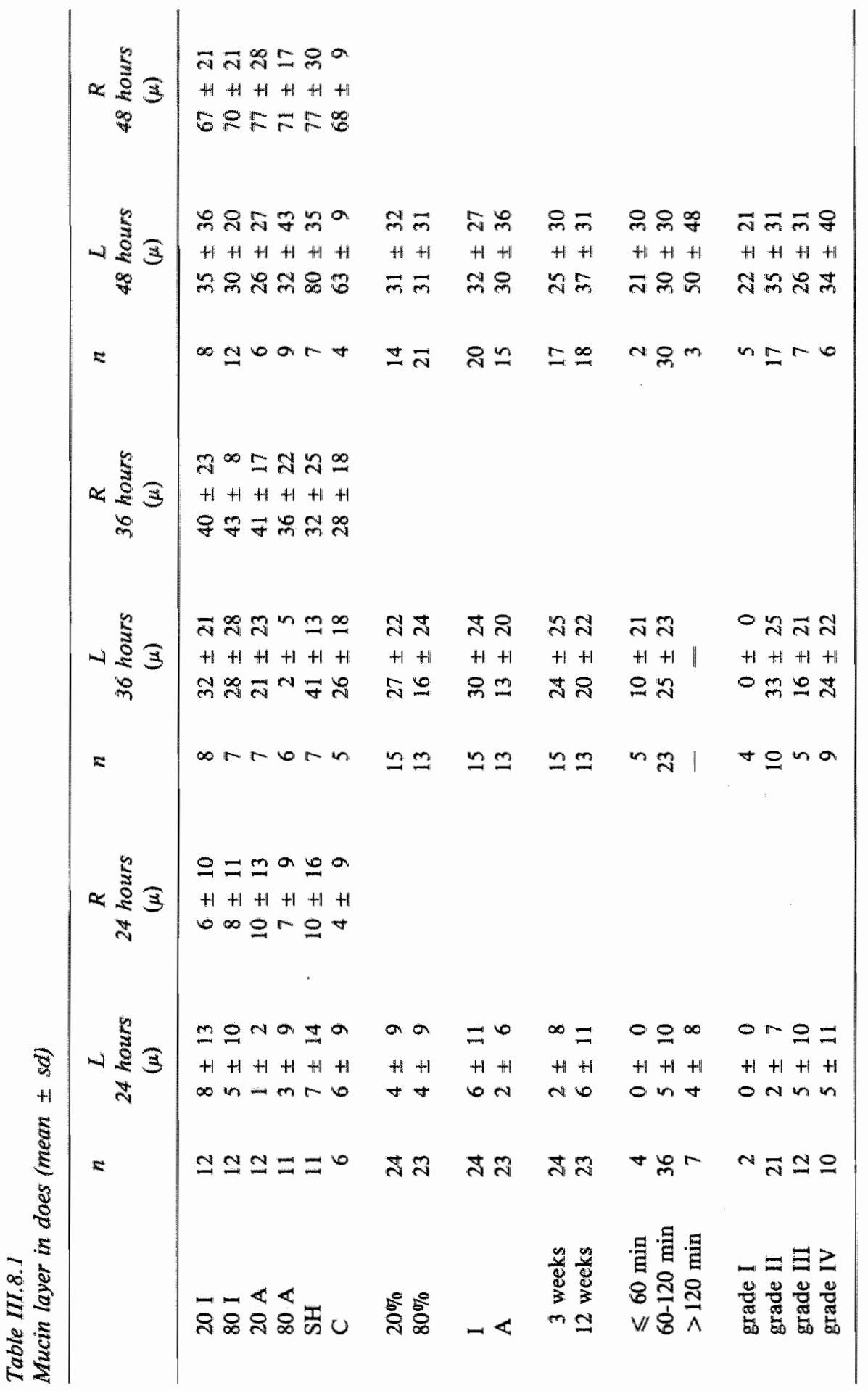


Mucin layer thickness on ova retrieved from the right (control) oviducts (mean $\pm s d$ )

\begin{tabular}{|c|c|c|c|c|c|c|}
\hline & $n$ & $\begin{array}{c}24 \text { hours } \\
(\mu)\end{array}$ & $n$ & $\begin{array}{l}36 \text { hours } \\
(\mu)\end{array}$ & $n$ & $\begin{array}{c}48 \text { hours } \\
(\mu)\end{array}$ \\
\hline segment $\mathbb{\|}$ & 5 & $8 \pm \mathbb{1}$ & 3 & $47 \pm 31$ & 2 & $120 \pm 0$ \\
\hline segment 2 & 248 & $8 \pm \mathbb{1 1}$ & 155 & $39 \pm 40$ & 141 & $69 \pm 25$ \\
\hline segment 3 & 15 & $8 \pm 13$ & 24 & $40 \pm 22$ & 70 & $71 \pm 26$ \\
\hline$C L \leqslant 5$ & 12 & $8 \pm 14$ & - & - & 8 & $78 \pm 17$ \\
\hline $\mathrm{CL} \geqslant 11$ & 23 & $13 \pm 11$ & 37 & $31 \pm 22$ & 30 & $64 \pm 27$ \\
\hline \multicolumn{7}{|l|}{ non-dlegenerate } \\
\hline - fertilized & 224 & $9 \pm 18$ & 131 & $43 \pm 19$ & 181 & $69 \pm 23$ \\
\hline - unfertilized & 9 & $4 \pm 9$ & 12 & $25 \pm 31$ & 12 & $68 \pm 40$ \\
\hline \multicolumn{7}{|l|}{ fertilized } \\
\hline - degenerate & 17 & $\mathbb{1} \pm 5$ & 4 & $33 \pm 25$ & 4 & $65 \pm 30$ \\
\hline - non-degenerate & 224 & $10 \pm 18$ & 131 & $43 \pm 19$ & 181 & $69 \pm 23$ \\
\hline $1-$ cell & 57 & $5 \pm 10$ & 49 & $21 \pm 23$ & 28 & $76 \pm 35$ \\
\hline $2-c e l l 1$ & 191 & $9 \pm 12$ & - & - & - & - \\
\hline 4-cell & 11 & $7 \pm 10$ & 11 & $35 \pm 13$ & 1 & $80 \pm 0$ \\
\hline 8-cell & - & - & 91 & $44 \pm 20$ & 11 & $55 \pm 20$ \\
\hline 12-cell & - & - & - & - & 36 & $64 \pm 20$ \\
\hline 14-cell & - & - & - & - & 41 & $70 \pm 17$ \\
\hline$>14$-cell & - & - & - & - & 77 & $77 \pm 24$ \\
\hline
\end{tabular}

lized and unfertilized ova 24,36 and 48 hours after mating. Between degenerate and non-degenerate ova a difference was noted 24 hours after mating $(\mathrm{p}<0.001)$. At 36 and 48 hours upon mating, however, no differences in mean mucin layer thickness were observed. For each individual mating-autopsy interval no statistically significant difference in mucin layer thickness was found between embryos recovered from the ampulla, from the ampullary-isthmic junction and from the isthmus. The presence of few or many corpora lutea appeared not to have an effect upon mucin layer thickness, and neither did the cleavage stage of the early embryo.

\subsubsection{Tubal transport}

Ovum transport was studied by recording the tubal segment (i.e. the ampullary segment, the ampullary-isthmic junction or the isthmic segment) from which the ova were recovered. Table III.9.1 shows the number and percentage of fertilized ova according to the tubal segment from which they were retrieved 24,36 , and 48 hours 
Table III.9.1

Number and percentage of fertilized ova recovered from segment 1,2 and 3 respectively

\begin{tabular}{|c|c|c|c|c|c|c|c|c|c|c|c|c|}
\hline $\begin{array}{l}\text { left oviduct } \\
\text { segmeni }\end{array}$ & $n$ & $\begin{array}{c}l \\
24 h \\
(\%)\end{array}$ & $\begin{array}{c}2 \\
24 \mathrm{~h} \\
(0 \%)\end{array}$ & $\begin{array}{c}3 \\
24 h \\
(0 \%)\end{array}$ & $n$ & $\begin{array}{c}1 \\
36 h \\
(0 \%)\end{array}$ & $\begin{array}{c}2 \\
36 h \\
(\%)\end{array}$ & $\begin{array}{c}3 \\
36 h \\
(0 \%)\end{array}$ & $n$ & $\begin{array}{c}1 \\
48 h \\
(07)\end{array}$ & $\begin{array}{c}2 \\
48 h \\
(\%)\end{array}$ & $\begin{array}{c}3 \\
48 h \\
(00)\end{array}$ \\
\hline $20 \mathrm{I}$ & 34 & - & 91.2 & 8.8 & 23 & - & 69.6 & 30.4 & 20 & - & 65.0 & 35.0 \\
\hline 801 & 27 & - & 77.8 & 22.2 & 18 & - & 100.0 & - & 33 & - & 81.8 & 18.2 \\
\hline $20 \mathrm{~A}$ & 22 & 22.7 & 77.3 & - & 14 & - & 100.0 & - & 12 & - & 91.7 & 8.3 \\
\hline $80 \mathrm{~A}$ & 16 & 56.3 & 43,8 & - & 15 & 26.7 & 73.3 & - & 21 & 23.8 & 76.2 & - \\
\hline $\mathrm{SH}$ & 39 & 2.6 & 94.9 & 2.6 & 24 & - & 91.7 & 8.3 & 24 & - & 79.2 & 20.8 \\
\hline $\mathrm{C}$ & 17 & - & 100.0 & - & 19 & - & 94.7 & 5.3 & 13 & - & 84.6 & 15.4 \\
\hline $20 \%$ & 56 & 8.9 & 85.7 & 5.4 & 37 & - & 81.1 & 18.9 & 32 & - & 75.0 & 25.0 \\
\hline $80 \%$ & 43 & 20.9 & 65.1 & 14.0 & 33 & 12.1 & 87.9 & - & 54 & 9.3 & 79.6 & 11.1 \\
\hline I & 61 & - & 85.2 & 14.8 & 41 & - & 82.9 & 17.1 & 53 & - & 75.5 & 24.5 \\
\hline A & 38 & 36.8 & 63.2 & - & 29 & 13.8 & 86.2 & - & 33 & 15.2 & 81.8 & 3.0 \\
\hline 3 weeks & 65 & 9.2 & 80.0 & 10.8 & 43 & 9.3 & 79.1 & 11.6 & 43 & 11.6 & 65.1 & 23.3 \\
\hline 12 weeks & 73 & 1.2 .3 & 83.6 & 4.1 & 51 & - & 92.2 & 7.8 & 67 & - & 86.6 & 13.4 \\
\hline fertillized & 155 & 9.7 & 83.9 & 6.5 & 113 & 3.5 & 87.6 & 8.8 & 123 & 4.1 & 78.9 & 17.1 \\
\hline unfertilized & 10 & 30.0 & 70.0 & - & 36 & 19.4 & 58.3 & 22.2 & 20 & 30.0 & 50.0 & 20.0 \\
\hline degenerate & 9 & - & 100.0 & - & 1 & - & 100.0 & - & 10 & - & 70.0 & 30.0 \\
\hline $\begin{array}{l}\text { non- } \\
\text { degenerate }\end{array}$ & 145 & 10.3 & 82.8 & 6.9 & 112 & 3.6 & 87.5 & 8.9 & 113 & 4.4 & 79.6 & 15.9 \\
\hline \multicolumn{13}{|l|}{$\begin{array}{l}\text { right oviduct } \\
\text { segment }\end{array}$} \\
\hline 20 & 38 & 2.6 & 97.4 & - & 30 & - & 90.0 & 10.0 & 32 & - & 59.4 & 40.6 \\
\hline 80 I & 47 & - & 91.5 & 8.5 & 21 & - & 81.0 & 19.0 & 42 & - & 64.3 & 35.7 \\
\hline $20 \mathrm{~A}$ & 53 & 5.7 & 94.3 & $-\infty$ & 32 & - & 75.0 & 25.0 & 32 & - & 62.5 & 37.5 \\
\hline $80 \mathrm{~A}$ & $3 !$ & - & 100.0 & - & 24 & 4.2 & 95.8 & - & 35 & 一 & 60.0 & 40.0 \\
\hline SH & 45 & - & 77.8 & 22.2 & 18 & - & 83.3 & 16.7 & 31 & - & 83.9 & 16.1 \\
\hline$C$ & 27 & - & 100.0 & - & 10 & - & 80.0 & 20.0 & 13 & - & 76.9 & 23.1 \\
\hline
\end{tabular}

after mating respectively. The comparison of tubal location between fertilized, unfertilized, degenerate and non-degenerate ova has been added to table III.9.1. Statistical comparison between degenerate versus non-degenerate, and fertilized versus unfertilized ova was performed by using Fisher's exact probability test. No statistically significant differences were found in tubal location between degenerate and non-degenerate ova 24,36 and 48 hours after mating. The location of fertilized and unfertilized ova did not differ significantly 24 hours after mating. The difference did reach a level of statistical significance 36 and 48 hours after mating, however (p-values <0.001). 
Table III.9.2

Mean cluster segment number, representing the calculated arithmetic mean of the tubal segments comtaining the cluster of fertilized ova, in does ( $t \mathrm{sd})$

\begin{tabular}{|c|c|c|c|c|c|c|c|c|c|}
\hline & n & $\begin{array}{c}\mathrm{L} \\
24 \text { hours }\end{array}$ & $\begin{array}{c}R \\
24 \text { hours }\end{array}$ & $\mathrm{n}$ & $\begin{array}{c}\text { L } \\
36 \text { hours }\end{array}$ & $\begin{array}{c}R \\
36 \text { hours }\end{array}$ & n & $\begin{array}{c}\text { L } \\
48 \text { hours }\end{array}$ & $\begin{array}{c}R \\
48 \text { hours }\end{array}$ \\
\hline $20 \mathrm{I}$ & 10 & $2.2 \pm 0.4$ & $2.0 \pm 0.0$ & 6 & $2.2 \pm 0.4$ & $2.2 \pm 0.4$ & 8 & $2.4 \pm 0.5$ & $2.4 \pm 0.5$ \\
\hline 801 & 11 & $2.2 \pm 0.4$ & $2.0 \pm 0.0$ & 6 & $2.0 \pm 0.0$ & $2.0 \pm 0.0$ & 10 & $2.2 \pm 0.4$ & $2.2 \pm 0.4$ \\
\hline $20 \mathrm{~A}$ & 11 & $1.6 \pm 0.5$ & $1.8 \pm 0.4$ & 7 & $2.0 \pm 0.0$ & $2.1 \pm 0.4$ & 6 & $2.0 \pm 0.0$ & $2.3 \pm 0.5$ \\
\hline $80 \mathrm{~A}$ & 10 & $1.4 \pm 0.5$ & $2.0 \pm 0.0$ & 8 & $1.8 \pm 0.4$ & $2.0 \pm 0.0$ & 9 & $1.8 \pm 0.5$ & $2.4 \pm 0.5$ \\
\hline SH & 11 & $2.0 \pm 0.0$ & $2.2 \pm 0.4$ & 6 & $2.2 \pm 0.4$ & $2.0 \pm 0.0$ & 8 & $2.1 \pm 0.4$ & $2.1 \pm 0.4$ \\
\hline $\mathrm{C}$ & 6 & $2.0 \pm 0.0$ & $2.0 \pm 0.0$ & 4 & $2.0 \pm 0.0$ & $2.0 \pm 0.0$ & 4 & $2.0 \pm 0.0$ & $2.0 \pm 0.0$ \\
\hline $20 \%$ & 20 & $1.9 \pm 0.6$ & & 11 & $2.1 \pm 0.3$ & & 12 & $2.3 \pm 0.6$ & \\
\hline $80 \%$ & 19 & $1.8 \pm 0.6$ & & 11 & $1.9 \pm 0.3$ & & 18 & $2.0 \pm 0.5$ & \\
\hline I & 20 & $2.2 \pm 0.4$ & & 12 & $2.1 \pm 0.3$ & & 18 & $2.3 \pm 0.5$ & \\
\hline A & 19 & $1.5 \pm 0.5$ & & 10 & $1.9 \pm 0.3$ & & 12 & $1.8 \pm 0.4$ & \\
\hline 3 weeks & 17 & $1.9 \pm 0.6$ & & 11 & $2.0 \pm 0.4$ & & 12 & $2.2 \pm 0.7$ & \\
\hline 12 weeks & 22 & $1.8 \pm 0.6$ & & 11 & $2.0 \pm 0.0$ & & 18 & $2.1 \pm 0.2$ & \\
\hline$\leqslant 60 \mathrm{~min}$ & 3 & $2.0 \pm 0.0$ & & 5 & $2.0 \pm 0.0$ & & 2 & $2.0 \pm 0.0$ & \\
\hline $60-120$ min & 30 & $1.9 \pm 0.5$ & & 17 & $2.0 \pm 0.4$ & & 25 & $2.1 \pm 0.5$ & \\
\hline$>120 \mathrm{~min}$ & 6 & $1.8 \pm 1.0$ & & - & - & & 3 & $2.3 \pm 0.6$ & \\
\hline grade I & 1 & $2.0 \pm 0.0$ & & 4 & $2.0 \pm 0.0$ & & 5 & $1.8 \pm 0.5$ & \\
\hline gradle II & 20 & $2.0 \pm 0.5$ & & 10 & $2.0 \pm 0.0$ & & 16 & $2.1 \pm 0.4$ & \\
\hline grade III & 9 & $1.6 \pm 0.7$ & & 4 & $2.3 \pm 0.5$ & & 5 & $2.2 \pm 0.4$ & \\
\hline grade IV & 7 & $1.7 \pm 0.5$ & & 4 & $1.8 \pm 0.5$ & & 4 & $2.5 \pm 0.6$ & \\
\hline
\end{tabular}

It is known that in the rabbit ova are transported in clusters: the difference in distance between the ovum which has traversed the longest way in the oviduct and the ovum which has travelled the shortest distance during the same period usually does not exceed 10\% of total tubal length (Greenwald, 1961; Perez et al, 1981b). For this reason tubal transport was studied by calculating for each rabbit the tubal segment which contained the cluster of ova (cluster segment number) at the three matingautopsy intervals studied. In each experimental or controll group the mean cluster segment number was calculated, based on the mathematical mean of the segments in which the oviduct had been divided for ovum retrieval (i.e. segment $1=$ ampulla, segment 2 = ampullary-isthmic junction, segment 3 = isthmus) and which contained the cluster of ova in the individual animals. The reduction to one observation only per animal equalizes the impact of all individual does, irrespective of the number of ova they contain, upon tubal transport outcome. Table III.9.2 summarizes these results. Does have been classified as described in chapter 3.2. Statistical comparison was performed by using analysis of variance and a t-test. In the left oviducts the tubal segments which contained the majority of ova 24 hours after mating did 
Mean segment in left oviducts containing the cluster of ova 24 hours after mating (t-test)

\begin{tabular}{|c|c|c|c|c|c|}
\hline & $20 I$ & $80 I$ & $20 \mathrm{~A}$ & $80 A$ & $S H$ \\
\hline \multicolumn{6}{|l|}{201} \\
\hline 801 & NS & & & & \\
\hline $20 \mathrm{~A}$ & $p<0.01$ & $\mathrm{p}<0.01$ & & & \\
\hline $80 \mathrm{~A}$ & $p<0.001$ & $p<0.001$ & NS & & \\
\hline SH & NS & NS & $p<0.05$ & $p<0.01$ & \\
\hline $\mathrm{C}$ & NS & NS & NS & $p=0.01$ & NS \\
\hline
\end{tabular}

differ significantly between the operated, sham-operated and control animals ( $p<0.001$ ). Table III.9.3 shows the p-values for the various t-tests. At 36 hours upon mating the difference between the tubal segments did not reach a level of statistical significance. The mean cluster segment number $\mathbf{4 8}$ hours after mating in does which had been subjected to a $80 \%$ ampullary resection reanastomosis was 1.8 . This differed significantly from the mean cluster segment number calculated in does in which a $20 \%$ isthmic resection was performed $(2.4 ; \mathrm{p}<0.01)$ as well as in does which had undergone a $80 \%$ isthmic resection reanastomosis $(2.2 ; \mathrm{p}<0.05)$. In the right oviducts the mean cluster segment numbers did not differ significantly between the operated, sham-operated and control does at the three intervals after mating studied. 


\section{CHAPTER IV. Discussion}

\subsection{Nomenclature}

The first few weeks after fertilization form a period during which rapid growth and differentiation of the conceptus takes place.

Fertilization of the oocyte by the spermatozoon results in the formation of a zygote which, by mitotic divisions, undergoes cleavage into daughter cells, or blastomeres. As the blastomeres continue to divide, a solid ball of cells, the morula, is produced ( < Lat. 'morum" = mulberry). By accumulation of fluid between the blastomeres the blastocyst is formed. At one pole a distinct mass of cells is found, the 'inner cell mass', which is destined to become the embryo.

Whereas in clinical medicine it is customary to refer to the human conceptus from fertilization through the first 8 weeks of development as an embryo, most embryologists do not use the term embryo until the second week after fertilization, when the bilaminar embryonic disc has formed. Some authors apply the term 'ovum' up to the blastocyst stage, others refer to the conceptus in this stage of development as 'egg'. O'Rahilly (1973a) stated that 'the term egg is best reserved for a nutritive object frequently seen on the breakfast table'. He coined the term 'schizolig' $(<\mathrm{Gr}$. 'schizein' = to cleave, and 'oligos' = few) to cover the early phases of cleavage between the 2 and 12 cell stages (O'Rahilly, 1973b). This term, however, never came into general use. Despite objections for anatomical and embryological reasons, in the present study the terms 'fertilized' or 'unfertilized ovum' (in case of a one-cell stage) and '(early) embryo' (from the 2-cell stage on) are used.

\subsubsection{Corpora lutea}

In mammals the ovulatory ovarian function is reflected in the formation of corpora lutea $(C L)$. The number of ova released at ovulation is influenced by various conditions.

The mean number of $\mathrm{CL}$ per ovulation is highest in large breeds. It also depends on the parity: the mean number of $C L$ is significantly higher in does in their second pregnancy as compared to does in their first pregnancy (Adams, 1960). The ovaries of wild rabbits are inactive in winter, but enlarge in spring after the perception of increasing day length (Turner and Bagnara, 1976). The natural breeding season of wild rabbits is from the end of February to the middle of June. The adult nonpregnant domestic rabbit can be in a state of estrus irrespective of the time of the year, although slight seasonal fluctuations may exist in its degree of sexual receptivity. Breeding will occur all the year round, but pregnancy outcome may be lower in fall 
and winter. The number of $\mathrm{CL}$ can be influenced by non-physiological conditions, e.g. by pharmacological means. Intraabdominal manipulation may be correlated with impaired ovulatory function (chapter 1.6).

In the present study virgin Dutch belted does were used: the Oryctolagus cuniculus discolor neerlandicus belongs to the small breeds. The does used were 4 months of age or older, and considered sexually mature.

The data in table III.2.1 demonstrate that in the majority of operated, shamoperated and control does the mean number of CL in the left ovaries was lower than in the right control ones. The quantitative differences between both sides did not reach a level of statistical significance, however. As shown in table III.2.1 in the operated does there was no correlation between the number of $\mathrm{CL}$ and the proximity of the anastomosis to the ipsilateral ovary, nor to the extent of the segment resected. The duration of the postoperative recovery period did not influence the number of ovulations. With regard to the mating-autopsy interval, 24 hours after mating the difference in mean number of $\mathrm{CL}$ between the left and right ovaries in does which had been subjected to tubal surgery, reached a level of statistical significance (table III.2.1). At 36 and 48 hours upon mating no significant differences were noted, however. No explanation can be offered for the observation 24 hours after mating. Matings took place from December until September. The constant light-dark cycles in the animal house supported the estrous state in the does. No significant difference was found in the mean number of $\mathrm{CL}$ in does mated in the period between February 15 th and June 15 th, and in those mated outside the natural breeding season (table III.2.2). These results exclude seasonal influences upon the ovulatory function in the does studied. All animals were weighed at admission to the experiments. In the 160 does the mean weight was $1974 \mathrm{gr}$. Considering the mean number of $\mathrm{CL}$ in the left ovaries in the animals whose weights were less than $1750 \mathrm{gr}$ ( 23 does, average weight $1680 \mathrm{gr}$ ) and animals weighing more than $2250 \mathrm{gr}$ ( 20 does, average weight $2470 \mathrm{gr}$ ), no statistically significant difference was found (table III.2.1). This indicates that in this study ovulatory function is not correlated to body weight in sexually mature does.

A decrease in ovulatory function is considered to be an expression of the impact of surgical trauma on the operated animal. The mechanism by which intraabdominal manipulation influences ovulatory function remains unclear. It is known from the work of Boeckx (1982) that considerable microsurgical training is required for optimal results to be achieved: in the early phases of training the function of both ovaries, expressed as the number of CL per ovulation, is impaired. After continued training the ovarian function improves on the control side, and finally on the operated side as well. The present study was started after a microsurgical training period of several months. In the experiments no marked left-right difference was found between the mean number of $C L$ in the successive groups of animals operated (figure 3.1; table III.2.2). These data demonstrate that the reduction in the number of $\mathrm{CL}$ in the left ovaries of all operated animals is consistent throughout the experiments, and that it is not due to microsurgical inexperience in the early phases. 
Table $I V_{n}$

Number of corpora lutea in control does (mean $\pm s d$ )

\begin{tabular}{lcc}
\hline $\begin{array}{c}\text { Awihor(s) } \\
\text { Adams (1958) }\end{array}$ & $\begin{array}{c}\text { Left } \\
\text { ovary }\end{array}$ & $\begin{array}{c}\text { Right } \\
\text { ovary }\end{array}$ \\
\hline Adams (1960) & $5.5 \pm 2.2$ & $5.9 \pm 1.9$ \\
Polidoro et al (1973) & $4.5 \pm 1.9$ & $5.4 \pm 1.7$ \\
Present study & 4.1 & 4.3 \\
\hline
\end{tabular}

In literature very few studies are available which concern ovulatory function in control rabbits. Authors who have studied $\mathrm{CL}$ in does which have not been subjected to tubal surgery, agree about the mean number of CL being higher in the right ovary compared to the left (table IV.1).

Numerous experiments have been performed to determine the impact of microsurgical tubal resection on the ovulatory function of the ipsilateral ovary (summarized in chapter 1.6). Most authors report a diminished number of CL on the operated side. Accidentally most investigators operate on the left oviducts and use the right untouched sides as controls. The lower count of CL in the operated left side may reflect a physiological left-right discrepancy. Ultrasound investigation in the human has provided evidence for preference of ovulations to occur in the right ovary (Wetzels, 1983). The asymmetry in left-right distribution of ovulations is unexplained. The results from the present study demonstrate that microsurgical tubal interventions, performed by a trained surgeon, are unlikely to impair ovulatory function in the rabbit.

\subsubsection{Recovery rate}

The mean overall ovum recovery rate in the control rabbits was $101.1 \%$, and in the sham-operated does $96.8 \%$. Most tubal recovery rates of ova reported in literature vary between $90 \%$ and $100 \%$ (Adams and Chang, 1962a; Longley and Black, 1968; Polidoro et al, 1973). Recovery rates depend on the technique used for ovum retrieval: recovery rates tend to be lower when the tubal segments which contain the ova are sectioned and flushed, as compared to the recovery rates obtained by the clearing technique according to Orsini (1962). The latter method consists of removing the oviducts in toto, clearing them with benzyl-benzoate and locating the ova in the 
cleared oviducts under a microscope. Dissection of the tube may cause muscular contractions and expulsion of ova from the segment cut, and ova may be lost through manipulation per se.

In the right untouched genital tracts of the operated animals the recovery rates did not differ markedly from those in the control and sham-operated does (table III.3.1). Rabbits subjected to an ampullary resection reanastomosis showed a significantly decreased recovery rate in their operated tubes (table III.3.1). There appeared to be no correlation between the recovery rate and the length (i.e. $20 \%$ or $80 \%$ ) of the tubal segment resected. The overall ovum recovery rate in the operated oviducts was not related to the duration of the postoperative recovery period (table III.3.1). The decrease in ovum recovery rates which was observed in ampullary reanastomosed oviducts seems to be permanent, since no significant differences were found between ovum recovery rates 3 weeks and 12 weeks after surgery $(66.1 \%$ and $61.1 \%$ respectively). In the operated sides no relation could be demonstrated between the ovum recovery rate and the adhesion score (table III.3.1).

Several hypotheses can be postulated to explain the decreased recovery rates in ampullary shortened tubes. It should be emphasized that the fimbriae were always left intact, and left untouched as much as possible. Although ovum pick-up is considered to be primarily a function of the fimbriae, ampullary manipulations may interfere with the pick-up mechanism. Peritubal adhesions and excision of a (large) segment of the distal oviduct may disrupt the normal tubo-ovarian spatial relationship. Intratubal adhesions and minor fibrosis can provide a physical obstacle, as they may alter tubal rheology and compromise ovum capture and retention. On the other hand, the decreased recovery rate might be the result of accelerated tubal transport and expulsion of the ova into the uterus and vagina. This hypothesis is not supported by the data obtained from the observation on tubal transport. In ampullary shortened tubes ovum transport was found to be even delayed (chapter 4.2.8). In the rabbit, ovum pick-up from the peritoneal cavity has been described (Winston and Margara, 1980). Polyovuly, i.e. the liberation of two or more ova from one follicle, probably occurred in $10 \%$ of the does studied by Adams (1960). Transmigration and polyovuly will influence recovery rates and may give rise to rates which exceed $100 \%$. In this study it was impossible to distinguish between transmigration, polyovuly and errors in determining the number of corpora lutea. Transmigration or polyovuly may have occurred when the number of ova retrieved from one oviduct exceeds the number of corpora lutea in the ipsilateral ovary. As table III.3.3 shows, in the unoperated right oviducts in does subjected to an ampullary resection reanastomosis, more of ten recovery rates over $100 \%$ were noted. These data suggest that transperitoneal migration of ova may occur more frequently in ampullary operated does: some ova lost from the operated sides seem to be picked up by the contralateral control oviduct. In spite of transmigration, the overall ovum recovery rate remains significantly reduced in ampullary operated animals.

The results from the present study demonstrate that the ovum recovery rate is significantly reduced in the operated side of does subjected to an ampullary resection 
reanastomosis. It seems likely that a disturbance of ovum pick-up is responsible for this decrease.

\subsubsection{Fertilization}

Several criteria can be applied to establish the occurrence of fertilization. In singlecell ova the presence of the fertilizing sperm tail, the swollen head of the spermatozoon in the ooplasm, the male and female pronucleus, the second polar body, or the presence of sperm on the zona pellucida or in the perivitelline space can be used as parameters.

In the rabbit, for the identification of the fertilizing sperm tail or the head of the spermatozoon, the ovum has to be stained. In the present study unstained ova were examined by light microscopy. One-cell ova were considered to be fertilized if sperm in the perivitelline space, two polar bodies or two pronuclei in the vitellus could be observed. The presence of one or more of these characteristics does not necessarily denote (normal) fertilization, but is highly indicative for the probability of fertilization. In the rabbit the second polar body is extruded from the vitellus 1-2 hours after sperm penetration; the time of appearance of the pronuclei is 4-5 hours after sperm penetration (Bedford, 1971). Cleavage has been used as a criterion of fertilization in embryos beyond the one-cell stage. Parthenogenetic activation of rabbit ova may occur, but spontaneous cleavage in vivo is rare in this species (Bedford, 1971). In the present study the mean fertilization rate (i.e. the number of ova fertilized, divided by the number of ova recovered, multiplied by one hundred) in the control does (left and right oviducts combined) was $87.1 \%$ (table III.4.1). The mean fertilization rate in the sham-operated animals was $93.7 \%$. Both these findings are in agreement with those reported in literature: the mean proportion of ova fertilized in control rabbits is about 90-95\% (Adams, 1960; Adams and Chang, 1962a, 1962b).

Table III.4.1 shows the mean fertilization rates in all operated and control animals. In animals subjected to tubal surgery mean fertilization rates were consistently lower 3 weeks after surgery as compared to 12 weeks postoperatively, and consistently lower in the operated sides as compared to the contralateral control sides. The differences between the fertilization rate in the left and right oviduct did not reach a level of statistical significance, however. Three weeks after surgery mean fertilization rates appeared to be lower in animals subjected to tubal surgery as compared to rates in the sham-operated and control does. Particularly in the ampullary operated animals fertilization rates were decreased, both in the operated oviduct and in the contralateral control side. Furthermore, results depicted in table III.4.1 demonstrate fertilization to be influenced unfavourably by extensive abdominal adhesions, particularly if matings took place shortly after surgery.

The mean fertilization rate will be influenced by animals with extremely differing 
individual rates as well as by (more gradual) variations in the whole population. For this reason a distinction was made between does with no fertilized ova at all $(0 \%$-fertilization rate) and does in which the percentage of fertilized ova ranged between one and $90 \%$ (1-90\%-fertilization rate). In table 111.4 .2 the rabbits are presented in which all ova retrieved appeared to be unfertilized. Their numbers are small, but $0 \%$-fertilization rates seem to be more frequently found in animals subjected to surgery, particularly to $80 \%$ resections or to ampullary resection reanastomoses. Table III, 4.2 shows that in the majority of rabbits with $0 \%$-fertilization rates mating had been performed 3 weeks after surgery.

Fertilization in the rabbit is considered to be an all-or-none phenomenon, and consequently fertilization rates between one and $90 \%$ are rare. Table III.4.3 depicts the $1-90 \%$-fertilization rate found in the present study. It demonstrates that $1-90 \%$-fertilization rates are more frequently encountered in does subjected to $80 \%$ tuball resection reanastomoses. The difference in 1-90\%-fertilization rate between the operated and unoperated oviduct in the rabbits which underwent a tubal reanastomosis, did not reach a level of significance. The 1-90\%-fertilization rates bear no correlation with the length of the postoperative recovery period; this suggests the disturbing effects to be of a more permanent character.

From the results obtained in this study it appears that fertilization rates can be influenced by surgical procedures in the abdomen. Although most differences noted are slight and deal with small numbers of rabbits, certain phenomena deserve attention. If matings took place shortly after surgery, a total lack of fertilization was noted more frequently as compared to fertilization rates after a longer postoperative recovery period. Disturbances in mating behaviour, because of discomfort due to the flank incision, may account for this observation. Ovulation still occurred in these does because human chorionic gonadotropin was administered after supposed insemination. A decrease in fertilization rate may be due to inadequate mating or insemination, but disturbances in sperm transport or interference with the processes involved in fertilization will give rise to decreased fertilization rates as well. Regarding tables III.4.1, III.4.2 and III.4.3, some factors which seem to influence fertilization rates unfavourably, in the operated oviduct and in the contralateral tube as well, can be identified: a postoperative recovery period of 3 weeks, $80 \%$ resection reanastomoses, ampullary resection reanastomoses and extensive adhesion formation. These factors may mirror the extent of tissue trauma induced. Moreover, fertilization is considered to take place in the distal ampulla. Consequently, ampullary resection reanastomoses may disturb the milieu in which fertilization processes are to be enacted. Rates of $1-90 \%$-fertilization were more frequently encountered in does which had been subjected to extensive resection reanastomoses. This implies that fertilized and unfertilized ova were observed in the same oviduct concomitantly, which renders disturbances in insemination and sperm transport unlikely. Hence it is the process of fertilization itself that must be affected. Several hypotheses can be postulated to explain the disruption in the fertilization process. As described in chapter 4.2 .4 , in one doe which had been subjected to tubal surgery, sperm was no- 
ted in a single-celled ovum in the perivitelline space 36 hours after mating. This suggests sperm incapable of fertilization to be present at the site. Spermatozoa have to be prepared in order to attain the ability to fertilize oocytes. The acrosome reaction and capacitation process depend on components present in the female genital tract. Processes associated with tubal surgery, as wound healing and tubal trauma, may alter the subtle composition of the fluids of the female genital tract, and subsequently modulate sperm penetrating ability. Furthermore, ovum investments might be altered by their environment, which may give rise to changes in permeability. Physico-chemical variations in tubal fluid might trigger premature cortical granule release in the oocyte, and prevent fertilization at the appropriate time. Finally, as discussed in chapter 4.2 .5 , changes at the level of the ripening follicle due to surgical intervention may cause the mating-ovulation interval to be altered. Consequently oocytes may become exposed to spermatozoa when oocyte maturation and sperm preparation are unattuned, which may result in failure of normal fertilization.

The impact of body weight on the fertilization rate was studied. In young rabbits body weight is correlated to age. As demonstrated in table III.4.1 the mean fertilization rate in the 'light' does (weight less than 1750 grams) differed from the mean rate in those weighing more than 2250 grams. The differences should be considered with caution as they are based on observations in a small number of rabbits. As can be concluded from the results depicted in tables III.4.2 and III.4.3, the differences found between the different weight categories, are mainly due to a relatively high percentage of 'light' does which had a $0 \%$-fertillization rate when mated 3 weeks postoperatively. These results suggest that although all animals used in the present study were sexually mature, in the younger ones fertility seemed to be temporarily more depressed after tubal surgery.

At the various mating-autopsy intervals different mean fertilization rates were observed (table 1II.4.1). These differences, however, were not statistically significant. Cleavage of the embryo was the criterion predominantly used to ascertain fertilization after elapse of 36 and 48 hours upon mating. At 24 hours upon mating in one-cell ova less reliable criteria had to be used, which probably resulted in an overestimation of the fertilization rate. Furthermore, in the control animals, the fertilization rate in ova retrieved after 24 and 48 hours after mating was $100 \%$, in those recovered after 36 hours $61.7 \%$ (together these individual fertilization rates constitute the mean fertilization rates of $89.3 \%$ and $84.9 \%$, presented in table III.4.1 for the left and right oviduct respectively). When flushing of the oviducts had to be performed 36 hours after insemination, matings took place early in the morning or in the evening. Both moments happened to be in the dark period during the light/dark cycle of $12 / 12$ hours in the laboratory animal house. Reproductive functions in other rodents, e.g. rats and mice, are known to depend on a diurnal cycle (Hoffmann, 1973). In the rabbit some diurnal variation may also exist. Mating at an unfavourable moment may interfere with normal endocrinological or sexual functions and result in a decreased fertilization rate. 
In summary, fertilization rates were shown to be influenced by (tubal) surgery. A total lack of fertilization was more frequently encountered in rabbits which were mated 3 weeks after surgery, as compared to does which were mated 12 weeks after surgery. Adequate insemination may have been prevented shortly after operation. After tubal resection reanastomoses, particularly after ampullary resections, fertilization rates were decreased. The decrease was more pronounced in the operated side, but fertilization was affected in the contralateral control oviduct as well. A relation between fertilization rate and postoperative recovery period, localization and extent of tissue trauma is suggested. Factors possibly influencing sperm-oocyte interaction are discussed.

\subsubsection{Spermatozoa}

The female reproductive tract plays an active role in sperm selection, transport and capacitation. The number of spermatozoa that reach the site of fertilization has been considered critical, and several mechanisms have been proposed to regulate sperm ascent. The cervix uteri and the utero-isthmic junction may act as barriers, and the proximal isthmus may serve as a reservoir from which an active ad-ovarian redistribution of sperm takes place (Hunter, 1984). There are indications that the mean number of spermatozoa present on the zona pellucida and in the perivitelline space are related to the number of spermatozoa that reach the oviduct (Adams, 1956; Hunter, 1984). Hunter and Léglise (1971) performed unilateral isthmic resection reanastomoses in rabbits. The isthmi were removed from the level of the ampullary-isthmic junction to within 1-2 mm proximal to the utero-isthmic junction. Care was taken to preserve the integrity of the latter junction. Consequently, they recorded the numbers of spermatozoa on the zonae pellucidae and in the perivitelline spaces in two does which had been mated. After staining and sectioning of the ova Hunter and Léglise observed in both animals a significantly increased mean number of spermatozoa in the ova recovered from the reanastomosed oviducts as compared to those in ova from the contralateral control sides ( 71 versus 17 on the zona pellucida, 49 versus 32 in the perivitelline space). Furthermore, they obtained three $(7 \%)$ polyspermically fertilized ova from the tubes without isthmus, versus none from the control oviducts. These observations led them to the conclusion that the isthmus exerts considerable control over sperm transport to the site of fertilization, and consequently plays a part in the prevention of polyspermic fertilization. Table III.5.I shows the mean numbers of spermatozoa on the zonae pellucidae and in the perivitelline spaces counted in a random sample of 510 ova recovered in the present study. These observations are in agreement with the numbers reported by Adams (1956), who examined unstained ova by using a microscope and made counts of the number of spermatozoa in the perivitelline space and on the zona pellucida in ova recovered from control oviducts. The mean numbers are tabulated in table IV. 2 . 
Tabel IV.2

Number of spermatozoa in ova recovered from control oviducts in 3 groups of does in which ligation of the contralateral oviduct or uterine horn had been performed at 3 different interwals after mating. The fertilization rates in these control oviducts were over $90 \%$ (Adams, 1956) (mean \pm sd)

\begin{tabular}{lcc} 
Number of ova & $\begin{array}{c}\text { Spermatazoa on } \\
\text { zona pellucida }\end{array}$ & $\begin{array}{c}\text { Spermatozoa in } \\
\text { perivitelline space }\end{array}$ \\
\hline 137 & $2.67 \pm 2.81$ & $4.20 \pm 4.33$ \\
46 & $6.20 \pm 3.73$ & $5.20 \pm 3.39$ \\
48 & $3.00 \pm 3.33$ & $5.37 \pm 4.09$ \\
\hline
\end{tabular}

The data reported by Adams emphasize the considerable variation between animals. This is also reflected by the large standard deviations found in our study (table III.5.1). In this study no significant differences were noted in the mean number of spermatozoa counted in the perivitelline spaces of ova recovered from all operated oviducts. Comparison of mean numbers of spermatozoa on the zonae pellucidae revealed that the numbers were highest in ova retrieved from oviducts in which a $80 \%$ resection reanastomosis was performed. The observations reported by Hunter and Léglise could not be confirmed, however. First, considerable variation was demonstrated to exist even between control animals. Second, if $80 \%$ isthmic resection reanastomoses would give rise to a significant increase in the number of spermatozoa in ova, one would expect these numbers to differ significantly from the counts in all animals subjected to any other type of tubal resection reanastomosis, as well as from the numbers in control animals and in the contralateral control sides in does with $80 \%$ isthmic resections. Furthermore, the sperm number in the perivitelline spaces in ova recovered from does in which $80 \%$ isthmic resections were performed, would be increased significantly as well, according to the findings published by Hunter and Léglise. These phenomena were not demonstrated in the present study. After extensive isthmic resections the number of spermatozoa that had penetrated the outer ovum investments was shown to have increased, which would suggest that a larger number of spermatozoa may have reached the site of fertilization. Nevertheless, the number of spermatozoa that had entered into the perivitelline space had not increased significantly after $80 \%$ isthmic resection reanastomoses. Data reported in literature support the hypothesis that an increase in the number of sperm present at the site of fertilization will not augment the risk of polyspermic penetration. Adams and Chang (1962b) artificially, by tubal insemination, increased the number of sperm that reached the site of fertilization by a factor up to a few thousand times the normal count by tubal insemination. No polyspermic fertilization was observed. This suggests that the restriction in the number of sperm, 
which takes place during their passage through the female genital tract, is of importance for other reasons than that of avoidance of the risk of polyspermy. Polyspermy is rare in vivo; from in vitro fertilization programs and research it has become clear that polyspermy is more common in in vitro fertilization. From the literature it seems probable that polyspermic penetration of mammalian oocytes is primarily induced by alterations in the block to polyspermy in the ovum (Edwards and Purdy, 1982a). This can presumably result from premature insemination and fertilization. of aged ova. Insemination immediately after ovum recovery may expose oocytes to spermatozoa before the completion of cortical granule migration, and result in an inadequate block to polyspermy. The appearance of three or more pronuclei at the time of examination of fertilization in in vitro fertilization protocols occurs in about 2-7\% of inseminated oocytes (Pike, 1984). Human embryos which have developed from polynuclear ova are able to progress in an apparently normal fashion through the early preimplantation stages (Van Blerkom et al, 1984; Mohr and Trounson, 1984). Chromosome examination showed no evidence of polyploidy in a number of cleaving embryos which appeared to have three or more pronuclei (Mohr and Trounson, 1984). It is not known whether the additional pronuclei are excluded from further cell division or whether the apparent multiplicity of pronuclei represents an artefact.

As discussed in chapter 1.4.4 the zona reaction is weak in Lagomorpha. Spermatozoa are permitted to continue to enter the perivitelline space for some time after fertiliztion has occurred (figure 4.1; page 29). Consequently, in rabbits the presence of several spermatozoa in the perivitelline space does not prove polyspermic fertilization to have taken place. In the present study ova were investigated by light microscopy, so accurate evaluation of mono- or polyspermic fertilization was impossible.

As described in chapters 2.1.8 and 4.2.3 one of the criteria for fertilization in singlecell ova was the presence of sperm on the zona pellucida or in the perivitelline space. Table III.5.3 depicts the percentage of fertilized and unfertilized ova, respectively, which contained neither spermatozoa on their zonae pellucidae, nor in their perivitelline spaces. From table III.5.3 it can be concluded that spermatozoa on the zona surface can be considered as no more than an indication of the probability of fertilization: $18.4 \%$ of ova which did not contain any sperm on the zona pellucida appeared to be fertilized according to other criteria, and $13.9 \%$ of ova in which spermatozoa were present on the zona appeared to be unfertilized after 36 and 48 hours upon mating. The presence of spermatozoa in the perivitelline space is highly indicative, but cannot be taken as unequivocal evidence of fertilization. As table III.5.3 shows, in the right control oviducts all unfertilized ova were devoid of spermatozoa in the perivitelline space. In a small number $(3 / 30)$ of unfertilized ova retrieved from the operated left oviducts, however, spermatozoa had entered the perivitelline space. It is reasonable to assume that viable spermatozoa present at the site of fertilization were not capable of fertilization. Two factors can be hypothesized to account for this incapability in the operated oviducts: the capacitation process may be disturbed by subtle changes in the tubal environment, or changes in the ovum 
may have been evoked, which alter oolemma permeability (discussed in chapter 4.2.3).

Table III.5.1 shows that the mean numbers of spermatozoa (in the perivitelline space as well as on the zona pellucida) do not differ markedly between the three mating-autopsy intervals studied. This indicates that spermatozoa do not penetrate ova during more than 24 hours after insemination, i.e. about 12 hours after ovulation. This may be due to diminishing sperm numbers present at the site of the ovum, a decrease in sperm mobility or ability to penetrate, or it may be due to alterations in permeability of the ovurn investments. These observations suggest the process of fertilization to be restricted to the first 12 hours after ovulation.

From the present study it can be concluded that after extensive isthmic resections the number of spermatozoa that penetrates the outer ovum investments had increased as compared to the sperm numbers after other types of resection reanastomoses and to the sperm numbers in control animals. Although this may indicate that more spermatozoa are present at the site of fertilization, the number of sperm that had entered the perivitelline space was not markedly greater. In some unfertilized ova spermatozoa were identified in the perivitelline space. This suggests that in the operated oviduct viable spermatozoa may be incapable of fertilization. When examined 36 and 48 hours after mating the number of spermatozoa in the tubal ova had not increased as compared to the numbers 24 hours after mating. This suggests the process of fertilization to be restricted in time.

\subsubsection{Embryonic cleavage}

The metabolic requirements of mammalian embryos are still incompletely understood. During the course of development metabolism is necessary for energy production and synthesis of macromolecules. Oviductal ova derive most of their energy from oxidative phosphorylation, a process catalyzed by dehydrogenase enzymes. During later stages in development the embryo derives its energy primarily from glyw colysis (Kane and Buckley, 1977). It is not known whether the energy required for development in mammalian ova is supplied by oxidation of endogenous substrates, by the degradation of exogenous substrates, or by both. Discussion exists about the relative autonomy of the mammalian ovum during the first days after fertilization. Some authors consider preimplantation development not to depend upon the provision of maternal components of either oviductal or uterine origin (Renfree, 1980), others assume normal development of the fertilized ovum to be modulated by the environmental, maternal system (David et al, 1973; Epstein, 1975).

From experimental work on laboratory animals it is known that the zona pellucida can be penetrated by low molecular weight substances as well as by macromolecules (McLaren, 1969). Maternal serum albumin passes into the nucleus of oocytes to become associated with the chromatin and the nucleolus (Glass, 1969). Albumin has 
a. strong affinity for ions, and the transferred albumin may act as a carrier for other molecules. Macromoleculles, presynthesized by the mother and transferred into the ovum or embryo are called heterosynthetic. Heterosynthetic transfer has been shown to take place into ovarian follicles, oviductal ova and uterine embryos (Glass, 1969). During heterosynthetic transfer no major degradation occurs, and therefore the macromolecules may retain their biological function. Synthesis of proteins and uptake of amino acids have been detected in fertilized as well as unfertilized ova. It has been demonstrated that at least some of the protein synthesis during the first stages of embryogenesis is controlled by maternal messenger RNAs (Epstein, 1975). Furthermore, it is believed that both parental sexes contribute nuclear information to the zygote genome (McGrath and Solter, 1984).

Saito et al (1984) tested in mice different protein supplements to in vitro culture media. There appeared to be no difference in embryonic growth in any of the protein supplemented media after 24 and 48 hours in culture. After 96 hours, however, embryonic growth was improved in all protein supplemented media compared with serum-free media.

In conclusion, even during the early stages of embryonic development incorporation of heterosynthetic mollecules takes place, which suggests that embryonic development may be regullated by endogenous as well as by exogenous, maternally derived, factors. The metabolism of the early-stage embryo seems to be unaffected by the absence of serum derived macromolecules, but as development proceeds the absence of these substances may exert its (unfavourable) influence.

In vivo cleavage rates are species specific. The doubling time of blastomeres varies from 10-12 hours in the mouse to over 20 hours in larger animals. So far no mechanism has been put forward which satisfactorily explains the regulation of embryonic cleavage. It has been postulated that all reactions which require a large amount of energy are inhibited before fertilization, that the inhibitory substances are removed at the time of sperm penetration and that subsequently the ovum is prompted to start cleaving (Hafez and Sugawara, 1961; Costello, 1971). The time taken by the cell to pass through the various stages of the cell cycle is variable. The G1-phase (when RNA and protein synthesis occurs) is the most heterogenous in length. Factors which control the rate of passage through the cell cycle and which are considered to be of importance are cyclic nucleotides (particularly cyclic AMP), cytoplasmic factors which act on the cell surface and at gene level, and the cell environment which acts at the level of the plasma membrane (Malpoix-Higgins, 1977). From experimental work it is known that the cleavage rate can be modified pharmacologically: administration of inhibitors of protein synthesis will inhibit cleavage (Daniel and Levy, 1964; Thompson, 1967; Kane and Buckley, 1977). McLaren (1969) observed that mouse embryos, derived from the same donor-mother, developed at different rates in different acceptors. This suggests that factors from the oviductal environment affect embryonic cleavage rate.

From in vitro fertilization studies it has become clear that in vitro the doubling rate of blastomeres becomes progressively slower. The discrepancy between in vitro and 
in vivo cleavage rates becomes pronounced only after several doubling times. The in vitro cleavage rate seems to depend upon the adequacy of the culture conditions: suboptimal conditions may retard embryonic development or may even result in embryonic degeneration (chapter 4.2.6). Results obtained from human in vitro fertilization programs indicate that if the time which embryos spend in culture is prolonged, their viability will decrease (Trounson, 1983; Leeton and Kerin, 1984). Nowadays, in most in vitro fertilization centers embryos are replaced between the 2-cell and 8-cell stage (Edwards and Purdy, 1982b; Feichtinger and Kemeter, 1985). As discussed in chapter 1.4.5, in the human synchrony between embryonic and maternal systems after ovulation is probably of minor importance to implantation. In other mammals, asynchrony between the embryonic developmental stage and the receptivity of the endometrium has been shown to affect profoundly the preimplantation events in the embryo. But aside from the progressing asynchrony, suboptimal (in vitro) culture conditions could affect embryonic metabolism as well, and consequently interfere with normal embryonic development at later stages. For example, Fishel et al (1983) hypothesized that in the preimplantation embryo culture conditions affect the release of products which are considered to play an important role in the regulation of implantation.

Proteins have been proven to be beneficial to embryonic development in vitro. Optimal conditions seem to be provided by whole serum (Saito et al, 1984). Investigations into the optimal composition of synthetic media have shown that serum proteins are able to compensate for deficiencies in media which had not been optimized (Ham, 1981). The composition of serum is complex as it contains substances released by various types of cells in the body. The primary role of serum in promoting cellular multiplication is to provide hormones and hormone-like factors ('growth factors'). Other proteins found stimulatory to multiplication are those that function primarily as carriers of essential substances. Many multiplication-promoting substances are present at concentrations that are too low to be detected directly by any means other than by determining their biological activity (Ham, 1981).

Results obtained in the present study are depicted in table III.6.1. This table shows the classification of fertilized ova in the control does according to age and stage of development: 24 hours after mating, i.e. about 12 hours after ovulation, most embryos were in the 2 -cell stage, 36 hours after mating in the 8 -cell stage, and after 48 hours most embryos were morulae. These findings are in agreement with the developmental classification reported by Adams (1956). Asynchronous cleavage of the blastomeres has been observed in normally fertilized ova: embryos consisting of three, five or seven blastomeres should not be considered abnormal (Hafez and Rajakoski, 1964; Bedford, 1971). Inequality in size of daughter blastomeres is frequently seen in embryos in which asynchronous cleavage is noted. Blastomeres which have already cleaved tend to be smaller than blastomeres which are about to undergo mitotic division. As cleavage proceeds, variation in developmental stage is encountered in embryos of the same age. Variation is more extensive between different females than between the embryos within the same mother (Bowman and 
McLaren, 1970). All these phenomena were observed in the present study also. The developmental stages in fertilized ova were expressed as the mathematical mean number of blastomeres in the embryos retrieved (table III.6.2). Comparison of embryonic development 24 and 36 hours after mating revealed no statistically significant differences in developmental stages between the operated, sham-operated and control does. Differences found were not permanent: tendencies noted 24 hours after mating could not be demonstrated to be present 36 hours after mating, and conversely. In the operated animals no significant differences existed between the developmental stages in embryos retrieved from the operated and from the contralateral control sides. In the operated does neither the extent of the reduction (20\% versus $80 \%$ ), nor the location of the resection (isthmus versus ampulla) did markedly influence the developmental stages at the intervals investigated (table III.6.2).

In addition embryonic developmental stages were expressed as percentages of embryos that contained a certain number of blastomeres, 24 and 36 hours after mating respectively (tables III.6.3 and III.6.4). Overall differences between the various groups of does were slight.

Although no statistically significant differences were encountered in the embryonic developmental stages, two consistent phenomena appeared to be present in the does investigated. First, more advanced cleavage stages were found in operated animals. In the control animals 24 hours after mating most embryos were in the 2-cell stage, $5.9 \%$ had cleaved further and had reached the 3-cell stage. Four- and 5-cell embryos were not encountered. After 36 hours upon mating the most advanced developmental stage found in the control does was the 8-cell stage. In all operated animals, i.e. the does subjected to sham-operations and in those with resection reanastomoses, developmental stages were found which had not yet been reached in the control animals: 4- and 5-cell after 24 hours post coitum and over 8-cell after 36 hours. With regard to these advanced cleavage stages no differences were noted between does which had been subjected to different surgical interventions, nor between the sides (i.e. operated or contralateral control oviduct) from which the embryos were recovered (tables III.6.3 and III.6.4). Second, embryonic development seemed to be influenced by the length of the postoperative recovery period: the overall embryonic development (depicted in table III.6.2) appeared to be more retarded 3 weeks as compared to 12 weeks after surgery. In the sham-operated does no marked correlation was found between embryonic cleavage rate and length of postoperative recovery period. In the animals subjected to a resection reanastomosis this retardation occurred in the operated as well as in the non-operated control sides, and in both sides to a comparable degree. The retardation in embryonic development was not related to the tubal segment resected.

From these observations it is tempting to suggest that embryonic cleavage is influenced by the surgical procedures performed. In all operated does more advanced cleavage stages were encountered, which suggests an acceleration in embryonic development. This is in agreement with the results obtained in a previous study (Evers et al, 1985). On the other hand, in the does in which tubal resections were 
performed, a temporary overall delay in embryonic development was found during the first postoperative weeks. Both phenomena were noted in the operated sides as well as in the contralateral control sides. This observation makes a local effect improbable. Severall hypotheses will be discussed which might contribute to the explanation for the altered cleavage patterns encountered in the present study.

In all operated does the most extensive trauma is probably provided by the flank incision. Peritoneal damage evokes various reactions. These include a secondary inflammatory reaction, which leads to an increase in vascular permeability. The resulting inflammatory fluid contains serum fractions and is rich in proteins. Degenerative changes occur in the area of the incision and the injured cells release a spectrum of substances. Injury of a certain tissue has been shown to release factors which stimulate mitosis in homologous tissues ( $R$ is, 1971). An early embryo consists of a few totipotential cells which are not yet differentiated. Mitosis stimulating substances, released by injured peritoneal cells, might exert influence upon an early embryo and modify its cleavage rate. The cleavage promoting effect observed in our study appeared to be active 3 weeks after surgery as well as after 12 weeks. No diminution in the cleavage promoting effect could be demonstrated. Mesothelium will regenerate within one week, and the underlying muscle in the next 2 weeks (Hubbard et al, 1967). Transport of proteins has been shown to take place from the maternal blood into ovarian follicles. Certain substances associated with tissue repair might be transported into the ovarian follicles and their effects may become manifest only later, in postovulatory oocytes. By this means peritoneal damage might be responsible for alterations in embryonic development at a time when wound healing is already complete.

Aside from the acceleration observed, a seemingly contradictory overall retardation in embryonic cleavage rate was noted in the does which had been subjected to a tubal resection reanastomosis. In these does a retardation was observed in embryos retrieved from their operated as well as from their contralateral control oviducts. In contrast, no marked delay was found in embryos recovered from the shamoperated does. These observations suggest the tubal intervention to be responsible for the effect, and its impact not to be restricted to the operated oviduct only. In the does in which retardation in embryonic cleavage was observed, more advanced cleavage stages (as described before) were noted concomitantly. If cleavage delay on the one hand, and acceleration on the other are brought about by the same deregulatory mechanism, one would expect to find retarded as well as accelerated developmental stages in the sham-operated animals as well. Consequently, the results obtained from our study support the hypothesis that embryonic cleavage retardation and cleavage acceleration are attributable to two distinct phenomena. Environmental factors do influence the rate of mitotic divisions. It seems plausible that tubal surgery temporarily alters the tubal fluid composition. Tubal trauma may give rise to the presence of various inflammatory products in tubal fluid and may alter its protein composition (Johnson, 1972; Bahrfield et al, 1976), thereby modifying embryonic development. As the same retardation was noted in embryos retrieved from 
the contralateral oviducts, the unfavourable environmental alterations have to be assumed to be effective there also. It is enigmatic why two interventions, which both elicit tissue trauma and wound healing processes, evoke apparently contradictory reactions in embryonic development. The kind of tissue injured may play a crucial role: tubal trauma may change tubal fluid composition more specifically and profoundly than peritoneal injury will. Oviductal embryonic development is modulated by its environment, and thus even subtle changes in tubal fluid constituents may exert their influence upon embryonic metabolism and cleavage. No correlation was found between either the extent or the localization of the tubal resection and the alterations in embryonic cleavage. This observation suggests that no particular tubal segment exerts indispensable effects on early embryonic development.

The ovulatory mechanism may have been influenced by abdominal surgery. If no extensive ovarian manipulation has been performed, the number of corpora lutea remains unaltered (discussed in chapter 4.2.1). Minor changes in the ovulatory process, however, not reflected in the number of ova released per ovulation, may have been brought about even by 'atraumatic' surgery. The interval between mating and ovulation may suffer alteration when ovulatory events are not optimally coordinated. Consequently, fertilization of ova very soon after their release, or late after ovulation, may give rise to developmental abnormalities. Variations in the mating-ovulation interval itself, however, are unlikely to be responsible for the alterations noted in the embryonic cleavage rate. Unless ovulation is retarded or accelerated for about one doubling period of the blastomeres, changes in the mating-ovulation interval cannot account for the alterations observed in the embryonic cleavage rate.

Although the mechanisms which regulate and modulate embryonic development remain uncertain, developmental acceleration or retardation may influence pregnancy outcome. The change in cleavage rate may reflect metabolic alterations, which might influence further development more profoundly. The acceleration or delay in cleavage rates found is slight during the period under investigation, but may well increase gradually with advancing gestation. An increasing discrepancy between embryonic development and uterine receptivity could give rise to embryonic loss at the implantational stage.

In summary: 24 and 36 hours after mating embryonic cleavage stages do not differ significantly in the operated does as compared to the controls. Two phenomena were noted, however: in does subjected to sham-operations and tubal resection reanastomoses more advanced cleavage stages were observed. Furthermore, in does subjected to tubal resection reanastomoses and mated 3 weeks after surgery the overall embryonic development was delayed as compared to embryonic development in does which were mated 12 weeks after surgery. 


\subsubsection{Degeneration}

Information on the incidence and etiology of degeneration in ova under physiological conditions and shortly after ovulation is scarce. In literature some reports (cited below) have been published on the loss of ova in the rabbit before implantation. In these studies laparotomies were performed 7-16 days after mating. The discrepancy found between the number of corpora lutea and implantations was defined as the loss of ova. The loss may have been due to failures in ovum pick-up, fertilization, cleavage or implantation. Halliday (1959) found in 67-79\% of does some loss to occur before implantation, which concerned $20-27 \%$ of ova ovulated. In studies by Adams (1960) 53.3\% of rabbits experienced some loss, which accounted for $9.7 \%$ of ovulations. In rabbits ovum degeneration can be evoked by various experimental conditions. It has been observed to occur in embryos placed prematurely in a progestational uterine environment (Adams, 1980), and in embryos prevented from entering the uterus at the appropriate time (Adams, 1958). Degeneration can be induced pharmacologically by altering tubal transport through application of estrogens (Chang and Yanagimachi, 1965) or of progesterone (Allen and Foote, 1973). These studies clearly indicate that synchronization of the embryo and its environment is a prerequisite for normal embryonic development in the rabbit. From in vitro fertilization programs it is known that fragmentation and degeneration are common sequelae of the attempted fertilization of immature human oocytes (Trounson et al, 1982).

Criteria of degeneration are yet to be established definitely. Discrepancy exists between morphological characteristics and actual viability: pregnancies have resulted from the transfer of embryos which contained normal blastomeres together with some fragmented blastomeres (Mohr and Trounson, 1984).

In our study ova were classified as degenerate if they showed one or more of the characteristics listed in chapter 2.1.8 (figure 2.4; page 65). In 160 does 1152 ova were retrieved, 666 from their right genital tracts and 486 from their left tracts. In the right sides $12.3 \%$ of the ova recovered met the criteria of degeneration, in the left sides $11.9 \%$ did. Most of the degenerate ova were unfertilized (table III.7.1).

The results which concern degenerate and fertilized ova exclusively are depicted in table III.7.2. In the right genital tracts 25 ova $(3.8 \%$ ) appeared both fertilized and degenerate. They were retrieved from 15 does. Fourteen does had 20 degenerate fertilized ova $(4.1 \%)$ in their left sides. Two rabbits had degenerate fertilized ova in both oviducts; in one of these two does all ova appeared to be degenerating. No differences were found in the percentage of fertilized degenerate ova between the operated, sham-operated and control animals (table III.7.2). In particular in does which had been subjected to isthmic resection reanastomoses, no significant increase in degeneration rate was found. This would have been expected in case the incidence of polyspermic fertilization would have been higher in these rabbits (chapter 4.2.4). There was neither a correlation of the rate of degeneration with the mating-autopsy 
interval, nor with the postoperative recovery period. The degeneration rate bore no significant correlation to body weight (table III.7.2).

The data from this study demonstrate that tubal resection reanastomoses do not influence the degeneration rate in embryos during the first 36 hours after ovulation. About half of all unfertilized ova are degenerating 48 hours after mating according to the criteria that were applied in this study.

\subsubsection{Mucin layer}

The rabbit is the sole placental mammal which has a thick mucopolysaccharide layer around the tubal ova (fugure 4.1; page 29). Estrogen has been demonstrated to be essential for the synthesis of mucus in the secretory cells in the tubal mucosa. After mating the mucus is released through the action of progesterone. Ova are supposed to play a completely passive role in the deposition of mucus, as mucin may coat any foreign object introduced into the oviduct (Greenwald, 1969).

In the present study the mucin layer surrounding the ova was measured 24,36 and 48 hours after mating. At these intervals the thickness of the mucin coat was not markedly different between ova retrieved from the right (control) oviducts in the operated does, the left and right tubes in sham-operated and control animals (table III.8.1): 24 hours after mating the mucin layer had a mean thickness of $7 \pm 13 \mu$, after 36 hours of $33 \pm 19 \mu$ and after 48 hours of $74 \pm 27 \mu$. Measurements were performed with a graduated eyepiece on the binocular stereo dissecting microscope. The eyepiece allowed accurate evaluation to $5 \mu$. Values obtained in the present study agree with those reported in literature (table IV.3).

In all unoperated oviducts the thickness of the mucin layer which surrounded the ova correlated with the time the ova had spent in the oviduct. The thickness was not significantly influenced by the distance traversed by the ova (table III.8.2): ova retrieved from the ampullary segment of unoperated oviducts had mucin coatings which did not differ significantly from the coatings which surrounded ova recovered from the isthmic segments after the same post coitum interval. Secretory cells of the ampulla and the isthmus have been described to differ morphologically and biochemically (Greenwald, 1969): as a consequence ampullary secretion products would not adhere to ova and coating of ova with mucus would be accomplished by isthmic secretory cells exclusively. The data from our study, however, indicate that in control oviducts mucin is deposited upon tubal ova in the ampulla as well as in the isthmus (table III.8.2).

Ova seem to play a passive role in the acquisition of a mucin layer. In the controll oviducts no correlation was found between the thickness of the mucin layer and the cleavage stage of the embryos at fixed intervals after mating. Fertilized and unfertilized ova had similar amounts of deposited mucin, and no significant difference was observed in mucin coating between degenerating and non-degenerating ova (table 


\begin{tabular}{lcc}
\hline Author & $\begin{array}{c}\text { Examined } \\
\text { (hours after mating) }\end{array}$ & $\begin{array}{c}\text { Mucin layer } \\
(\mu)\end{array}$ \\
\hline Greenwaild (1957) & 24 & 25.0 \\
& 48 & 70.5 \\
& 72 & 125.5 \\
Adams (1958) & 24 & $11.2 \pm 9.1$ \\
& 48 & $55.0 \pm 21.3$ \\
& 60 & $71.9 \pm 8.2$ \\
Present study & 72 & $102.8 \pm 17.2$ \\
& 24 & $7.3 \pm 13.2$ \\
& 36 & $32.7 \pm 19.0$ \\
\hline
\end{tabular}

III.8.2). The latter finding indicates that during early embryonic development ovum degeneration is unlikely to be caused by alterations in the thickness of the mucin layer.

Mucin production in the secretory mucosal cells is under estrogenic control. The follicle is the main source of ovarian estrogen in the rabbit (Eaton and Hilliard, 1971). Theoretically, the amount of mucin released after mating may be influenced by the number of follicles in the ovaries. In the present study no difference was found in the thickness of the mucin layers on ova retrieved from rabbits with five corpora lutea or less, and on ova retrieved from rabbits with 11 or more corpora lutea (table III.8.2). In conclusion, the amount of mucin deposited on ova under physiological conditions primarily depends on the time spent by the ova in the oviduct.

Table III.8.1 shows that in the operated oviducts the mucin deposition on the ova was reduced. The differences in thickness of the mucin layers between ova in the operated and unoperated contralateral oviducts reached a level of statistical significance 36 and 48 hours after mating. Comparison of mucin layer thickness between ova recovered from oviducts with an isthmic resection reanastomosis, from oviducts with an ampullary resection reanastomosis and from control oviducts was performed. From 24 hours after mating onwards mucin layer thickness was reduced in ova retrieved from ampullary resected oviducts. Mucin layer thickness on ova retrieved from isthmic resected oviducts did not differ from mucin coatings in control oviducts until 48 hours after mating. At this mating-autopsy interval mucin layer thickness on ova recovered from ampullary as well as isthmic resected oviducts was significantly less than mucin layer thickness on ova retrieved from control oviducts. Mucin layer thickness was evaluated also as related to ova retrieved from oviducts in which a $20 \%$ (ampullary or isthmic) resection reanastomosis or a $80 \%$ resection 
reanastomosis had been performed respectively. At 36 hours upon mating mucin layers on ova from oviducts with a $80 \%$ resection were thinner than mucin layers on ova from oviducts with a $20 \%$ resection reanastomosis. No differences were found at the other mating-autopsy intervals studied.

These results indicate mucin deposition upon tubal ova to be decreased in oviducts in which total secretory area has been reduced, irrespective of the fact whether an isthmic or an ampullary part was resected. Temporary differences were demonstrated to exist in mucin deposition after different kinds of resection reanastomosis. When the mucin layer thickness was measured shortly after mating, diminution of mucin deposition reached statistical significance only on ova recovered from oviducts in which $80 \%$ resections or ampullary resections had been performed. As the mating-autopsy interval lengthened, diminution of mucin deposition became statistically significant on ova from oviducts in which $20 \%$ resections or isthmic resections had been made as well.

During the embryonic period investigated, most ova were located in the ampullaryisthmic junction (chapter 4.2.8). Isthmic resections might exert less influence, or exert influence later on, because less ova were exposed to the isthmus. Comparison of mucin layer thickness on ova retrieved from rabbits subjected to isthmic resection reanastomoses, however, revealed no difference in mucin layer thickness between ova which were flushed from the ampullary segment and those flushed from the shortened isthmic segment. This indicates that isthmic reductions also influence mucin deposition upon ampullary ova. Consequently, ovum location is unlikely to be the factor responsible for the temporary differences found between the different resection reanastomoses performed. Greenwald (1969) reported a correlation to exist between the amount of mucin deposited upon tubal ova and the amount of mucin stored in the secretory epithelium. Ova may acquire their mucin investment by direct contact with the secretory cells in the tubal mucosa. But the reduction in mucin layer found on ampullary ova in oviducts with isthmic resections, suggests still another mechanism to be active. Secretory cells may extrude their mucin contents into the tubal fluid. Mucus released into the lumen may be transported by tubal peristalsis and ciliary beat and adhere to ova present, also those in the lateral parts of the oviduct. Coating may be carried out primarily either by tubal fluid or by secretory cell contact, or both mechanisms may be complementarily active.

No explanation can be offered for the initial differences observed in mucin deposition after resection reanastomoses of the isthmus and of the ampulla respectively, and after $20 \%$ and $80 \%$ resection reanastomoses respectively. Various hypotheses can be proposed: the secretory cells of the ampulla and the isthmus have been shown to differ both morphologically and biochemically (Greenwald, 1969). Qualitative differences in the mucin produced may cause differences in the mucin coating of ampullary and isthmic ova. Mucin storing capacity in secretory cells will determine the period during which mucin release, and subsequent deposition upon ova, will take place after mating. Differences in mucin storing capacity between secretory cells in ampulla and isthmus may account for the temporary discrepancies in coating 
observed. Mucin coating on ova may be influenced by the direction of ciliary beat and tubal peristalsis in the different segments. In the rabbit cilia in the ampulla beat towards the uterus, but ciliary currents in some parts of the isthmus have been shown to be pro-ovarian in direction (Gaddum-Rosse and Blandau, 1973, 1976). Differences in tubal fluid rheology may be responsible for (temporary) differences in mucin deposition on ova recovered from oviducts in which an ampullary or isthmic resection has been performed respectively. An additional factor which may be responsible for the temporary difference in mucin coating of ova, recovered from ampullary and isthmic resected oviducts respectively, is the apparent disturbance in ovum pick-up noted after ampullary resections (chapter 4.2 .2 ). The resulting delay of entrance of the ovum into the tubal lumen may shorten the time of exposure of the ovum to mucin deposition.

The length of the postoperative recovery period did not influence mucin deposition: comparison of mucin layer thickness between ova recovered 3 weeks and $\mathbb{1 2}$ weeks postoperatively revealed no significant differences. This demonstrates the reduction in mucin layer thickness found on ova in operated oviducts to be permanent, due to resection of secretory epithelium.

Various theories have been proposed to account for the role of the mucin layer surrounding rabbit ova. Hartman (1925) postulated that the coating is a primitive membrane, which is commonly found in Lagomorpha and Marsupials. Others have assigned a protective role to the mucin layer. Greenwald (1957) hypothesized that the mucin coat is involved in the expansion of the blastocyst. Binkerd and Anderson (1979) postulated it to aid in the process of implantation.

Authors who dealt with the role of the mucin layer have studied the fate of embryos with reduced mucin coatings. The reduction in mucin layer usually has been achieved by administration of estrogens to the donor doe, or by growing the embryos in vitro. The results obtained, i.e. a reduction in embryonic viability and in implantation rate, may be ascribed to the reduced mucin layer, but more probably reflect the unfavourable (artificially altered) conditions during early embryonic de velopment. The present study does not allow to draw a conclusion concerning the impact of reduced mucin layers upon embryonic development. The reduction may exert its influence, if any, later on. For this purpose observations on embryonic development will have to be performed past the implantation stage.

This study demonstrates that microsurgery is an alternative means for the acquisition of tubal ova with reduced mucin investments: in oviducts subjected to resection reanastomoses the amount of mucin deposited on ova is markedly reduced.

\subsubsection{Tubal transport}

Table III.9.1 shows that in the period under investigation, i.e. between 24 and 48 hours after mating, most ova were located in the ampullary-isthmic junction. Data 
published in literature concerning the position of ova in the rabbit oviduct agree that 24-48 hours after mating most ova are situated in the ampullary-isthmic junction (Longley and Black, 1968; Polidoro et al, 1973; Tsutsumi and Hafez, 1974).

In the present study the localization of fertilized ova in the sham-operated and control animals 24,36 and 48 hours after mating respectively, was found to be comparable. In the unoperated control oviducts of does which had been subjected to a tubal reanastomosis, the distribution of fertilized ova did not differ markedly from the distribution noted in the sham-operated and control animals (table III.9.2). In the reanastomosed oviducts, however, ovum transport differed. As tables III.9.1 and III.9.2 show, fertilized ova in ampullary resected oviducts, particularly in oviducts in which $80 \%$ resection reanastomoses had been performed, had passed through a shorter distance as compared to ova in isthmically resected oviducts and in control oviducts at all postovulatory intervals studied. No correlation was observed between the postoperative recovery period and the localization of ova. Ovum transport was not significantly influenced by the postoperative adhesion score.

Experimental work has offered evidence that it is mainly the activity of the cilia that effectuates ampullary ovum transport in rabbits. In the isthmus ovum transport is supposed to be mainly effectuated by muscular contractions. Ovarian steroids, prostaglandins and adrenergic nerves modulate tubal diameter by regulating muscular activity or subserosal venous plexus distention (chapter 1.4.6).

Healing processes in injured tubal tissue have been subjected to study. After macrosurgical transection, repair with serosal sutures of $4 / 0$ catgut and a stent left in situ for several weeks, a noticeable incidence of anatomic disturbances accurred (Khoo and Mackay, 1972; Mackay and Khoo, 1972). These included marked epithelial irregularities, degenerative changes in the myosalpinx and absence or reduction in the number of ciliated and secretory cells. The disturbances were observed until 6 weeks after surgery. Inflammatory reactions and fibroblastic proliferation were noted even 6 months after surgery if a stent was left in situ for that period of time. The microsurgical approach has been shown to avoid or minimize these problems through the use of relatively atraumatic surgery, non-reactive microsutures, meticulous apposition of tissue layers and avoidance of stents in the postoperative period. Cellular death is prevented to a great extent, and subsequently healing by scar tissue formation and fibrosis is limited. Eddy and Bajpai (1982) performed midampullary transection reanastomoses in rabbits by microsurgical methods, and histologically examined the oviducts afterwards. Tissue damage was restricted to within several millimeters of the anastomosis. The immediate responses to surgical trauma noted in the adjacent parts of the oviduct were cessation of secretory activity, deciliation and occurrence of tissue edema. These reactions reached a maximum during the first 3 postoperative days. Resolution of tissue edema, active ciliogenesis and resumption of secretory activity were present by day 7 . Two weeks after surgery a high degree of functional integration had been restored. Three weeks after microsurgical transection reanastomosis, oviducts were shown to exhibit normal generation of spontaneous action potentials adjacent to and across the sites of anastomoses in the am- 
pulla as well as in the isthmus (Archer et al, 1979).

Although functional continuity and electrophysiologic function seem to be restored shortly after (micro)surgery, irregularities in the mucosal pattern have been noted for a longer postoperative period. Scanning electron microscopic evaluation of isthmic anastomoses showed that postoperatively the mucosal fold pattern and the ciliated cells did not return to normal until after 3 months (Boeckx, 1982). Furthermore, the final restoration of oviductal mucosal architecture is dependent on the skillfulness of the surgeon: Boeckx (1982) observed in the early training period stenosis and persistent deepithelialization to occur in the majority of cases at the anastomosis site. In the ampulla the more complex and elongated mucosal folds have been noted not to rejoin completely after tubal reanastomosis. A persistent interdigitation of individually healed mucosal folds was observed across the anastomosis site by Eddy et al (1978).

Ovum transport across the ampulla is considered to be very fast. In the present study transport in reanastomosed ampullae appeared to be retarded (tables III.9.1 and III.9.2). As discussed in chapter 4.2.2 ampullary resection reanastomoses may interfere with ovum pick-up from the ovarian surface. This may delay or even prevent ovum entrance into the infundibulum. The time lag in ovulation and/or ovum pickup from the ovarium surface is unlikely to be the only factor responsible for the differences found in ovum transport into the ampullary-isthmic junction, since most ova reach this junction within several minutes after ovulation. As ovum transport in the ampulla is primarily brought about by ciliary beat, minor disturbances in ampullary mucosa (e.g. discontinuity between adjacent folds, deciliation by scar tissue formation) are likely to interfere with ovum propulsion. The localization of ova in the ampulla was not influenced by the length of the postoperative recovery period. This is in agreement with the reports on scanning electron microscopic evaluation mentioned above, which have provided evidence that tubal tissue healing after microsurgery takes place within the first 2-3 postoperative weeks. Tubal mucosal damage still present after that period has to be considered permanent.

Halbert et al (1981b) performed isthmic transection reanastomoses and observed a delay in ovum transport 63-65 hours after mating. Clearing of the genital tracts revealed that the anastomosis had detained most of the ova, although all oviducts were fully patent. They postulated the impediment to movement of ova to be due to the inability of the myosalpinx to dilate in the region of the anastomosis, due to minor fibrosis. In our study, during the mating-autopsy intervals investigated, transport of fertilized ova in isthmically resected and reanastomosed oviducts was not delayed. Ova seem to pass the anastomosis site without observable retardation. On the other hand, the results obtained from the isthmically resected and reanastomosed oviducts show no extreme acceleration of tubal transport to occur during the first 48 hours after mating either. The presence of even a small length of isthmus seems to be sufficient to achieve ovum retention and to prevent ova from entering into the uterus shortly after ovulation. These findings confirm the physiological sphincter function of the isthmus not to be confined to a localized segment (e.g. the 
ampullary-isthmic or utero-isthmic junction), but to occur along the length of the entire isthmus. Excision of the total isthmus, including the ampullary-isthmic and utero-isthmic junctions, has been reported to be associated with absolute infertility (McComb et al, 1981c).

Comparison of tubal transport between fertilized degenerate and fertilized nondegenerate ova revealed no marked differences (table III.9.1). With the exception of findings in the horse (Betteridge and Mitchell, 1974) it is generally accepted that fertilized and unfertilized ova are transported at the same rate in mammals. The results from the present study (table III.9.1) suggest unfertilized owa to be grouped less closely together during tubal transport as compared to the clusters which fertilized ova tend to form. Comparison of tubal location between fertilized and unfertilized ova at the individual mating-autopsy intervals showed a greater proportion of unfertilized ova to have been transported at a slower rate. Mean fertilization rates have been demonstrated to be reduced in operated oviducts, and particularly in ampullary operated oviducts (chapter 4.2.3). Thus of all unfertilized ova a relatively high proportion is recovered from oviducts in which an ampullary resection reanastomosis has been performed. Since in ampullary resected and reanastomosed oviducts tubal transport is delayed (table III.9.2), the retardation found in transport of unfertilized ova may (partly) arise from their more frequent recovery from oviducts with ampullary resection reanastomoses. The concomitant acceleration in tubal transport rate found in other unfertilized ova, however, cannot be explained only in terms of surgical procedures performed in the tubes from which the ova were retrieved. The data obtained in this study suggest unfertilized ova to be transported in a different manner as compared to tubal transport of fertilized ova. These findings provide evidence that tubal transport may be influenced by properties of the oviductal ova themselves.

The duration of ovum transport in the oviduct is considered to be critical. If entry into the uterus is delayed experimentally (e.g. by tubal ligation) ova fail to develop, and degenerate. On the other hand, ova placed prematurely during the early progestational phase into the uterus fail to survive, because they either are expelled or degenerate in situ (Adams, 1980). In our study (minor) variations in tubal transport were noted: ovum transport was retarded in ampullary operated oviducts. If this tendency is to become more pronounced during the remaining preimplantation period, it probably could influence embryonic development unfavourably, by providing an inappropriate tubal environment during early embryonic development or by producing asynchrony between the embryo and the endometrium as well.

\subsubsection{Fecundity}

After resection reanastomosis the residual length of the oviduct has been shown to correlate with the pregnancy rate. In the human, after reanastomosis for reversal 
Table IV.4

Fecundity after tubal surgery in the rabbit:

Expected embryonic loss based on data from the present study (24-48 hours after mating) 3 weeks and 12 weeks postoperatively and embryonic loss noted by Boeckx (1982) 3 weeks after operation and 10 days after mating

\begin{tabular}{|c|c|c|c|c|c|c|}
\hline \multirow[t]{2}{*}{$\begin{array}{l}\text { Surgical } \\
\text { procedure }\end{array}$} & \multirow{2}{*}{$\begin{array}{c}\text { Recovery } \\
\text { rate } \\
\\
\%\end{array}$} & \multicolumn{2}{|c|}{$\begin{array}{c}\text { Expected } \\
\text { fertilization } \\
\text { rate }\end{array}$} & \multicolumn{2}{|c|}{$\begin{array}{c}\text { Expected } \\
\text { embryonic } \\
\text { loss }\end{array}$} & \multirow{2}{*}{$\begin{array}{c}\text { Embryomic } \\
\text { loss } \\
\text { Boeckx (1982) } \\
\%\end{array}$} \\
\hline & & $\begin{array}{c}3 w k \\
\%\end{array}$ & $\begin{array}{c}12 w k \\
\%\end{array}$ & $\begin{array}{c}3 w k \\
0 \%\end{array}$ & $\begin{array}{c}12 w k \\
\%\end{array}$ & \\
\hline 201 & 92.1 & 73.2 & 75.6 & 26.8 & 24.4 & 35 \\
\hline $80 \mathrm{I}$ & 97.2 & 74.2 & 77.0 & 25.8 & 23.0 & 60 \\
\hline $20 \mathrm{~A}$ & 62.7 & 34.2 & 61.1 & 65.8 & 38.9 & 55 \\
\hline $80 \mathrm{~A}$ & 64.5 & 42.6 & 57.3 & 57.4 & 42.7 & 100 \\
\hline
\end{tabular}

of sterilization, a tube with an extrauterine length of $3 \mathrm{~cm}$ or less gives a poor prognosis (Silber and Cohen, 1980; Winston and Margara, 1980).

The impact of tubal resection reanastomosis on pregnancy outcome in the rabbit has been studied by McComb and Gomel (1979). A significant correlation was found between the remaining tubal length and the number of implantations: more than $47 \%$ of an oviduct must remain intact lateral to the utero-isthmic junction for implantations to occur. Boeckx (1982) performed tubal resection reanastomoses and determined 3 weeks after surgery the number of uterine implantations 10 days after mating. The nidation index was calculated, i.e. the number of implantations divided by the number of ovulations multiplied by one hundred. In does which had been subjected to $20 \%$ and $80 \%$ isthmic resection reanastomoses respectively, the mean nidation index on the operated sides was $65 \%$ and $40 \%$ respectively. In animals which had undergone $20 \%$ or $80 \%$ ampullary resections the mean nidation index found was $45 \%$ and $0 \%$ respectively. In the contralateral control sides the mean nidation index was above $70 \%$.

The results obtained in this study cannot explain the obvious embryonic loss which was noted 10 days after mating by Boeckx (table IV.4). As discussed above, most differences between experimental and control animals found in our study appeared to be only minor. Furthermore, most differences observed were not clearly restricted to a particular type of resection reanastomosis. All our observations were done within 48 hours after mating. Tendencies, which could be shown to exist in the period investigated, may become more pronounced as time elapses. For example, the variations noted in cleavage rate and ovum transport in reanastomosed oviducts may become more evident, and consequently give rise to asynchrony between em- 
bryonic development and endometrial receptivity at the moment of implantation. As embryonic development proceeds, new phenomena, unnoticed during earlier stages, may become obvious. The transition from morula into blastocyst is considered to be criticall, and unfavourable conditions prevailing during previous stages of embryonic differentiation may become manifest in this developmental stage only. In conclusion: the poor pregnancy outcome, particularly in does subjected to $80 \%$ ampullary resection reanastomoses, which has been reported (Boeckx, 1982), cannot be explained by the alterations in early embryonic development found in the present study. Further research into embryonic development in the microsurgically altered oviduct beyond the first 48 hours after ovulation will have to be done.

\subsection{Conclusions}

- Ovulatory function may be influenced by intraabdominal surgery. In the rabbit the number of corpora lutea per ovulation is considered to reflect ovulatory function. No significant decrease in the number of corpora lutea was found in the animals operated in the present study.

- In ampullary reanastomosed oviducts the ovum recovery rate was decreased to a mean value of $63.7 \%$, probably due to disturbances in ovum pick-up from the ovarian surface or from the peritoneal cavity. Peritoneal transmigration is likely to occur in ampullary operated does: a portion of ova lost from the experimental side may be picked up by the contralateral control side.

No decrease was found in ovum recovery rates in oviducts in which an isthmic reduction had been performed.

- Fertilization was expressed as $0 \%$-fertilization rate (i.e. the proportion of does without fertilized ova among the ova recovered) or as $1-90 \%$-fertilization rate (i.e. the proportion of does which had between one and $90 \%$ of their ova fertilized).

The proportion of does which had a $0 \%$-fertilization rate was significantly greater 3 weeks after surgery than 12 weeks after surgery. After 3 weeks does may exhibit disturbances in mating behaviour because of abdominal discomfort due to the flank wound.

In the rabbit the normal fertilization rate is over $90 \%$. After tubal resection reanastomoses, particularly after ampullary resections, fertilization rates decreased. The decrease was more pronounced in the operated side, but fertilization was affected in the contralateral control side as well. A correlation between fertilization rate and postoperative recovery period, localization and extent of tubal tissue trauma is suggested. The fertilization rate may also reflect in part ovulatory (dys)function. Minor changes which do not affect the number of ova released (corpora lutea) may disturb the delicate process which finally results in fertilization. 
- After extensive isthmic resections the number of spermatozoa that had penetrated the outer ovam investments was greater than the sperm numbers after other types of resection reanastomoses and than the one in control does. Although this may indicate that more spermatozoa are present at the site of fertilization, the number of spermatozoa that had entered into the perivitelline space was not markedly increased.

In some unfertilized ova spermatozoa were identified in the perivitelline space. This suggests that in the operated oviducts viable spermatozoa were incapable of fertilization. This led to the hypothesis that disturbances in fertilization may be primarily due to alterations in the oocyte. Abdominal surgery may induce changes at follicular level, in the mating-ovulation interval or in the tubal fluid composition, each of which could impair the fertilizability of the oocyte.

After 24 hours upon mating the number of spermatozoa in the tubal ova retrieved did not increase. This suggests the process of fertilization to be restricted in time.

- In does subjected to tubal reanastomoses overall embryonic cleavage was noted to be slightly delayed 3 weeks after surgery, as compared to cleavage stages 12 weeks postoperatively. Simultaneously, however, in all sham-operated and reanastomosed oviducts, farther advanced cleavage stages were observed, which were not seen in the control animals.

Factors which modulate and regulate cleavage in mammalian ova are poorly understood. Substances present in tubal fluid and 'growth factors' involved in tissue repair after surgery may play a role in the (dys)regulation of embryonic cleavage.

- Degeneration of fertilized oocytes was neither caused by tubal interventions, nor by abdominal surgery.

- Tubal ova in Lagomorpha are surrounded by a mucin layer. The thickness of this layer is primarily correlated to the time ova have spent in the oviduct. Coating takes place in the ampulla as well as in the isthmus and in both tubal segments to about the same extent. The significance of the mucin layer is unknown.

The thickness of the mucin coating was reduced in ova recovered from reanastomosed oviducts. Microsurgery is preferable to pharmacologic methods in order to study the impact of reduced mucin investments on early embryonic development.

- Tubal ovum transport was delayed in ampullary reanastomosed oviducts. Mucosall irregularities, which interfere with normal ampullary transport by cilia activity, may account for the delay noted in ovum transport in ampullary operated oviducts. No changes were noted in isthmically operated oviducts, in particular no acceleration was found after $80 \%$ isthmic resection reanastomoses: no ova had entered the uterus within 48 hours after mating. This observation indicates that even a small segment of isthmus is sufficient to prevent premature ovum entrance into the uterus. 
Fertilized and unfertilized ova were transported at differing rates. This suggests tubal transport to be influenced by properties of owiductal ova.

- A poor pregnancy outcome has been reported in does subjected to extensive tubal resection reanastomoses (Boeckx, 1982). This significant decrease in fecundity cannot be explained by the (minor) alterations in early embryonic development which were observed in our study.

Further research needs to be done into embryonic development in the microsurgically altered oviduct beyond the first 48 hours after ovulation that have been object of this study. Especially the delicate processes of implantation deserve further attention. The events taking place at ovulation should be investigated accurately in rabbits subjected to microsurgical tubal intervention, since ovulation seems to be a crucial point in embryonic development. Minor variations in the final phase of follicular maturation and in the ovulatory process are likely to influence subsequent fertilization and embryonic cleavage.

Further experimental laboratory work is a prerequisite for the identification of the critical parameters in anatomical and functional repair after tubal surgery. The rabbit model is imperfect in so far as it does not entail resection of tissue followed by an intervening period between transection and subsequent repair. Experimental work on rabbits, however, will contribute to the solution of the problem why pregnancy rates do not equal patency rates, even in oviducts with untouched mucosa. Research into the impact of tubal intervention on tubal processes will provide a better understanding of tubal physiology and embryonic development. This understanding in basic reproductive processes is a prerequisite for future improvements in reconstructive tubal microsurgery and in vitro fertilization. 


\section{Summary}

Recent advances in (micro)surgical techniques generally permit satisfactory reconstruction of damaged Fallopian tubes and restoration of pelvic anatomy. But although technical improvement has resulted in increased success in restoring tubal patency, proportional restoration of normal function has not been achieved: a remarkable discrepancy exists between tubal patency rates and pregnancy rates. In order to study the critical length and the relative importance of various segments of the oviduct in reproductive processes, microsurgical resection reanastomoses have been performed in the rabbit, and pregnancy outcome has been evaluated afterwards. Most authors agree about fecundity to be depressed after a tubal resection reanastomosis. This study was undertaken to examine the impact of microsurgically altered tubal conditions upon early embryonic development in the rabbit, to identify some of the factors which could be responsible for the embryonic loss reported in literature.

In Dutch belted rabbits four different types of microsurgical tubal resection reanastomosis were performed, i.e. $20 \%$ isthmic, $80 \%$ isthmic, $20 \%$ ampullary and $80 \%$ ampullary resections. Care was taken to leave untouched the fimbriae and the utero-isthmic junction. The does were mated either 3 weeks or 12 weeks after surgery. The animals were sacrificed and autopsies were performed either 24,36 or 48 hours after mating respectively, and the oviducts were flushed to retrieve the embryos. Parameters concerning early embryonic development were studied. The results obtained in the operated sides were compared to those obtained from the contralateral control sides in the operated animals, to those obtained from sham-operated does and to those from unoperated control does.

No significant decrease was found in the number of corpora lutea in the operated animals. This indicates that ovulatory function was not interfered with by the intraabdominal surgery.

In ampullary reanastomosed oviducts the ovum recovery rate was decreased, probably due to disturbances in ovum pick-up from the ovarian surface or from the peritoneal cavity.

Mean fertilization rates decreased after tubal resection reanastomoses, particularly in does mated 3 weeks after surgery and in does which had been subjected to ampullary resections. A decrease in fertilization may be due to inadequate copulation, disturbances in sperm transport or interference with the processes involved in fertilization itself.

Extensive isthmic resections increased the number of spermatozoa that penetrated the outer ovum investments. The number of spermatozoa that had entered into the perivitelline space, however, was not increased. 
In does subjected to tubal reanastomoses overall embryonic cleavage was noted to be slightly delayed 3 weeks after surgery. Simultaneously, in all reanastomosed and sham-operated oviducts some further advanced cleavage stages were observed; these were not found in control animals. Substances present in tubal fluid and 'growth factors' involved in tissue repair after surgery may play a role in (dys)regulation of embryonic cleavage.

Degeneration of fertilized oocytes was not caused by tubal interventions, nor by abdominal surgery.

In rabbits tubal ova are surrounded by a mucin layer. It was shown that the thickness of the mucin layer is primarily correlated to the time ova have spent in the oviduct, and that coating takes place in the ampulla as well as in the isthmus. The thickness of the mucin coating was reduced in ova recovered from reanastomosed oviducts.

Tubal ovum transport was delayed in ampullary reanastomosed oviducts. Mucosal irregularities, which interfere with normal ampullary transport by cilia activity, may account for the delay. No changes in tubal transport were noted in isthmically operated oviducts, in particular no acceleration was found. Even a small residual segment of isthmus seems to prevent premature ovum entrance into the uterus.

A poor pregnancy outcome has been reported in literature to be found in does subjected to extensive tubal resection reanastomoses. This significant decrease in fecundity cannot be explained by the minor alterations in early embryonic development during the first 48 hours following mating which were observed in this study. 
Ontwikkelingen van de laatste jaren binnen de (micro)chirurgie hebben ertoe bijgedragen dat doorgaans bevredigend continuilteitsherstel mogelijk is bij operaties aan afgesloten eileiders. Hoewel de technische verfijning heeft geresulteerd in een toename van het aantal doorgankelijke eileiders, heeft het postoperatief bereikte functionele herstel daarmee geen gelijke tred gehouden: er bestaat een verschil tussen het aantal geopereerde patiënten bij wie doorgankelijkheid van de eileiders bewerkstelligd wordt en het aantal patiënten dat uiteindelijk zwanger wordt. Dierexperimenteel onderzoek is gedaan naar de rol van de lengte en de invloed van de verschillende delen van de eileider op processen betrokken bij de voortplanting. In het konijn zijn inkortingen van de eileider verricht, en is het aantal innestelingen of het aantal geboren jongen na operatie bestudeerd. Uit de literatuur blijkt dat na eileider-inkortingen bij het konijn het aantal jongen per worp afneemt. In dit onderzoek is de vroeg-embryonale ontwikkeling bestudeerd bij konijnen die een microchirurgische inkorting van een eileider ondergaan hadden. Het doel was om in dit model faktoren te bestuderen die (mede)verantwoordelijk zouden kunnen zijn voor de afname van het zwangerschapspercentage zoals dat in de literatuur wordt opgegeven na inkortingen, c.q. hersteloperaties van de eileiders.

In Hollander-konijnen werden met behulp van microchirurgische technieken vier verschillende soorten inkortingen van de eileider verricht, n.l. een $20 \%$ isthmische, $80 \%$ isthmische, $20 \%$ ampullaire of $80 \%$ ampullaire inkorting. De fimbriae en de utero-isthmische overgang werden intakt gelaten. De konijnen werden of 3 weken òf 12 weken na operatie gekoppeld, en 24,36 of 48 uur na koppelen gedood. Hierna werden de embryos verzameld door de eileiders uit te spoelen. Kenmerken met betrekking tot de vroeg-embryonale ontwikkeling werden vastgelegd. De gegevens verkregen uit de geopereerde zijden werden vergeleken met die uit de tegenover gelegen niet-geopereerde zijden, en met gegevens uit zowel sham-geopereerde controledieren als niet-geopereerde controledieren.

Het aantal corpora lutea (ovulatiestigmata) was niet verminderd in de geopereerde dieren. Het ovulatiemechanisme bleek niet ongunstig beïnvloed te worden door de operatie.

Het aantal embryos dat werd gevonden bij spoelen, vergeleken met het aantal corpora lutea in het ovarium aan dezelfde zijde (de recovery rate), was het laagst bij ampullair ingekorte eileiders. Dit zou veroorzaakt kunnen worden door stoornissen in de opvang van de eicel van het ovariumoppervlak of uit het cavum Douglasi.

Het gemiddelde bevruchtingspercentage nam af na inkortingen, met name in die dieren die 3 weken na operatie gekoppeld waren en in die dieren die een ampullaire inkorting ondergaan hadden. Vermindering van het aantal bevruchtingen kan ver- 
oorzaakt worden door stoornissen bij het koppelen, stoornissen in transport van zaadcellen of verstoring van bij de versmelting van de gameten betrokken processen.

$\mathrm{Na}$ uitgebreide isthmische inkortingen werden meer zaadcellen in de zona pellucida waargenomen, maar het aantal zaadcellen dat doorgedrongen was in de perivitelline ruimte was niet duidelijk toegenomen.

Bij onderzoek 3 weken na operatie bleek in het algemeen de delingssnelheid van embryos afkomstig uit ingekorte eileiders enigszins vertraagd. Tegelijkertijd werden in ingekorte en sham-geopereerde eileiders ook embryos aangetroffen welke in een verder gevorderd delingsstadium waren dan de embryos in de controledieren. Tubavloeistof zou componenten en "groeifactoren"' kunnen bevatten die betrokken zijn bij helingsprocessen en die de embryonale deling zouden kunnen verstoren.

Degeneratie van bevruchte eicellen leek niet te worden beïnvloed door de verrichte ingrepen.

Eicellen van konijnen worden in de eileider omgeven door een slijmlaag. De dikte van deze omringende laag wordt hoofdzakelijk bepaald door de tijd welke de eicellen in de eileider doorbrengen. De afzetting vindt zowel in de ampulla als in de isthmus plaats. Eicellen afkomstig uit ingekorte eileiders hadden dunnere slijmlagen.

In ampullair ingekorte eileiders was het transport van eicellen vertraagd. Onregelmatigheden in de mucosa ten gevolge van de operatie kunnen de werking van de trilhaardragende cellen (welke hoofdzakelijk zorg dragen voor het transport van eicellen door de ampulla) ongunstig beïnvloeden en het transport vertragen. In eileiders met isthmische inkortingen werd geen verandering in transport waargenomen, met name bleek geen versnelling op te treden. Ook kleine delen isthmus lijken vroegtijdige aankomst van eicellen in de baarmoeder te kunnen voorkomen.

In de literatuur wordt beschreven dat bij konijnen met uitgebreide inkortingen van de eileider het aantal jongen per worp sterk afneemt. Deze grote vermindering kan niet verklaard worden met de (geringe) veranderingen in de vroeg-embryonale ontwikkeling zoals die in dit onderzoek tijdens de eerste 48 uur na de koppeling zijn waargenomen. 
Viime vuosina kehittyneen mikrokirurgian avulla on käynyt mahdolliseksi saavuttaa tyydyttäviä tuloksia tukkeutuneiden munatorvien hoidossa. Mutta vaikka paremmalla tekniikalla saadaankin avoimien munatorvien lukumäärä nousemaan, ei niiden toimintakyky kehity leikkauksen jälkeen yhtä suotuisasti. On näet olemassa huomattava ero toisaalta onnistuneen leikkauksen läpikäyneiden ja toisaalta leikkauksen jälkeen raskaiksi tulleiden potilaiden lukumäärässä. Eläinkokeilla on tutkittu sekä munatorven pituuden että sen eri osien vaikutusta hedelmöittymisprosessiin. Kaneille on suoritettu munatorven lyhennyksiä ja tutkittu leikkauksen jälkeen kiinnittyneiden munasolujen tai poikasten lukumäärä. Kirjallisuudesta ilmenee, että kaneilla munatorven lyhennysleikkauksen jälkeen poikasten lukumäärä pesuetta kohden pienenee. Tässä tutkimuksessa syvennyttiin erikoisesti varhaisembryon kehitykseen kaneilla, joille oli suoritettu munatorven lyhennys mikrokirurgisin keinoin. Tarkoituksena oli koettaa löytää joitakin tekijöitä jotka voisivat aiheuttaa kirjallisuudessa mainitun lyhennysleikkausten jälkeisen embryohukan.

Hollantilaisrotuiselle kanille suoritettiin mikrokirurgista tekniikkaa apuna käyttäen neljä erilaista munatorven lyhennysleikkausta nim. 20\%:n istminen, 80\%:n istminen, 20\%:n ampullaarinen tai 80\%:n ampullaarinen lyhennys. Fimbriat ja utero-istminen liittymäkohta jätettiin koskematta. Kanien annettiin paritella kun joko 3 viikkoa tai 12 viikkoa leikkauksesta oli kulunut. Kanit lopetettiin 24,36 tai 48 tuntia parittelun jälkeen ja embryot kerättiin talteen munatorvia huuhtellemalla. Nyt tarkastettiin erikoisesti varhaisembryoiden kehitysvaihetta operoiduilla puolilla ja verrattiin sitä vastakkaisilla, ei operoiduilla puolilla tavattujen embryoiden kehitysvaiheeseen sekä myös valeoperoitujen kontrollikanien ja tyystin operoimattomien kontrollikanien embryoiden kehitykseen.

Operoitujen eläinten corpus luteum-määrä ei ollut vähentynyt, joten leikkauksella ei näyttänyt olleen epäsuotuisaa vaikutusta ovulatiomekanismiin.

Huuhtelun avulla saatujen embryoiden lukumäärä verrattuna corpus luteum lukumäärään saman puolen ovariossa (recovery rate) oli alhaisin ampullaarisesti lyhennetyissä munatorvissa. Tämä voisi johtua vastaanottohäiriöistä munasolun saapuessa ovarion pinnalta tai cavum Douglasista.

Hedelmöittymisprosentin keskiarvo pieneni lyhennysleikkauksien jälkeen etenkin niiden eläinten kohdalla, joiden parittelu oli tapahtunut 3 viikkoa leikkauksen jälkeen sekä niiden kohdalla, joille oli suoritettu ampullaari-osan lyhennys. Hedelmöittymisten lukumäärän väheneminen voi johtua riittämättömästä parittelusta, sperman kulkuhäiriöistä tai itse solujen yhtymisprosessissa tapahtuneista häiriöistä.

Laajojen istmus-osaleikkausten jälkeen havaittiin runsaammin siittiösoluja munasolun ulkokerroksessa. Sensijaan perivitelliniini-tilaan tunkeutuneiden siittiösolujen lukumäärä ei ollut lisääntynyt. 
Lyhennetyissä munatorvissa kehittyneiden embryoiden jakaantumisnopeus osoittautui 3 viikkoa leikkauksen jälkeen hieman hidastuneeksi. Samanaikaisesti tavattiin lyhennetyissä ja valeleikatuissa munatorvissa embryoita, jotka olivat edistyneet jakaantumisvaiheessaan pitemmälle kuin kontrollieläinten embryot. Tubassa olevassa nesteessä voi olla aineita ja "kasvutekijöitä", jotka kuuluvat operoidun kudoksen paranemisvaiheeseen ja jotka voivat häiritä embryon jakautumista.

Suoritetut leikkaukset eivät näyttäneet aiheuttavan degeneroitumista hedelmöittyneissä munasoluissa.

Kanien munasolujen ympärille muodostuu munatorvessa limakerros. Sen paksuus riippuu ajasta, jonka munasolut viipyvät munatorvessa. Limakerros muodostuu sekä ampullaari- että istmus-osassa. Lyhennetyistä munatorvista peräisin olleilla munasoluilla limakerros oli ohuempi.

Ampullaari-osasta lyhennetyissä munatorvissa oli munasolujen läpikulku hidastunut. Leikkauksesta johtuvat limaerityksen epäsäännöllisyydet voivat vaikuttaa epäedullisesti värekarvoihin (jotka pääasiassa huolehtivat munasolujen kulusta ampullan läpi) ja hidastaa läpikulkua. Istmus-osasta lyhennetyissä munatorvissa ei todettu läpikulun muutoksia, erikoisesti nopeutumista ei todettu. Pienetkin istmusosat näyttävät voivan estää munasolun liian aikaisen tulon uterukseen.

Kirjallisuudessa todetaan, että kaneilla, joille on suoritettu laajoja munatorwilyhennyksiä, poïkasten lukumäärä pesuetta kohden huomattavasti pienenee. Näin suurta lukumäärän piennemistä ei voida selittää niìn vähäisillä muutoksilla embryon varhaiskehityksessä, jotka todettiin tässä tutkimuksessa ensimmäisten 48 tunnin aikana parittelun jälkeen. 


\section{Literature}

Adams, CE

A study of fertilization in the rabbit: the effect of post-coital ligation of the fallopian tube or uterine horn

J. Endocrinol. 1956, 13: 296-308

Adams, $\mathrm{CE}$

Egg development in the rabbit: the influence of post-coital ligation of the uterine tube and of ovariectomy

J. Endocrinol. 1958, 16: 283-293

Adams, $\mathrm{CE}$

Studies on prenatal mortality in the rabbit, Oryctolagus cuniculus: the amount and distribution of loss before and after implantation

J. Endocrinol. 1960, 19: 325-344

Adams, $C E$

Asynchronous egg transfer in the rabbit

J. Reprod. Fertil. 1974, 35: 613-614

Adams, CE

Consequences of accelerated ovum transport including a re-evalution of Estes: operation

J. Reprod. Fertil. 1979, 55: 239-246

Adams, CE

Retention and development of eggs transferred to the uterus at various times after ovulation in the rabbit

J. Reprod. Fertil. 1980, 60: 309-315

Adams, $C E$, Chang, $M C$

The effect of delayed mating on fertilization in the rabbit

J. Exp. Zool. 1962a, 151: 155-158

Adams, CE, Chang, MC

Capacitation of rabbit spermatozoa in the fallopian tube and in the uterus

J. Exp. Zool. 1962b, 151: 159-166

Afzelius, BA, Camner, P, Mossberg, B

On the function of cilia in the female reproductive tract

Fertil. Steril. 1978, 29:72-74

Ahlgren, $M$

Sperm transport to and survival in the human fallopian tube

Gynecol. Invest. 1975, 6: 206-214

Aitken, R.J

Changes in the protein content of mouse uterine flushings during normal pregnancy and delayed implantation, and after ovariectomy and oestradiol administration

J. Reprod. Fertil. 1977, 50:29-36

Aitken, RJ

Tubal and uterine secretions; the possibilities for contraceptive attack

J. Reprod. Fertil. 1979, 55: 247-254

Allen, MC, Foote, RH

The effect of progesterone on the early dewelopment of the rabbit embryo

Fertil. Steril. 1973, 24: 220-226 
Alvarez-Sanchez, F, Segal, SJ, Brache, V, Adejuevon, CA, Leon, P, Faundus, A Pituitary-ovarian function after tubal ligation

Fertil. Steril. 1981, 36: 606-609

Archer, DR, Eddy, CA, Pauerstein, CJ

Electrophysiology of the rabbit oviduct following tubal microsurgery

Fertil. Sterill. 1979, 31: 423-427

Aref, I, Hafez, ESE, Kamar, GAR

Post coital prostaglandins, in vivo oviductal motility and egg transport in rabbits

Fertil. Sterill. 1973, 24: 671 676

Arronet, GH, Eduljee, SY, O'Brien, $J \mathbb{R}$

A nine-year survey of fallopian tube dysfunction in human infertility

Fertil. Sterill. 1969, 20: 903-918

Arthur, AT, Chang, MC

Induction of blastokinin by oral contraceptive steroids: implications for fertility control

Fertil. Steril. 1974, 25:217.221

Arthur, AT, Daniel, JC

Progesterone regulation of blastokinin production and maintenance of rabbit blastocysts transferred into uteri of castrate recipients

Fertil. Steril. 1972, 23: 115-122

Asch, RH

Laparoscopic recovery of sperm from peritoneal fluid in patients with negative or poor Sims-Hühmer test

Fertil. Steril. 1976, 27: 1111-1114

Assen, FJJ van

A simple scoring system to determine the operability and prognosis in tubal surgery

Fertil. Steril. 1977, 28: 285

Atger, M, Milgrom, $\mathrm{E}$

Progesterone-induced messenger RNA. Translation, purification, and preliminary characterization of uteroglobin mRNA

J. Biol. Chem. 1977, 252: 5412-5418

Austin, $\mathrm{CR}$

The "capacitation' of the mammalian sperm

Nature (Lond.) 1952, 170: 326

Austin, CR

Capacitation of spermatozoa

lint. J. Fertil. 1967, 12: 25-31

Austin, CR

Sperm fertility, viability and persistance in the female tract

J. Reprod. Fertil. 1975a, suppl. 22: 75-89

Austin, CR

Membrane fusion events in fertilization

J. Reprod. Fertil. 1975b, 44: 155-166

Austin, CR, Braden, AWH

Early reactions of the rodent egg to spermatozoon penetration

J. Exp. Biol. 1956, 33: 358-365

Barfield, MA, Stambaugh, R, Mastroianni, L jr, Storey, BT

Factors in dirninution of uteroglobin secretion in the rabbit

Fertil. Steril. 1976, 27: 39-46

Bedford, JM

Ultrastructural changes in the sperm head during fertilization in the rabbit

Am. 1. Anat. 1968, 123: 329-358 
Bedford, JM

Sperm capacitation and fertilization in mammals

Biol. Reprod. 1970, suppl.2: 128-158

Bedford, JM

Techniques and criteria used in the study of fertilization

In: Methods in mammalian embryology

Daniel, JC, ed

WH Freedman and Company, San Francisco, 1971

Bedford, JM

Form and function of eutherian spermatozoa in relation to the nature of egg vestments

In: Fertilization of the human egg in witro

Beier, HM, Lindner, HR, eds

Springer-Verlag, New York, 1983

Bedford, JM, Cross, NL

Normal penetration of rabbit spermatozoa through a trypsin- and acrosin-resistant zona pellucida

J. Reprod. Fertil. 1978, 54: 385-392

Beier, HM

Uteroglobin: a hormone-sensitive endometrial protein inwolwed in blastocyst development

Biochim. Biophys. Acta 1968, 160: 289-291

Beier, HM

Oviductal and uterine fluids

J. Reprod. Fertil. 1974, 37; 221-237

Beier, HM

Die Entwicklung der Blastocyste: Differenzierung vom Embryoblast und Trophoblast

Anat. Ges. 1979, 73: 353-378

Beier, HM

Uteroglobin and other endometrial proteins: biochemistry and biological significance in beginning pregnancy

In: Proteins and steroids in early pregnancy

Beier, HM, Karlson, $\mathrm{P}$, eds

Springer-Verlag, New York, 1982

Beier, HM, Beier-Hellwig, K, Delbos, R

Hormones and proteins involved in uterine preparation for implantation

In: Fertilization of the human egg in vitro

Beier, $H M$, Lindner, $H R_{\text {, eds }}$

Springer-Verlag, New York, 1983b

Beier, HM, Maurer, RR

Uteroglobin and other proteins in rabbit blastocyst fluid after development in vivo and in vitro

Cell Tiss. Res. 1975, 159:1-10

Beier, HM, Mootz, U, Fischer, B, Ströbele-Müller, R.

Growth and differentiation of rabbit blastocysts in defined culture media

In: Fertilization of the human egg in witro

Beier, HM, Lindner, HR, eds

Springer-Verlag, New Y'ork, 1983a

Berger, GS, Radwanska, E, Hammond, JE

Possible ovulatory deficiency after tubal ligation

Am. J. Obstet. Gynecol. 1978, 132: 699-700

Betteridge, KJ, Mitchell, D

Direct evidence of retention of unfertilized ova in the oviduct of the mare

I. Reprod. Fertil. 1974, 39: 145-148

Beyth, Y, Winston, RML

Ovum capture and fertility following microsurgical fimbriectomy in the rabbit

Fertill. Sterill. 1981, 35: 464-466 
Binkerd, PE, Anderson, GB

Transfer of cultured rabbit embryos

Gamete Res. 1979, 2: 65-73

Bishop, DW

Active secretion in the rabbit oviduct

Am. J. Physiol. 1956, 187: 347-352

Blair, WD, Beck, LR

Demonstration of post ovulatory sphincter action by the isthmus of the rabbit oviduct

Fertil. Sterill. 1976, 27: 431-441

Blandaw, $\mathbb{R J}$

Observing ovulation and egg transport

In: Methods in mammalian eimbryology

Daniel, JC, ed

WH Freman and Co, San Francisco, 1971

Blandau, IIR

Mechanism of tubal transport - comparative aspect

In: Reversibility of female sterillization

Brosens, IA, Winston, RWL, eds

Academic Press, London, 1978

Blandau, RJ

In vitro fertilization and embryo transfer

Fertil. Steril. 1980, 33: 3-11

Blandau, R.J. Bourdage, R, Halbert, $S$

Tubal transport

In:" The biology of the fluids of the female genital tract

Beller, FK, Schumacher, GFB, eds

Elsevier North-Holland, Amsterdam, 1979

Blerkom, J van, Henry, $G_{3}$ Porreco, $R$

Preimplantation human embryonic development from polypronuclear eggs after in vitro fertilization

Fertil. Steril. 1984, 41: 686-696

Bodkhe, RR, Harper, MJK

Changes in the amount of adrenergic neurotransmitter in the genital tract of untreated rabbits, and rabbits given reserpine or iproniazid during the time of egg transport

Biol. Reprod. 1972, 6: 288-299

Boeckx, WD

Reconstructive microsurgery of the rabbit oviduct

Academic Thesis, Leuven, 1982

Boeckx, WD, Desmedt., G

A simple adjustable table and retractors for tubal microsurgery in rabbits

In: Proceedings of microsurgery congress. Lyon, 1977

Boeckx, WD, Vasquez, $G_{\text {, }}$ Brosens, IA

Reversibility of tubal ring sterilization

Contraception 1977, 15: 505-512

Boer-Meisel, ME, te Velde, ER, Habbema, JDF, Kardaun, JWPF

Predicting the pregnancy outcome in patients treated for bydrosalpinx: a prospective study

1985 (in press)

Bogaert, LJ van, Maldague, P. Staguet, JP

The percentage of granulocyte-like cells in human oviduct epithelium

Br. J. Obstet. Gynaecol. 1978, 85: 373-375

Boling, JL, Blandau, RJ

Egg transport through the ampullae of the oviducts of rabbits under various experimental conditions

Biol. Reprod. 1971, 4: 174-184 
Bousquet, D, LAeveill4e, MC, Roberts, KD, Chapdeleine, A, Bleau, G

The cellular origin of the zona pellucida antigen in the human and in the hamster

J. Exp. Zool. 1981, 215:215-218

Böving, $\mathrm{BG}$

Rabbit egg coverings

Anat. Rec. 1957, 127: 270

Bowman, $\mathrm{P}$, McLaren, A

Cleavage rate of mouse embryos in vivo and in vitro

J. Embryol. exp. Morphol. 1970, 24: 203.207

Brenner, RM

Renewal of oviduct cilia during the menstrual cycle of the rhesus monkey

Fertil. Steril. 1969, 20: 599-611

Brinster, RL

Studies on the development of mouse embryos in vitro. Il. The effect of energy source

J. Exp. Zool. 1965, 158: 59-68

Brinster, RL

Culture of two-cell rabbit embryos to morulae

J. Reprod. Fertil. 1970, 21: 17-22

Brinster, RL

Nutrition and metabolism of the ovum, zygote and blastocyst

In: Handbook of physiology, Section 7: Endocrinology

Greep, RO, Astwood, EB, eds

American Physiological Society, Washington DC, 1973

Brosens, IA, Vasquez, G

Fimbrial microbiopsy

J. Reprod. Med. 1976, 16:171-178

Brundin, J, Wirsén, C

The distribution of adrenergic nerve terminals in the rabbit oviduct

Acta Physiol. Scand. 1964, 61: 203-204

Brunton, WJ, Busilow, S

In: Oviducte et fertilité

Brosens, IA, Cognat, M, Constantin, A, Thibier, M, eds

Masson. Paris, 1979, p. 113

Chang, MC

Development and fate of transferred rabbit ova or blastocyst in relation to the ovulation time of recipients

J. Exp. Zool. 1950, 114: 197-225

Chang, $\mathrm{MC}$

Fertilizing capability of spermatozoa deposited into the fallopian tubes

Nature (Lond.) 1951, 168: 697-698.

Chang, MC

Fertilization and normal development of follicular oocytes in the rabbit

Science $1955,121: 867-869$

Chang, $\mathrm{MC}$

A detrimental effect of seminal plasma on the fertilizing capability of sperm

Nature (Lond.) 1957, 179: 258-259

Chang, MC

Effects of progesterone and related compounds on fertilization, transportation and development of rabbit eggs

Endocrinol. 1967, 81: 1251-1260 
Chang, MC, Harper, MJK

Effects of ethinyl estradiol on egg transport and development in the rabbit

Endocrinol. 1966, 78: 860-872

Chang, MC, Hunt, MD

Effects of proteolytic enzymes on the zona pellucida of fertilized and unfertilized mammalian eggs Exp. Cell. Res. 1956, 11:497-499

Chang, MC, Hunt, DM

Effects of vartious progestins and estrogen on the gamete transport and fertilization in the rabbit Fertil. Steril. 1970, 21:683-686

Chang, MC, Hunt, DM

Effect of prostaglandin F2 $\alpha$ on early pregnancy of rabbits

Nature (Lond.) 1972, 236: 120-121

Chang, $\mathrm{MC}$, Yanagimachi, $\mathrm{R}$

Effect of estrogens and other compounds as oral antifertility agents on the development of rabbit ova and hamister embryos

Fertil. Steril. 1965, 16:281-291

Clewe, TH, Mastroianni, L jr

Mechanisms of ovum pickup

Fertil. Steril. 1958, 9: 13-17

Cline, EM, Randall, PA, Oliphant, $G$

Homone-mediated oviductal influence on mouse embryo development

Fertil. Sterill. 1977, 28: 766-771

Clyman, MJ

Electron micrascopy of the human fallopian tube

Fertill. Steril. 1966, 17: 281-301

Cohen, BM, Katz, M

The significance of the convoluted oviduct in the infertile woman

J. Reprod. Med. 1978, 21: 31-35

Cohen, MR, Stein, IF

Sperm survival at the estimated ovulation time

Fertil. Steril. 1951, 2: 20-28

Cook, B, Hunter, RHF

Systemic and local hormonal requirements for implantation in domestic animals

J. Reprod. Fertil, 1978, 54: 471-482

Corson, SL, Levinson, CJ, Batzer, FR, Otis, C

Hormonal levels following sterilization and hysterectomy

J. Reprod. Med. 1981, 26: 363-370

Costello, DP

Cleavage, blastulation and gastrulation

In: Analysis of devellopment, section $\mathrm{V}$

Willier, BH, Weiss, PA, Hamburger, $V$, eds

Hafner Publishing Company, New York, 1971

Coutinho, EM, Maina, HS

The contractile response of the human uterus, fallopian tubes, and ovary to prostaglandins in vivo Fertil. Steril. 1971, 22; $539-543$

Crane, $M_{0}$ Woodruff, JD

Factors influencing the suctess of tuboplastic procedures

Fertil. Sterill. 1968, 19: 810-820

Croxatto, HB, Fuentealba, B, Diaz, S, Pastene, L, Tatum, HJ

A simple nonsurgical technique to obtain unimplanted eggs from human uter

Am. J. Obstet. Gynecol. 1972a, 112: 662-668 
Croxatto, HB, Diaz, S, Fuentealba, B, Croxatto, HD, Carillo, D, Fabres, C

Studies on the duration of egg transport in the human oviduct.

I. The time interval between evaluation and egg recovery from the uterus in normal women Fertil. Steril. 1972b, 23: $447-458$

Croxatto, HB, Ortiz, MES

Egg transport in the Fallopian tube

Gynecol. Invest. 1975, 6: 215-225

Croxatto, HB, Ortiz, ME, Diaz, S, Hess, R, Balnaleda, J, Croxatto, HD

Studies on the duration of egg transport by the human oviduct.

II. Ovum location at various intervals following luteinizing hormone peak

A.m. J. Obstet. Gynecol. 1978a, 132: 629-634.

Croxatto, HB, Ortiz, ME, Guiloff, E, Ibarra, A, Salvatierra, AM, Croxatto, HD, Spilman, CH Effect of 15(s)-15-methyl prostaglandin $\mathrm{F} 2 \alpha$ on human oviductal motility and owum transport Fertil. Steril. 1978b, 30: 408-414

Croxatto, HB, Ortiz, ME, Diaz, S, Hess, R

Attempts to modify ovum transport in women

J. Reprod. Fertil. 1979, 55: 231-237

Daniel, $\mathrm{IC}$

Local production of protein during implantation in the rabbit

J. Reprod. Fertil. 1972, 31: 303-306

Danüel, JC

A blastokinin-like component from the human uterus

Fertil.Steril. 1973, 24: 326-328

Daniel, JC, Levy, JD

Action of progesterone as a cleavage inhibitor of rabbit ova in vitro

J. Reprod. Fertil. 1964, 7: 323-329

Daniel, JC, Olson, JD

Amino acid requirements for cleavage of the rabbit ovum

J. Reprod. Fert. 1968, 15: 453-455

Darling, MRN

Conservative surgery in the pelvis

In: Tubal infertility diagnosis \& treatment

Chamberlain, GVP, Winston, RWL, eds

Blackwell Scientific Publications, London, 1982

David, A, Brackett, BG, Garcia, CR

Effect of microsurgical removal of the rabbit uterotubal junction

Fertil. Steril. 1969, 20: 250-257

David, A, Serr, DM, Czernobilsky, B

Chemical composition of human oviduct fluid

Fertil. Steril. 1973, 24: 435-439

DeCherny, AH, Mezer, HC, Naftolin, F

Analysis of failure of microsurgical anastomosis after midsegment, non-coagulation tubal ligation

Fertil. Steril. 1983, 39: 618-622

Decker, A

Culdoscopic observations on the tubo-owarian mechanism of ovum reception

Fertil. Steril. 1951, 2: 253-259

Delbeke, LO, Gomel, V, McComb, PF, Jetha, N

Histologic reaction to four synthetic microsutures in the rabbit

Fertil. Steril. 1983, 40: 248-252

Denker, HW, Gerdes, MJ

The dynamic structure of rabbit blastocyst coverings

Anat. Embryol. 1979, 157: 15-34 


\section{Diamond, E}

Microsurgical reconstruction of the uterine tube in sterilized patients

Fertil. Steril. 1977, 28: 1203-1210

Diamond, E

A comparison of gross and microsurgical techniques for repair of cornual occhusion in infertility: a retrospective study, 1968-1978

Fertil. Stetil. 1979, 32: 370-376

Dickmann, Z

Denudation of the rabbit egg: time-sequence and mechanism

Am. J. Anat. 1963, 113: 303-316

Dixon, WJ, Brown, MB, eds

Biomedical computer program P-series (BMDP-81)

University of California Press, Berkeley, 1981

Donnez, $J$ "Wauters, $M$, Thomas, $K$

Luteal function after tubal sterilization

Obstet. Gynecol. 1981, 57: 65 68

Ducibella, T, Anderson, E

Cell shape and membrane changes in the eight-cell mouse embryo: prerequisites for morphogenesis of the blastocyst

Develop. Biol. 1975, 47: 45-58

\section{Eagle, $\mathrm{H}$}

Amino acid metabolism in mammalian cell cultures

Science 1959, 130: 432-437

Eaton, LWM, Hilliard, $J$

Estradiol- $17 \beta$, progesterone and $20 \alpha$-hydroxypregn-4-en-3-one in rabbit ovarian venous plasma,

I. Steroid secretion from paired ovaries with and without corpora lutea; effect of LH

Endocrinol. 1971, 89: 105-111

\section{Eddy, CA}

Tuboplastic microsurgery - appropriate sites for tubal repair

In: Reversibility of female sterilization

Brosens, IA, Winston, RWL, eds

Acædemic Press, London, 1978

Eddy, CA, Hoffman, JJ, Pauerstein, CJ

Pregnancy following segmental isthmic reversal of the rabbit oviduct

Experientia 1976, 32: 1194-1196

Eddy, CA, Antonini, R, Panerstein, $\mathrm{CJ}$

Fertility following microsurgical removal of the ampullary-istmic junction in rabbits

Fertil. Steril. 1977, 28: 1090-1093

Eddy, CA, Flores, JJ, Archer, DR, Pauerstein, CJ

The rolle of cilia in infertility: an evaluation by selective microsurgical modification of the rabbit oviduct

Am. J. Obstet. Gynecol . 1978, 132: 814-821

Eddy, CA, Asch, RH, Balmaceda, JP

Pelvic adhesions following microsurgical and macrosurgical wedge resection of the ovaries

Fertil. Steril. 1980, 33: 557-561

Eddy, CA, Bajpai, VK

Healing and restoration of fertility following microsurgical transection and anastomosis of the rabbit oviduct

Fertil. Steril. 1982, 38: 354-363

Edwards, RG

Maturation in vitro of human ovarian oocytes

Lancet 1965, ii: 926-929 
Edwards, RG

Early human development from the oocyte to implantation

In: Scientific foundations of obstetrics and gynaecology

Philipp, EE, Barnes, J, Newton, M, eds

William Heinemann Medical Books Lid, London, 1977

Edwards, RG

Conception in the human female

Academic Press, London, 1980a, p. 559

1980 b, p. 592

1980 c, p. 651

1980 d, p. 687

Edwards, RG, Gates, AH

Timing of the stages of the maturation divisions, ovulation, fertilization and the first cleavage of eggs of adult mice treated with gonadotrophins

J. Endocrinol. 1959, 18: 292-304

Edwards, RG, Purdy, JM

In: Human conception in vitro

Edwards, $\mathrm{RG}_{\mathrm{g}}$ Purdy, JM, eds

Academic Press, London, 1982a, p. 227-228

Edwards, RG, Purdy, JM

In: Human conception in vitro

Edwards, RG, Purdy, JM, eds

Academic Press, London, 1982b, p. 413-420

El-Banna, AA, Daniel, JC jr

Stimulation of rabbit blastocysts in vitro by progesterone and uterine proteins in combination

Fertil. Steril. 1972, 23: 101-104

El-Badrawi, HH, Hafez, ESE

Factors and mechanisms affecting success of in vitro fertilization and embryo transfer

In: In witro fertilization and embryo transfer

Hafez, ESE, Semm, K, eds

MTP Press Ltd, Lancaster, 1982

El Etreby, MF, Beier, HM, Elger, W, Mahrous, AT, Topert, M

Immunocytochemical localization of uteroglobin in the genital tract of male rabbits

Cell Tissue Res. 1983, 229: 61-73

Epstein, CJ

Gene expression and macromolecular synthesis during preimplantation embryonic development

Biol. Reprod, 1975, 12: 82-105:

Espey, LL

Ovarian proteolytic enzymes in ovulation

Biol. Reprod. 1974, 10: 216-235

Evers, JLH, Land, JA, Pijnenborg, R, Boeckx, WD, Brosens, IA

Cleavage rate of embryos in the rabbit owiduct following tubal surgery

Int. J. Fert. 1985 (in press)

Fadel, HE, Berns, D, Zaneweld, LJD, Willbanks, GD, Brueschke, EE

The human uterotubal junction: a scanning electron microscope study during different phases of the menstrual cycle

Fertil. Steril. 1976, 27: 1176-1186

Falloppio, G

Observationes Anatomicae

Venetiê, 1561

Universiteitsbibliotheek Leiden, sectienummer 461 F 17 
Feichtinger, W, Kemeter, $P$

Early stage embryotransfer - a possible reason for a highly reduced abortion rate

In: Gamete quality and fertility regulation

Rolland, R, Heineman, $M J$, Hillier, $\mathrm{SG}$, Vemer, $\mathrm{H}$, eds

Elsevier Science Publishers, Amsterdam, 1985

Feigelson, M, Kay, $\mathrm{E}$

Protein patterns of rabbit owiductal fluid

Biol. Reprod. 1972, 6: 244-252

Firor, WM

Hypophysectomy in pregnant rabbits

Am. J. Physiol. 1933, 104: 204-215

First, A

Transperitoneal migration of ovum or spermatozoon

Obstet. Gynecol. 1954, 4: 431-434

Fishel, $\mathrm{SB}$, Edwards, RG, Purdy, JM

In vitro fertilization of human oocytes factors associated with embryonic development in vitro,

replacement of embryos and pregnancy

In: Fertilization of the human egg in vitro

Beier, HM, Lindner, HR, eds

Springer-Verlag, New York, 1983

Fleming, AD, Yanagimachi, $\mathbb{R}$

Fertille life of acrosome-reacted guinea pig spermatozoa

J. Exp. Zool. 1982, 220: 109-115

Frrantzen, $C_{x}$ Schlösser, HW

Microsurgery and postinfectious tubal infertility

Fertil. Steril. 1982, 38: 397-402

Fraser, LR, Dandekar, PV

The relationship between zona digestion and cortical gramule disappearance in rabbit eggs inseminated in vitro

Biol. Reprod. 1975, 13: 123-125

Fredericks, CM, Anderson, WR, Smith, CE, Mathur, RS

Patterns of periovulatory oviductal motility and progesterone in the unanesthetized rabbit

Biol. Reprod. 1982, 27: 340-350

Friz, M, Mey, R

Early embryonal death before implantation

Int. J. Fertil. 1959, 4: 306-308

Gaddum-Rosse, P, Blandau, RJ

In vitro studies on ciliary activity within the oviducts of the rabbit and pig

Am. J. Anat. 1973, 136: 91-104

Gaddum-Rosse, P, Blandau, RI

Comparative observations on ciliary currents in mammalian oviducts

Biol. Reprod. 1976, 14: 605-609

Gaddurn-Rosse, P, Blandau, RJ, Thiersch, JB

Ciliary activity in the human and Macaca nemestrina oviduct

Am. J. Anat. 1973, 138: 269-275

Glass, LE

Immunocytological studies of the mouse oviduct

In: The mammalian oviduct

Hafez, ESE, Blandau, RJ, eds

University of Chicago Press, Chicago, 1969 
Goldfarb, JM, Utian, WH, Weiss, R

Microscopic versus macroscopic tubal anastomosis in rabbit fallopian tubes

Fertil. Steril. 1983, 40:373-377

Gomel, v

Tubal reanastomosis by microsurgery

Fertil. Steril. 1977, 28: 59-65

Gomel, $\mathrm{V}$

Causes of failed reconstructive tubal microsurgery

J. Reprod. Med. 1980, 24: 239-243

Gomel, V, McComb, P, Boer-Meisel, M

Histologic reactions to polyglactin-910, polyethylene and nylon microsuture

J. Reprod. Med. 1980, 25: 56-59

Goswami, A, Feigelson, $M$

Differential regulation of a low molecular-weight protein in oviductal and uterine fluids by ovarian hormones

Endocrinol. 1974, 95: 669-675

Greenwald, GS

Interruption of pregnancy in the rabbit by the administration of estrogen

J. Exp. Zool. 1957, 135: 461-482

Greenwald, GS

Endocrine regulation of the secretion of mucin in the tubal epithelium of the rabbit

Anat. Rec. 1958, 130: 477-495

Greenwald, GS

A study of the transport of ova through the rabbit oviduct

Fertil. Steril. 1961, 12: '80-95

Greenwald, GS

The role of the mucin layer in development of the rabbit blastocyst.

Anat. Rec. 1962, 142: 407-415

Greenwald, GS

Endocrinology of oviductal secretions

In: The mammialian oviduct

Hafez, ESE, Blandau, RJ, eds

University of Chicago Press, Chicago, 1969

Gregoire, AT, Gongsakdi, D, Rakof, AE

The free amino acid content of the femalle rabbit genital tract

Fertil. Steril. 1961, 12: 322-327

Gulyas, BJ

Electron microscopic observations on advanced stages of spontaneous polyspermy in rabbit zygotes

Anat. Rec. 1974, 179: 285-296

Gupta, DN, Karkun, J, Kar, AB

Biochemical changes in different parts of the rabbit fallopian tube during passage of ova

Am. J. Obstet. Gynecol. 1970, 106: 833×837

Gwatkin, RBL

Chemically defined media for mammalian eggs and early enbryos in vitro

In Vitro 1972, 8: 59-67

Gwatkin, RBL

Receptor for sperm on the mammalian ovum

In: In vitro fertilization and embryo transfer

Hafez, ESE, Semm, K, eds

MTP Press Ltd, Lancaster, 1982 
Hackenberg, R, Beier, HM

Proteinase inhibitor identification in the ateroglobin fraction of rabbit uterine secretion

Arch. Gynecol. 1982, 231: 289-297

Hafez, ESE, Rajakoski, E

Crowth and survival of blastocysts in the domestic rabbit

1. The effect of maternal factors

J. Reprod. Fertil. 1964, 7:229-240

Hafez, ESE, Sugawara, s

Biochemistry of oviductal eggs in mammals

In: The mammalian owiduct

Hafez, ESE, Blandau, RJ, eds

University of Chicago Press, Chicago, 1969

Halbert, SA, Tam, PY, Adams, RJ, Blandau, RJ

An analysis of the mechanisms of egg transport in the ampulla of the rabbit oviduct

Gymecol. Invest. 1976a, 7:306-320

Halbert, SA, Tam, PY, Blandau, RJ

Egg transport in the rabbit oviduct the roles of cilia and muscle

Science 1976b, 191: 1052-1053

Halbert, SA, Patton, DL

Egg transport in the rabbit oviduct following ampullary resection and microsurgical end-to-end anastomosis

Fertill. Steril. 1979, 32: 687-690

Halbert, SA, Patton, DL

Ovum pick-up following fimbriectomy and infundibular salpingostomy in rabbits

J. Reprod. Med. 1981, 26: 299-304

Halbert, $\mathrm{SA}$, McComb, $\mathrm{PF}$

Function and structure of the rabbit oviduct following fimbriectomy.

II. Proximal ampullary salpingostomy

Fertil. Steril. 1981, 35: 355-358

Hallbert, SA, McComb, PF, Patton, DL

Function and structure of the rabbit oviduct following fimbriectomy.

I. Distal ampullary salpingostomy

Fertil. Steril. 1981a $35: 349-354$

Halbert, SA, MoComb, PF, Bourdage, RJ

The structural and functional impact of microsurgical anastomosis on the rabbit oviductal isthmus

Fertil. Steril. 1981 b, 36: 653-658

Halliday, $\mathbf{R}$

The occurrence of corpora lutea atretica in the ovaries of pregnant domestic rabbits

Ji. Endocrinol. 1959, 19: 10-15

Halme, J, Rong, $\mathrm{ZJ}$, Wing, R, Raj, MHG, Raj, $\mathrm{S}$

The removal of fallopian tubes has no adverse effect on subsequent ovarian function in rabbits

Fertil. Steril. 1982, 38: 621-624

Ham, RG

An improved nutrient solution for diploid chinese hamster and human cell lines

Exp. Cell. Res. 1963, 29: 515-526

Ham, RG

Survival and growth requirements of nontransformed cells

In: Tissue growth factors

Handbook of experimental pharmacology, volume 57

Baserga, $R$, ed

Springer-Verlag, New York, 1981 
Hamilton, CJCM, Evers, MLH, Hoogland, HJ

Ovulatory disorders and inflammatory adnexal damage: a neglected cause of the failhure of fertility microsurgery

Br. J. Obstet. Gynaecol. 1985 (in press)

Hamner, CE, Williams, WL

Identification of sperm stimulatory factor of rabbit owiduct fluid

Proc. Soc. Exp. Biol. Med. 1964, 117: 240-243

Hamner, CE, Williams, WL

Composition of rabbit owiduct secretions

Fertil. Steril. 1965, 16:170-176

Harper, MJK

The time of ovulation in the rabbit following the injection of huteinizing hormone

J. Endocrinol. 1961, 22: 147-152

Harper, MJK

Ovulation in the rabbit: the time of follicular rupture and expulsion of the eggs, in rellation to injection of luteinizing hormone

J. Endocrinol. 1963, 26: 307-316

Harper, MJK

Transport of eggs in cumulus throughth the ampulla of the rabbit oviduct in relation to day of pseudopregnancy

Endocrinol, 1965, 77: 114-123

Harrington, FE, Rothermel, JD

Daily changes in peripheral plasma progesterone concentrations in pregnant and pseudopregnant rabbits

Life Sci. 1977, 20B: 1333-1340

Hartman, CG

On some characters of taxonomic vallue appertaining to the egg and the ovary of rabbits

J. Mammal. 1925, 6: 114-121

Hedon, B, Wineman, $M$, Winston, RML

Loupes or microscope for tubal anastomosis? An experimental study

Fertil. Steril. 1980, 34: 264-268

Hilliard, J, Eaton, LW jr

Estradiol-17 $\beta$, progesterone and 20- $\alpha$-hydroxypregn-4-en-3-one in rabbit ovarian venous plasma.

II. From mating through implantation

Endocrinol. 1971, 89:522-527

Hodgson, BJ

Effects of Indomethacin and ICI 46,474 administered during ovum transport on fertility in rabbits

Biol. Reprod. 1976, 14: 451-457

Hodgson, BJ, Patuerstein, CJ

The effect of ovulation on the response of rabbit oviduct to adrenergic agonists in vitro

Biol. Reprod. 1974, 10: 346-353

Hodgson, BJ, Pauerstein, CJ

Comparison of oviductal transport of fertilized and unfertilized ova after HCG or coiltus-induced ovulation in rabbits

Biol. Reprod. 1976, 14: 377-380

Hoffmann, $\mathrm{IC}$

The influence of photoperiods on reproductive functions in female mammals

In: Handbook of physiology, section 7, Endocrinology

Greep, RO, Astwood, EB, eds

American Physiological Society, Washington DC, 1973

Holmdahl, TH, Mastroianni, L jr

Continuous collection of rabbit oviduct secretions at low temperature

Fertil. Steril. 1965, 16: 587-595 
Howe, GR, Black, DL

Autonomic nervous system and oviduct function in the rabbit.

I. Hormones and contraction

J. Reprod. Fertil. 1973, 33: 425-430

Hubbard, TB, Khan, MZ, Carag, VR, Albites, VE, Hricko, GM

The pathology of peritoneal repair its relation to the formation of adhesions

Ann. Surg. 1967, $165: 908-916$

Hulka, JF, Ulberg, LC

Reversibility of clip sterilization

Fertil. Steril, 1975, 26:1132-1134

Hunter, RHF

Pre-ovulatory arrest and peri-ovulatory redistribution of competent spermatozoa in the isthmus of the pig owiduct

J. Reprad. Fertil. 1984, 72: 203-211

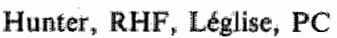

Tubal surgery in the rabbit: fertilization and polyspermy after resection of the isthmus

Am. J. Anat. $1971,132: 45-52$

Iklé, FA

Schwangerschaft nach Implantation des Ovars in den Uterus

Gynaecologia 1961, 151: 95-99

Jacobson, JH, Suarez, EL

Microsurgery in anastomosis of small vessels

Surg. Forum 1960, 11: 243-245

Jaffe, LA

Fast block to polyspermy in sea urchin eggs is electrically mediated

Nature (Lond.) $1976,261: 68-71$

Janiak, MI

Das Endokrine System bei der Fortpflanzung der Versuchs und Nutztiere und des Menschen

M\&H Schaper Verlag, Hannover, 1971, p. 129-132

Jean, Y, Langlais, J, Roberts, KD, Chapdelaine, A, Bleau, G

Fertility of a woman with nonfunctional eiliated cells in the fallopian tubes

Fertil. Steril. 1979, 31: 349-350

Jones, GS, Pourmand, $\mathrm{K}$

An evaluation of etiologic factors and therapy in 555 private patients with primary infertility

Fertil. Steril. 1962, 13: 398-410

Jones, HW, Rock, JA

On the reanastomosis of fallopian tubes after surgical sterilization

Fertil. Steril. 1978, 29: 702-704

Johnson, $\mathrm{MH}$

The protein composition of secretions from pregniant and pseudopregnant rabbit uteri with and without a copper intrauterine device

Fertil. Steril. 1972, 23: 123-130

Joshi, SG, Ebert, KM, Swartz, DP

Detection and synthesis of a progesteron-dependent protein in human endometrium

J. Reprod. Fertil. 1980a, 59: 273-285

Joshi, $\mathrm{SG}_{8}$ Ebert, KM, Smith, RA

Properties of the progesteron-dependent protein of the human endometrium

J. Reprod. Fertil., 1980b, 59: 287-296 
Kane, MT, Buckley, NJ

The effects of inhibitors of energy metabolism on the growth of one-cell rabbit ova to blastocysts. in vitro

J. Reprod. Fertil. 1977, 49: 261-266

Kay, $\mathrm{E}$, Feigelson, $M$

An estrogen modulated protein in rabbil oviductal fluid

Biochim. Biophys. Acta 1972, 271: 436-441

Khoo, SK, MacKay, EV

Reactions in rabbit fallopian tube after plastic reconstruction.

I. Gross pathology, tubal patency and pregnancy

Fertil. Steril. 1972, 23: 201-206

Kille, JW, Hamner, CE

The influence of oviductal fluid on the development of one-cell rabbit embryos in vitro

J. Reprod. Fertil. 1973, 35: 415-423

Kirchner, $\mathrm{C}$

Immune histologic studies on the synthesis of a uterime-specific protein in the rabbit and its passage through the blastocyst coverings

Fertil. Steril. 1972, 23: 131-136

Kirchner, $\mathrm{C}$

Uteroglobin in the rabbit. II. Intracellular localization in the oviduct, uterus and preimplantation blastocyst

Cell Tiss. Res. 1976, 170: 415-424

Kosasa, TS, Mulligan, WJ, Ehrmann, RL, Brooks, DC

Microscopic appearance of the human fallopian tube following a reanastomosis procedure

Fertil. Steril. 1976, 27: 1422-1424

Krishnan, RS, Daniel, JC

'Blastokinin': inducer and regulator of blastocyst development in the rabbit uterus

Science $1967,158: 490-492$

Krishnan, RS, Daniel, JC

Composition of 'blastokinin' from rabbit uterus

Biochim. Biophys. Acta 1968, 168: 579-582

Kulangara, AC, Crutchfield, FL

Passage of bovine serum albumin from the mother to rabbit blastocysts.

II. Passage from uterine lumen to blastocyst fluid

J. Embryol. exp. Morphol. 1973, 30: 471-482

Kumar, NM, Bullock, DW

Analysis of steady-state levels of uteroglobin mRNA in rabbit uterus and liung during early pregnancy

J. Endocrinol. 1982, 94: 407-414

Leeton, J, Kerin, J

Embryo transfer

In: Clinical in vitro fertilization

Wood, C, Trounson, A, eds

Springer-Verlag, New York, 1984

Lienert, GA

Verteilungsfreie Methoden in der Biostatistik, Tafelband

Verlag Anton Hain, Meisenheim am Glan, 1975, p. 1

Lippes, J

Analysis of human oviductal fluid for low molecular weight compounds

In: The biology of the fluids of the female genital tract

Beller, FK, Schumacher, GFB, eds.

Elsevier North Holland, Amsterdam, 1979 
Lippes, J, Ogra, S, Tomasi, TB, Tourville, DR

Immunohistological localization of $\gamma \mathrm{G}, \gamma \mathrm{A}$, and $\gamma \mathrm{M}$, secretory piece and lactoferrin in the human female genital tract

Contraception $1970,1: 163-183$

Lippes, J, Enders, RG, Pragay, DA, Bartholomew, WR

The collection and analysis of human fallopian tubal fluid

Contraception $1972,5: 85-103$

Lippes, J, Wasner, J, Alfonso, LA, Dacalos, ED, Lucero, R

Human oviductall fluid proteins

Fertil.Steril. 1981, 36: 623-629

Longley, WJ, Black, DL.

Comparisons of methods for locating ova in the oviduct of the rabbit

J. Reprod. Fertil. 1968, 16: 69-72

Lopata, A, Kohlman, D, Johnston, I

The fine structure of normal and abnormal human embryos developed in culture

In: Fertilization of the human egg in vitro

Beier, HM, Lindner, $H R$, eds

Springer-Verlag, New York, 1983

Lopata, A, McMaster, R, McBain, JC, Johnston, WIH

In-vitro fertilization of preovulatory human eggs

J. Reprod. Fertil. 1978, 52: 339-342

Lopata, A

Factors influencing the growth of human preimplantation embryos in vitro

In: Human Conception in vitro

Edwards, RG, Purdy, JM, eds

Academic Press, London, 1982

Ludwig, H, Metzger, $\mathrm{H}$

The human female reproductive tract. A scanning electron microscopic atlas

Springer-Verlag, New York, 1976

Lutwak-Mann, C, Boursnell, JC, Bennett, JP

Blastocyst-uterine relationships: uptake of radioactive ions by the early rabbit embryo and its environment

J. Reprod. Fertil. 1960, 1: 169-185

Maas, DHA

Studies on the protein content of human oviductal flushings

In: The biology of the fluids of the female genital tract

Beller, FK, Schumacher, GFB, eds

Elseviers North Holland, Amsterdan, 1979

Maathuis, JB Aitken, RJ

Gyclic variation in concentrations of protein and hexose in human uterine flushings collected by an improved technique

J. Reprod. Fert. 1978a, 52: 289-295

Maathuis, JB, Aitken, RJ

Protein patterms of human uterine flushings collected at various stages of the menstrual cycle

J. Reprod. Fert. 1978b, 53: 343-348

MacKay, EV, Khoo, SK

Reactions in the rabbit fallopian tube after plastic reconstruction. II. Histopathology

Fertil. Steril. 1972, 23: 207-216 
Malpoix-Higgins, $\mathbf{P}$

The liwing cell

In: Scientific foundations of obstetrics and gynaecology

Philipp, EE, Barnes, J, Newton, M, eds

William Heinemann Medical Books Ltd, London, 1977

Margara, RA, Winston, RML

as cilted by: Winston, RML.

Microsurgery of the fallopian tube: from fantasy to reality

Fertil. Steril. 1980, 34: 521-530

\section{Marsafy, YM, Hafez, ESE}

Egg transport and postcoital isthmic contractility in the rabbit

J. Reprod. Med. 1981, 26: 558-562

Mastroianni, $\mathrm{L}$ jr, Wallach, $\mathrm{RC}$

Effect of ovulation and early gestation on oviduct secretions in the rabbit

Am. J. Physiol. 1961, 200: 815-818

Mastroianmi, L jr, Winternitz, WW, Lowi, NP

The in vitro metabolism of the human endosalpinx

Fertil. Steril. 1958, 9: 500-509

Maurer, RR, Beier, HM

Uterine proteins and development in vitro of rabbit preimplantation embryos

J. Reprod. Fertil. 1.976, 48: 33-41

McCarthy, SM, Foote, RH, Maurer, RR

Embryo mortality and altered uterine luminal proteins in progesterone-treated rabbits

Fertil.Steril. 1977, 28: 101-107

McComb, $\mathbf{P}_{\text {, Gomel, } \mathrm{V}}$

The influence of fallopian tube length on fertility in the rabbit

Fertil. Steril. 1979, 31: 673-676

McComb, PF, Boer-Meisel, M, Gomel, V

The influence of fallopian tube ampullary length on the fertility of the rabbit

Int. J. Fertil. 1981a, 26: 30-34

McComb, PF, Bourdage, RJ, Halbert, SA

Suppressed ovulatory function and owiductal microsurgery in the rabbit

Fertil. Steril. 1981b, 35: 481:482

McComb, PF, Halbert, SA, Gomel, V

Pregnancy, ciliary transport and the reversed ampullary segment of the rabbit fallopian tube

Fertil. Steril. 1980, 34: 386-390

McComb, PF, Newman, H, Halbert, SA

Reproduction in rabbits after excision of the oviductal isthmus, ampullary-isthmic junction, and uteroisthmic junction

Fertill. Sterill. 1981c, 36: 669-677

McGrath, J, Solter, D

Completion of mouse embryogenesis requires both the maternal and paternal genomes

Cell 1984, 37: 179-183

McLaren, A

Mechanisms affecting embryo development

In: The mammalian oviduct

Hafez, ESE, Blandau, RJ, eds

University of Chicago Press, Chicago, 1969

McLaughlin, KC, Hamner, $\mathrm{CE}$

Preliminary characterization of rabbit oviduct fluid trypsin inhibitors

Biol. Reprod. 1975, 12: 556-565 
Metz, KGP, Mastroianni, L, jr

Dispensability of fimbriae; ovum pickup by tubal fistulas in the rabbit

Fertil. Steril. 1979; 32: 329-334

Miyamoto, $\mathrm{H}$, Chang, $\mathrm{CM}$

The importance of serum albumin and metabolic intermediates for capacitation of spermatozoa and fertilization of mouse eggs in vitro

J. Reprod. Fertill. 1973, 32:193-205

Moghissi, KS

Human fallopian tube fluid. I. Protein composition

Fertil. Steril. 1970, 21:821-829

Mohr, L, Trounson, A

In vitro fertilization and embryo growth

In: Clinical in vitro fertilization

Wood, $C$, Trounson, $A_{\text {, }}$ eds

Springer-Verlag, New York, 1984

Neuwirth, RS, Khalaf, SM

Effect of thirty-two percent dextran 70 on peritoneal adhesion formation

Am. J. Obstet. Gynecol. 1975, 121: 420-422.

Nisell, $H$, Larsson, B

Role of blood and fibrinogen in development of intraperitoneal adhesions in rats

Fertil. Steril. 1978, 30: 470-473

Nishimura, K, Nakamura, RM, DiZerega, GS

Biochemical evaluation of postsurgical wound repair: prevention of intraperitoneal adhesion formation with ibuprofen

J. Surg. Res. 1983, 34: 219-226

Nishimura, K, Nakamura, RM, DiZerega, GS

lbuprofen inhibition of postsurgical adhesion formation: a time and dose response biochemical evaluation in rabbits

J. Surg. Res. 1984, 36: 115-124

Noske, IG, Feigelison, M

Immunological evidence of uteroglobin blastokinin in the male reproductive tract and in nonreproductive ductal tissues and their secretions

Biol. Reprod. 1976, 15: 704-713

Novak, E, Everett, HS

Cyclical and other variations in the tubal epithelium.

Am. J. Obstet. Gynecol. 1928, 16:499-530

Novak, ER, Woodruff, JD, eds

Novak's gynecologic and obstetric pathology

W.B. Saunders Company, Philadelphia, 8th edition 1979, p. 306-311

Noyes, RW, Thibault, $\mathrm{C}$

Endocrine factors in the survival of spermatozoa in the female reproductive tract

Fertil. Steril. 1962, 13: 346-365

Odor, DL

The question of 'basal' cells in oviductal and endocervical epithelium

Fertil. Steril. 1974, 25: 1047-1062

Odor, DL, Blandau, RJ

Egg transport over the fimbrial surface of the rabbit oviduct under experimentall conditions

Fertill. Sterill. 1973, 24: 292-300

Ogra, SS, Kirton, KI, Tomasi, TB, Lippes, J

Prostaglandins in the human fallopian tube

Fertil. Sterill. 1974, 25: 250-25.5 


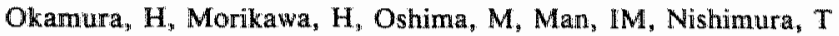

A morphological and physiological study of mesotubarium ovarica in humans

Int. J. Fertil. 1977, 22: 179-183

$\mathrm{O}^{\prime}$ Rahilly, $\mathrm{R}$

Developmental stages in human embryos. Part A: Embryos of the first three weeks.

Carnegie Institution of Washington, Washington DC, 1973a, p. 9, $1973 \mathrm{~b}$, p. 15

Orsini, MW

Technique of preparation, study and photography of benzyl-benzoate cleared material of embryologic studies

J. Reprod. Fertil. 1962, 3:283-287

Overstreet, JW, Cooper, GW

Sperm transport in the reproductive tract of the female rabbit.

I. The rapid transit phase of transport

Biol. Reprod. 1978a, 19: 101-114

Overstreet, JW, Cooper, GW

Sperm transport in the reproductive tract of the female rabbit.

II. The sustained phase of transport

Biol. Reprod. 1978b, 19: 115-132

Owman, C, Rosengren, E, Sjöberg, NO

Adrenergic innervation of the human female reproductive organs: A histochemical and chemical investigation

Obstet. Gynecol. 1967, 30: 763-773

Patek, E

The proliferative behaviour of the human fallopian tube epithelium

Obst. Gynecol. Survey 1979, 34: 146-148

Patek, E, Nilsson, L, Johannisson, E

Scanning electron microscopic study of the human fallopian tube.

Report I. The prolliferative and secretory stages

Fertil. Steril. 1972a, 23: 459-465

Patek, E, Nilsson, L, Johannisson, E

Scanning electron microscopic study of the human fallopian tube.

Report II. Fetal life, reproductive life, and postmenopause

Fertil. Steril. 1972b, 23: 719-733

Paterson, P, Wood, C

The use of microsurgery in the reanastomosis of the rabbit fallopian tube

Fertil. Steril. 1974, 25: 757-761

Pauerstein $\mathrm{CJ}$

From Fallopius to fantasy

Fertil. Steril. 1978, 30: 133-140

Pauerstein, C.J, Anderson, V, Chatkoff, ML, Hodgson, BJ

Effect of estrogen and progesterone on the time-course of tubal ovum transport in rabbits

Am. J. Obstet. Gynecol. 1974a, 120: 299-308

Pauerstein, CJ, Eddy, CA

The role of the owiduct in reproduction; our knowledge and our ignorance

J. Reprod. Fertil. 1979, 55: 223-229

Pauerstein, CJ, Fremming, BD, Hodgson, BJ, Martin, JE

The promise of pharmacological modification of owum transport in contraceptive development Am. J. Obstet. Gynecol. 1973, 116:161-166

Pawerstein, $C J$, Fremming, BD, Martin, JE

Estrogen-induced tubal arrest of ovum; antagonism by alpha adrenergic blockade

Obstet. Gynecol. 1970a, 35: 671-675 
Pauerstein, CJ, Fremming, BD, Martin, JE

Influence of progesterone and alpha adrenergic blockade upon tubal transport of ova

Gynecol. Invest. 1970b, 1: 257-267

Pauerstein, CJ, Hodgson, BJ, Fremming, BD, Martin, JE

Effects of sympathetic denervation of the rabbit oviduct on mormal ovum transport and on transport modified by estrogen and progesterone

Gynec. Invest. 1974b, $5: 121-132$

Pauerstein, CJ, Sabry, A, Hodgson, BJ

Temporall relationships critical to estrogen induced delay of ovum transport

Fertil. Steril. 1976, 27: 1308-1311

Pauerstein, Cy, Woodruff, JD

The role of the 'indifferent' cell of the tubal epithellium

Am. J. Obstet. Gynecol. 1967, 98: 121-125

Perez, LD, Flores, JJ, Bajpai, VK, Asch, RH, Eddy, CA

Fertility following fimbriectomy and tubo-ovarian microsurgery in the rabbit

Fiertil. Steril. 19811a, 35: 573-579

Perez, LD, Rajkumar, K, Eddy CA

Fertility and ovum transport after microsurgical removal of the uterotubal junction in rabbits

Fertil. Steril. 1981b, 36: 803-807

Peters, $\mathbf{H}$

The human ovary in childhood and early maturity

Europ. J. Obstet. Gynec. Reprod. Biol. 1979, 9: 137-144

Peters, $\mathrm{H}, \mathrm{McNatty}, \mathrm{KP}$

The ovary - A correlation of structure and function in mammals

Chapter 2: Morphology of the ovary

Granada Publishing, London, 1980

Pike, IL

Biological risks of in vitro fertilization and embryo transfer

In: Clinical in vitro fertilization

Wood, C, Trounson, A, eds

Springer-Verlag, New York, 1984

Polidoro, JP, Howe, GR, Black, DL

The effects of adrenergic drugs on ovum transport through the rabbit oviduct

J. Reprod. Fertil. 1973, 35: 331-337

Quinn, P, Whittingham, DG

Albumin, seminal plasma and mammalian fertilization

In: In vitro fertilization and embryo transfer

Hafez, ESE, Semm, K, eds

MTP press Ltd, Lancaster, 1982

Renfree, MB

Signals exchanged between the blastocyst and endometrium in the period leading to implantation

Prog. reprod. Biol. 1980, 7: 1-13

Reyes, A, Goicoechea, B, Rosado, A

Calcium ion requirement for rabbit spermatozoal capacitation and enhancement of fertilizing ability by ionophore $\mathrm{A} 23187$ and cyclic adenosine $3^{4}: 5^{4}$-monophosphate

Fertil. Steril. 1978, 29: 451-455

Ris, $H$

Cell division

In: Analysis of development, section III

Willier, BH, Weiss, PA, Hamburger, V

Hafner Publishing Company, New York, 1971 
Roberts, GP, Parker, JM, Henderson, SR

Proteins in human uterine fluid

J. Reprod. Fertil. 1976, 48: 153-157

Roblero, $\mathbb{L}$, lzquierdo, $L$

Effect of progesterone on the cleavage rate of mouse embryos in vitro

J. Reprod. Fertil. 1976, 46: 475-476

Rondell, $P$

Biophysical aspects of ovulation

Bioll. Reprod. 1970, suppl.2: 64-89

Rosenblum, I, Stein, AA

Autonomic responses of the circular muscles of the isolated human fallopian tube

Am. J. Physiol. 1966, 210: 1127-1129

Saito, $H$, Berger, $T$, Mishell, DR, Marrs, RP

The effect of serum fractions on embryo growth

Fertil. Steril. 1984, 41: 761-765

Saksena, SK, Harper, MJK

Relationship between concentration of prostaglandin F (PGF) in the oviduct and egg transport in rabbits

Biol. Reprod. 1975, 13: 68-76

Sathananthan, $\mathrm{AH}$, Trounson, $\mathrm{AO}$

Ultrastructural observations on cortical granules in human follicular oocytes cultured in vitro

Gamete Res. 1982, 5: 191-198

Seitz, HM, Schenker, JG, Epstein, S, Garcia, CR

Postoperative intraperitoneal adhesions: a double-blind assessment of their prewention in the monkey

Fertil. Steril. 1973, 24: 935-940

Seki, K, Eddy, CA, Smith, NK, Pauerstein CI

Comparison of two techniques of suturing in microsurgical anastomosis of the rabbit oviduct

Fertil. Steril. 1977, 28: 1215-1219

Settlage, DSF, Motoshima, M, Tredway, DR

Sperm transport from the external cervical os to the fallopian tubes in women: a time and quantitation study

Fertil. Steril. 1973, 24: 655-661

Shirai, $\mathbb{E}_{\mathrm{y}}$ lizuka, $R$, Notake, $Y$

Analysis of human uterine fluid protein

Fertill. Steril. 1972, 23: 522-528

Siegler, AM, Kontopoulos, $\mathrm{V}$

An analysis of macrosurgical and microsurgical techniques in the management of the tuboperitoneal factor in infertility

Fertil. Steril. 1979, 32: 377-383

Siegler, AM, Kontopoulos, V, Wang, CF

Prevention of postoperative adhesions in rabbits with ibuprofen, a nonsteroidal anti-inflammatory agent

Fertil. Steril. 1980, 34: $46-49$

Silber, $S I_{\text {" Cohen, } R}$

Microsurgical reversal of female steritization: the role of tubal length

Fertil. Steril. 1980, 33: 598-601

Singh, JP, Babcock, DF, Lardy, DA

Increased calcium-ion influx is a component of capacitation of spermatozoa

Biochem. J. 1978, 172: 549-556

Sjöberg, NO, Owman, C, Walles, B

Sympathetic nerves mediating motor functions in the human fallopian tube

Fertil. Steril. 1977, 28: 283 
Sloan, MH, Johnson, AD

The influence of a cannula in the rabbit oviduct. 1. Oviduct fluid lipids and proteins

J. Reprod. Fertil. 1974, 37: 149-153

Sloan, MH, Coley, SL, Johnson, AD

The influence of a cannula in the rabbit oviduct. II. Effect on embryo survival

J. Reprod. Fertil. 1974, 37: 155-158

Speroff, L, Glassis, RH, Kase, NG

Clinical gynecologic endocrinology and infertility

The Williams and Wilkins Company, Baltimore, 3rd edition 1984, p. 469

Spilman, $\mathrm{CH}$

Oviduct response to prostaglandins: influence of estradiol and progesterone

Prostaglandinis 1974, 7: 465-472

Spilman, $\mathrm{CH}$, Harper, MJK

$\mathbb{2}$ ffects of prostaglandins on owiductal motility and egg transport

Gynecol. Invert. 1975, 6: 186-205

Spilman, CH, Shaikh, AA, Harper, MJK

Oviductal motillity amplitude and ovarian steroid secretion during egg transport in the rabbit

Biol. Reprod. 1978, 18: 409-417

Stambaugh, R, Noriega, C, Mastroianni, L.jr

Bicarbonate ion; the corona cell dispersing factor of the rabbit tubal fluid

J. Reprod. Fertil. 1969, 18: 51-58

Stone, $\mathrm{SL}_{\text {" Harnner, } \mathrm{CE}}$

Biochemistry and physiology of oviductal secretions

Gynecol. Invest. 1975, 6: 234-252

Stone, SL, Hamner, CE

Hormonal and regional influences of the oviduct on the development of rabbit enbryos

Biol. Reprod. 1977, 16: 638-646

Stone, SL, Richardson, LL, Hamner, CE, Oliphant, G

Partial characterization of hormone-mediated inhibition of embryo development in rabbit oviduct

fluid

Biol. Reprod. 1977, 16: 647-653

Sutcliffe, RG, Bolton, AE, Sharp, F, Nicholson, LVB, MacKinnon, $R$

Purification of human alpha-uterine protein

J. Reprod. Fertill. 1980, 58: 435-442

Sutcliffe, RG, Brock, DJH, Nicliolson, LVB, Dunn, E

Fetal- and uterine-specific antigens in human amniotic fluid

J. Reprod. Fertil. 1978, 54: 85-90

Talbot, $\mathrm{P}$

Events leading to fertilization in mammals

In: The proceedings of the Xlth world congress on fertility and sterility, Dublin, 1983

Harrison, RF, Bonnar, J, Thompson, W, eds

MTP press Limited, Lancaster, 1984

Talbot, P, Franklin, LE

Morphology and kinetics of the hamster sperm acrosome reaction

J. Exp. Zool. 1976, 198: 163-176

Tangen, $O$, Wik, $\mathrm{KO}$, Almquist, IAM, Arfors, KE, Hint, HC

Effects of dextran on the structure and plasmin-induced lysis of human fibrin

Thromb. Res. 1972, 1: 487-492

Thibault, $\mathrm{C}$

Physiology and physiopathology of the fallopian tube

Int. J. Fertil. 1972, 17: 1-13 
Thompson, $\mathrm{JL}$

Effect of inhibitors of carbohydrate metabolism on the development of preinplantation mouse embryos

Exp. Cell. Res. 1967, 46: 252-262

Thompson, RS, Smith, DM, Zamboni, L

Fertilization of mouse ova in vitro an electron microscope study

Fertil. Steril. 1974, 25: 222-249

Tietze, $C$

Probability of pregnancy resulting from a single unprotected coitus

Fertil. Steril. 1960, 11: $485-488$

Trevit, HR, Whittingham, DG, Rowson, LEA

Successful culture in vitro of sheep and cattle ova

J. Reprod. Fertill. 1972, 30: 493-497

Trounson, AO

In: Human conception in vitro

Edwards, RG, Purdy, JM, eds

Academic Press, London, 1982, p. 39

Trounson, A

Factors controlling normal embryo development and implantation of human oocytes fertilized in vitro

In: Fertilization of the human egg in vitro

Beier, HM, Lindner, HR, eds

Springer-Verlag, New York, 1983

Trounson, A, Hoppen, HO, Lutjen, PJ, Mohr, LR, Rogers, PAW, Sathananthan, AH

In vitro fertilization: the state of the art

In: Gamete quality and fertility regulation

Rolland, R, Heineman, MJ, Hillier "SJ, Vemer, H, eds

Elsevier Science Publishers, Amsterdam, 1985

Trounson, AO, Mohr, LR, Wood, C, Leeton, JF

Effect of delayed insemination on in-vitro fertilization, culture and transfer of human embryos

J. Reprod. Fertil. 1982, 64: 285-294

Tsutsumi, T, Hafez, ESE

Distribution patterns of rabbit embryos during preimplantation stage

J. Morphol. 1974, 144: 323-336

Turner, CD, Bagnara, JT

Endocrinology of the ovary

In: General endocrinology

WB Saunders Company, Philadelphia, 1976

Urzua, MA, Stambaugh, R, Flickinger, G, Mastrojannü, L jr

Uterine and oviduct fluid protein patterns in the rabbit before and after ovulation

Fertil. Steril. 1970, 21: 860-865

Varma, SK, Srivastava, LM, Talwar, GP

Changes in the activity and isozyme forms of lactic dehydrogenase in the rabbit oviduct

following copulation

J. Reprod. Fertil. 1974, 39:131-134

Vasen, LCLM

The intramural part of the fallopian tube

Int. I. Fertil. 1959, 4: 309-314

Vasquez, G, Boeckx, WD, Winston, RML. Brosens, IA

Human tubal mucasa and reconstructive microsurgery

In: Microsurgery in female infertility

Crosignani, PG, Rubin, BL, eds

Academic Press, London, 1980a 
Vasquez, G, Winston, RML, Boeckx, WD, Brosens, IA

Tubal lesions subsequent to sterilization and their relation to fertility after attempts at reversal

Am. J. Obstet. Gynecol. 1980b, 138: 86-92

Verco, CJ, Gamnon, BJ, Jones, WR

Rabbil oviduct microvascular architecture after tubal ligation

Fertil. Steril. 1983,40:127-130

Verco, CJ, Gannon, BJ, Jones, WR

Variations in rabbit oviduct microvascular architecture after ovulation induced by hCG

J. Reprod. Fert. 1984, 72: 15-19

Verhage, $H G$, Bareither, $M L$, Jaffe, $R C$, Akbar, $M$

Cyctic changes in ciliation, secretion and cell height of the oviductal epithelium in women

Am. J. Anat. 1979, 156: 505-511

Verhoeven, HC, Lott, D, Reichman, J

Ovulatory function after tubal microsurgical procedures in the rabbit

Am. J. Obstet. Gynecol. 1982, 143: 835-838

Verhoeven, HC, Lott, D, Schneider, J, Schlösser, HW

Surgical alteration of the mesosalpinx and its influence upon ovarian ovulatory function in the rabbit

Am. J. Obstet. Gynecol. 1983, 147: 825-830

Willalón, M, Ortiz, ME, Aguayo, C, Munoz, J, Croxatto, HB

Differential transport of fertilized and unfertilized ova in the rat

Biol. Reprod. 1982, 26: 337-341

Wakeling, AE, Spilman, $\mathrm{CH}$

Prostaglandin specific binding in the rabbit oviduct

Prostag\|andins 1973, 4: 405-414

Wallach, J

Interpretation of diagnostic tests

A handbook synopsis of laboratory medicine

Little, Brown and Company, Boston, 1978, p. 13

Walz, W

Sterilitätsoperationen an der Tube mit Hilfe eines Operationsmikroskopes

Z. Geburtshilfe Gynaekol. 1959, 153: 49-55

Wetzels, LCG

Uitrasonographical aspects of follicle growth

Academic Thesis, Maastricht, 1983

Wheeler, JE

Pathology of the fallopian tube

In: Pathology of the female genital tract

Blaustein, A, ed

Springer-Verlag, New York, 1982

Winston, 住ML

Microsurgical reanastomosis of the rabbit oviduct and its functional and pathological sequelae

Br. J. Obstet. Gynaecol. 1975, 82" 513-522

Winston, RML

Why 103 women asked for teversal of sterilization

Br. Med. J. 1977, 2: 305-307

Winston, RML

The future of microsurgery in infertility

Clin. Obstet. Gynaecol. 1978, 5: 607-622 
Winston, RML

Microsurgery of the fallopian tube: from fantasy to reality

Fertil. Steril. 1980, 34:521-530

Winston, RML, Frantzen, $\mathrm{C}$, Oberii, $\mathrm{C}$

Oviduct function following resection of the ampullary-isthmic junction

Fertil. Steril. 1977, 28: 284

Winston, RML, Margara, RA

Techniques for the improvement of microsurgical tubal anastomosis

In: Microsurgery in female infertility

Crosignani, $\mathbf{P G}$, Rubin, BL, eds

Academic Press, London, 1980

Winston, RML, McClure Brown, JC

Pregnancy following autograft transplantation of fallopian tube and ovary in the rabbit

Lancet 1974, ii: $494-495$

Wolf, DP

The block to sperm penetration in zona-free mouse eggs

Develop. Biol. 1978, 64: 1-10

Wolf, DP

Mammalian fertilization

In: The biology of the fluids of the female genital tract

Beller, FK, Schumacher, GFB, edis

Elsevier North Holland, 1979

Wolf, DP, Mastroianni, L jr

Protein composition of human uterine fluid

Fertil. Steril. 1975, 26: 240-247

Yaffe, H, Reinhartz, $T$, Laufer, N, Beyth, Y

Potentially deleterious effect of cornstarch glove powder in tubal reconstructive surgery

Fertil. Steril. 1978, 29: 699-701

Yanagimachi, $R$

In vitro acrosome reaction and capacitation of golden hamster spermatozoa by bovine follicular fluid and its fractions

J. Exp. Zool. 1969, 170: 269-280

Yanagimachi, R

In vitro capacitation of golden hamster spermatozoa by homologous and heterologous blood sera Biol. Reprod. 1970, 3: 147-153

Yanagimachi, $\mathbf{R}$

In vitro sperm capacitation and fertilization of golden-hamster eggs in a chemically defined medium

In: In vitro fertilization and embryo transfer

Hafez, ESE, Semm, K, eds

MTP Press Ltdl, Lancaster, 1982

Yanagimachi, R, Yanagimachi, $H$, Rogers, BJ

The use of zona-free animal ova as a test-system for the assessment of the fertilizing capacity of human spermatozoa

Biol. Reprod. 1976, 15:471-476

Zamboni, L

Ultrastructure of mammalian oocytes and ova

Biol. Reprod. 1970, suppl 2 2: $44-63$

Zamboni, L, Hongsanand, $C$, Mastroianni, $L \mathrm{j} r$ Influence of tubal secretions on rabbit tubal ova

Fertil. Steril. 1965, 16: 177-184 
Met dank aan Organon Nederland B.V. en Schering Nederland B.V. 


\section{Curriculum Vitae}

1957

1975

1976-1982 studie geneeskunde aan de Rijksuniversiteit Limburg te Maastricht

1982

1983-1984 werkzaam als wetenschappelijk assistent bij de capaciteitsgroep Obstetrie en Gynaecologie van de Rijksuniversiteit Limburg

1985-heden opleiding tot gynaecoloog in het Sint Annadal Ziekenhuis te Maastricht (opleider Prof.Dr J. de Haan) 